MAURÍCIO BARBOSA DE CAMARGO SALLES

\author{
MODELAGEM E ANÁLISES DE \\ GERADORES EÓLICOS DE VELOCIDADE VARIÁVEL \\ CONECTADOS EM SISTEMAS DE ENERGIA ELÉTRICA
}


MAURÍCIO BARBOSA DE CAMARGO SALLES

\section{MODELAGEM E ANÁLISES DE GERADORES EÓLICOS DE VELOCIDADE VARIÁVEL CONECTADOS EM SISTEMAS DE ENERGIA ELÉTRICA}

Tese apresentada à Escola Politécnica da Universidade de São Paulo para obtenção do Título de Doutor em Engenharia Elétrica 
MAURÍCIO BARBOSA DE CAMARGO SALLES

MODELAGEM E ANÁLISES DE GERADORES EÓLICOS DE VELOCIDADE VARIÁVEL CONECTADOS EM SISTEMAS DE ENERGIA ELÉTRICA

Tese apresentada à Escola Politécnica da Universidade de São Paulo para obtenção do Título de Doutor em Engenharia Elétrica

Área de Concentração:

Sistemas de Potência

Orientador: Professor Titular

José Roberto Cardoso

(PEA/EPUSP)

Co-orientador: Professor Livre Docente

Walmir de Freitas Filho

(DSEE/FEEC/UNICAMP)

São Paulo 


\section{FICHA CATALOGRÁFICA}

Salles, Maurício Barbosa de Camargo Modelagem e análises de geradores eólicos de velocidade variável conectados em sistemas de energia elétrica / M.B.C. Salles. -- São Paulo, 2009. $124 \mathrm{p}$.

Tese (Doutorado) - Escola Politécnica da Universidade de São Paulo. Departamento de Engenharia de Energia e Automação Elétricas.

1. Energia eólica (Modelagem; Análise) 2. Energia elétrica (Sistemas) 3. Engenharia elétrica I. Universidade de São Paulo. Escola Politécnica. Departamento de Engenharia de Energia e Automação Elétricas II. t. 
Dedico esse trabalho às pessoas cujo incentivo e apoio foram essenciais no decorrer dessa longa jornada, e que sem elas nada disso teria sentido:

Ana Maria, Veide, Fumika, Myrthes, Amaury e Benedito. 


\section{AGRADECIMENTOS}

- Ao professor José Roberto Cardoso, pelo grande apoio e orientação no desenvolvimento deste trabalho;

- Ao professor Walmir de Freitas Filho, pela ajuda, apoio e orientação desde o início do meu mestrado;

- Ao professor Kay Hameyer, pela grande oportunidade concedida, de integrar sua equipe por quase dois anos na Alemanha;

- Aos professores do Laboratório de Eletromagnetismo Aplicado (LMAG) e do Grupo de Máquinas Elétricas e Acionamentos (GMAcq), pelo apoio e pelas importantes discussões técnicas;

- Aos colegas que passaram pelo LMAG durante meu doutorado;

- Aos amigos do DSEE/Unicamp;

- Às secretárias do PEA, que sempre me ajudaram prontamente;

- Aos amigos que pude conhecer na Alemanha;

- À Fundação de Amparo à Pesquisa do Estado de São Paulo (FAPESP), ao Conselho Nacional de Desenvolvimento Científico e Tecnológico (CNPQ), à Coordenação de Aperfeiçoamento de Pessoal de Nível Superior (CAPES) e ao Deutscher Akademischer Austausch Dienst (DAAD) pelo apoio financeiro;

- À minha família e aos meus amigos, pelo apoio e pelo suporte emocional;

- Especialmente à minha esposa Ana, pela força e motivação para seguir em frente, nas horas mais difíceis deste período.
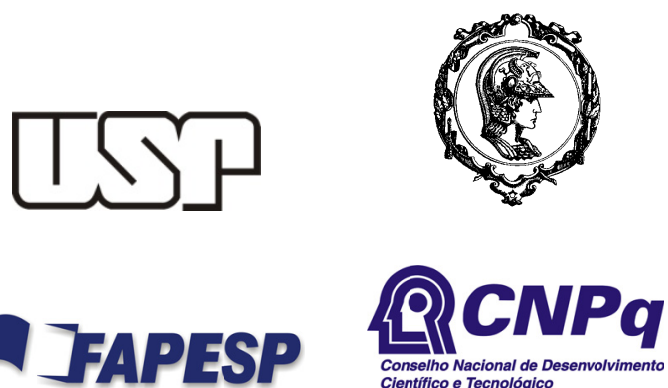

Conselho Nacional de Desentifico e Tecnológico
Cientificis
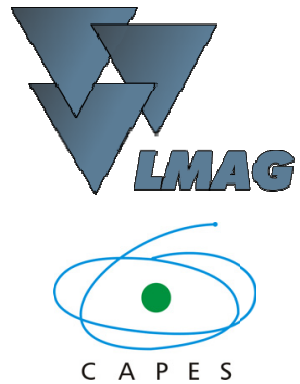

口EQM RWTH INSTITUT FÜR ELEKTRISCHE MASCHINEN 


\section{RESUMO}

Nesta tese apresenta-se 0 desenvolvimento de diversos modelos computacionais de turbinas eólicas equipadas com diferentes tipos de geradores elétricos, com ênfase no gerador de indução duplamente alimentado. Tais modelos foram desenvolvidos para investigar o desempenho de diferentes estratégias de controle, bem como diferentes estratégias do uso do sistema de proteção do conversor AC/DC/AC. Desenvolveu-se adicionalmente um método analítico para investigar a estabilidade de geradores de indução duplamente alimentados durante grandes perturbações na rede elétrica. Tal método foi validado por meio de comparações entre os resultados da aplicação das fórmulas propostas e de simulações, utilizando uma simplificação dos modelos dinâmicos desenvolvidos. Considerando os modelos dinâmicos, os resultados obtidos por simulações mostram que as escolhas adequadas da estratégia de controle e do sistema de proteção permitem maior injeção de potência reativa durante curto-circuitos na rede elétrica. O método analítico proposto apresentou resultados suficientemente precisos para análise da estabilidade frente a grandes perturbações, reduzindo o esforço necessário para realização de simulações dinâmicas sem a necessidade de compra de licenças de programas específicos.

Palavras-chave: Geração de energia eólica. Geradores de indução com dupla alimentação. Métodos analíticos. Modelagem computacional. 


\begin{abstract}
The development of computational models of wind turbines equipped with different electrical machines is presented in this thesis, emphasizing the doubly fed induction generator. Such models were developed to investigate the performance of different control strategies as well as different protection system of the back-to-back converters. Additionally, this thesis present an original analytic method to investigate the stability of doubly fed induction generators during large disturbance on the electric system. The methodology is validated by comparing results from the developed dynamic models to the results from the analytical equations. For the dynamic models, the obtained results by simulations show that the chosen of the appropriate control strategies and the protection system can permit more reactive power injection during short circuits in the network. The proposed analytic method is sufficiently precise to analyze large disturbance stability reducing the necessary effort spending on dynamic simulation without the need of buying a specific license to run the software.
\end{abstract}

Keywords: Wind power generation. Doubly fed induction generator. Analytic methods. Computational modeling. 


\section{LISTA DE FIGURAS}

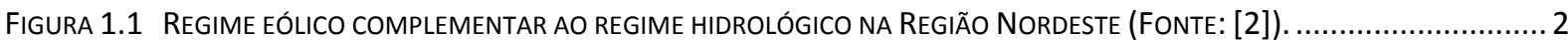

FIGURA 1.2 CAPACIDADE ACUMULATIVA DE GERAÇÃO DE ENERGIA EÓlICA NO BRASIL (FONTE: [4])..................................... 6

FIGURA 1.3 POTENCIAL EÓLICO POR REGIÃO, CONSIDERANDO VENTOS A 50 M (FONTE: [5]) ............................................ 7

FIGURA 1.4 CONTRATOS DE COMPRA DE ENERGIA ELÉTRICA NO BRASIL (FONTE: [17]) . ................................................ 11

FIGURA 2.1 SISTEMA KRÄMER, POTÊNCIA-CONSTANTE COM CONTROLE DE FATOR DE POTÊNCIA E DE VELOCIDADE. ......................15

FIGURA 2.2 SISTEMA SCHERBIUS PARA OPERAÇÃO CONJUGADO-CONSTANTE ABAIXO DA VELOCIDADE SÍNCRONA. .........................16

FIGURA 2.3 SISTEMA CLYMER, POTÊNCIA-VARIÁVEL COM CONTROLE DE FATOR DE POTÊNCIA E DE VELOCIDADE.......................... 17

FIGURA 2.4 CONFIGURAÇÃO ESQUEMÁTICA DOS ENROLAMENTOS DO MOTOR SCHRÄGE. ................................................ 18

FIGURA 2.5 DIAGRAMA ESQUEMÁTICO DO DESENVOLVIMENTO DA TESE DE DOUTORADO..................................................20

Figura 3.1 CuRVAS $C_{p}$ SUGERIDAS POR HEIER, PARA DIFERENTES VALORES DE ÂNGULO DE PASSO...................................... 30

FIGURA 3.2 CURVAS $C_{p}$ SUGERIDAS POR SLOOTWEG, PARA DIFERENTES VALORES DE ÂNGULO DE PASSO..................................30

FIGURA 3.3 POTÊNCIA MECÂNICA GERADA PARA DIFERENTES VELOCIDADES DE OPERAÇÃO DO ROTOR...................................... 31

FIGURA 3.4 POTÊNCIA MECÂNICA GERADA PARA DIFERENTES VELOCIDADES DE VENTO........................................................ 32

FIGURA 3.5 COMPARAÇÃO ENTRE A POTÊNCIA MECÂNICA PARA OPERAÇÃO COM VELOCIDADE FIXA E VARIÁVEL............................32

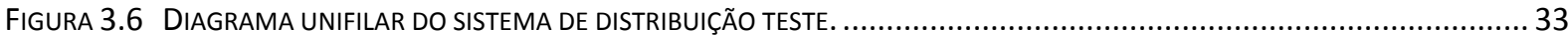

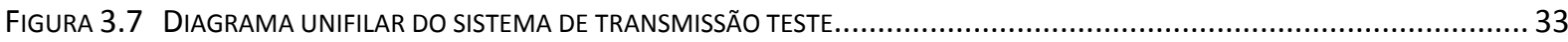

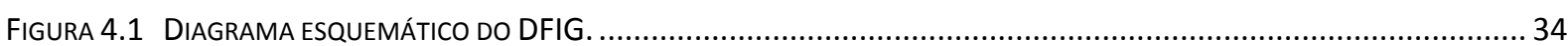

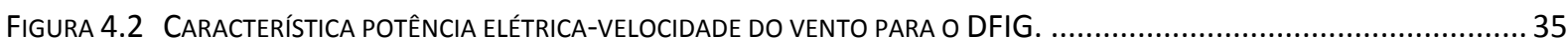

FIGURA 4.3 CiRCUITO EQUIVALENTE DO MODELO COMPLETO DA MÁQUINA DE INDUÇÃO. ................................................ 36

FIGURA 4.4 DIAGRAMA ESQUEMÁTICO DO CONTROLE DO RSC DO DFIG EM REGIME PERMANENTE.....................................39

FIGURA 4.5 DIAGRAMA ESQUEMÁtICO DO CONTROLE DO GSC DO DFIG EM REGIME PERMANENTE..................................... 40

FIGURA 4.6 DIAGRAMA ESQUEMÁTICO DO CONTROLE MODIFICADO DO GSC DO DFIG PARA CONTROLE DE TENSÃO. ..................42

FIGURA 4.7 TENSÃO TERMINAL DA FAZENDA EÓLICA DURANTE CURTO-CIRCUITO ELIMINADO EM 150 MS................................42

FIGURA 4.8 CORRENTE NO GSC DURANTE CURTO-CIRCUITO ELIMINADO EM 150 MS.................................................43

FIGURA 4.9 POTÊNCIA REATIVA INJETADA PELO GSC DURANTE CURTO-CIRCUITO ELIMINADO EM 150 MS.............................43

FIgURA 4.10 POTÊNCIA REATIVA INJETADA PELO DFIG DURANTE CURTO-CIRCUITO ELIMINADO EM 150 MS............................ 44

FIGURA 4.11 TENSÃO NO LINK CC DURANTE CURTO-CIRCUITO ELIMINADO EM 150 MS. .................................................. 44

FIGURA 4.12 PotêNCIA ELÉTRICA INJETADA PELO DFIG DURANTE CURTO-CIRCUITO ELIMINAdO EM 150 MS...........................44

FIGURA 4.13 VELOCIDADE DO DFIG DURANTE CURTO-CIRCUITO ELIMINADO EM 150 MS. ..............................................45

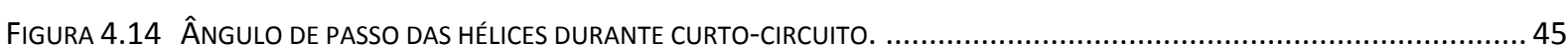

FIGURA 4.15 ESTRATÉGIA A: DIAGRAMA ESQUEMÁTICO DO CONTROLE DO RSC DO DFIG DURANTE CURTO-CIRCUITO................46

FIGURA 4.16 ESTRATÉGIA C: DIAGRAMA ESQUEMÁTICO DO CONTROLE DO RSC DO DFIG DURANTE CURTO-CIRCUITO..................47

FIGURA 4.17 TENSÃO TERMINAL DA FAZENDA EÓLICA DURANTE CURTO-CIRCUITO NA B5, ELIMINADO EM 150 MS. .....................48

FIGURA 4.18 POTÊNCIA REATIVA INJETADA DURANTE CURTO-CIRCUITO NA B5, ELIMINADO EM 150 MS...............................49

FIGURA 4.19 POTÊNCIA ATIVA INJETADA DURANTE CURTO-CIRCUITO NA B5, ELIMINADO EM 150 MS. .................................. 49

FIGURA 4.20 TENSÃO NO LINK CC DURANTE CURTO-CIRCUITO NA B5, ELIMINADO EM 150 MS.......................................... 50 
FIGURA 4.21 VELOCIDADE DO ROTOR DURANTE CURTO-CIRCUITO NA B5, ELIMINADO EM 150 MS. 50

FIGURA 4.22 ÂNGULO DE PASSO DAS PÁS DURANTE CURTO-CIRCUITO NA B5, ELIMINADO EM 150 MS.... 50

FIGURA 4.23 TENSÃO TERMINAL DA HIDROELÉTRICA DURANTE CURTO-CIRCUITO NA B5, ELIMINADO EM 150 MS......................51

FigURA 4.24 VELOCIDADE DO GERADOR SínCRONO (B3) DURANTE CURTO-CIRCUITO NA B5, ELIMINADO EM 150 MS. ...............5 51

FIgURA 4.25 TENSÃO TERMINAL DA FAZENDA EÓLICA DURANTE CURTO-CIRCUITO NA B7, ELIMINADO EM 150 MS....................52

FiguRA 4.26 TENSÃO NO LINK CC DURANTE CURTO-CIRCUITO NA B7, ELIMINADO EM 150 MS.........................................52

FIgURA 4.27 TENSÃO TERMINAL DA FAZENDA EÓLICA DURANTE CURTO-CIRCUITO NA B5, ELIMINAdO EM 150 MS....................55

FIGURA 4.28 POTÊNCIA REATIVA INJETADA DURANTE CURTO-CIRCUITO NA B5, ELIMINADO EM 150 MS.................................56

FiguRA 4.29 CORRENTE REATIVA INJETADA TOTAL DURANTE CURTO-CIRCUITO NA B5, ELIMINADO EM 150 MS. ........................56

Figura 4.30 POtÊNCIA ATIVA INJETAdA DURANTE CURTO-CIRCUITO NA B5, ELIMINAdO EM 150 MS.................................57

FiguRA 4.31 TENSÃO NO LINK CC DURANTE CURTO-CIRCUITO NA B5, ELIMINADO EM 150 MS..........................................57

Figura 4.32 CORRENTE REATIVA INJETADA PELO GSC DURANTE CURTO-CIRCUITO NA B5, ELIMINADO EM 150 MS....................58

FIGURA 4.33 POTÊNCIA DISSIPADA NO DC-CHOPPER DURANTE CURTO-CIRCUITO NA B5, ELIMINADO EM 150 MS......................58

FIGURA 4.34 VELOCIDADE DO ROTOR DURANTE CURTO-CIRCUITO NA B5, ELIMINADO EM 150 MS....................................59

FIGURA 4.35 ÂNGULO DE PASSO DAS HÉLICES DURANTE CURTO-CIRCUITO NA B5, ELIMINADO EM 150 MS................................59

FIGURA 4.36 TENSÃO TERMINAL DA HIDROELÉTRICA DURANTE CURTO-CIRCUITO NA B5, ELIMINADO EM 150 MS.......................59

FIGURA 4.37 TENSÃO TERMINAL DA FAZENDA EÓLICA DURANTE CURTO-CIRCUITO NA B7, ELIMINADO EM 150 MS....................60

FIGURA 4.38 POTÊNCIA REATIVA INJETADA DURANTE CURTO-CIRCUITO NA B7, ELIMINADO EM 150 MS...............................60

FiguRA 4.39 CORRENTE REATIVA INJETADA PELO GSC DURANTE CURTO-CIRCUITO NA B7, ELIMINADO EM 150 MS...................61

Figura 4.40 CoRRENTE REATIVA INJETADA TOtAL DURANTE CURTO-CIRCUITO NA B7, ELIMINADO EM 150 MS. ......................61

FigURA 4.41 PotÊNCIA ATIVA INJETAdA DURANTE CURTO-CIRCUITO NA B7, ELIMINADO EM 150 MS. ................................ 62

Figura 4.42 CONJUGado ElETROMAGNÉTICO NEGATIVO DURANTE CURTO-CIRCUITO NA B7, ELIMINAdO EM 150 MS. ..............62

FiguRA 4.43 TENSÃO NO LINK CC DURANTE CURTO-CIRCUITO NA B7, ELIMINADO EM 150 MS.........................................63

FIGURA 4.44 POTÊNCIA DISSIPADA NO DC-CHOPPER DURANTE CURTO-CIRCUITO NA B7, ELIMINADO EM 150 MS.....................63

FIGURA 4.45 VELOCIDADE DO ROTOR DURANTE CURTO-CIRCUITO NA B7, ELIMINADO EM 150 MS.....................................64

FIGURA 4.46 ÂNGULO DE PASSO DAS HÉLICES DURANTE CURTO-CIRCUITO NA B7, ELIMINADO EM 150 MS..............................64

FIGURA 4.47 TENSÃO TERMINAL DA HIDROELÉTRICA DURANTE CURTO-CIRCUITO NA B7, ELIMINADO EM 150 MS......................64

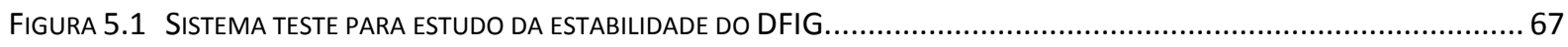

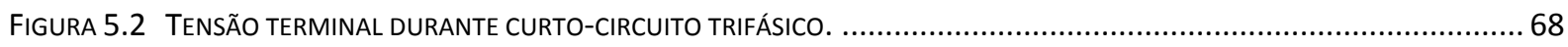

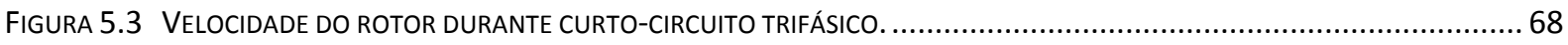

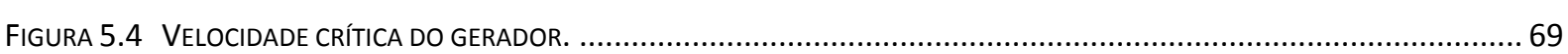

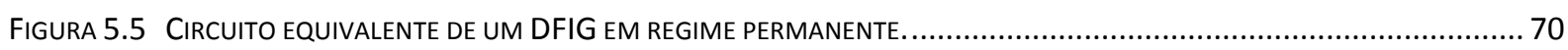

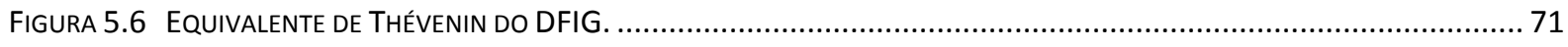

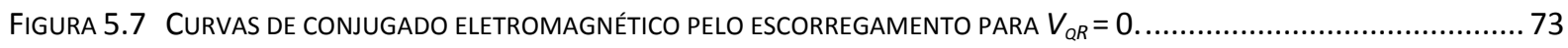

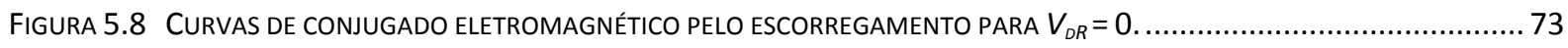

FIGURA 5.9 CURVA DE CONJUGADO ELETROMAGNÉTICO NEGATIVO PARA OPERAÇÃO COMO GERADOR. ....................................74

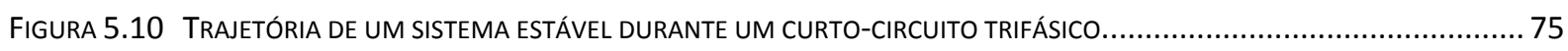

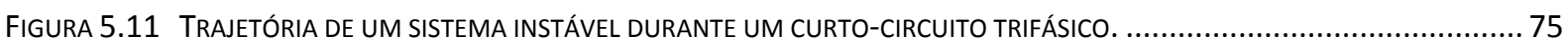


Figura 5.12 CirCUITO EQUiVALENTE DO SISTEMA COMPLETO. .77

FiguRA 5.13 Equivalente de THÉVENIN DO SISTEMA TESTE. 78

FIGURA 5.14 CURVAS DE CONJUGADO ELETROMAGNÉTICO CONSIDERANDO OS PARÂMETROS DA REDE. .79

FIGURA 5.15 ESTUdO DE SENSIBILIDADE: VARIAÇÃO DA TENSÃO DE EIXO EM QUADRATURA NO ROTOR $\left(\mathrm{V}_{\mathrm{QR}}\right)$. 81

FIGURA 5.16 ESTUdO DE SENSIBILIDADE: VARIAÇÃO DA TENSÃO DE EIXO DIRETO APLICADA AO ROTOR $\left(\mathrm{V}_{\mathrm{DR}}\right)$ 81

FIGURA 5.17 VELOCIDADE EM FUNÇÃO DA TENSÃO DE EIXO EM QUADRATURA APLICADA AO ROTOR $\left(V_{\mathrm{Q}}\right)$..............................8. 82

FIGURA 5.18 VELOCIDADE EM FUNÇÃO DA TENSÃO DE EIXO DIRETO APLICADA AO ROTOR $\left(\mathrm{V}_{\mathrm{DR}}\right)$........................................8. 82

FIGURA 5.19 POTÊNCIA REATIVA EM FUNÇÃO DA TENSÃO DE EIXO EM QUADRATURA APLICADA AO ROTOR................................83

FIGURA 5.20 POTÊNCIA REATIVA EM FUNÇÃO DA TENSÃO DE EIXO DIRETO APLICADA AO ROTOR...........................................8 84

FIgURA 6.1 DIAGRAMA GENÉRICO DOS GERADORES SÍNCRONOS A ÍMÃS PERMANENTES (PMG) ESTUDADOS. ...........................86

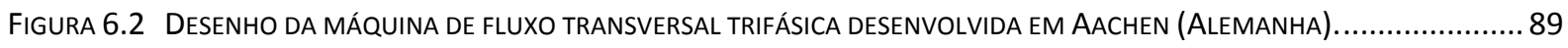

FIGURA 6.3 UM PAR DE PÓLOS LINEARIZADO DA FASE A DA MÁQUINA DESENVOLVIDA EM AACHEN........................................90

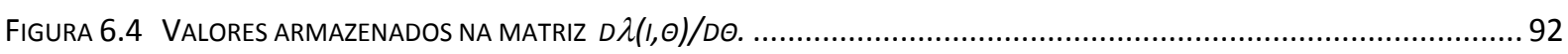

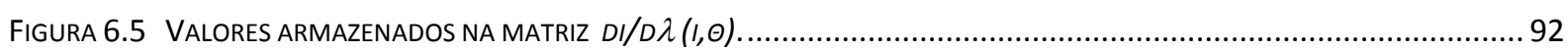

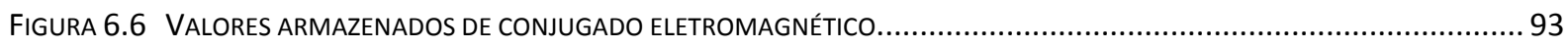

FIGURA 6.7 REPRESENTAÇÃO DA FASE A UTILIZANDO LOOK-UP TABLES NO SIMPOWERSYSTEMS.........................................93

FIGURA 6.8 CONTROLADOR DO CONVERSOR CONECTADO AO GERADOR (GENSC) ...................................................95

FIGURA 6.9 DIAGRAMA ESQUEMÁTICO DO CONTROLE GSC DO PMSG EM REGIME PERMANENTE. .......................................96

FIGURA 6.10 POTÊNCIA ELÉTRICA DO TFG PARA DIFERENTES VALORES DE VELOCIDADE DO VENTO.........................................98

FIGURA 6.11 VELOCIDADE DE OPERAÇÃO DO TFG PARA DIFERENTES VELOCIDADE DO VENTO. .............................................98

FIGURA 6.12 ÂNGULO DE PASSO DO TFG PARA DIFERENTES VALORES DE VELOCIDADE DO VENTO.....................................98

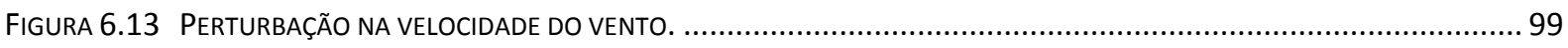

FIGURA 6.14 VELOCIDADE DO TFG DURANTE PERTURBAÇÃO NA VELOCIDADE DO VENTO................................................... 100

FIgURA 6.15 ATUAÇÃo do CONTROLE DE ÂNGULO DE PASSO DURANTE A PERTURBAÇÃO NA VELOCIDADE DO VENTO. .................100

FiguRA 6.16 POTÊNCIA ELÉTRICA DESENVOLVIDA PELO TFG DURANTE PERTURBAÇÃO NA VELOCIDADE DO VENTO. ................... 100

FIgURA 6.17 TENSÃO TERMINAL DA FAZENDA EÓLICA DURANTE CURTO-CIRCUITO NA B5, ELIMINADO EM 150 MS...................102

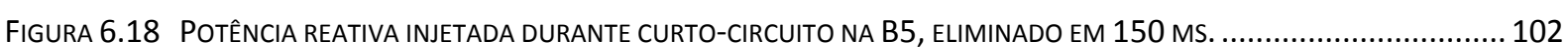

FIGURA 6.19 CORRENTE REATIVA INJETADA PELO GSC DURANTE CURTO-CIRCUITO NA B5, ELIMINADO EM 150 MS..................102

Figura 6.20 POTÊNCIA ATIVA INJETADA DURANTE CURTO-CIRCUITO NA B5, ELIMINADO EM 150 MS. ............................... 103

Figura 6.21 TENSÃo No LINK CC DURANTE CURTO-CIRCUITO NA B5, ELIMINAdO EM 150 MS........................................ 103

FigURA 6.22 VelocidAdE DO ROTOR DURANTE CURTO-CIRCUITO NA B5, ELIMINADO EM 150 MS. .................................. 104

\section{LISTA DE FIGURAS DOS APÊNDICES}

FIgURA B. 1 REQUISITOS DO OPERADOR DO SISTEMA DE TRANSMISSÃO ALEMÃo (E.on NETZ) PARA OPERAÇÃo dURANTE CURTO-

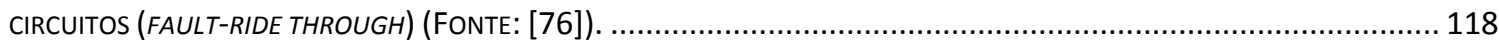

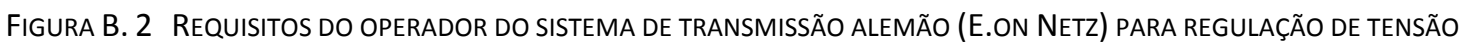
TERMINAL, DURANTE CURTO-CIRCUITOS (INJEÇÃO DE CORRENTE REATIVA) (FONTE: [76]). 
FIGURA B. 3 REQUISITOS DO OPERADOR DO SISTEMA DE TRANSMISSÃO ESPANHOL PARA OPERAÇÃO DURANTE CURTO-CIRCUITOS

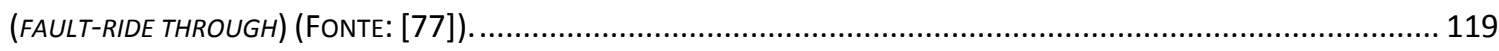

FIGURA B. 4 REQUISITOS DO OPERADOR DO SISTEMA DE TRANSMISSÃO ESPANHOL PARA REGULAÇÃO DE TENSÃO TERMINAL DURANTE CURTO-CIRCUITOS (INJEÇÃO DE CORRENTE REATIVA) (FONTE: [77]). 120

Figura B. 5 Requisitos do Operador NaCional do Sistema ElÉtrico (ONS) PARA operação duRANTE CURTO-CIRCUITOS (FAULT-RIDE THROUGH) (FONTE: [78]).

FIgURA C. 1 DIAGRAMA UNIFILAR DO SISTEMA DE DISTRIBUIÇÃO TESTE.

FIGURA C. 2 DIAGRAMA UNIFILAR DO SISTEMA DE TRANSMISSÃO TESTE - WSCC3 MODIFICADO. 122

FIGURA C. 3 SISTEMA TESTE PARA ESTUDO DA ESTABILIDADE DO DFIG. 


\section{LISTAS DE TABELAS}

TABELA 1.1 CAPACIDAdE ACUMULATIVA INSTALADA DE GERAÇÃo DE ENERGIA EÓLICA NO MUNDO EM 2008 ([4])...................... 3

TABELA 1.2 CAPACIDADE NOVA INSTALADA DE GERAÇÃO DE ENERGIA EÓLICA NO MUNDO EM 2008 ([4]).............................. 4

TABELA 1.3 PenETRAÇÃO NO MERCAdo MUNDIAL DE 2008 dOS DEZ PRINCIPAIS FABRICANTES ([13])................................... 5

TABELA 1.4 CAPACIDADE INSTALADA E EM CONSTRUÇÃO DE ENERGIA EÓLICA, DADOS DE AGOSTO DE 2009. .............................. 7

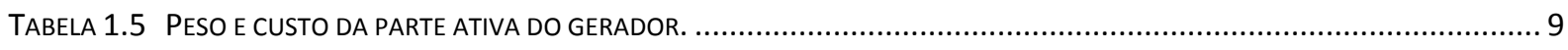

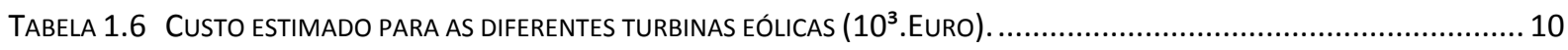

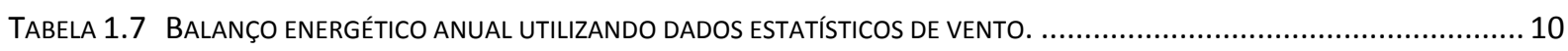

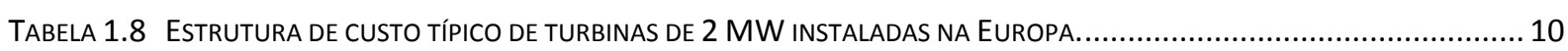

TABELA 3.1 VALORES PARA APROXIMAÇÃO DAS CURVAS DO COEFICIENTE DE POTÊNCIA. .................................................29

TABELA 4.1 RESUMO DAS ESTRATÉGIAS DE CONTROLE DO RSC E DO GSC ANALISADAS................................................ 48

TABELA 4.2 Resumo dAS ESTRATÉGIAS DURANTE CURTO-CIRCUITOS DE PROTEÇÃo E DE CONTROLE ANALISADAS..........................55

TABELA 5.1 RESUMO DOS EFEITOS DA VARIAÇÃO DA TENSÃO APLICADA NO ENROLAMENTO DO ROTOR DO DFIG........................ 84

\section{LISTA DE TABELAS DOS APÊNDICES}

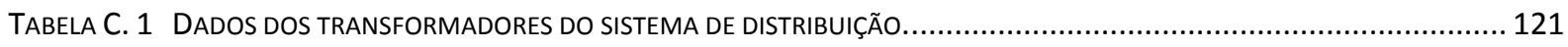

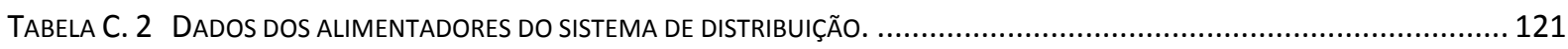

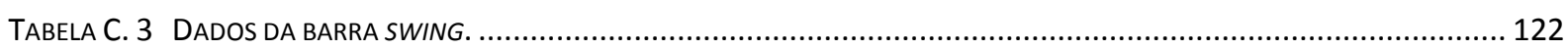

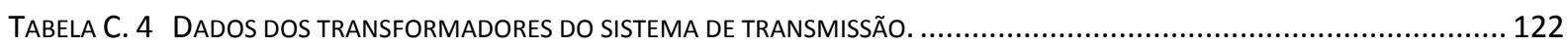

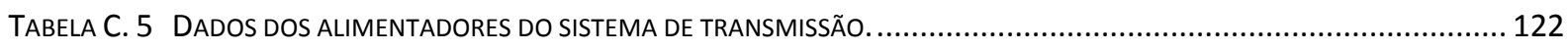

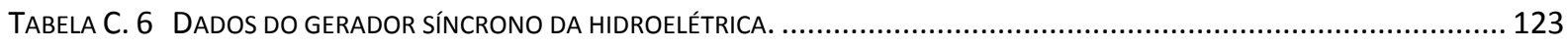

TABELA C. 7 DAdOS do SISTEMA DE EXCITAÇÃo (IEEE - TIPO 1) DO GERAdOR SínCRONO DA HIDROELÉTRICA. ...........................123

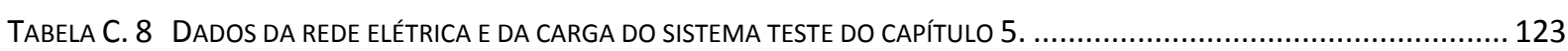

TABELA C. 9 DADOS DOS GERADORES DE INDUÇÃO DUPLAMENTE ALIMENTADO UTILIZADO NO CAPÍTULO 4. .............................123

TABELA C. 10 DADOS DO GERADOR DE INDUÇÃO DUPLAMENTE ALIMENTADO UTILIZADO NO CAPÍTULO 5............................... 123

TABELA C. 11 DADOS DO GERADOR DE INDUÇão DUPLAMENTE ALIMENTADO UTILIZADO NO CAPÍTULO 6.................................124

TABELA C. 12 DADOS DOS REGULADORES PI'S EMPREGADOS NOS CONVERSORES DO DFIG (SEÇÕES 4.3 E 4.4)........................124

TABELA C. 13 DAdOS DOS REgULAdORES PI'S EMPREgAdoS PELOS CONVERSORES DO DFIG (SEÇÃO 4.5) ..............................124

TABELA C. 14 DAdOS DOS REgULAdORES PI'S EMPREgAdoS PELOS CONVERSORES DO PMSG (SEÇÃo 6.5)............................ 124

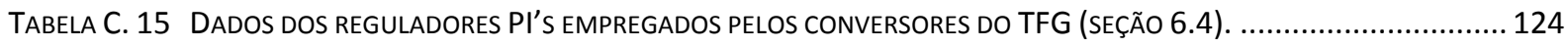




\section{SUMÁRIO}

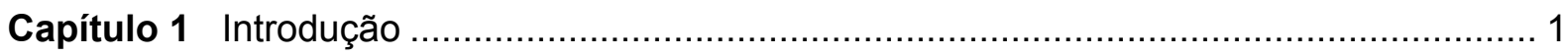

1.1 Vantagens e Desvantagens da Geração de Energia Eólica .................................. 1

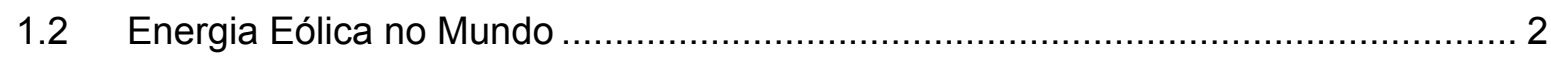

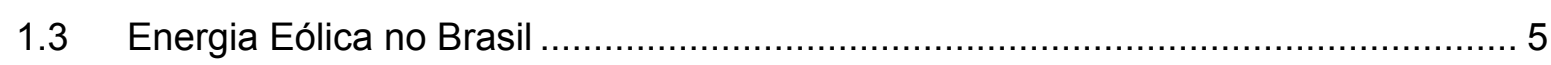

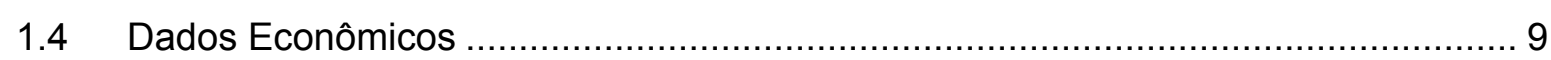

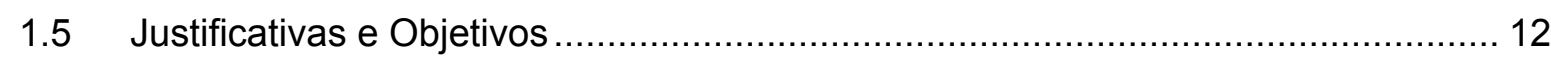

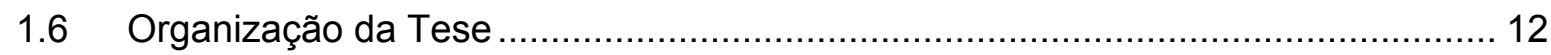

Capítulo 2 Discussão sobre a Evolução e o Estado da Arte .............................................. 14 2.1 Evolução do Controle de Velocidade de Máquinas de Indução Duplamente

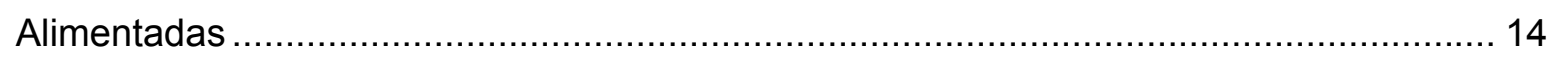

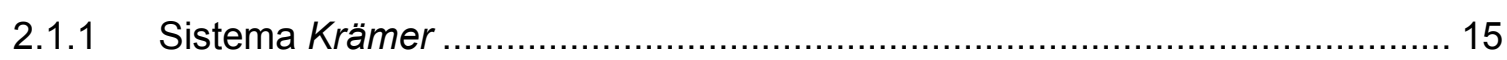

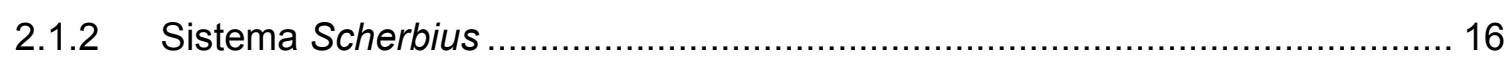

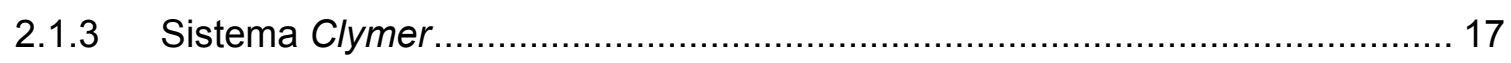

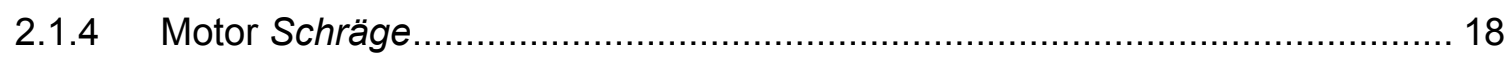

2.1.5 Sistemas utilizando Eletrônica de Potência ...................................................... 19

2.2 Estado da Arte e Modelos Dinâmicos de Turbinas Eólicas.................................... 20

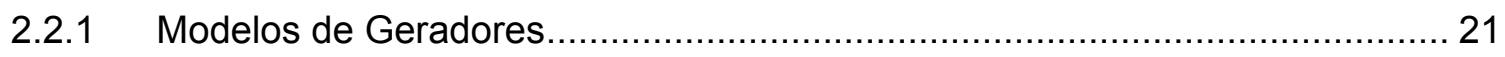

2.2.2 Modelos de Conversores e de Rede Elétrica.............................................. 21

2.2.3 Modelos de Controles de Conversores.......................................................... 22

2.2.4 Modelos Aerodinâmicos da Turbina Eólica..................................................... 24

2.3 Análise Dinâmica de Fazendas Eólicas ......................................................... 25

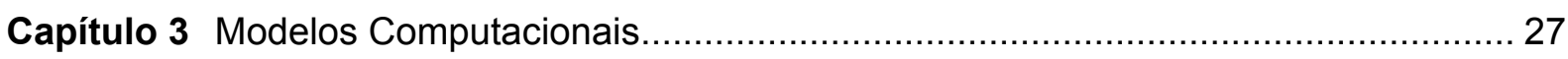

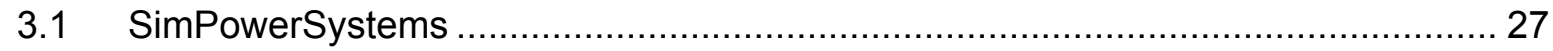

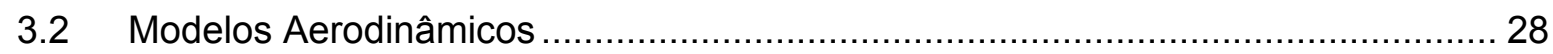

3.3 Turbinas Eólicas de Velocidade Variável ............................................................ 30

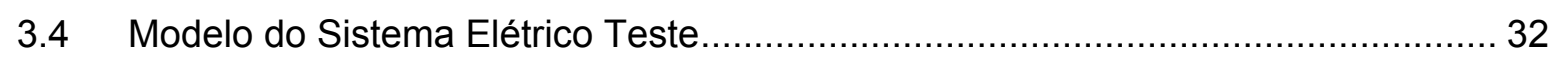

Capítulo 4 Gerador de Indução Duplamente Alimentado (DFIG) ................................. 34

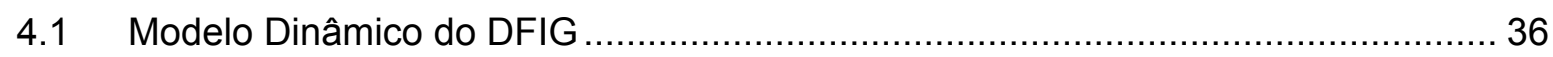

4.2 Modelos de controle do RSC e do GSC em Regime Permanente......................... 39

4.3 Análises Dinâmicas da Capacidade do GSC ................................................... 41 
4.4 Análises Dinâmicas de Diferentes Estratégias de Controle ................................ 46

4.4.1 Curto-Circuito no Sistema de Transmissão ................................................. 48

4.4.2 Curto-Circuito nos Terminais da Fazenda Eólica......................................... 51

4.5 Análises Dinâmicas de Diferentes Estratégias de Proteção ................................. 53

4.5.1 Curto-Circuito no Sistema de Transmissão .................................................... 55

4.5.2 Curto-Circuito nos Terminais da Fazenda Eólica........................................... 60

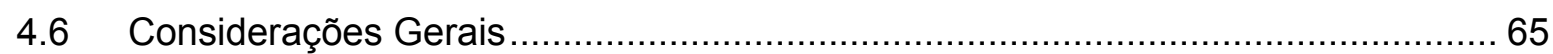

Capítulo 5 Método Analítico para Análise de Estabilidade de Geradores de Indução

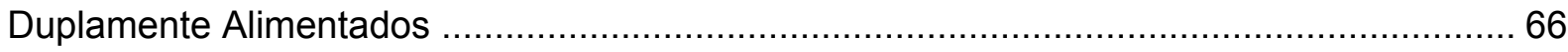

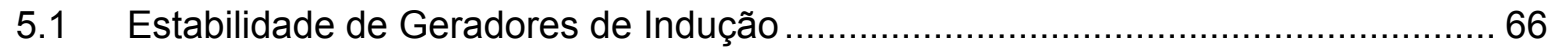

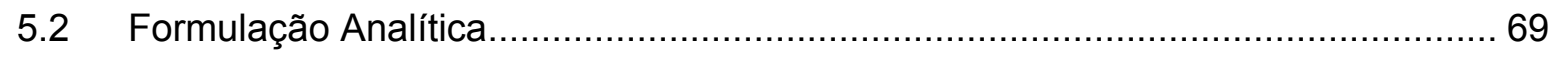

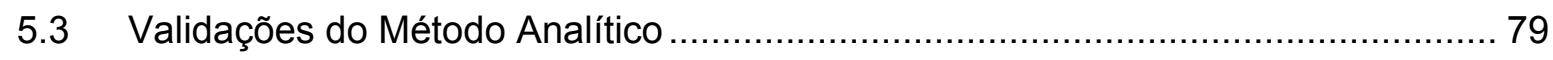

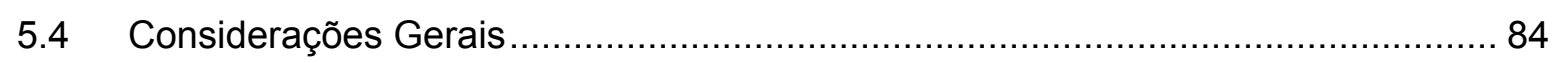

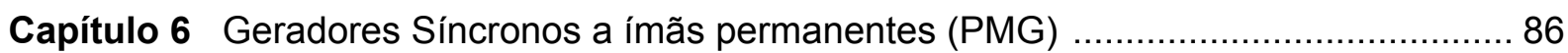

6.1 Modelo Dinâmico do Gerador Síncrono a Ímãs Permanentes de Fluxo Radial

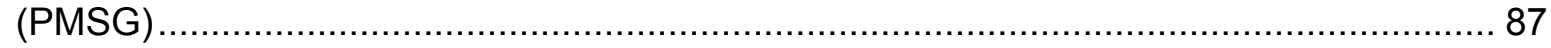

6.2 Modelo Dinâmico do Gerador Síncrono a Ímãs Permanentes de Fluxo Transversal

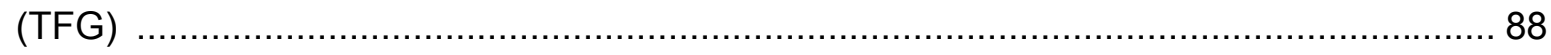

6.3 Modelo do controle dos Conversores em Regime Permanente............................ 94

6.4 Análise Dinâmica de Turbinas Eólicas equipadas com TFG ................................. 97

6.5 Análise Dinâmica de Turbinas Eólicas equipadas com PMSG ........................... 101

6.6 Considerações Gerais ............................................................................... 104

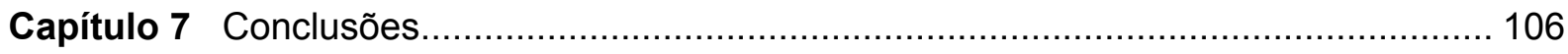

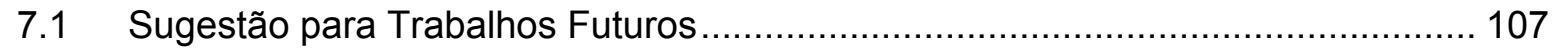

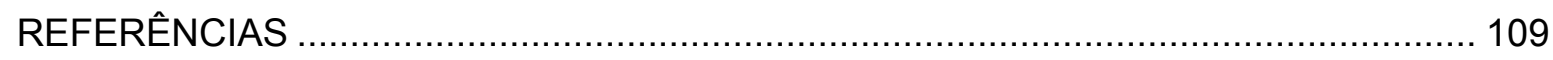

APÊNDICE A - Publicações Durante o Doutorado ................................................. 116

APÊNDICE B - Requisitos para Operação de Turbinas Eólicas .................................... 118

APÊNDICE C - Dados de Simulação................................................................ 121 


\section{Capítulo 1}

\section{INTRODUÇÃO}

No mundo todo, o aumento do uso de energias renováveis na matriz energética vem sendo amplamente abordado pela mídia. Contudo, a comunidade científica investe há décadas em pesquisas relacionadas a este tema. No campo da produção de energia elétrica, o meteorologista "Poul la Cour" foi o inventor das primeiras turbinas eólicas modernas, instalada na Askov Folk High School em Askov, Dinamarca. Sua invenção de 4 pás, construída em 1891, era equipada com um gerador elétrico de corrente contínua ([1]).

\subsection{Vantagens e Desvantagens da Geração de Energia Eólica}

Uma vantagem não muito mencionada na literatura é o fato de as turbinas eólicas não necessitarem de água para a produção de eletricidade, como é o caso das termoelétricas, incluindo as nucleares, podendo ser instaladas em regiões secas. Além deste fato, podemos enumerar os seguintes benefícios de seu uso:

- Tempo reduzido de construção do parque eólico.

- Construção modular, de fácil expansão.

- Não emissão de gases de efeito estufa.

- Independência da variação dos preços de combustíveis.

- Possibilidade de uso do terreno para outros fins (por exemplo, agricultura e pecuária).

- Regime de vento complementar ao regime hidrológico, possibilitando armazenamento de água durante período de poucas chuvas (por exemplo, vazão do Rio São Francisco e o vento típico do litoral da Região Nordeste - Figura 1.1).

- Criação de novos empregos especializados (na Alemanha, o mercado criado em torno da energia eólica já emprega mais pessoas do que o da indústria automobilística).

- Facilidade de aplicação em sistemas híbridos (por exemplo, uma planta de geração solar-eólica). 


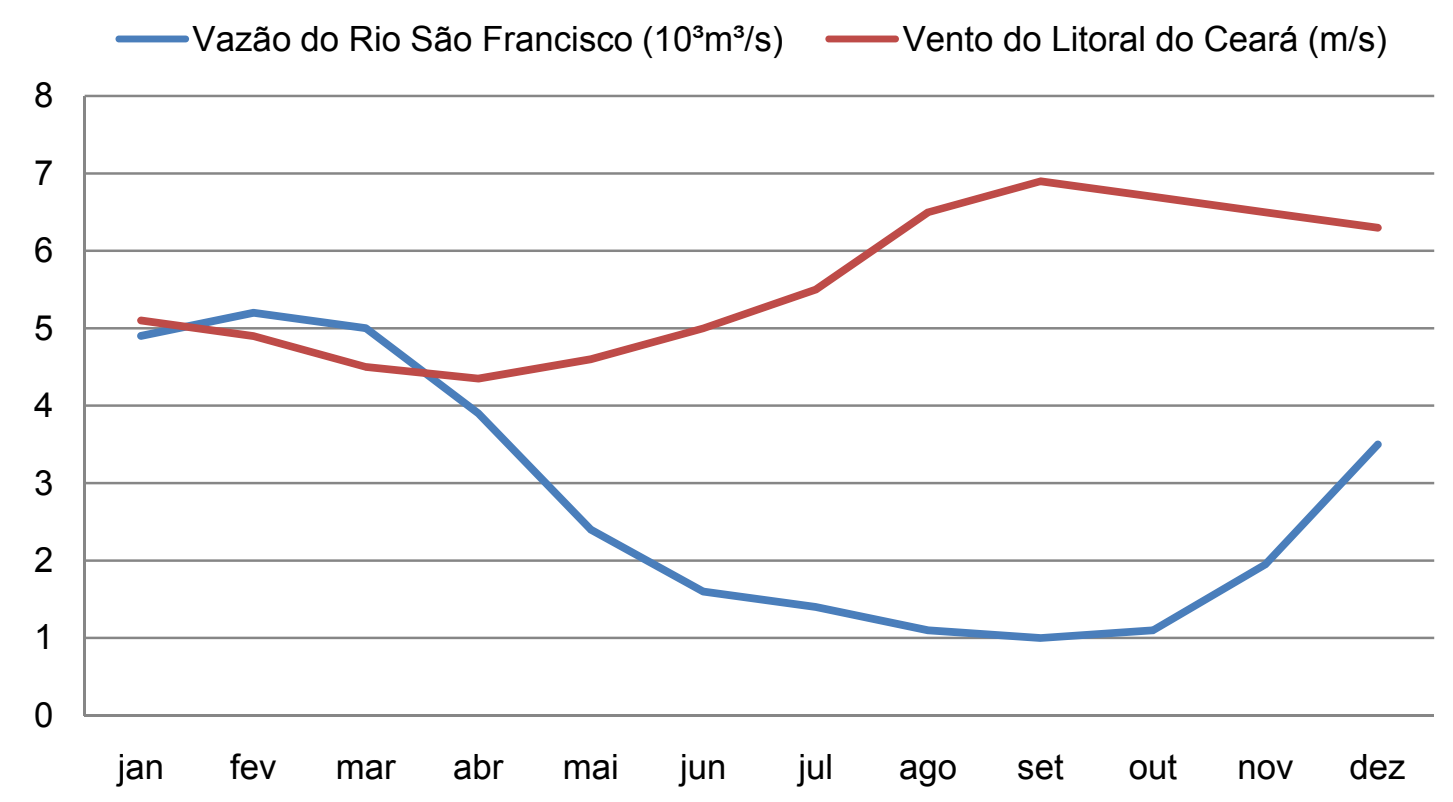

Figura 1.1 Regime eólico complementar ao regime hidrológico na Região Nordeste (Fonte: [2]).

A desvantagem mais evidente, talvez seja a necessidade de uma grande área devido à baixa densidade da energia contida nos ventos. Além dessa, outras desvantagens podem ser enumeradas:

- Poluição visual.

- Instalação em rotas de pássaros.

- Cintilação luminosa (luz do sol através das pás em movimento).

- Ruído audível durante rotação das pás.

- Alto custo inicial.

- Deformação da forma de onda da tensão, quando do uso de conversores.

- Velocidade dos ventos com intensidades variáveis e intermitentes.

- Difícil previsibilidade da velocidade do vento.

\subsection{Energia Eólica no Mundo}

$\mathrm{Na}$ última década, o interesse pelo uso da energia eólica cresceu consideravelmente. Trinta por cento de toda capacidade nova anual instalada na União Européia, entre 2002 e 2006, foi de geração de energia eólica. Em 2007, essa participação anual subiu para $40 \%$ da capacidade total instalada, tornando-a a forma 
de geração de energia elétrica que mais cresce na Europa, incluindo a geração de energia elétrica a partir do gás natural ([3]). Em 2008, a geração de energia eólica manteve a primeira posição em novas instalações ([3]).

Na América do Norte, a instalação de fazendas eólicas se intensificou apenas nos últimos 5 anos, sendo que os Estados Unidos se tornaram, no fechamento do ano de 2008 , o país com a maior capacidade instalada de geração de energia eólica do mundo, ultrapassando a Alemanha ([4]). Na América do Sul, o país que mais investiu neste segmento de geração foi o Brasil, atingindo $417 \mathrm{MW}$ de capacidade instalada em agosto de 2009 ([5]), totalizando ínfimos 0,4\% da capacidade total instalada, muito inferior a de países com menor potencial total de aproveitamento, como é o caso de Portugal, onde há $2.862 \mathrm{MW}$ de capacidade instalada ([4]).

A Tabela 1.1 apresenta os dez principais países em capacidade instalada de geração de energia eólica no mundo, considerando o fechamento do ano de 2008. Os dez países que mais instalaram turbinas eólicas de médio e grande porte, no ano de 2008, são mostrados na Tabela 1.2.

Tabela 1.1 Capacidade acumulativa instalada de geração de energia eólica no mundo em 2008 ([4]).

\begin{tabular}{clcc}
\hline Posição & \multicolumn{1}{c}{ Países } & MW & $\%$ \\
\hline $1^{\text {a }}$ & Estados Unidos & 25.170 & 20,8 \\
$2^{\mathrm{a}}$ & Alemanha & 23.903 & 19,8 \\
$3^{\mathrm{a}}$ & Espanha & 16.754 & 13,9 \\
$4^{\mathrm{a}}$ & China & 12.210 & 10,1 \\
$5^{\mathrm{a}}$ & Índia & 9.645 & 8,0 \\
$6^{\mathrm{a}}$ & Itália & 3.736 & 3,1 \\
$7^{\mathrm{a}}$ & França & 3.404 & 2,8 \\
$8^{\mathrm{a}}$ & Reino Unido & 3.241 & 2,7 \\
$9^{\mathrm{a}}$ & Dinamarca & 3.180 & 2,6 \\
$10^{\mathrm{a}}$ & Portugal & 2.862 & 2,4 \\
& Outros países & 16.693 & 13,8 \\
& Total 10 primeiros & 104.104 & 86,2 \\
& Total & 120.798 & 100,0 \\
\hline
\end{tabular}


Tabela 1.2 Capacidade nova instalada de geração de energia eólica no mundo em 2008 ([4]).

\begin{tabular}{clcc}
\hline Posição & \multicolumn{1}{c}{ Países } & MW & $\%$ \\
\hline $1^{\mathrm{a}}$ & Estados Unidos & 8.358 & 30,9 \\
$2^{\mathrm{a}}$ & China & 6.300 & 23,3 \\
$3^{\mathrm{a}}$ & Índia & 1.800 & 6,7 \\
$4^{\mathrm{a}}$ & Alemanha & 1.665 & 6,2 \\
$5^{\mathrm{a}}$ & Espanha & 1.609 & 5,9 \\
$6^{\mathrm{a}}$ & Itália & 1.010 & 3,7 \\
$7^{\mathrm{a}}$ & França & 950 & 3,5 \\
$8^{\mathrm{a}}$ & Reino Unido & 836 & 3,1 \\
$9^{\mathrm{a}}$ & Portugal & 712 & 2,6 \\
$10^{\mathrm{a}}$ & Canadá & 526 & 1,9 \\
& Outros países & 3.285 & 12,2 \\
& Total 10 primeiros & 23.766 & 87,8 \\
& Total & 27.051 & 100,0 \\
\hline
\end{tabular}

As primeiras fazendas eólicas (nome dado a instalações com mais de uma turbina eólica), equipadas com turbinas de médio e grande porte, eram conectadas diretamente em sistemas de distribuição ou subtransmissão de energia elétrica, sendo elas consideradas como geração distribuída ([6]-[8]). Porém, com o aumento da potência elétrica gerada individualmente por cada turbina, muitas fazendas eólicas modernas passaram a ser conectadas diretamente no sistema de transmissão, sendo consideradas geração centralizada de energia elétrica ([9], [10]).

O interesse pela instalação de novas fazendas eólicas continua em plena ascensão, porém tal interesse apresenta características diferentes quando comparado entre os dez países citados na Tabela 1.1 e o resto do mundo. De forma geral, os dez principais países que utilizam a energia eólica estão investindo fortemente em pesquisa e desenvolvimento para viabilizarem fazendas eólicas no mar (offshore wind farms). Somente na costa da Alemanha (Mar do Norte e Mar Báltico), planejava-se instalar gradativamente $20 \mathrm{GW}$ até 2020 ([9]), porém, devido às novas diretrizes do Governo alemão, este valor passou para $10 \mathrm{GW}$ ([11]). Os países que não fazem parte desse grupo devem concentrar seus investimentos em fazendas eólicas em terra. Contudo, não há um consenso sobre qual o tipo mais adequado de gerador elétrico para equipar turbinas eólicas modernas ([12]). Analisando-se a penetração de mercado dos principais fabricantes mundiais em 
2008, constata-se que o gerador de indução duplamente alimentado (em inglês Doubly Fed Induction Generator - DFIG) é ainda o tipo mais vendido (Tabela 1.3). Os geradores síncronos com ímãs permanentes de fluxo radial (em inglês Permanent Magnet Synchronous Generator - PMSG) ou os geradores síncronos com excitação elétrica (em inglês Electrical Excited Synchronous Generator - EESG) ainda possuem penetração de mercado limitada ([13]). Porém, de encontro a essa generalização, a empresa alemã Enercon, cujas turbinas são equipadas com EESG, vem obtendo, no mercado alemão, mais de $50 \%$ de participação na instalação anual de novas turbinas ([14]).

Tabela 1.3 Penetração no mercado mundial de 2008 dos dez principais fabricantes ([13]).

\begin{tabular}{llccc}
\hline \multicolumn{1}{c}{ Empresa } & \multicolumn{1}{c}{ País } & MW negociado & $\%$ & Gerador Elétrico \\
\hline Vestas & Dinamarca & 5.647 & 19,0 & DFIG \\
GE Energy & Estados Unidos & 5.350 & 18,0 & DFIG \\
Gamesa & Espanha & 3.270 & 11,0 & DFIG \\
Enercon & Alemanha & 2.675 & 9,0 & EESG \\
Suzlon & Índia & 2.080 & 7,0 & DFIG \\
Siemens & Alemanha & 2.080 & 7,0 & DFIG \\
Sinovel & China & 1.486 & 5,0 & DFIG \\
Goldwind & China & 1.189 & 4,0 & PMSG \\
Acciona WP & Espanha & 1.189 & 4,0 & DFIG \\
Nordex & Alemanha & 1.189 & 4,0 & DFIG \\
& $\quad$ Total & 29.724 & 100 & \\
\hline
\end{tabular}

\subsection{Energia Eólica no Brasil}

O Brasil é o país da América Latina (incluindo o Caribe) que mais investiu em energia eólica, instituindo pela lei 10.438, de abril de 2002, o Programa de Incentivo às Fontes Alternativas de Energia Elétrica (PROINFA). Dentro do PROINFA, programa gerenciado pela Eletrobrás, foram selecionados 1.422,92 MW de 54 parques eólicos que deveriam entrar em operação parte até 2006 e parte até 2008, porém, o prazo final foi estendido até dezembro de 2010. Estes empreendimentos têm a garantia da compra de toda a energia gerada por 20 anos pela própria Eletrobrás, além disso, ela também garante uma receita mínima de $70 \%$ da energia contratada durante o período de financiamento. $O$ programa apresentou muitas falhas e suas metas não foram atingidas plenamente dentro do cronograma inicial, 
visto que em agosto de 2009 ainda faltam praticamente $1.000 \mathrm{MW}$. A metade deste montante deve entrar em operação até o final de 2009, sendo que o restante até final de 2010. Contudo, tal programa colaborou para o aumento da potência instalada de $22 \mathrm{MW}$ para $417 \mathrm{MW}$, considerando o período de 2002 a 2009, como mostra a Figura 1.2.

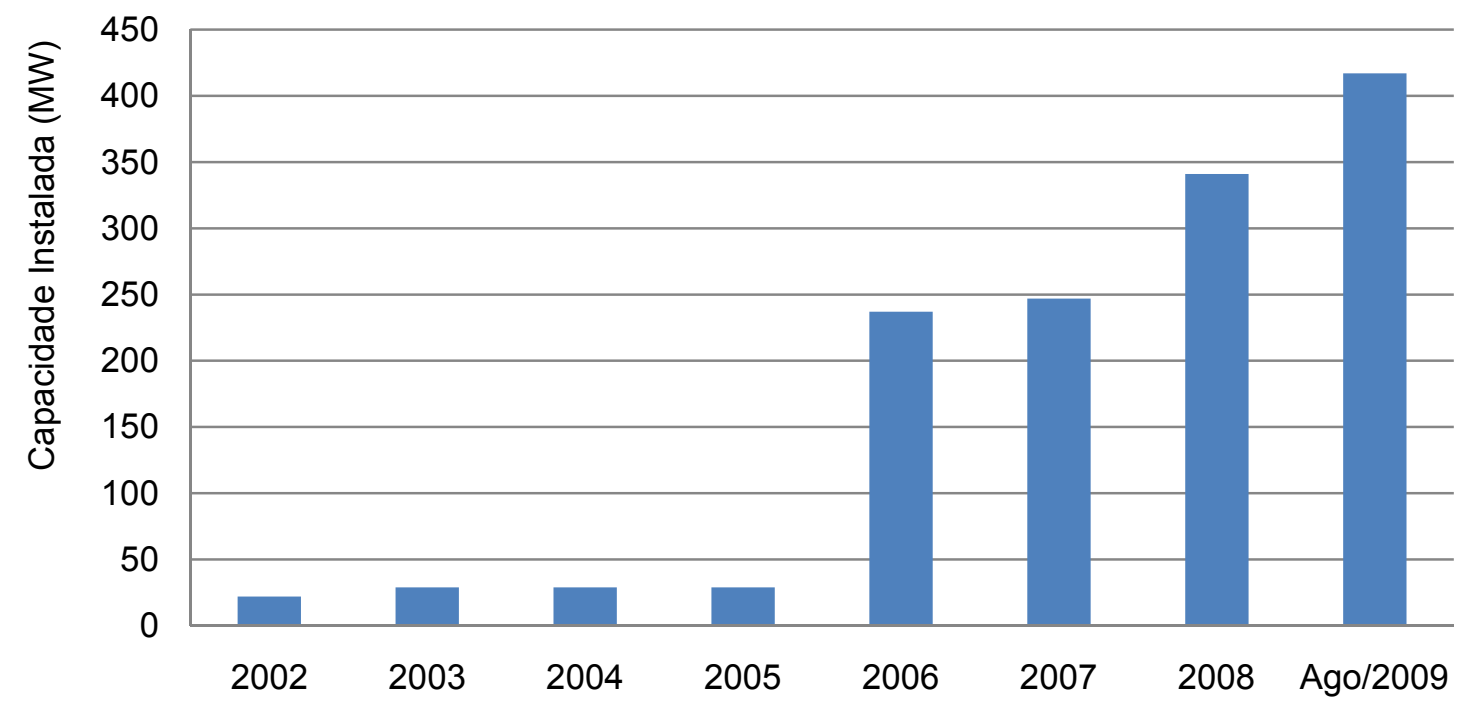

Figura 1.2 Capacidade acumulativa de geração de energia eólica no Brasil (Fonte: [4]).

O potencial total de geração de energia eólica no Brasil, considerando ventos a $50 \mathrm{~m}$ de altura, equivale a mais de 10 usinas de Itaipu (14 GW), totalizando 143,4 GW. Esperam-se ainda acréscimos consideráveis para os estudos que vão verificar ventos a $100 \mathrm{~m}$ de altura. A distribuição do potencial eólico, por região do Brasil, é apresentada na Figura 1.3, com base em resultados de estudos publicados em 2001, no Atlas do Potencial Eólico Brasileiro ([2]).

Não obstante todo o potencial de geração de energia eólica disponível no Brasil, a capacidade instalada, por região, é, ainda, muito baixa, como mostram os dados de geração da ANEEL ([5]). Além disso, as regiões Norte e Sudeste não contam com nenhum parque eólico em operação, como mostra a Tabela 1.4. Porém, os dados relativos a empreendimentos em construção mostram que um total de 441,55 MW serão conectados, em breve, ao sistema elétrico brasileiro ([5]). Este acréscimo irá dobrar a capacidade atual instalada no país. 
Tabela 1.4 Capacidade instalada e em construção de energia eólica, dados de agosto de 2009.

\begin{tabular}{|c|c|c|c|}
\hline Região & Capacidade instalada (MW) & Percentual atual (\%) & Em construção (MW) \\
\hline Centro-Oeste & 4,2 & 1 & 0 \\
\hline Norte & - & 0 & 0 \\
\hline Sul & 137,6 & 33 & 0 \\
\hline Sudeste & - & 0 & 28,05 \\
\hline Nordeste & 275,2 & 66 & 438,745 \\
\hline Total & 417 & 100 & 441,55 \\
\hline
\end{tabular}

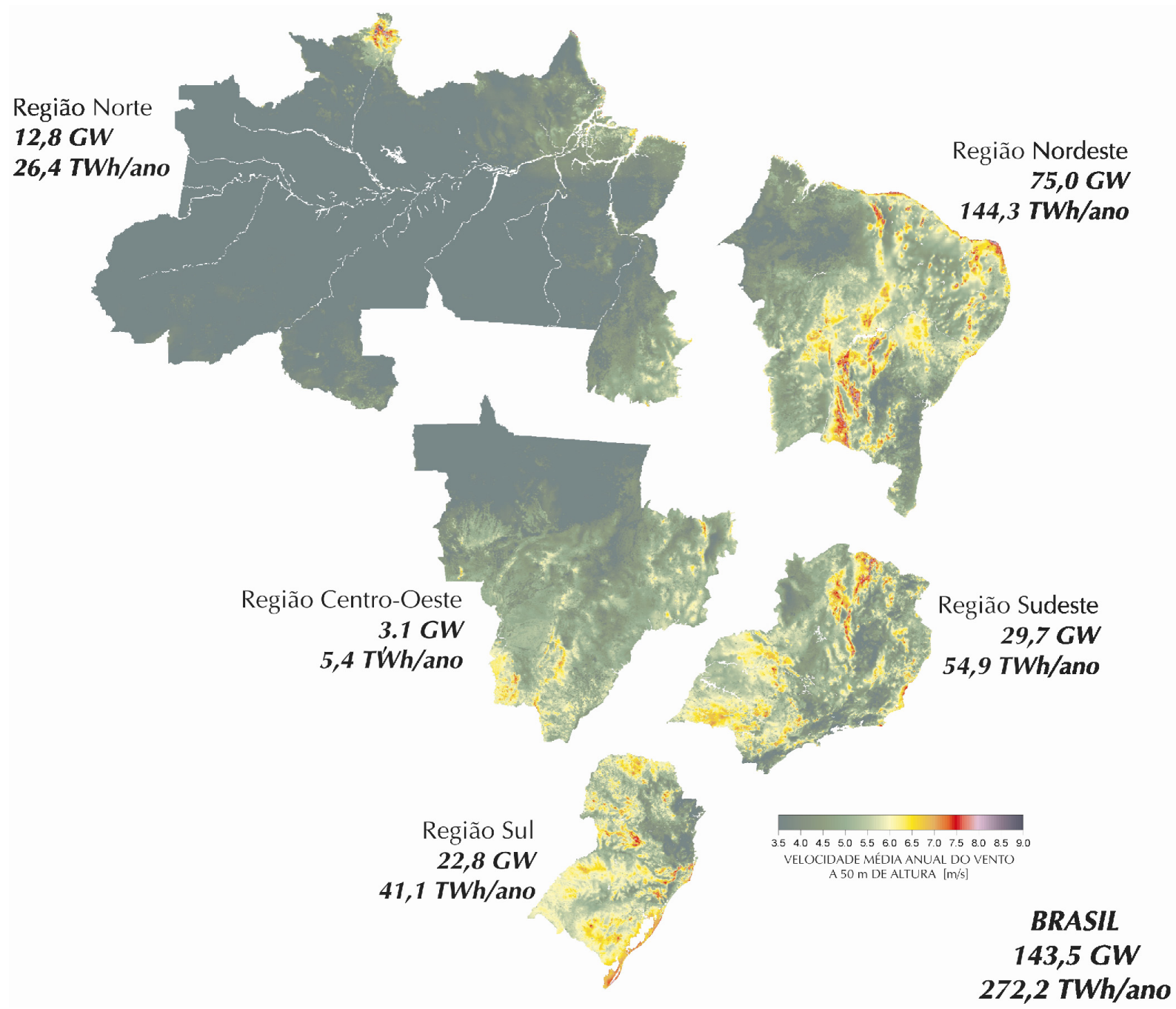

Figura 1.3 Potencial eólico por região, considerando ventos a 50 m (fonte: [5]).

Até o momento, apenas dois fabricantes de turbinas eólicas de grande porte instalaram fábricas no Brasil. A Wobben Windpower, que é subsidiária da alemã 
Enercon, foi o primeiro fabricante a se instalar no Brasil, inicialmente em Sorocaba (em 1997) expandindo-se, mais recentemente, para o Ceará (em 2002). A Wobben possui 337,7 MW operando no Brasil em 16 parques eólicos, ou seja, $81 \%$ da capacidade instalada no Brasil, adotando a tecnologia EESG. O segundo fabricante de turbinas eólicas de grande porte a se instalar no Brasil foi a Impsa Wind (em 2008), empresa subsidiária do grupo centenário argentino Impsa, o qual já está instalado no Brasil há mais de 20 anos. Até o presente momento, não há parques eólicos operando com as turbinas baseadas no PMSG da Impsa Wind, porém, a previsão é que $100 \mathrm{MW}$, divididos em três parques eólicos no Ceará, entrarão em operação até o final de 2009. A tecnologia envolvida no projeto e na fabricação destas turbinas foi negociada com a empresa alemã Vensys, sendo que qualquer modernização feita pela Vensys é automaticamente repassada para a Impsa e viceversa. Vale ressaltar que o Brasil conta com o segundo maior fabricante de pás para turbinas eólicas de grande porte do mundo. A empresa de capital nacional Tecsis, localizada em Sorocaba-SP, começou no mercado de fabricação de pás há 10 anos e atualmente exporta praticamente toda sua produção para equipar turbinas dos maiores fabricantes do mundo.

Outro fato, que promete impulsionar o mercado de energia no Brasil, são os leilões específicos para contratação de energia eólica. O próximo será realizado no dia 25 de novembro deste ano. Na fase inicial, 441 novos projetos foram habilitados distribuídos por 11 Estados brasileiros, totalizando $13.341 \mathrm{MW}$. Deste total, $72 \%$ na região Nordeste e $27 \%$ na Sul, sendo que o Rio Grande do Sul e o Ceará concentram juntos $79 \%$ dos empreendimentos, como noticiou o jornalista Leonardo Goy ([15]). A quantidade de projetos habilitados expressa a disposição do mercado brasileiro em investir na geração de energia eólica, embora menos da metade destes projetos terá a produção de energia contratada pelo Governo.

Diante desse quadro, outros fabricantes de turbinas eólicas manifestam interesse em instalar, em médio prazo, novas fábricas no Brasil, sendo que alguns deles, já mantêm escritórios para a importação de turbinas eólicas fabricadas em outras fábricas no mundo. Assim sendo, é de se esperar, nos próximos anos, um aumento significativo no uso da energia eólica no Brasil e uma diversificação das tecnologias das turbinas utilizadas, principalmente, um aumento no uso do DFIG. 


\subsection{Dados Econômicos}

Em 2007, a União Européia já contava com 108.600 postos de trabalho diretamente ligados à geração de energia eólica e mais 42.716 ligados indiretamente. É preciso assinalar que os três países pioneiros (Dinamarca, Alemanha e Espanha) concentram $75 \%$ dos postos diretamente ligados à geração de energia eólica. Os fabricantes de turbinas eólicas concentram $37 \%$ do total de postos de trabalho. Dentro da Europa, uma média de 12 novos postos de trabalho são criados para cada MW instalado, como mostra o estudo publicado em $2008 \mathrm{em}$ ([16]). Considerando, de forma simplificada, que toda a capacidade dos projetos habilitados para o leilão específico de geração de energia eólica, que será realizado em novembro, fosse contratada pelo Governo, o Brasil criaria 160.092 novos postos de trabalho no setor. Esse número ultrapassa os 128.000 postos de trabalho, de dezembro de 2008, de toda indústria automotiva brasileira (incluindo autoveículos, máquinas agrícolas e automotrizes), de acordo com dados publicados pelo DIEESE em ([17]).

Embora os preços das turbinas eólicas tenham diminuído consideravelmente nos últimos 15 anos, um patamar de estabilidade foi atingido, recentemente. A comparação direta entre os preços dos três principais tipos de turbinas eólicas foi estimada e publicada, em 2006, por Polinder et al. ([18]). A Tabela 1.5, a Tabela 1.6 e a Tabela 1.7 apresentam uma síntese dos principais resultados obtidos pelos autores para turbinas de $3 \mathrm{MW}$, sendo necessário ressaltar que estes dados não são suficientes para a escolha de tecnologia, que requer um estudo bem mais complexo, incluindo análise do investimento total e a receita durante 20 anos.

Tabela 1.5 Peso e custo da parte ativa do gerador.

\begin{tabular}{lcccccc}
\hline & \multicolumn{2}{c}{ DFIG } & \multicolumn{2}{c}{ EESG } & \multicolumn{2}{c}{ PMG } \\
\hline & peso (ton) & custo (Euro) & peso (ton) & custo (Euro) & peso (ton) & custo (Euro) \\
Ferro & 4,03 & 12.090 & 32,5 & 97.500 & 18,1 & 54.300 \\
Cobre & 1,21 & 18.150 & 12,6 & 189.000 & 4,3 & 64.500 \\
PM & -- & -- & -- & -- & 1,7 & 42.500 \\
Total & 5,25 & 30.200 & 45,1 & 286.500 & 24,1 & 161.300 \\
\hline
\end{tabular}


Tabela 1.6 Custo estimado para as diferentes turbinas eólicas (10³.Euro).

\begin{tabular}{lccc}
\hline & DFIG & EESG & PMG \\
\hline Parte ativa do gerador & 30,2 & 286,5 & 161,3 \\
\hline Construção do gerador & 30 & 160 & 150 \\
\hline Multiplicador de velocidade & 220 & -- & -- \\
Conversores & 40 & 120 & 120 \\
Sistema elétrico da turbina & 320 & 567 & 432 \\
\hline Outras partes comuns & 1.300 & 1.300 & 1.300 \\
\hline Margem para custos & 250 & 250 & 250 \\
\multicolumn{1}{r}{ Custo total } & $1.870,2$ & $2.116,5$ & $1.981,3$ \\
\hline \multicolumn{1}{c}{ Custo relativo } & $88,3 \%$ & $100 \%$ & $93,6 \%$ \\
\hline
\end{tabular}

Tabela 1.7 Balanço energético anual utilizando dados estatísticos de vento.

\begin{tabular}{lccc}
\hline & DFIG & EESG & PMG \\
\hline Perdas no cobre (MWh) & 82 & 456 & 189 \\
Perdas no ferro (MWh) & 70 & 40 & 89 \\
\hline Perdas no conversor (MWh) & 78 & 243 & 235 \\
$\begin{array}{l}\text { Perdas no multiplicador de } \\
\text { velocidade (MWh) }\end{array}$ & 533 & -- & -- \\
Perdas totais (MWh) & 763 & 739 & 513 \\
Produção de energia (MWh) & 7730 & 7880 & 8040 \\
\hline
\end{tabular}

Tabela 1.8 Estrutura de custo típico de turbinas de $2 \mathrm{MW}$ instaladas na Europa.

\begin{tabular}{|c|c|c|}
\hline & Investimento $(1.000 € / \mathrm{MW})$ & Parcela do custo total (\%) \\
\hline Turbina & 928 & 75,6 \\
\hline Conexão com a rede & 109 & 8,9 \\
\hline Fundações & 80 & 6,5 \\
\hline Aluguel do terreno & 48 & 3,9 \\
\hline Sistema elétrico & 18 & 1,5 \\
\hline Consultoria & 15 & 1,2 \\
\hline Custo financeiro & 15 & 1,2 \\
\hline Construção de vias de acesso & 11 & 0,9 \\
\hline Sistema de controle & 4 & 0,3 \\
\hline Total & 1.227 & 100 \\
\hline
\end{tabular}


O custo total de uma turbina eólica instalada e comissionada na Europa está em torno de 1,23 milhões de Euros/MW. Somente o custo da turbinas eólicas representa $75 \%$ do total. A estrutura de custos para um parque eólico instalado na Europa e equipado com turbinas de $2 \mathrm{MW}$ é mostrada na Tabela 1.8. Estes dados foram apresentados em 2009 no relatório da EWEA ([19]), com base em cálculos de projetos recentes.

O preço de venda da energia gerada por parques eólicos é o principal mecanismo para impulsionar e incentivar a instalação de novos empreendimentos. Em países pioneiros no uso de geração eólica, o incentivo governamental foi um fator estratégico e determinante para impulsionar o setor. Nos Estados Unidos, a energia produzida por geração eólica custava, em 1980, 260 U\$/MWh. Porém, em 2005, o custo atingiu o valor de 50 U\$MWh, sofrendo uma redução de $81 \%$ em 25 anos. As previsões futuras indicam que até 2020 o custo da energia eólica deverá ser reduzido nos Estados Unidos para 26 U\$/MWh, segundo dados publicados, em 2006, por Mathew ([20]). No Brasil, o custo da energia eólica ainda é elevado, porém, este custo deve diminuir nos próximos anos com a instalação de novas fábricas e a criação de uma demanda específica, a serem negociadas nos leilões periódicos de energia eólica. A Figura 1.4 apresenta os custos de energia no país publicado pelo Departamento de Gestão do Setor Elétrico (DGSE), em ([17]).

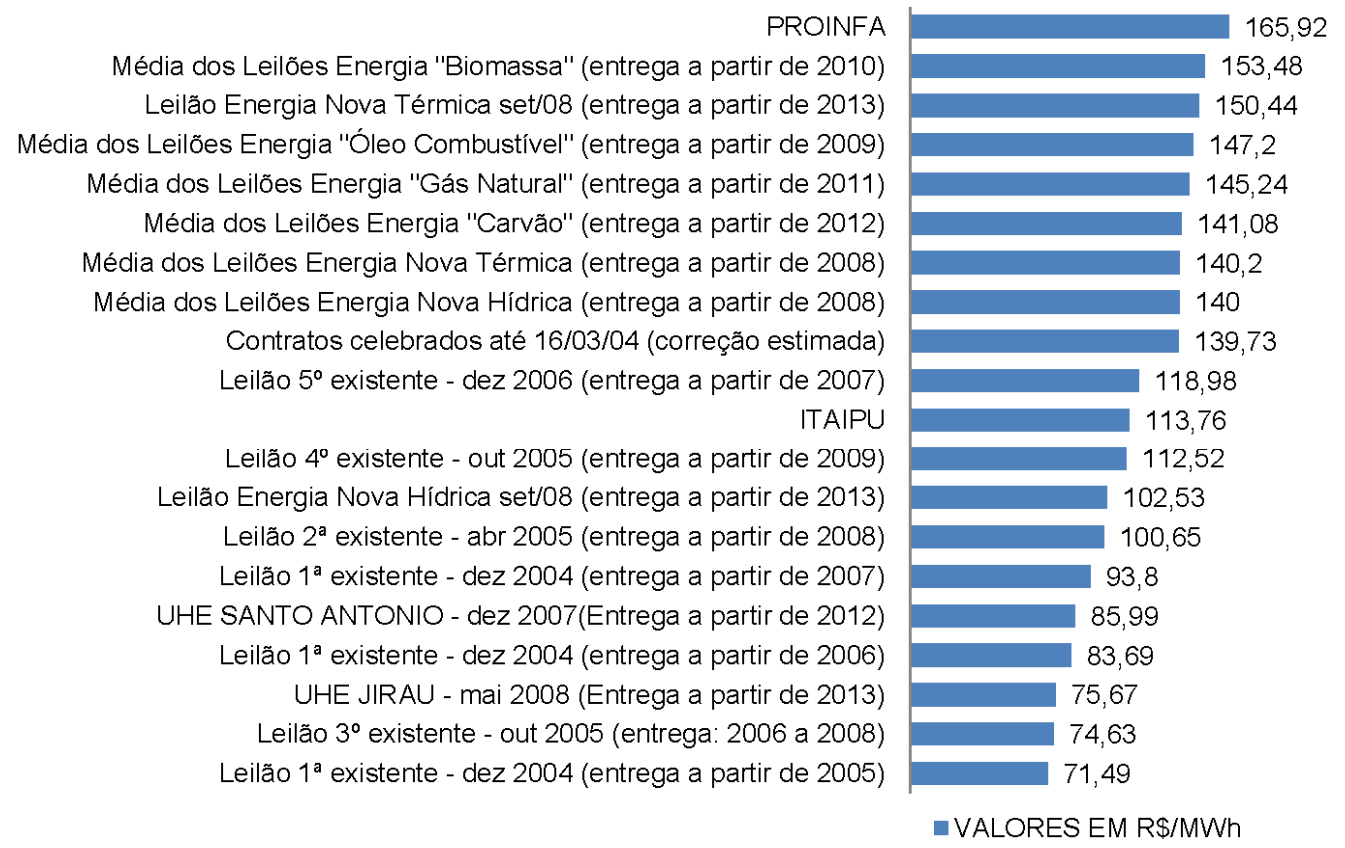

DGSE/SEE/MME - valores corrigidos pelo IPCA (IBGE) até maio/2009

Figura 1.4 Contratos de compra de energia elétrica no Brasil (fonte: [17]). 


\subsection{Justificativas e Objetivos}

O cenário mundial de turbinas eólicas apresentado anteriormente, juntamente com as intenções de investimentos futuros em energia eólica no Brasil, motivaram o tema desta tese de doutorado, tendo, como objeto principal de estudo, turbinas eólicas equipadas com DFIG. O uso de geradores de indução duplamente alimentados é relativamente recente, requerendo o desenvolvimento de metodologias de análise e de modelos computacionais que representem, de forma específica, este tipo de máquina e seus controles. Além disso, modelos computacionais de geradores síncronos a ímãs permanentes de fluxo radial e de fluxo transversal também foram desenvolvidos.

Apesar de um grande número de artigos técnicos sobre modelagem computacional do DFIG terem sido publicados recentemente, são poucos os que descrevem modelos computacionais completos, incluindo controles dos conversores e sistema de proteção (crowbar e dc-chopper). Estes sistemas de proteção foram recentemente incorporados a turbinas eólicas para possibilitar a operação intermitente durante curto-circuitos. Não obstante o reconhecimento da existência de diversos aspectos técnicos importantes, referentes à operação e instalação de turbinas eólicas em redes de energia elétrica, e que poderiam estar sendo analisados, delimitou-se o presente estudo em aspectos relacionados à modelagem computacional e à estabilidade.

Adicionalmente, a complexidade na utilização de programas computacionais comerciais para modelagem dinâmica de turbinas eólicas equipadas com DFIG, motivou o desenvolvimento de uma metodologia analítica, inédita, com vistas a contribuir para a simplificação do estudo de estabilidade desses geradores.

\subsection{Organização da Tese}

Esta tese de doutorado está organizada como segue:

- O Capítulo 1 apresenta um panorama sobre a energia eólica no Brasil e no mundo. Além disso, apresenta as justificativas e os objetivos dessa tese de doutorado. 
- O Capítulo 2 apresenta a evolução do controle de velocidade de máquinas de indução de rotor bobinado e o estado da arte dos principais modelos computacionais desenvolvidos, incluindo modelos aerodinâmicos, modelos dos geradores elétricos, modelos dos conversores e de seus controles. Adicionalmente, apresenta-se uma discussão sobre as contribuições originais desta tese.

- O Capítulo 3 descreve sucintamente os modelos computacionais que representam a aerodinâmica de turbinas eólicas de velocidade variáveis, bem como as redes teste utilizadas.

- O Capítulo 4 descreve sucintamente os modelos computacionais que representam turbinas eólicas equipadas com geradores de indução duplamente alimentados (DFIG) e o desempenho de novas estratégias de controle, bem como de novos sistemas e proteção.

- O Capítulo 5 apresenta a metodologia analítica desenvolvida para investigação da estabilidade de geradores de indução duplamente alimentados.

- No Capítulo 6, os modelos e os resultados das análises para os geradores síncronos a ímãs permanentes são apresentados e discutidos.

- O Capítulo 7 resume as conclusões obtidas durante o desenvolvimento desta tese, considerando os modelos desenvolvidos e os resultados obtidos através das simulações computacionais. 


\section{Capítulo 2}

\section{DISCUSSÃO SOBRE A EVOLUÇÃO E O ESTADO DA ARTE}

Devido ao grande número de temas envolvidos nesta tese de doutorado, optou-se por discutir, no capítulo normalmente reservado ao estado da arte, a evolução do uso de velocidade variável em máquinas de indução de rotor bobinado, bem como as contribuições originais desta tese.

\subsection{Evolução do Controle de Velocidade de Máquinas de Indução Duplamente Alimentadas}

A necessidade de variar a velocidade de operação de motores elétricos foi tema de discussões e de pesquisa desde os primeiros sistemas de energia elétrica. Nos primeiros sistemas do século XIX, tal operação com velocidade variável era mais restrita aos motores de corrente contínua. Podemos constatar tal fato na série de artigos publicados em 1902 ([22]-[24]) em um mesmo volume da extinta Transactions da AIEE (American Institute of Electrical Enginners, atualmente IEEE). Porém, com a transição no início do século XX ([25]) dos sistemas de corrente contínua e dos sistemas de corrente alternada monofásico (e bifásico) para sistemas de corrente alternada trifásicos, o uso das máquinas de indução trifásicas passou a se tornar mais comum, substituindo, gradativamente, as máquinas de corrente contínua em muitas aplicações.

Uma série de cinco artigos escritos mais recentemente por Thomas J. Blalock ilustra a substituição do uso de corrente contínua na eletrificação de plantas industriais para fabricação de aço. O primeiro artigo da série ([26]) descreve a eletrificação da maior planta industrial de fabricação de aço da América do Norte, a Bethlehem Steel Company, no início dos sistemas de energia elétrica em corrente contínua (CC). O segundo artigo descreve o desenvolvimento do sistema de $25 \mathrm{~Hz}$ nesta planta ([27]). O terceiro artigo diz respeito à introdução do uso de $60 \mathrm{~Hz}$ em Bethlehem ([28]). Somente no quarto artigo é descrita a substituição das máquinas a vapor, as quais eram responsáveis pela força motriz que giravam pares de rodas para moldar o aço ([29]). Tal substituição aconteceu em algumas plantas de produção de aço em meados de 1920. A operação em velocidade variável dos 
motores era feita com máquinas de indução com diferentes números de pólos no estator ou através do conjunto motor AC/gerador CC que alimentava outro motor CC de velocidade variável. Contudo, tais configurações eram ineficientes, muito complexas e necessitavam de constante manutenção nos comutadores das máquinas $\mathrm{CC}$, que, muitas vezes, eram de alta potência (4.000 hp). No quinto e último artigo da série, Blalock descreve dois sistemas (Krämer e Scherbius) para utilizar máquinas de indução operando com velocidade variável. Tais sistemas foram introduzidos nas plantas de Bethlehem ([30]). O uso de resistências variáveis nos enrolamentos do rotor também era uma alternativa, porém para variações de velocidade mais baixas e limitadas.

\subsubsection{Sistema Krämer}

O sistema Krämer utiliza um link comum de corrente contínua interligando máquinas convencionais (uma máquina de corrente contínua e um conversor síncrono). As escovas de saída do conversor síncrono de freqüência alimentam os anéis coletores dos enrolamentos do rotor do motor de indução. A freqüência do secundário do motor bobinado é a freqüência do conversor rotativo. O controle do fator de potência é feito variando a posição de fase das escovas do conversor rotativo. O aumento de velocidade é feito elevando-se a tensão aplicada aos enrolamentos do rotor. Este sistema foi proposto em 1908 por C. Krämer ([31]). A Figura 2.1 apresenta uma configuração simples do sistema Krämer para operação com potência-constante, com controle de velocidade e de fator de potência.

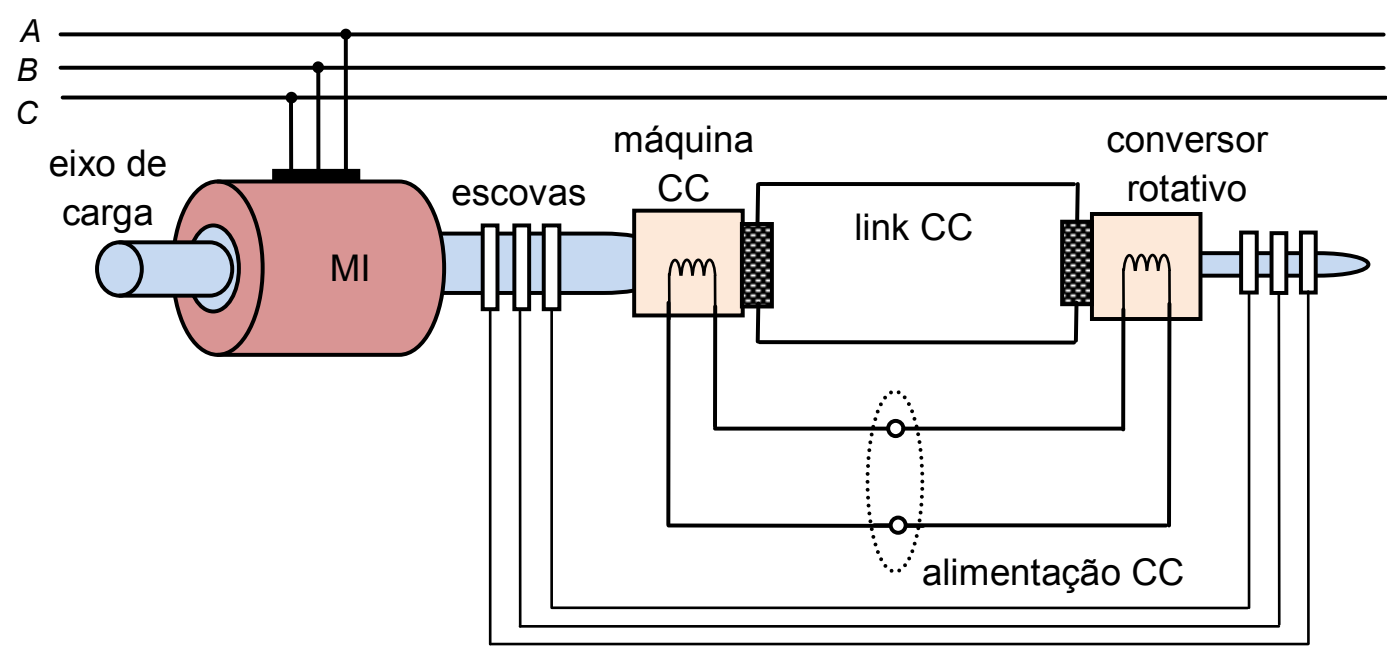

Figura 2.1 Sistema Krämer, potência-constante com controle de fator de potência e de velocidade. 


\subsubsection{Sistema Scherbius}

O sistema Scherbius é baseado na aplicação de tensão e freqüência variáveis no rotor da máquina de indução em função da velocidade desejada (como no Krämer). Esta tensão e freqüência variáveis eram produzidas por uma máquina comutadora auxiliar, na qual as bobinas eram projetadas para operação trifásica. Três grupos de escovas eram espaçados de 120 graus elétricos uma das outras, por onde passava apenas uma fração da potência nominal do motor. Portanto, não havia necessidade de tais escovas serem tão robustas quanto às das máquinas CC do sistema Krämer. Dependendo da configuração adotada, era possível reutilizar a potência do enrolamento do rotor no próprio eixo ou reinjetá-la na rede elétrica. 0 primeiro sistema Scherbius foi comercializado pela General Electric por volta de 1916 ([30]). A Figura 2.2 apresenta uma configuração simples do sistema Scherbius para operação com conjugado-constante e velocidade variável abaixo da síncrona.

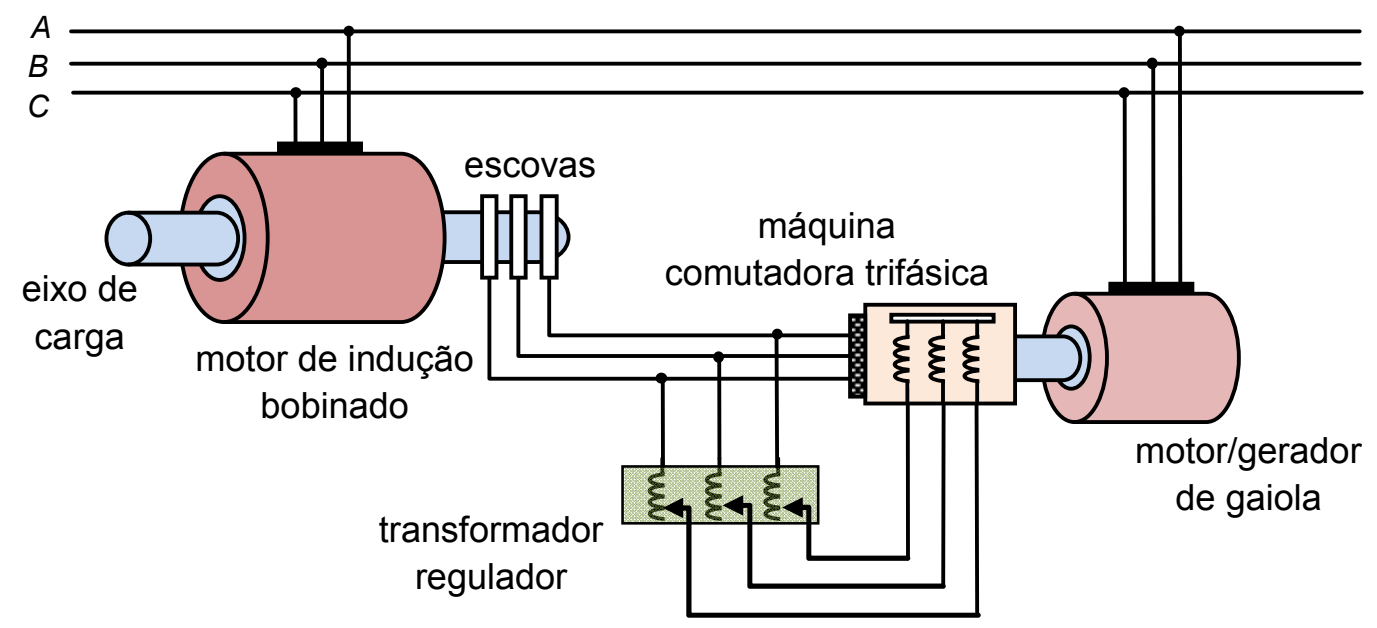

Figura 2.2 Sistema Scherbius para operação conjugado-constante abaixo da velocidade síncrona.

Outras configurações e variações dos sistemas Krämer e Scherbius podem ser encontradas em livros raros de máquinas elétricas. O livro de B. A. Behrend, de 1921, constitui material bem completo e de fácil entendimento a respeitos destes tópicos ([32]). Um pouco mais simples, porém bem informativo, é o livro de controle de máquinas elétricas de Irving L. Kosow, de 1973 ([33]). Porém, em 1912, um artigo sobre controle de máquinas elétricas de indução para aplicação em plantas de produção de aço já havia sido escrito por Meyer e Sykes ([34]). Neste artigo, os autores incluíram uma série de possibilidades de controle de velocidade, além de descreverem em detalhes a máquina comutadora trifásica. 


\subsubsection{Sistema Clymer}

Em 1915, o Congresso americano cria a agência que seria a predecessora da NASA (National Aeronautics and Space Administration), chamada NACA (National Advisory Committee for Aeronautics). Uma série de centros de pesquisa foi instalada nos Estados Unidos para suprir a necessidade de inovações e de desenvolvimento do setor aeronáutico. Todos estes centros de pesquisas eram equipados com túneis de vento de alta potência para diversas necessidades, que podem ser agrupados em cinco famílias: túneis de baixas velocidades, túneis de altas velocidades, túneis próximos da velocidade do som, túneis supersônicos e túneis hipersônicos. À medida que esses túneis de vento foram evoluindo (desde os de baixa velocidade aos hipersônicos), a necessidade de utilizar motores de potência elevada (15.000 a $40.000 \mathrm{hp}$ ) limitou o uso de motores $\mathrm{CC}$, que na época, chegavam ao máximo a $10.000 \mathrm{hp}$. O engenheiro da General Electric, Charles C. Clymer, desenvolveu no início os anos 40 um sistema de alimentação que passou a ser usado na maioria dos túneis de vento até a invenção de dispositivos baseados em eletrônica de potência ([35]).

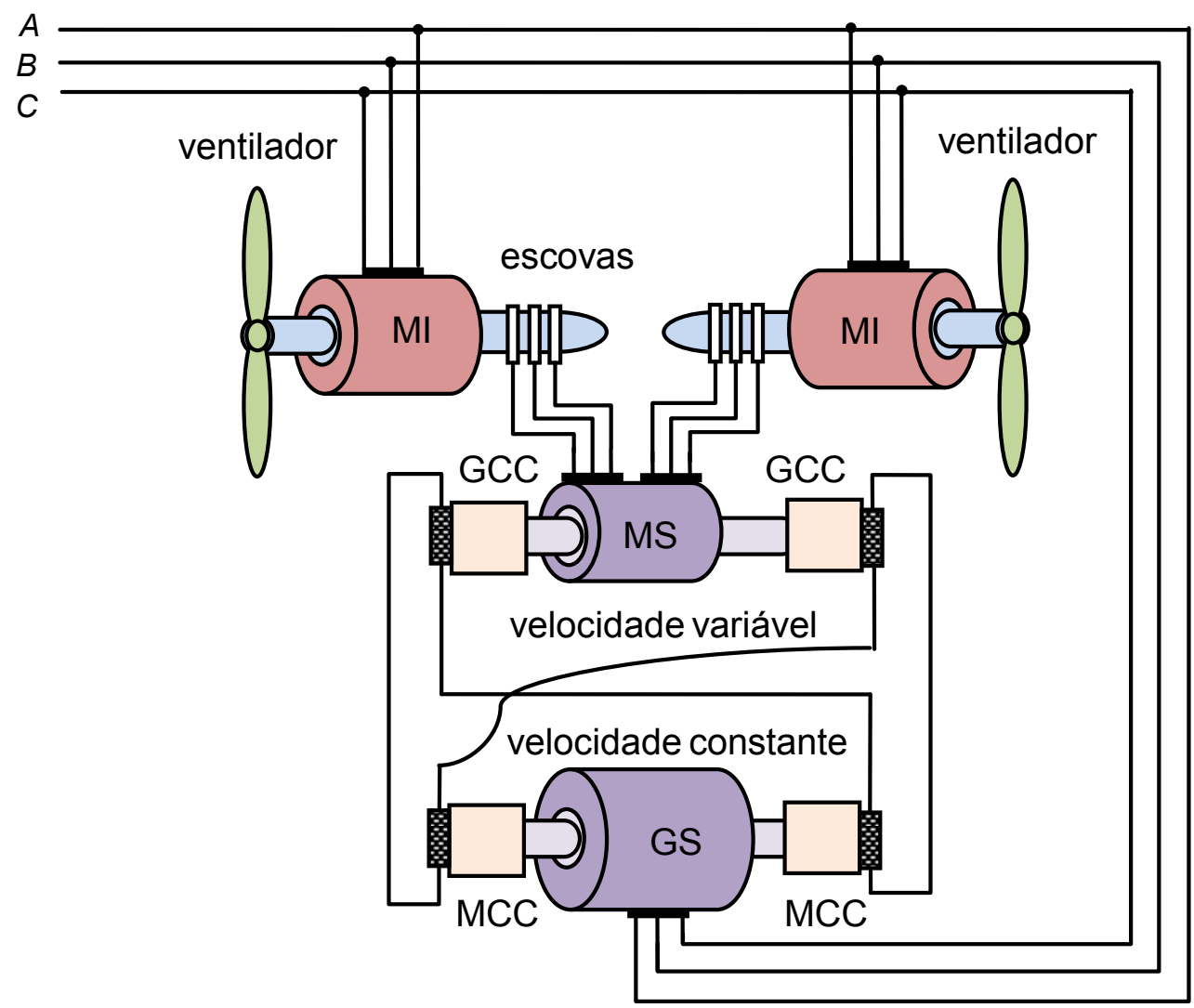

Figura 2.3 Sistema Clymer, potência-variável com controle de fator de potência e de velocidade. 
A Figura 2.3 apresenta uma das configurações propostas por Clymer, descrita em um artigo publicado em 1942 ([36]). Nesta configuração, os dois motores de indução de rotor bobinado (MI) operam em sincronismo absoluto, pois os enrolamentos rotóricos estão ligados em série, como no controle Selsyn, garantindo a mesma posição angular relativa entre os dois rotores. Porém, um motor síncrono (MS) em vazio é ligado também em série com os enrolamentos rotóricos entre os dois Ml's, de forma a injetar tensão e freqüência para controlar o fator de potência e a velocidade dos Ml's. O sistema completo inclui, ainda, dois geradores de corrente contínua (GCC), um gerador síncrono (GS) para alimentação do sistema e dois motores de corrente contínua (MCC).

\subsubsection{Motor Schräge}

Para uma faixa de potência nominal mais limitada do que a dos três sistemas descritos anteriormente, um motor que combinava uma máquina de indução de rotor bobinado com uma máquina de comutação trifásica em um só equipamento foi introduzido pelo alemão H. K. Schräge em 1914 ([37]). Esse motor eliminava a necessidade de máquinas auxiliares, tornando o sistema mais simples e mais barato. Como mostrado na Figura 2.4, o enrolamento primário é montado no rotor do motor Schräge, por meio do qual é alimentado pela rede elétrica trifásica, via anéis coletores. O comutador é montado no rotor, sendo este conectado ao enrolamento ajustável convertendo a freqüência da rede elétrica para a freqüência desejada no enrolamento secundário estatórico ([38], [39]). Os ajustes de velocidade e de correção do fator de potência são feitos mecanicamente variando a posição angular das escovas ([40], [41]). Estas máquinas foram muito usadas na indústria têxtil.

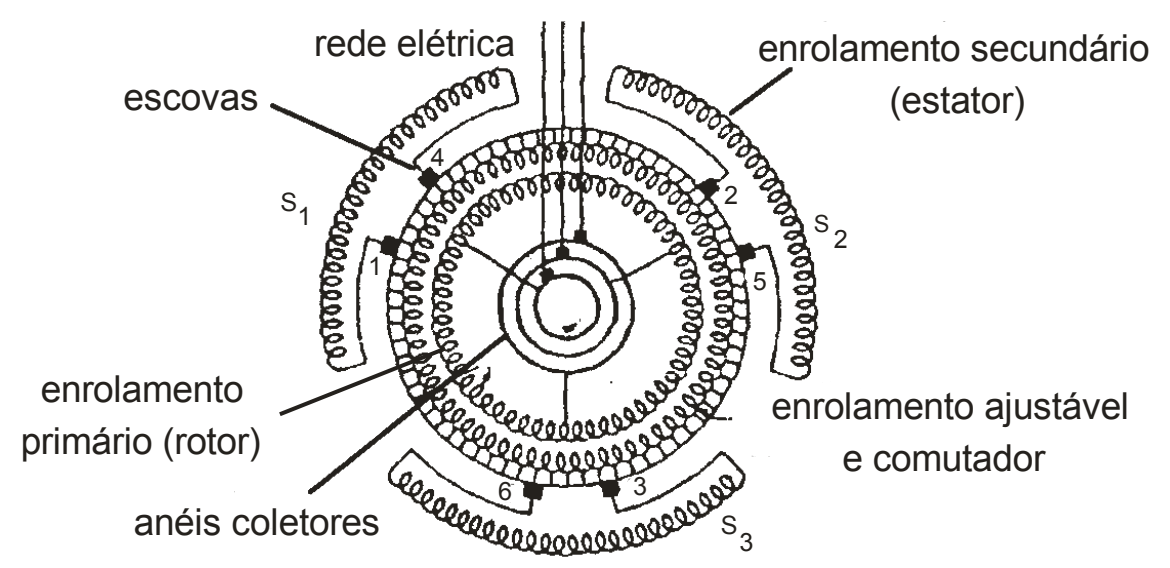

Figura 2.4 Configuração esquemática dos enrolamentos do motor Schräge. 


\subsubsection{Sistemas utilizando Eletrônica de Potência}

Desde o início do século XX até meados de 1950, foram desenvolvidos gradualmente o retificador de tanque metálico, o retificador em tubo a vácuo de grade controlada, o ignitron e o tiratron. A tendência à substituição dos conversores eletromecânicos, discutidos anteriormente para controlar a velocidade de máquinas de indução de rotor bobinado, por inversores eletrônicos teve início durante esse período. A título de exemplo, em 1938, Alexanderson et al. ([42]) descrevem a substituição do conversor síncrono rotativo do sistema Krämer, apresentado na Figura 2.1, por um conversor estático não-controlável utilizando válvulas de potência (uma variação do tubo a vácuo). Um ano mais tarde, o alemão Stöhr ([43]) propõe uma versão eletrônica do sistema Scherbius, apresentado na Figura 2.2, substituindo a combinação de máquina comutadora trifásica e motor de indução por dois conversores a arco de mercúrio (ignitron). Desta forma, a configuração apresentava o conjunto retificador-inversor para devolver a potência do rotor à rede elétrica ([43]). Tais sistemas não tiveram muito sucesso comercial e seu uso foi restrito.

Com o início da fabricação e do desenvolvimento de transistores $p-n-p$ e $n-p-n$ no começo dos anos 50 ([44]), a possibilidade do uso de tais componentes eletrônicos para o controle de velocidade de máquinas elétricas convencionais (de corrente contínua, de indução e síncrona) foi descrita, em 1952, por Alexanderson et al. ([45]). Assim, teve início uma nova etapa na história do controle e na operação das máquinas elétricas. Os sistemas apresentados anteriormente foram sendo substituídos, de forma gradual, até meados dos anos 90, sendo que aplicações como gerador, também passaram a ser mais utilizadas, como descritas no capítulo 1 (introdução). Com referência aos sistemas Krämer e Scherbius, estes continuaram a ser usados, porém, com a utilização da eletrônica de potência de estado sólido, passaram a ser chamados de sistema estático Krämer (ou Scherbius).

Segundo relatório técnico, escrito em 2001, por Carlin et al. ([46]), o primeiro protótipo de uma turbina eólica de grande porte (3 MW), equipada com gerador de indução com dupla alimentação, começou a ser projetada em 1978/1979 pela empresa Growian GmbH. Tal protótipo foi testado durante 1982 a 1987, contudo, problemas construtivos impediram que outras máquinas fossem construídas. 


\subsection{Estado da Arte e Modelos Dinâmicos de Turbinas Eólicas}

A Figura 2.5 apresenta, esquematicamente, os modelos desenvolvidos, além de uma síntese das análises realizadas. Com isso, pretende-se que o leitor tenha uma compreensão mais clara e objetiva do texto.

\section{Modelos Computacionais Desenvolvidos}

\begin{tabular}{|c||c|c|c|c|}
\hline Geradores & Conversores & Rede Elétrica & Controles & Aerodinâmico \\
\hline PMSG & $\begin{array}{c}\text { Conversor } \\
\text { Capacidade } \\
\text { Nominal }\end{array}$ & Distribuição & GenSC & Slootweg \\
\hline TFG & \begin{tabular}{c|c|c|c|}
\hline Conversor \\
Capacidade \\
Parcial
\end{tabular} & Distribuição & RSC & Heier \\
\hline Transmissão & GSC & Slootweg \\
\hline
\end{tabular}

\section{Análises Dinâmicas Realizadas}

TFG

Operação durante variações do vento

DFIG

- 3 diferentes capacidades do conversor - 3 filosofias de controles

\section{PMSG}

Operação durante curto-circuito na rede

DFIG

Determinação do tempo crítico de eliminação de falta para comparação com metodologia analítica

Turbina eólica equipada com geradores síncronos de ímãs permanentes

Turbinas eólicas equipadas com DFIG

Contribuição original

Figura 2.5 Diagrama esquemático do desenvolvimento da tese de doutorado. 


\subsubsection{Modelos de Geradores}

O modelo dinâmico completo das máquinas elétricas convencionais, para análise de transitórios eletromagnéticos, apresenta grau de maturidade avançado, sendo descrito em diversas fontes ([47]-[49]). Porém, para estudos de estabilidade transitória, tais modelos podem ser simplificados, desconsiderando a parte diferencial das equações de tensão do estator (representação fasorial), sem perda na precisão dos resultados ([47]-[49]). O modelo simplificado é utilizado nesta tese para representar a máquina de indução de rotor bobinado.

O gerador síncrono a ímãs permanentes, de fluxo magnético transversal (TFG), apresenta uma importante característica que vem despertando interesse em pesquisadores de várias partes do mundo para utilização em turbinas eólicas instaladas no mar. Entre as máquinas elétricas modernas, ele apresenta a maior relação entre o conjugado eletromagnético e a massa de sua parte ativa ([12]), como também mostrou Gieras, em seu estudo experimental, em ([50]). Com base nessa constatação, foi desenvolvido, neste trabalho, um modelo computacional específico para o gerador síncrono a ímãs permanentes de fluxo transversal (TFG). Pretendese que o modelo desenvolvido possa constituir contribuição original desta tese de doutorado, uma vez que esse gerador elétrico não possui equações gerais analíticas que representem seu comportamento dinâmico ([51]), como é o caso das duas máquinas citadas anteriormente. O modelo utiliza o Método dos Elementos Finitos (MEF) para calcular o fluxo magnético concatenado por fase, cujo detalhamento é apresentado no capítulo 6 . 0 uso de geradores síncronos a ímãs permanentes ainda é recente em turbinas eólicas, porém muito promissor ([6], [9], [12]).

\subsubsection{Modelos de Conversores e de Rede Elétrica}

Os conversores com modulação por largura de pulso (conversores PWM), tanto para gerador de indução duplamente alimentado, quanto para os a ímãs permanentes, foram modelados como fonte de tensão (Voltage Source Converter). Para análises de estabilidade transitória, os modelos consideram os Insulated Gate Bipolar Transistors (IGBT's) como ideais ([52]-[57]). Assim, neste tipo de análise, o modelo do controle dos conversores é mais importante do que seu modelo físico. A representação da rede de distribuição utiliza um sistema radial simples. A rede de 
transmissão utilizada é baseada na configuração descrita por M. A. Pai de um sistema real americano ([58]). Os elementos de rede para estes dois sistemas foram modelados, segundo Kundur ([48]) e Arrillaga ([59]). Tais modelos apresentam elevado grau de maturidade.

\subsubsection{Modelos de Controles de Conversores}

\section{A) Geradores Síncronos a ímãs Permanentes}

Em 2003, Akhmatov et al. ([60]) descreveram um modelo genérico para geradores a ímãs permanentes, para estudos de estabilidade, incluindo a parte relativa a seus controles típicos. Neste artigo, descrevem a aplicação em geração de energia eólica conectada à rede elétrica, apontando a necessidade de operação como gerador com velocidade variável, controlado pelo conversor do lado do gerador (GenSC), e de injeção de potência reativa pelo conversor do lado da rede (GSC). Em 2006, Akhmatov ([61]) acrescenta uma discussão e um modelo de controle dos geradores a ímãs permanentes durante curto-circuitos na rede elétrica. Mais recentemente, em 2007 e 2008, o controle para amortecimento ativo das oscilações torcionais do conjunto rotor-da-turbina-eólica/eixo/rotor-do-gerador começou a ser proposto, porém, em alguns casos, com mais algumas outras combinações. Conroy e Watson ([62]) incluíram também controle de um sistema de Braking Resistor para amortecimento de oscilações de injeção de potência elétrica devido a turbulências na velocidade do vento, Jauch ([63]) incluiu um efetivo controle de amortecimento contra oscilações na rede elétrica (diminuindo a oscilação angular de geradores síncronos conectados em barramentos próximos) e Hansen e Michalke ([64]), também, incluíram ao modelo o amortecimento durante turbulências na velocidade do vento. Dentre eles, o modelo discutido por Akhmatov ([61]) mostrouse atender plenamente às necessidades de estudos de estabilidade, razão pela qual foi adotado no presente trabalho.

\section{B) Geradores de Indução Duplamente Alimentados}

Modelos computacionais de controles de conversores do gerador de indução duplamente alimentado (DFIG) começaram a ser propostos no início dos anos de 1980. Smith et al., em 1981 ([65]), além de utilizarem um modelo computacional e compararem com simulações em bancada, propunham, também, uma modificação 
no sistema estático Scherbius (baseado em tiristores). Tal modificação introduzia um gerador de sinal de freqüência variável para o controle do disparo dos tiristores, ligados aos enrolamentos do rotor, desta forma, possibilitando operação abaixo e acima da velocidade síncrona e com fator de potência unitário. Em 1988, Krause et al. ([66]) expandiram a teoria dos eixos de referência d-q de Park ([67], [68]), inicialmente desenvolvida para máquinas síncronas, para as máquinas de indução de rotor bobinado com recuperação de energia via inversor e retificador. Com essa teoria, foi possível o desenvolvimento de novos controles para o DFIG. Em 1991, um controle independente de potência ativa e reativa, utilizando tal teoria foi sugerido por Yamamoto e Motoyoshi ([69]), comparando simulação computacional com simulações em bancada, utilizando, ainda, tiristores. Desde então, novas filosofias de controle foram surgindo, além da substituição dos tiristores por IGBT's.

No início de 2001, ano do envio do artigo, Akhmatov ([70]) propõs a operação em conjunto com o controle de ângulo das pás da turbina para melhorar a margem de estabilidades de geradores de indução durante curto-circuitos na rede elétrica. Desde então, uma série de artigos sobre modelos computacionais dos controles dos conversores do DFIG começaram a ser divulgados. Em 2002, Müller et al. ([71]) descreveram um modelo computacional do controle vetorial, utilizado por eles e implementados em uma turbina eólica da empresa alemã SEG, considerando variações na velocidade do vento. Em artigo publicado por Slootweg et al., em 2003, analisaram o desempenho dinâmico durante variações na velocidade do vento para os três principais tipos de geradores eólicos, comparando e validando os modelos desenvolvidos com medidas de campo. Em 2003, Ekanayake et al. ([72]) mostraram que, mediante seleção adequada dos ganhos dos controles de velocidade e de fator de potência, era possível melhorar a estabilidade da fazenda eólica durante curtocircuitos no sistema elétrico, porém, consideraram o link de corrente contínua com tensão constante. Em 2003, Akhmatov começou a propor e discutir modelos para o conversor do DFIG ([53]-[55]). Posteriormente, em seu artigo ([73]), propõs e analisou o uso do conversor do lado da rede (GSC) controlando potência reativa durante curto-circuitos no sistema elétrico, quando se fazia necessário o bloqueio do conversor do lado do rotor (RSC), devido a altas correntes induzidas nos enrolamentos do rotor, ou devido a altas tensões no link CC durante curto-circuitos severos, possibilitando, desta forma, a operação ininterrupta. Em 2005, Morren e 
Haan ([74]) propuseram um controle que limita o efeito dos transitórios de tensão e de corrente nos enrolamentos do rotor durante a inclusão e a exclusão de resistências, em série, no rotor. Estas resistências limitam a corrente do rotor, durante curto-circuitos no sistema elétrico (sistema crowbar).

Em 2006, em dois países europeus, ocorreu importante mudança nos requisitos para conexão à rede de transmissão de energia elétrica. Além da exigência de que as turbinas eólicas não se desconectassem do sistema elétrico durante curto-circuitos, comum, também, em outros países com elevados índices de penetração de geração de energia eólica (como descrito por Jauch et al. em [75]), a Alemanha e a Espanha passaram a exigir a injeção de corrente reativa. Tal requisito exige a injeção de $100 \%$ e $90 \%$, respectivamente ([76], [77]), de corrente reativa durante curto-circuitos que afundem a tensão terminal, no ponto de conexão da fazenda eólica, para níveis abaixo de 50\%. Em 2007, Erlich et al. ([79]) descreveram em detalhes o uso do sistema crowbar e do dc-chopper para permitir a operação durante curto-circuitos na rede de transmissão. Em 2009, Qiao et al. ([80]) desenvolveram o modelo computacional para o estudo do uso do STATCOM no ponto de conexão com a rede de fazendas eólicas equipadas com DFIG, propondo controles coordenados dos conversores do DFIG e do STATCOM para melhorar a injeção de potência reativa durante curto-circuitos.

Destaca-se que esta tese de doutorado apresenta uma contribuição original na modelagem de diferentes filosofias de controle de potência reativa (através do GSC e do conversor conectado ao rotor - RSC) e do sistema de proteção do DFIG (crowbar e dc-chopper), de forma a permitir o estudo da operação ininterrupta durante curto-circuitos.

\subsubsection{Modelos Aerodinâmicos da Turbina Eólica}

Modelos aerodinâmicos computacionais de turbinas eólicas, para estudos dinâmicos, começaram a ser propostos por volta de 1983 ([81]), incluindo o controle simplificado do ângulo das pás, sendo este, ainda, utilizado em estudos publicados no ano 2000 ([82]). O modelo proposto considerava turbinas eólicas com duas pás, sendo que o controle de ângulo de passo as rotacionava apenas parcialmente, devido à própria tecnologia, em uso, na época. A idéia por trás de tal modelo 
representava as turbinas eólicas, basicamente, por uma equação utilizando o coeficiente de potência. Em 1998, um modelo que considerava turbinas eólicas de três pás, apresentado por Heier ([83]), passou a ser mais utilizado. Modelos mais complexos utilizam o Blade Element Momentum (BEM), que consiste na representação individual de diferentes seções ao longo das pás. Porém, um estudo apresentado na tese de doutorado defendida por V. Akhmatov, em 2003 ([56]), constatou que a representação por curvas de coeficiente de potência $(C p)$ é suficientemente precisa para estudos de estabilidade transitória. Ainda em 2003, Slooweg apresentou valores aprimorados de coeficientes utilizados por Heier, de forma a representar mais precisamente a aerodinâmica de turbinas eólicas modernas ([84], [57]). A precisão das curvas $C p$ resultantes desses novos valores foi comprovadas com dados reais de operação de uma fazenda eólica ([84], [57]). Porém, há que assinalar que esses modelos são genéricos, pois cada fabricante mantém em segredo o conjunto de curvas $C p$ que determinaram experimentalmente.

\subsection{Análise Dinâmica de Fazendas Eólicas}

O aprimoramento dos modelos computacionais, que representam turbinas eólicas contribuiu para o desenvolvimento, a partir de 2001, de uma série de novos estudos e artigos técnicos sobre estabilidade em sistemas de potência, considerando geração de energia eólica em diferentes países e sistemas elétricos. A esse respeito, duas teses de doutorado importantes foram publicadas em 2003: a tese defendida por Slootweg ([84]), que estuda a estabilidade do sistema de potência holandês, considerando elevada penetração de geração de energia eólica, e a defendida por Akhmatov ([56]), que analisa o sistema elétrico dinamarquês.

O Energy Research Centre of the Netherlands (ECN) desenvolveu o projeto ERAO (2004-2007), em parceria com a Universidade Tecnológica de Delft, de analise e desenvolvimento de modelos computacionais na representação das fazendas eólicas instaladas na Holanda (em terra e no mar), validando tais modelos com medições em campo ([85], [86]). Muljadi et al. ([87]), através do centro de pesquisa americano National Renewable Energy Laboratoy (NREL), analisaram, em 2007, o impacto na rede de transmissão da conexão de uma fazenda eólica de 100 MW equipada com DFIG, constatando que tal fazenda eólica melhorava a estabilidade transitória do sistema de transmissão onde estava conectada. 
Inspirados nestes e em outros estudos, operadores dos sistemas de transmissão dos países da União Européia criaram o European Wind Integration Study (EWIS), em colaboração com a European Commission (EC), tendo, por objetivo, desenvolver e facilitar a integração da energia eólica nos países da União Européia. O grupo de trabalho WG3 Power System Analysis publicou, em dezembro de 2008, um estudo com a validação de diferentes modelos computacionais de turbinas eólicas, respeitando as normas vigentes em cada país, com relação à conexão e à operação, durante curto-circuitos na rede elétrica ([88]).

Nesse cenário, intenciona-se que o presente estudo contribua originalmente, na análise dinâmica de turbinas eólicas equipadas com TFG, durante variações na velocidade do vento, determinando a curva de potência para diferentes pontos de operação. Mais do que isso, esforços foram empenhados nos estudos dinâmicos de estratégias de controle e do sistema de proteção dos conversores do DFIG, como contribuição para um melhor entendimento do funcionamento ininterrupto dessas turbinas eólicas, durante curto-circuito na rede elétrica. Adicionalmente, é apresentada proposta de método analítico para determinação do tempo crítico de eliminação de falta para o DFIG, como contribuição original, resultante do estudo desenvolvido para elaboração desta tese. 


\section{Capítulo 3}

\section{MODELOS COMPUTACIONAIS}

Neste capítulo, descreve-se sucintamente o programa computacional utilizado, bem como os modelos desenvolvidos para análises dinâmicas.

\subsection{SimPowerSystems}

O SimPowerSystems é uma ferramenta computacional relativamente recente para análise de transitórios em sistemas eletromecânicos ([49]). Tal ferramenta acompanha, na forma de um Blockset, a plataforma computacional Matlab/Simulink. O conjunto de bibliotecas do SimPowerSystems é bastante completo, fornecendo modelos de diversos componentes de rede, por exemplo, elementos RLC concentrados; cargas não-lineares; diversos modelos de máquinas elétricas e controles associados; modelos de linhas de transmissão e cabos concentrados (modelo $\pi$-equivalente) e distribuídos (modelo de Bergeron); disjuntores (circuit breakers); componentes de eletrônica de potência e controles associados; etc. Tais componentes podem ser utilizados em conjunto com modelos existentes no Simulink, assim como com modelos desenvolvidos pelo usuário empregando Simulink, Matlab (arquivos .m), linguagem de programação Fortran ou C. Uma importante característica das versões mais recentes do SimPowerSystems é permitir a realização de estudos tanto de simulação eletromagnética, em que variáveis da rede são representadas por valores instantâneos, quanto de estabilidade transitória, em que as variáveis da rede são representadas por fasores. Além disso, há um mecanismo de inicialização das variáveis das máquinas elétricas e controles associados usando um fluxo de carga.

Neste projeto, um dos objetivos foi determinar a resposta dinâmica dos geradores de corrente alternada e das variáveis elétricas da rede durante curtocircuitos no sistema elétrico, portanto, os fenômenos de interesse podem ser considerados transitórios lentos ([48], [59]). Além disso, todos os componentes de rede, incluindo geradores de corrente alternada, foram representados por modelos trifásicos. 


\subsection{Modelos Aerodinâmicos}

De forma simplificada, o modelo aerodinâmico permite calcular o valor do conjugado mecânico (ou da potência mecânica) aplicado ao eixo do gerador elétrico, considerando diferentes velocidades do vento e diferentes posições do ângulo de passo das hélices. Este modelo depende do tipo de turbina eólica a ser representado (eixo vertical ou horizontal, quantidade de hélices, controle de ângulo das pás, etc.). O modelo aerodinâmico independe do tipo de gerador elétrico escolhido ou do tipo de controle utilizado nos conversores. Desta forma, ele pode ser estudado utilizando diferentes tipos de geradores elétricos. As equações do conjugado mecânico (3.1) e da potência mecânica (3.2), que podem ser extraídos do vento, são dados respectivamente por ([9], [12], [52], [83]-[84]):

$$
\begin{aligned}
& T_{m}=\frac{1}{2} \cdot A \cdot \rho \cdot V^{2} \cdot C_{p}(\lambda, \beta) \\
& P_{m}=\frac{1}{2} \cdot A \cdot \rho \cdot V^{3} \cdot C_{p}(\lambda, \beta)
\end{aligned}
$$

sendo:

$$
\begin{array}{ll}
T_{m} & =\text { conjugado mecânico (N.m). } \\
P_{m} & =\text { potência mecânica }(\mathrm{W}) . \\
A & =\text { área varrida pelas hélices da turbina }\left(\mathrm{m}^{2}\right) . \\
\rho & =\text { densidade do ar }\left(\mathrm{kg} / \mathrm{m}^{3}\right) . \\
V & =\text { velocidade do vento }(\mathrm{m} / \mathrm{s}) . \\
C_{p} & =\text { coeficiente de potência. } \\
\lambda & =\text { relação linear de velocidade }\left(\omega_{m} \cdot \mathrm{R} / \mathrm{V}\right) . \\
\omega_{m} & =\text { velocidade angular da turbina }(\mathrm{rad} / \mathrm{s}) . \\
\beta & =\text { ângulo de passo das hélices da turbina (grau). }
\end{array}
$$


O coeficiente de potência $\left(C_{p}\right)$ indica a eficiência com que a turbina eólica transforma a energia cinética contida nos ventos em energia mecânica girante. Segundo o limite de Betz para turbinas de eixo horizontal com três pás, o valor máximo possível é aproximadamente 0,59 ([56], [83], [92], [93]). O coeficiente de potência depende do ângulo de passo das hélices $(\beta)$ e da relação linear entre a velocidade do vento e a velocidade da ponta da hélice $(\lambda)$. Usualmente, um conjunto de curvas $C_{p}$, relacionando $\lambda$ e $\beta$, é obtido experimentalmente para cada modelo de turbina eólica, visto que as características aerodinâmicas, mesmo entre as de 3 hélices, diferem umas das outras. Nesta tese, foi utilizado o modelo geral sugerido por S. Heier ([83]), sendo suas equações apresentadas a seguir:

$$
\begin{aligned}
& C_{p}(\lambda, \beta)=c 1 \cdot\left(c 2 / \lambda_{i}-c 3 \cdot \beta-c 4 \cdot \beta^{c 5}-c 6\right) \cdot e^{-c 7 / \lambda_{i}} \\
& \lambda_{i}=\frac{1}{\frac{1}{\lambda+c 8 \cdot \beta}-\frac{c 9}{\beta^{3}+1}}
\end{aligned}
$$

Dois conjuntos de valores das constantes c1-c9 foram adotados. O primeiro foi o sugerido por S. Heier ([83]) e o segundo por Slootweg ([84], [57]). Slootweg ajustou os valores dos coeficientes utilizados por Heier, de forma a representar mais precisamente a aerodinâmica de turbinas eólicas modernas. Estes valores são apresentados na Tabela 3.1.

Tabela 3.1 Valores para aproximação das curvas do coeficiente de potência.

\begin{tabular}{cccccccccc}
\hline & $\mathrm{c} 1$ & $\mathrm{c} 2$ & $\mathrm{c3}$ & $\mathrm{c} 4$ & $\mathrm{c5}$ & $\mathrm{c6}$ & $\mathrm{c7}$ & $\mathrm{c8}$ & $\mathrm{c9}$ \\
\hline Heier & 0,5 & 116 & 0,4 & 0 & 0 & 5 & 21 & 0,08 & 0,035 \\
Slootweg & 0,73 & 151 & 0,58 & 0,002 & 2,14 & 13,2 & 18,4 & $-0,02$ & $-0,003$ \\
\hline
\end{tabular}

As curvas $C p$, calculadas utilizando as equações (3.3) e (3.4), são mostradas respectivamente na Figura 3.1 e na Figura 3.2. Nota-se que nas curvas que representam melhor a aerodinâmica de turbinas eólicas mais modernas (Figura 3.2), o valor máximo do $\mathrm{Cp}$ teve um aumento significativo (em torno de 2 a $3 \%$ ), refletindo positivamente na produção anual de energia elétrica. Além disso, a diminuição do valor máximo de $\lambda$ (de 16 para 12) contribui para uma maior eficiência do controle mecânico de velocidade, através da variação do ângulo de passo $(\beta)$. 


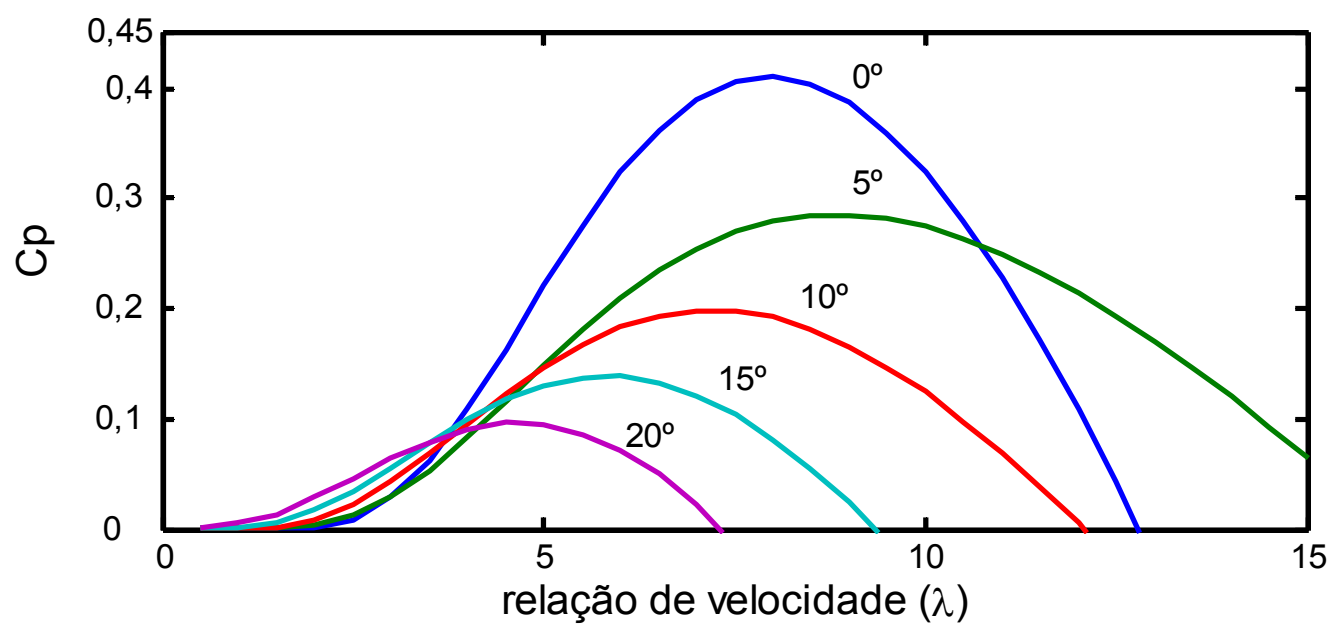

Figura 3.1 Curvas $C_{p}$ sugeridas por Heier, para diferentes valores de ângulo de passo.

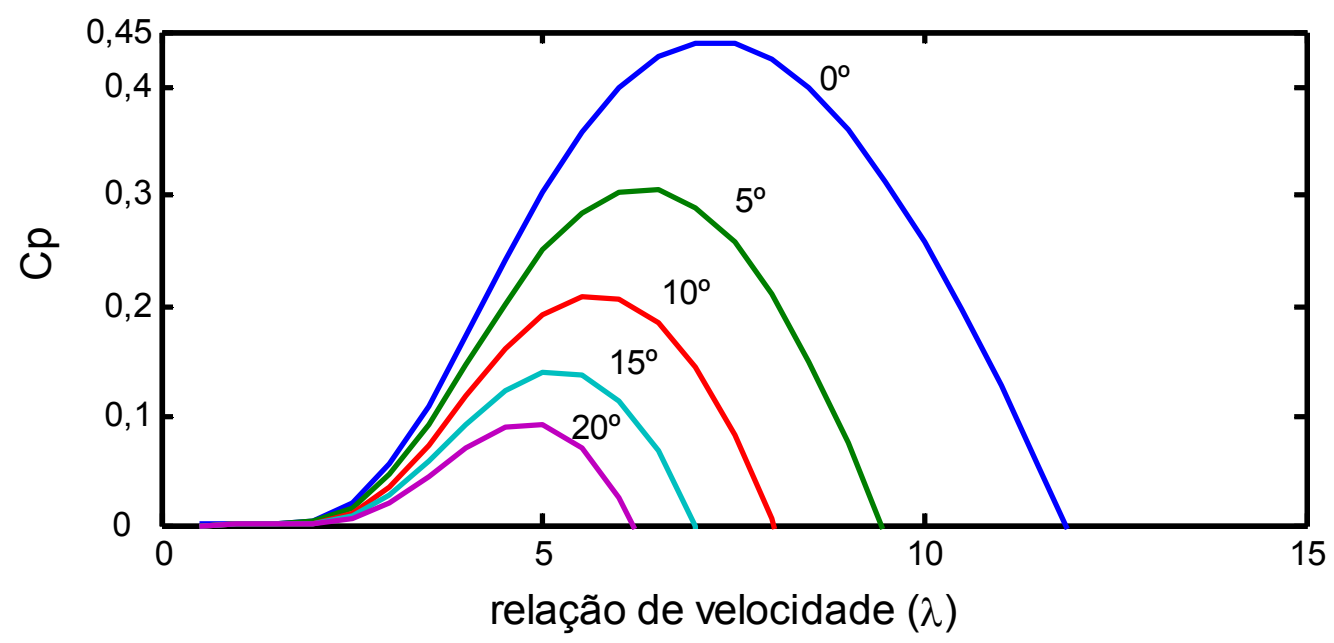

Figura 3.2 Curvas $C_{p}$ sugeridas por Slootweg, para diferentes valores de ângulo de passo.

\subsection{Turbinas Eólicas de Velocidade Variável}

Na segunda metade de 1990, a fabricação de turbinas eólicas de velocidade variável passou a ganhar espaço. Um dos principais motivos foi a diminuição do preço (e também do aumento da eficiência) dos IGBT's. Dessa forma, o ganho em produção de energia de um gerador eólico, operando com velocidade variável, não se anularia devido às elevadas perdas na eletrônica de potência ([12]). Tais fatos tornavam, praticamente, injustificáveis os investimentos em tecnologias baseadas em eletrônica de potência. Destaca-se que na Dinamarca, por ter sido um país pioneiro no desenvolvimento de turbinas eólicas, ainda contava, em 2007, com 
$71,6 \%$ de sua geração de energia eólica, vinda de turbinas de velocidade fixa, equipadas com gerador de indução de gaiola de esquilo ([89]).

Na equação (3.2), verifica-se que a potência mecânica $\left(P_{m}\right)$, gerada pela força do vento, depende diretamente do coeficiente de potência $\left(C_{p}\right)$. Por sua vez, considerando o ângulo de passo das hélices fixo na posição zero, o coeficiente de potência depende, exclusivamente, da relação entre a velocidade do vento e a velocidade linear da ponta da hélice $(\lambda)$. Considerando apenas uma velocidade de vento fixa $(V=11,8 \mathrm{~m} / \mathrm{s})$ e, utilizando os coeficientes sugeridos por Slootweg e as equações (3.2), (3.3) e (3.4), podemos traçar uma curva de potência apenas impondo diferentes velocidades de operação do gerador (Figura 3.3).

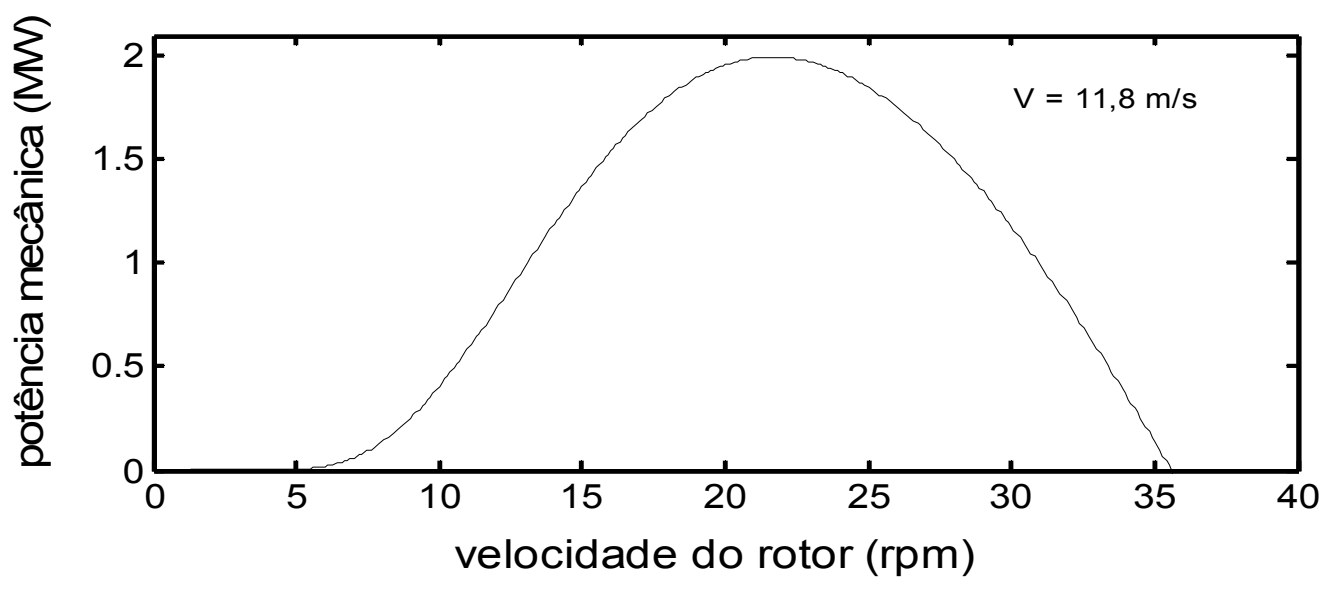

Figura 3.3 Potência mecânica gerada para diferentes velocidades de operação do rotor.

Constata-se, através da Figura 3.3, que é possível controlar a potência mecânica, gerada por uma turbina eólica, variando-se sua velocidade de operação. Contudo, podemos estender este raciocínio traçando outras curvas de potência para diferentes velocidades do vento (Figura 3.4). Considerando a Figura 3.4, nota-se que, para cada valor de velocidade do vento existe uma região, na qual a velocidade do rotor maximiza a potência mecânica gerada. Portanto, para velocidades do vento, abaixo da velocidade nominal (11,8 m/s, no caso desta turbina eólica de $2 \mathrm{MW})$, a operação com velocidade variável do rotor aumenta a eficiência na geração de energia. A Figura 3.5 compara a potência mecânica gerada considerando operação com velocidade variável e com velocidade fixa. 


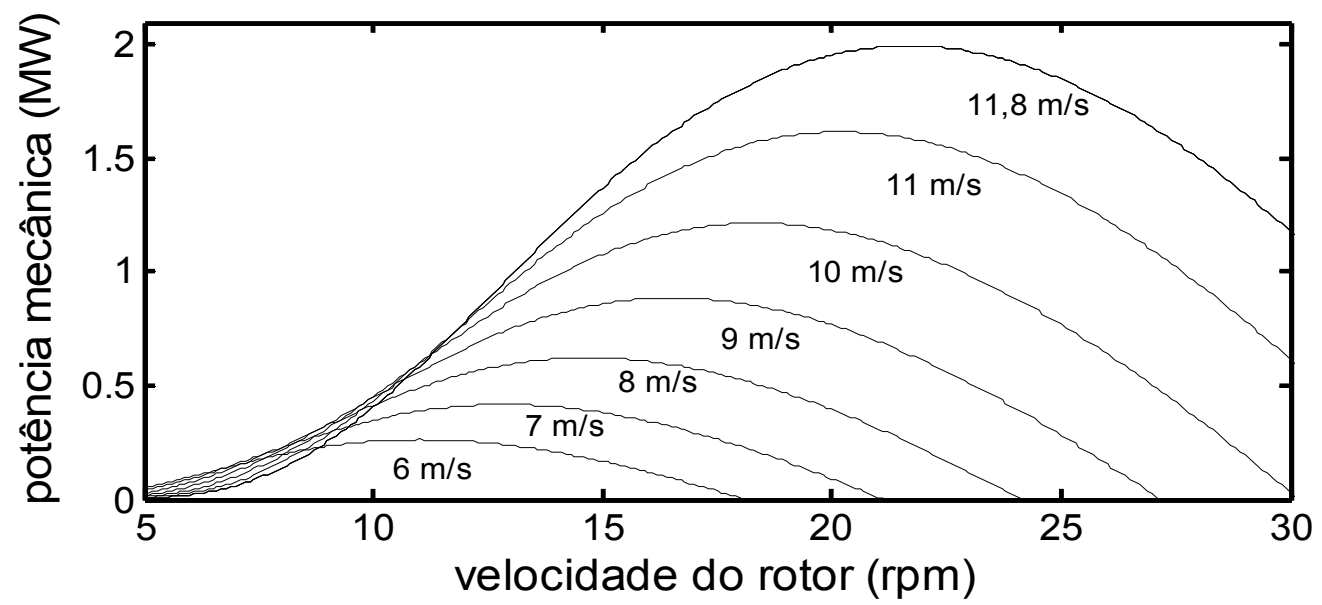

Figura 3.4 Potência mecânica gerada para diferentes velocidades de vento.

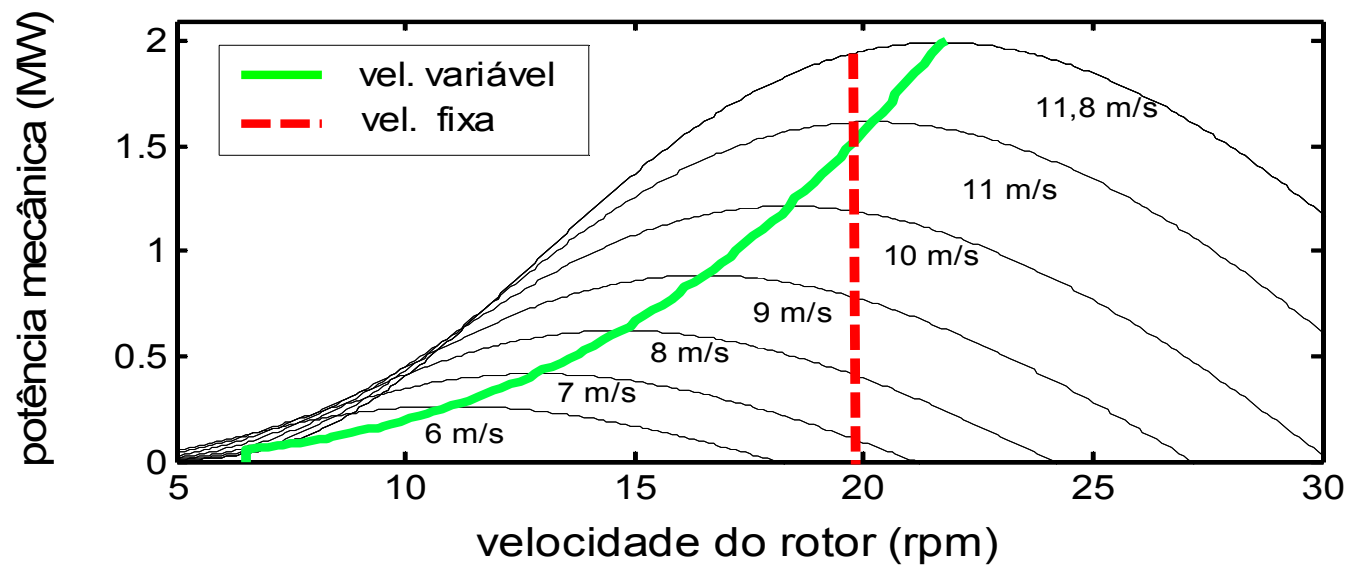

Figura 3.5 Comparação entre a potência mecânica para operação com velocidade fixa e variável.

Para valores de velocidade do vento acima do valor nominal, o controle de ângulo de passo das hélices é acionado, para manter a potência mecânica gerada na turbina eólica, coerente com a potência nominal que o gerador elétrico pode injetar na rede.

\subsection{Modelo do Sistema Elétrico Teste}

A rede de distribuição foi utilizada desde o início do estudo, que resultou nesta tese, assim, os estudos iniciais foram feitos nesta rede (Figura 3.6). Para análises da conexão das turbinas eólicas baseadas no DFIG em redes de transmissão, utilizou-se uma adaptação de uma rede de transmissão americana (WSCC-9), descrita por M. A. Pai ([58]). Tal rede de transmissão é mostrada na 
Figura 3.7. Os elementos de rede para estes dois sistemas foram modelados segundo Kundur ([48]) e Arrillaga ([59]). Dados mais específicos e os parâmetros de cada elemento podem ser encontrados no Apêndice $C$.

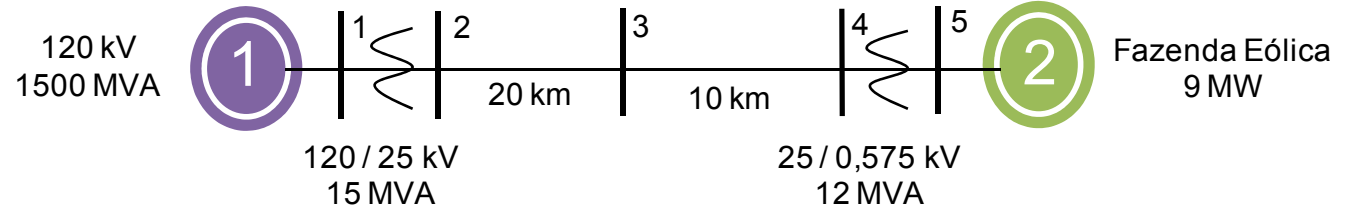

Figura 3.6 Diagrama unifilar do sistema de distribuição teste.

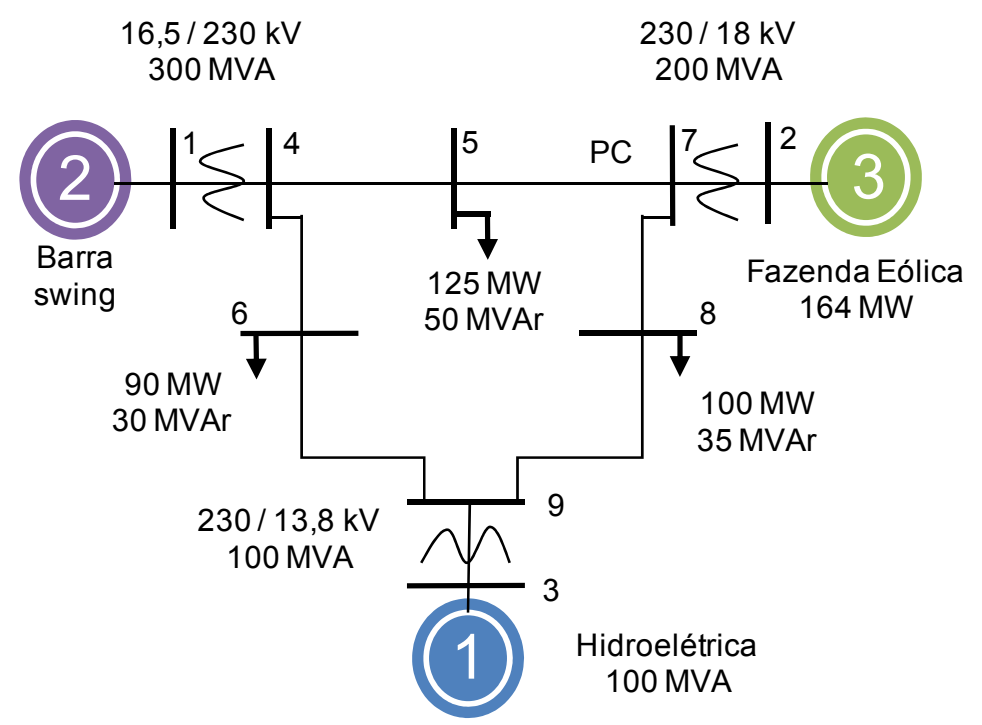

Figura 3.7 Diagrama unifilar do sistema de transmissão teste. 


\section{Capítulo 4}

\section{GERADOR DE INDUÇÃO DUPLAMENTE ALIMENTADO (DFIG)}

O estator da máquina é conectado diretamente á rede elétrica, sendo que o rotor é alimentado através de dois conversores de potência conectados back-toback. Um dos conversores é conectado à rede e o outro, aos enrolamentos do rotor. Os dois conversores são interligados através de um ramo de corrente contínua com um capacitor. O diagrama esquemático do gerador de indução com dupla alimentação, é mostrado na Figura 4.1. Os conversores são constituídos por IGBT's, permitindo a operação nos quatro quadrantes, controlando potência reativa e ativa. Em geral, a capacidade dos conversores é 30\% da capacidade do gerador de indução. Esta configuração permite a adoção de uma grande diversidade de estratégias de controle ([52], [55], [56], [71]-[73], [84]).

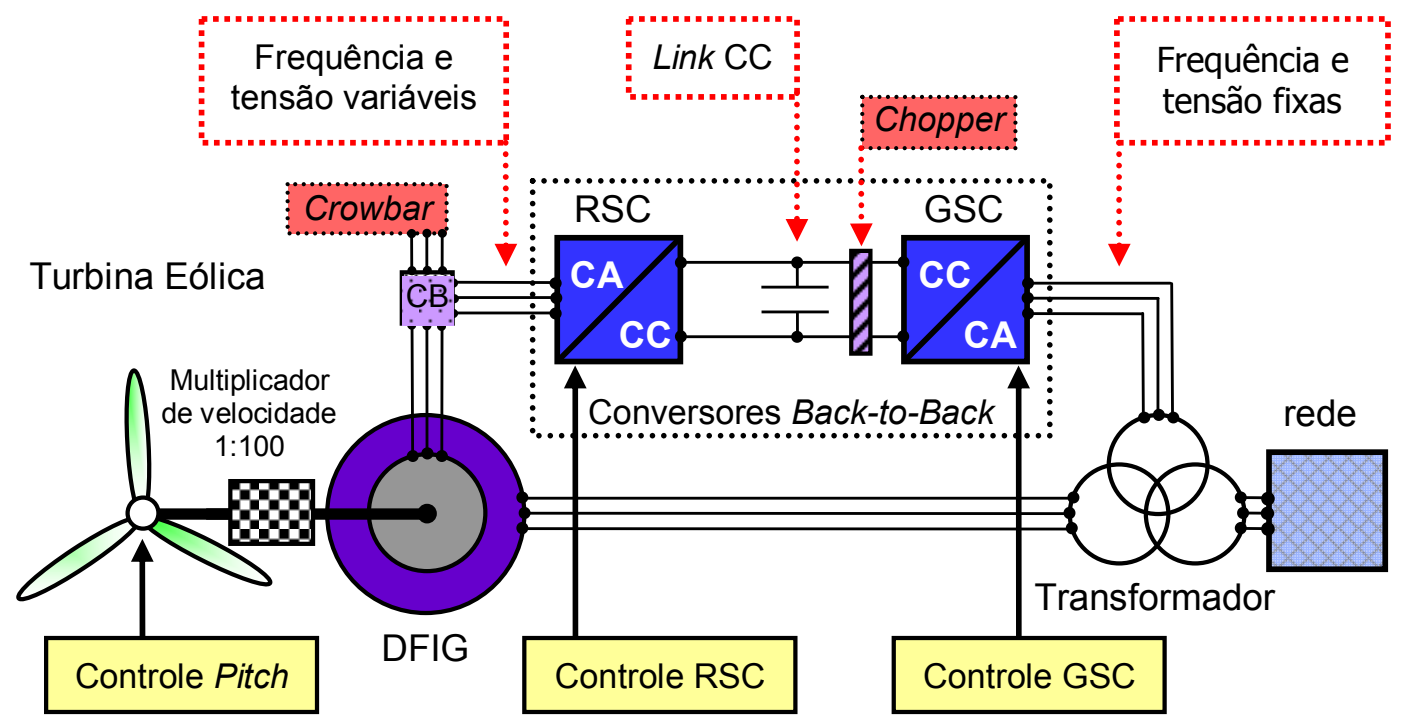

Figura 4.1 Diagrama esquemático do DFIG.

Contudo, uma estratégia de controle típica, que objetiva melhorar o desempenho energético do sistema, é descrita a seguir (Figura 4.2):

Velocidade do vento abaixo da velocidade nominal: nesta condição, o controle de ângulo de passo não atua. Controla-se indiretamente a velocidade, através da 
tensão e da freqüência aplicada nos enrolamentos do rotor. Além disso, a potência ativa e reativa injetada/consumida pelo gerador também são controladas.

Velocidade do vento acima da velocidade nominal: nesta condição, o controle de ângulo de passo atua para limitar a potência gerada. Mantêm-se a velocidade do gerador constante, através da tensão e da freqüência aplicadas no rotor. Além disso, também se controla a potência ativa e reativa injetada/consumida pelo gerador.

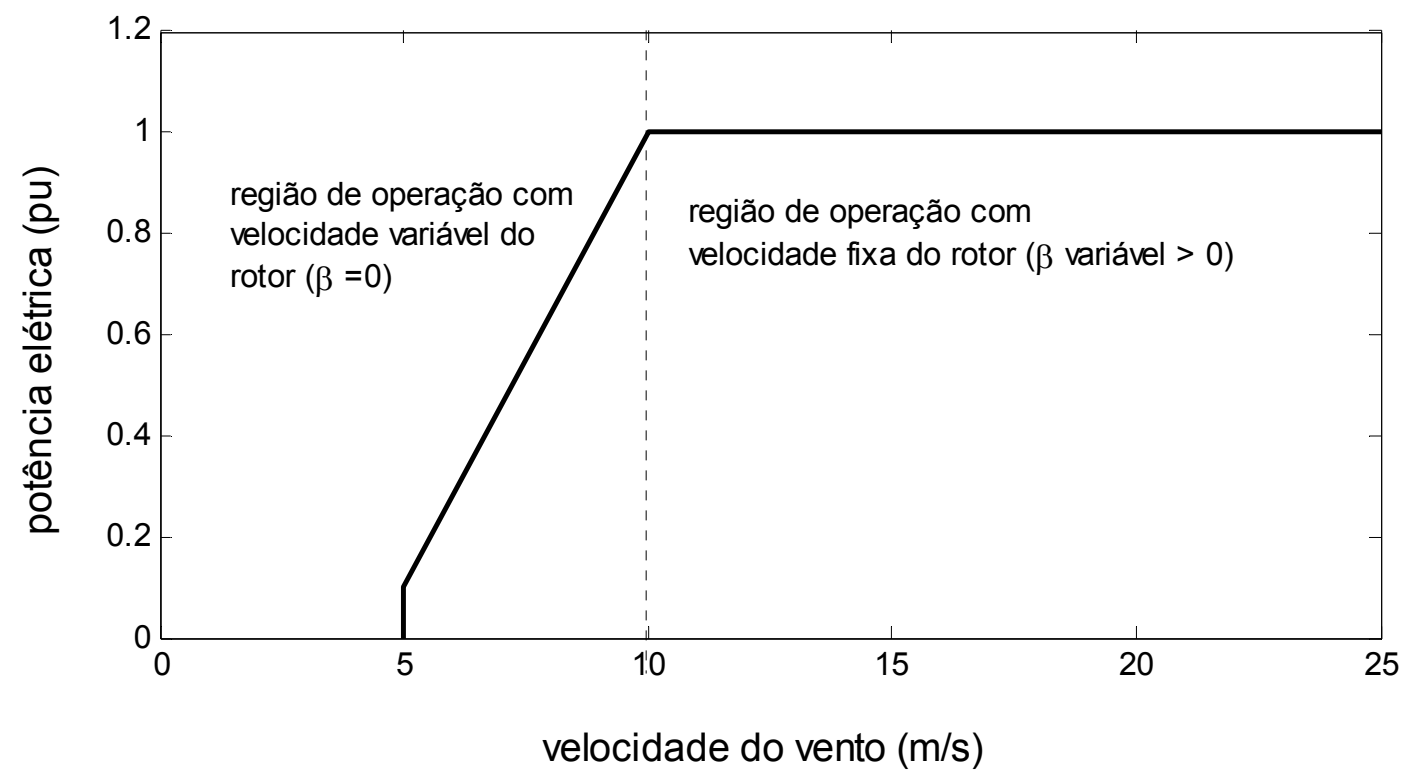

Figura 4.2 Característica potência elétrica-velocidade do vento para o DFIG.

Durante operação em velocidades sobressíncronas $(s<0)$, o rotor fornece potência ativa para rede. Porém, durante operação em velocidades subssíncronas $(s>0)$, o rotor consome potência ativa a partir da rede. De forma simplificada, negligenciando as perdas em regime permanente, as relações entre potência elétrica e mecânica podem ser calculadas por ([71]):

$$
\begin{aligned}
& P_{s}=\frac{P_{m}}{(1-s)} \\
& P_{r}=-s \cdot P_{s} \\
& P_{T}=P_{S}+P_{r}
\end{aligned}
$$


sendo:

$P_{m} \quad=\quad$ potência mecânica $(\mathrm{pu})$.

$P_{s}=$ potência elétrica injetada pelo estator $(\mathrm{pu})$.

$P_{r}=$ potência elétrica injetada/consumida pelo rotor (pu).

$P_{T}=$ potência elétrica total fornecida pelo gerador $(\mathrm{pu})$.

$s \quad=\quad$ escorregamento.

\subsection{Modelo Dinâmico do DFIG}

A representação dinâmica completa da máquina de indução trifásica, para análise de transitórios eletromagnéticos, é baseada no modelo de eixos $d-q([47])$. $A$ Figura 4.3 descreve o circuito equivalente da máquina de indução, em que todos os parâmetros são referidos ao estator da máquina. Neste modelo, não são consideradas as perdas no ferro e os efeitos da saturação. As equações completas, que representam a máquina de indução de rotor bobinado, com eixo de referências fixado no rotor e em condições balanceadas, são descritas a seguir ([47]-[49]):
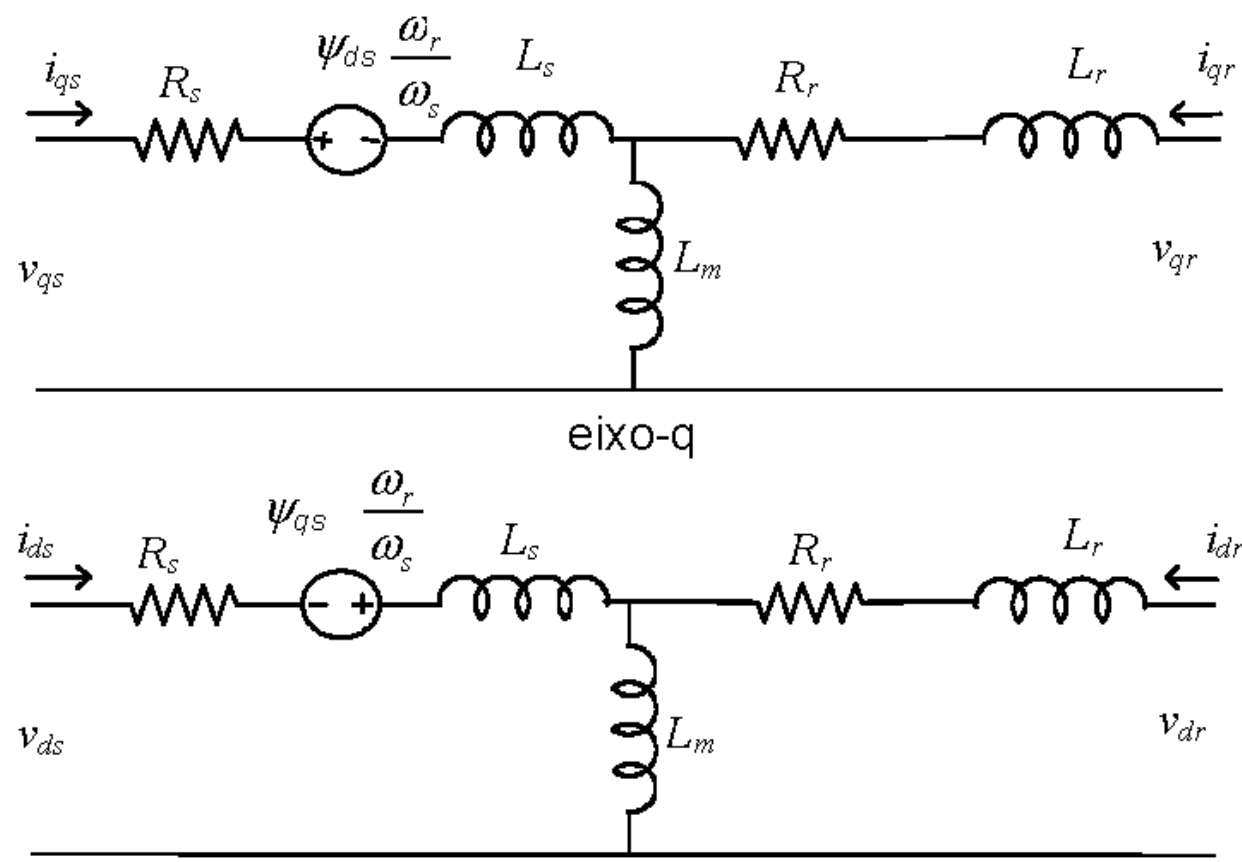

eixo-d

Figura 4.3 Circuito equivalente do modelo completo da máquina de indução. 
- Sistema Elétrico

$$
\begin{aligned}
& v_{q s}=R_{s} \cdot i_{q s}+\omega_{r} \cdot \psi_{d s}+\frac{d}{d t} \psi_{q s} \\
& v_{d s}=R_{s} \cdot i_{d s}-\omega_{r} \cdot \psi_{q s}+\frac{d}{d t} \psi_{d s} \\
& v_{q r}=R_{r} \cdot i_{q r}+\frac{d}{d t} \psi_{q r} \\
& v_{d r}=R_{r} \cdot i_{d r}+\frac{d}{d t} \psi_{d r} \\
& T_{e}=1,5 \cdot p \cdot\left(\psi_{d s} \cdot i_{q s}-\psi_{q s} \cdot i_{d s}\right)
\end{aligned}
$$

sendo:

$$
\begin{aligned}
& \psi_{q s}=\left(L_{s}+L_{m}\right) \cdot i_{q s}+L_{m} \cdot i_{q r} \\
& \psi_{d s}=\left(L_{s}+L_{m}\right) \cdot i_{d s}+L_{m} \cdot i_{d r} \\
& \psi_{q r}=\left(L_{r}+L_{m}\right) \cdot i_{q r}+L_{m} \cdot i_{q s} \\
& \psi_{d s}=\left(L_{r}+L_{m}\right) \cdot i_{d r}+L_{m} \cdot i_{d s}
\end{aligned}
$$

- Sistema Mecânico

$$
\begin{aligned}
& \frac{d}{d t} \omega_{r}=\frac{1}{2 \cdot H} \cdot\left(T_{e}-T_{m}\right) \\
& \frac{d}{d t} \theta_{r}=\omega_{r}
\end{aligned}
$$

em que:

$$
\begin{array}{lll}
R_{s} & = & \text { resistência do estator }(\mathrm{pu}) ; \\
L_{s} & = & \text { indutância de dispersão do estator }(\mathrm{pu}) ; \\
L_{m} & = & \text { indutância de magnetização }(\mathrm{pu}) ; \\
L_{r} & = & \text { indutância de dispersão do rotor referida ao estator }(\mathrm{pu}) ;
\end{array}
$$




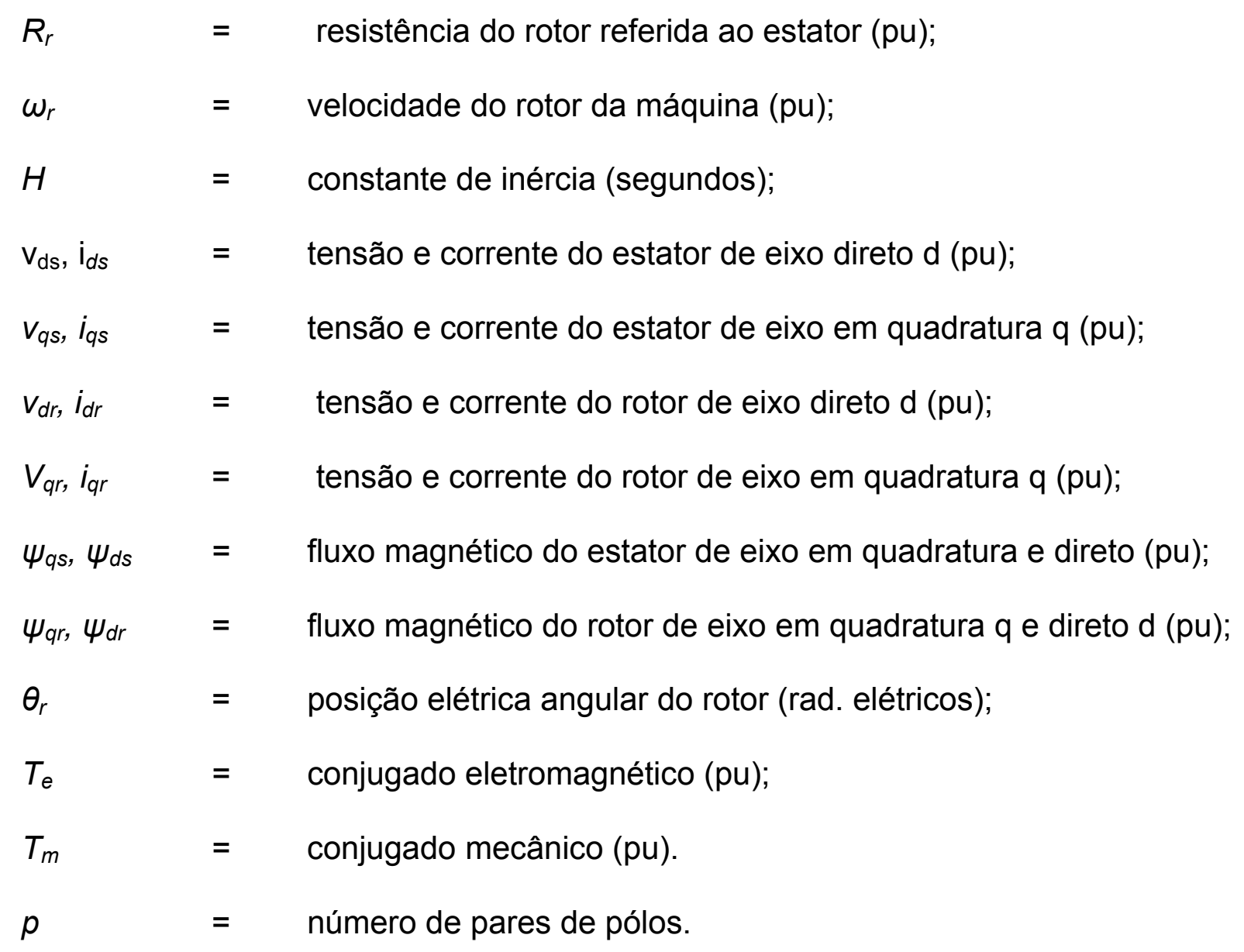

Em análise de estabilidade de sistemas de potência, usualmente os transitórios da rede elétrica são desprezados, sendo esta representada pelo modelo fasorial ([48], [49], [59]). Desta forma, os transitórios do estator da máquina também são desprezados ([47]-[49]), substituindo as equações (4.4) e (4.5) pelas equações (4.15) e (4.16), respectivamente. As demais equações se mantêm inalteradas.

$$
\begin{aligned}
& v_{q s}=R_{s} \cdot i_{q s}+\omega_{r} \cdot \psi_{d s} \\
& v_{d s}=R_{s} \cdot i_{d s}-\omega_{r} \cdot \psi_{q s}
\end{aligned}
$$

Ressalta-se que o modelo de máquina de indução apresentado acima, já está disponível nas bibliotecas do SimPowerSystems ([49]). Tal modelo pode ser utilizado para representar, tanto motores, como geradores de indução. O que determina a forma de operação da máquina é o sinal do conjugado mecânico, o qual deve ser negativo para representação de gerador. 


\subsection{Modelos de controle do RSC e do GSC em Regime Permanente}

O RSC controla, indiretamente, a velocidade ótima de operação e o fator de potência unitário do DFIG. A velocidade ótima de operação é determinada, de acordo com a velocidade atual do vento e de acordo com as características da turbina, como mostrado na Figura 3.5. Com o valor da potência mecânica ótima calculada (descontando as perdas mecânicas e elétricas), determina-se a potência elétrica ótima de referência $\left(P^{*}{ }_{\text {opt }}\right)$. Esta potência de referência é comparada com a potência atual, sendo que o erro é processado por um regulador PI. A saída desse regulador fornece a corrente de referência de eixo em quadratura $I_{q}^{*}$ desejada no rotor. Este valor de referência é comparado com a corrente de eixo em quadratura atual $I_{q}$ e processado por um segundo regulador PI. Este fornece a tensão de referência de eixo em quadratura $V_{q}^{*}$ desejada no rotor (Figura 4.4).

A segunda função do RSC é manter o fator de potência unitário no ponto de conexão com a rede, por meio do controle da troca de potência reativa. Para isso, a potência reativa no ponto de conexão é medida e comparada com o valor de referência $\left(Q^{*}=0\right)$. O erro é processado por um regulador $\mathrm{PI}$, fornecendo a corrente de referência de eixo direto $I_{d}^{*}$ desejada no rotor. $O$ valor de referência $I_{d}^{*}$ é comparado com a corrente de eixo direto atual $l_{d}$, sendo processado por um segundo regulador PI. Este segundo PI fornece a tensão de referência de eixo direto $V_{d}^{*}$ desejada no rotor (Figura 4.4).

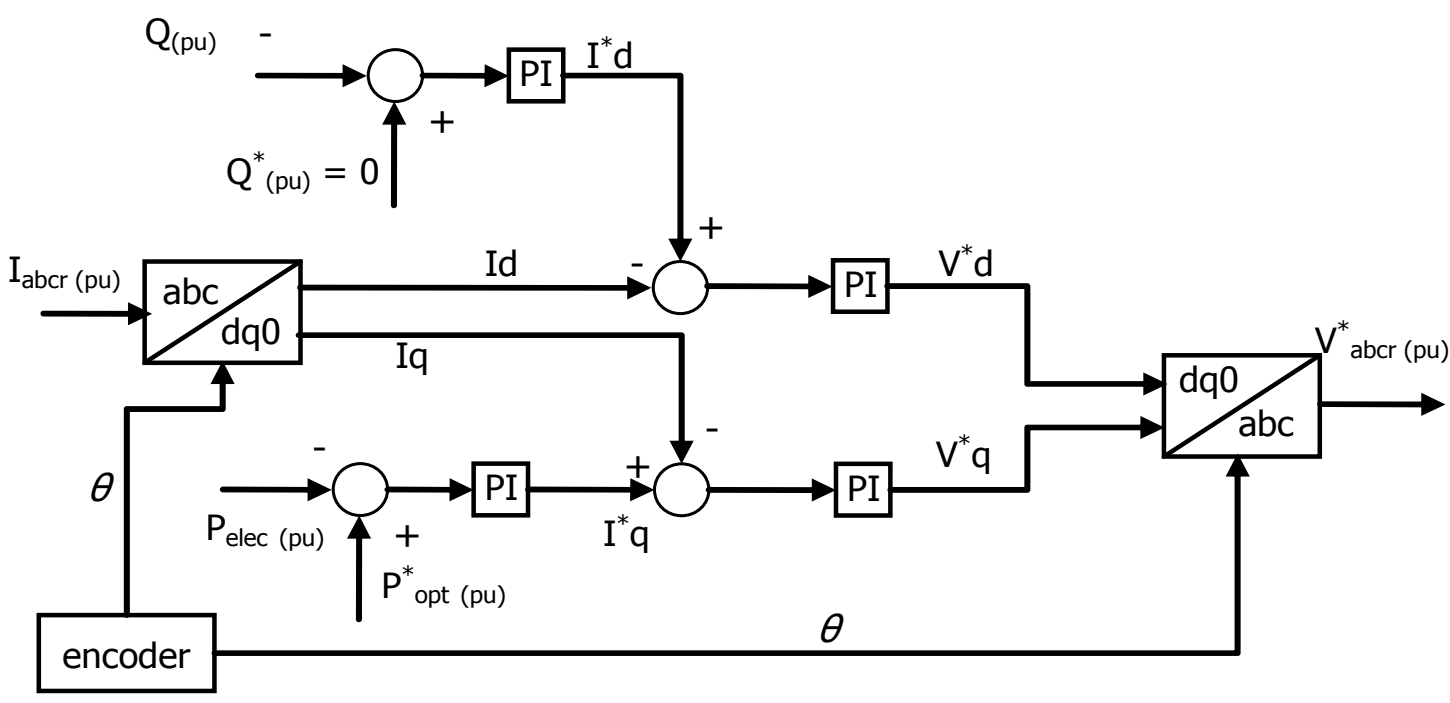

Figura 4.4 Diagrama esquemático do controle do RSC do DFIG em regime permanente. 
A primeira função do GSC é manter a tensão constante no link de corrente contínua (link CC), por meio da injeção/absorção de potência ativa da rede elétrica. Para isso, a tensão atual no link CC é medida e comparada com o valor de referência $\left(V_{d c}^{*}=1 \mathrm{pu}\right)$, o erro é processado por um regulador PI que fornece a corrente de referência de eixo direto $I_{d}^{*}$. O valor de referência $I_{d}^{*}$ é comparado com a corrente de eixo direto atual $l_{d}$ e processado por um segundo regulador PI, o qual fornece a tensão de referência de eixo direto $V_{d}^{*}$ (Figura 4.5).

A corrente de referência do eixo em quadratura $\left(I_{q}^{*}=0\right)$ é comparada com a corrente de eixo em quadratura atual $\left(I_{q}\right)$, o erro é processado por um regulador $\mathrm{PI}$. A saída desse regulador fornece a tensão de referência de eixo em quadratura $V_{q}^{*}$ desejada no GSC. Dessa forma, a corrente injetada/consumida pelo conversor não assume valores imaginários e, por consequência, não há injeção/absorção de potência reativa (Figura 4.5).

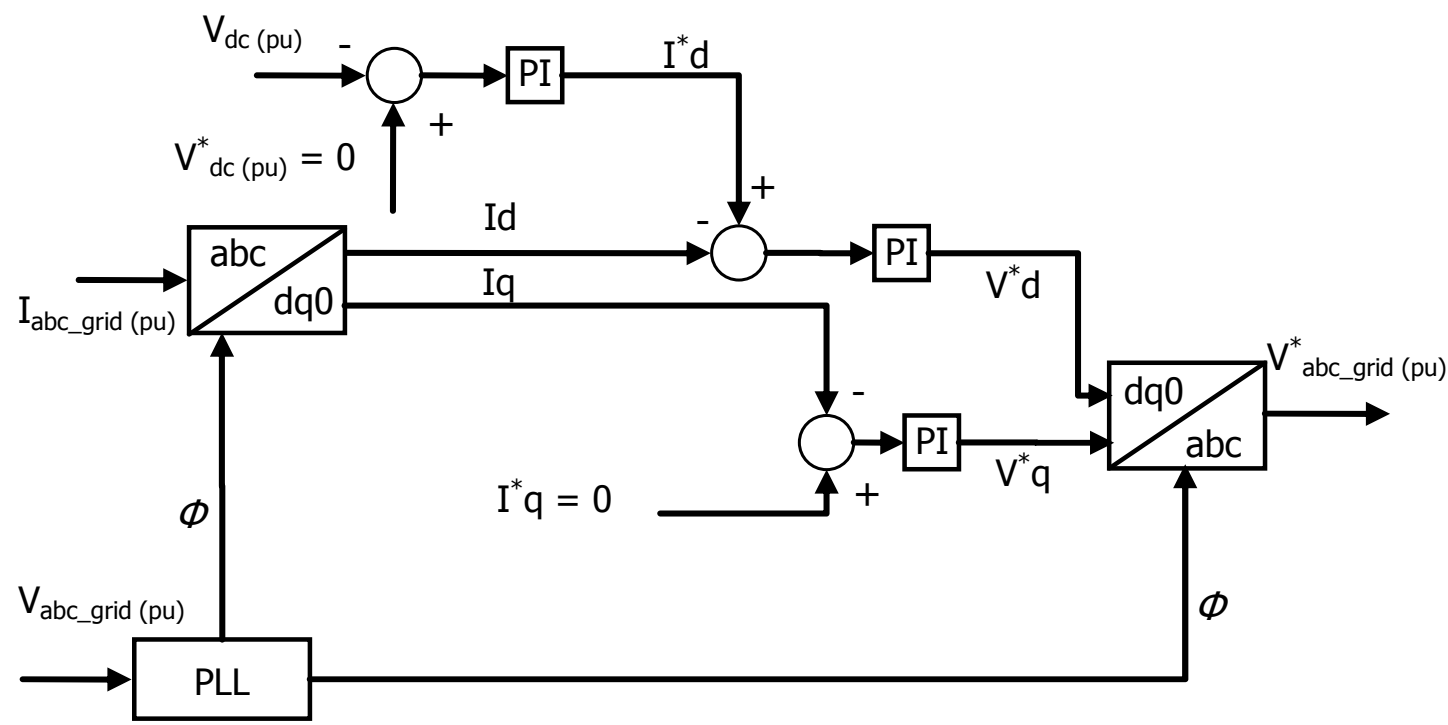

Figura 4.5 Diagrama esquemático do controle do GSC do DFIG em regime permanente.

Da mesma forma que para o RSC, a tensão trifásica senoidal desejada na saída do GSC é determinada transformando-se os valores de tensão da estrutura de referência dq0 para a estrutura de referência abc, tendo, como base, o ângulo determinado pelo PLL (ou pelo encoder, no caso do RSC). As formas de tensão desejadas $\left(V_{\text {abcr (pu) }}^{*}\right.$ e $\left.V_{\text {abc_grid (pu) }}^{*}\right)$ são enviadas aos respectivos conversores com modulação por largura de pulso (conversores PWM), para que sejam aplicadas na rede elétrica. Destaca-se que os modelos do RSC e do GSC, descritos acima, fazem 
parte da biblioteca do SimPowerSystems. Porém, estes dois modelos foram profundamente modificados para a operação durante faltas na rede elétrica.

\subsection{Análises Dinâmicas da Capacidade do GSC}

Para analisar o impacto de diferentes capacidades do GSC no desempenho dinâmico do DFIG, durante faltas na rede elétrica, o modelo, descrito anteriormente, foi modificado, de forma a possibilitar o controle da tensão terminal pelo GSC durante curto-circuitos. O sistema de distribuição teste, mostrado na Figura 3.6, foi utilizado para análises durante um curto-circuito trifásico de $150 \mathrm{~ms}$ de duração, aplicado à barra 2. Os dados da turbina eólica e do gerador podem ser encontrados em ([57]). Considerou-se a velocidade do vento constante durante a falta, simplificação esta comumente utilizada em análises de estabilidade de sistemas elétricos ([56], [57]). O modelo mecânico do eixo entre rotor da turbina e rotor do gerador foi considerado inelástico, conforme sugerido em artigos recentes ([57], [90], [91]), portanto somam-se os valores das constantes de inércia do rotor da turbina eólica e do rotor do gerador, diretamente na equação (4.13).

Durante a falta analisada, o RSC bloqueia o controle de fator de potência, quando a tensão terminal atinge valores inferiores a $0.9 \mathrm{pu}$, iniciando, imediatamente, o controle de tensão terminal, via GSC. Destaca-se que o RSC continua controlando a velocidade do rotor (o crowbar não é inserido) e o GSC continua controlando a tensão do link CC (por meio da componente de eixo direto). O controle do GSC é modificado, incluindo-se um controlador PI para a comparação da tensão terminal atual com a de referência na componente de eixo em quadratura, de acordo com a Figura 4.6. É, também, incluída uma característica em declive (droop) para evitar oscilações nas variáveis de controle.

Para representar a capacidade nominal do RSC e do GSC, foi acrescentada uma lógica, que limita a corrente de referência total $\left(I^{*}\right)$ do controlador. Tal limite, que visa representar as características nominais do conversor, é mostrado na equação (4.17).

$$
I^{*}=\sqrt{\left(I_{d}^{*}\right)^{2}+\left(I_{q}^{*}\right)^{2}}
$$


Como o modelo do gerador de indução implementado não possibilita a utilização de um valor específico para a relação de espiras entre enrolamentos do rotor e do estator, todos os parâmetros e variáveis do rotor são dados em por unidade (pu) e são referidos ao estator. Desta forma, o limite para $I^{*}$ deve ser $1 \mathrm{pu}$, porém para o GSC esse limite pode ser variado com maior flexibilidade. Os valores utilizados no GSC, para estas análises, consideram três níveis de capacidade nominal, sendo elas $25 \%, 35 \%, 50 \%$ da capacidade total do gerador.

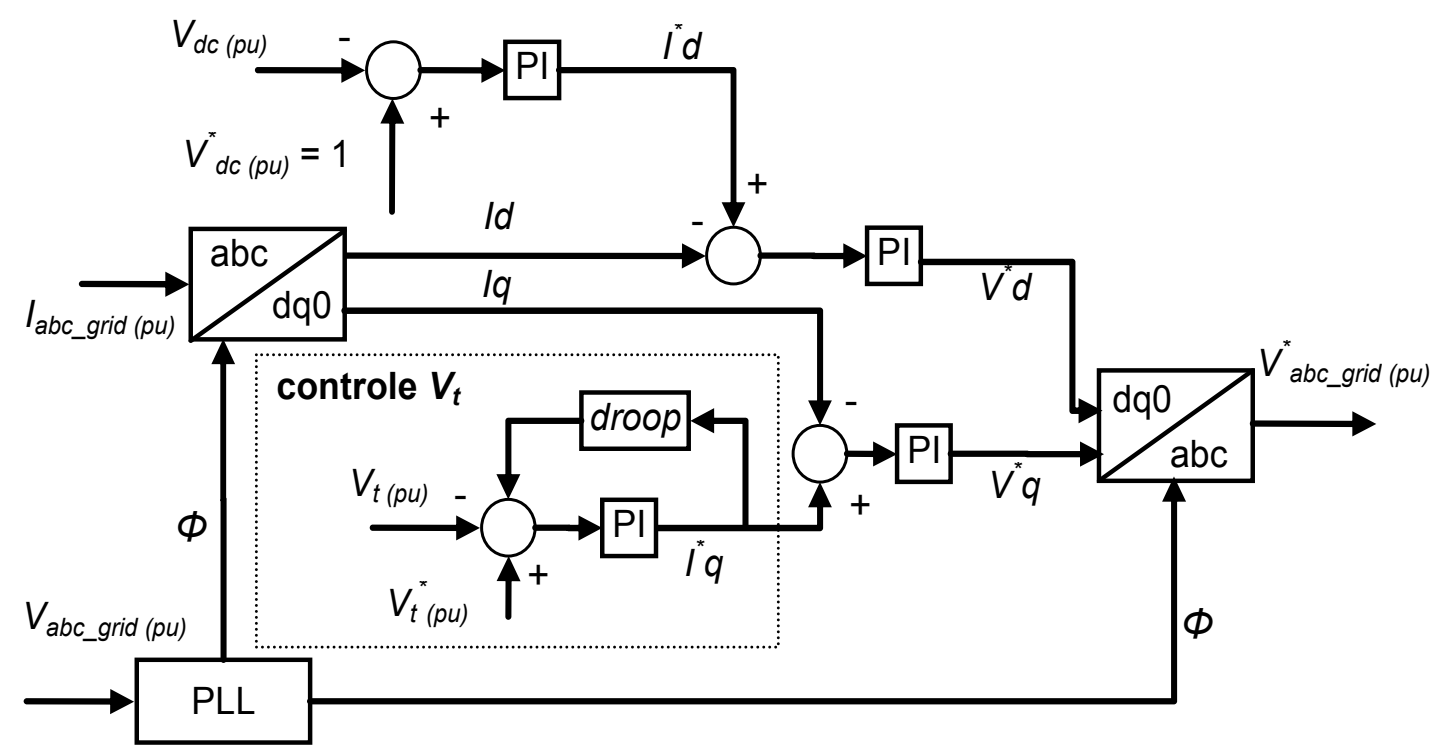

Figura 4.6 Diagrama esquemático do controle modificado do GSC do DFIG para controle de tensão.

A evolução das principais variáveis, relacionadas ao parque eólico, é apresentada na sequência (da Figura 4.7 até a Figura 4.14). Observando a Figura 4.7, constatamos que a tensão terminal, no ponto de conexão, atinge o valor mais elevado, quando o conversor de $50 \%$ é utilizado.

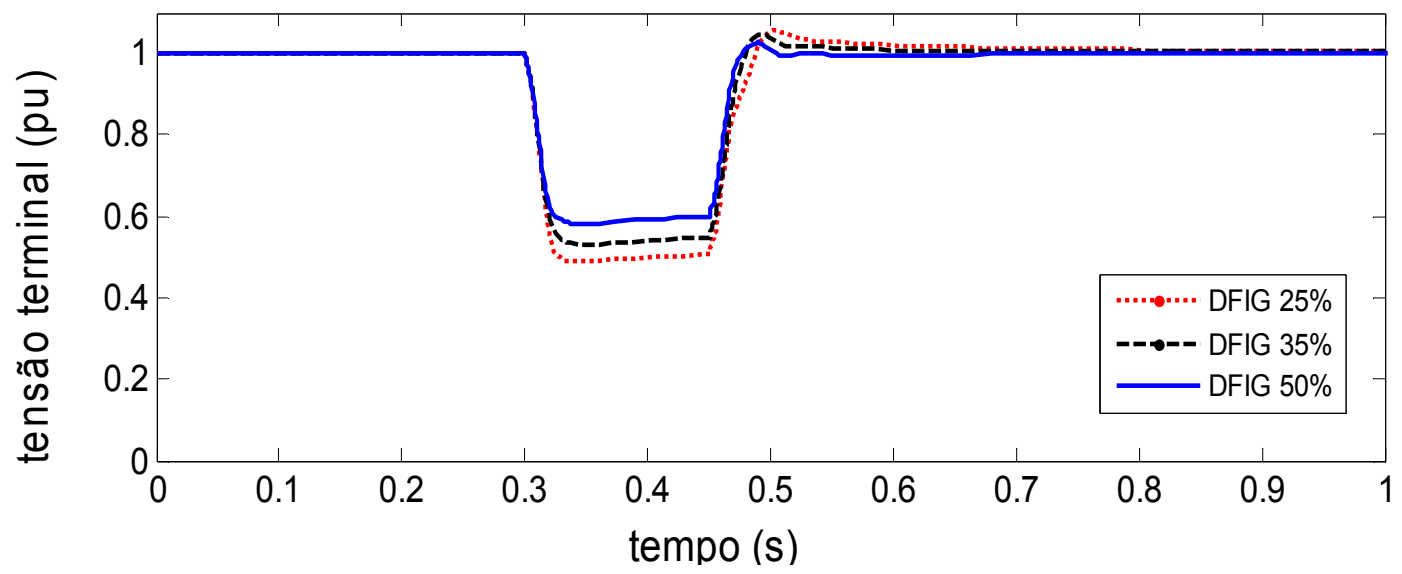

Figura 4.7 Tensão terminal da fazenda eólica durante curto-circuito eliminado em 150 ms. 
A Figura 4.8 mostra que as correntes totais, nos diferentes conversores, atingiram seus valores nominais durante o curto-circuito. A potência reativa, injetada somente pelo GSC, é mostrada na Figura 4.9, porém os três conversores injetam potência reativa próxima à nominal, pois uma parcela pequena da corrente é reservada para controlar a tensão no link CC.

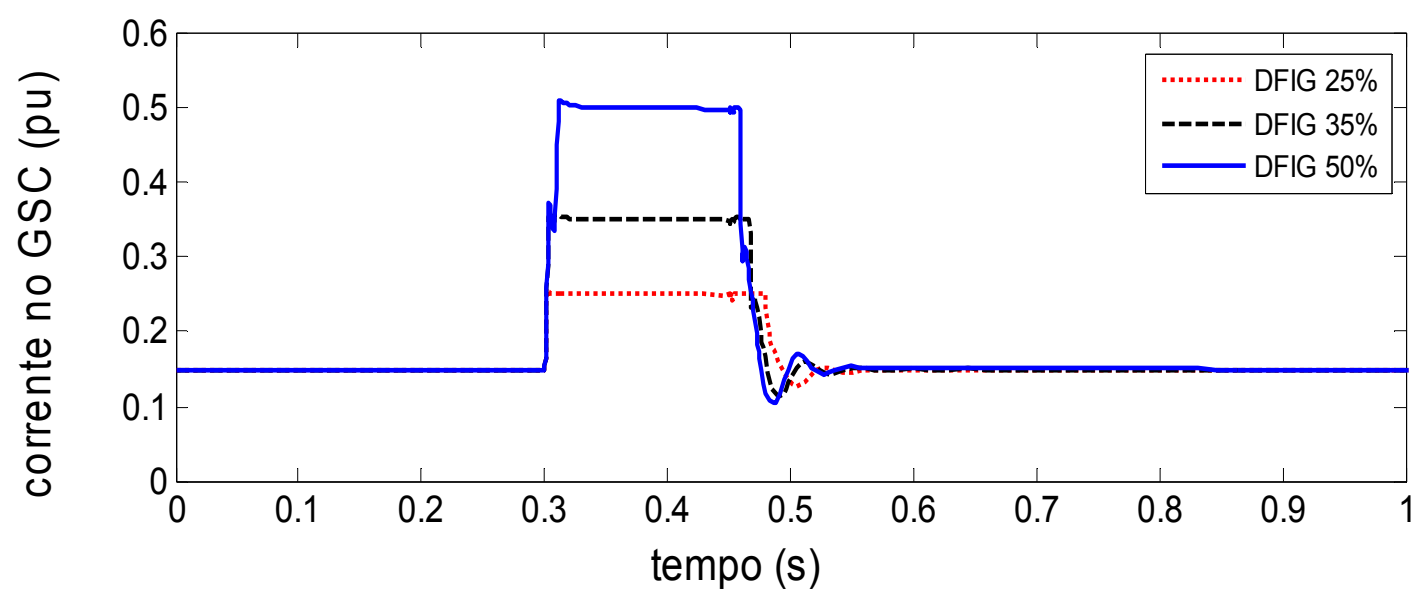

Figura 4.8 Corrente no GSC durante curto-circuito eliminado em $150 \mathrm{~ms}$.

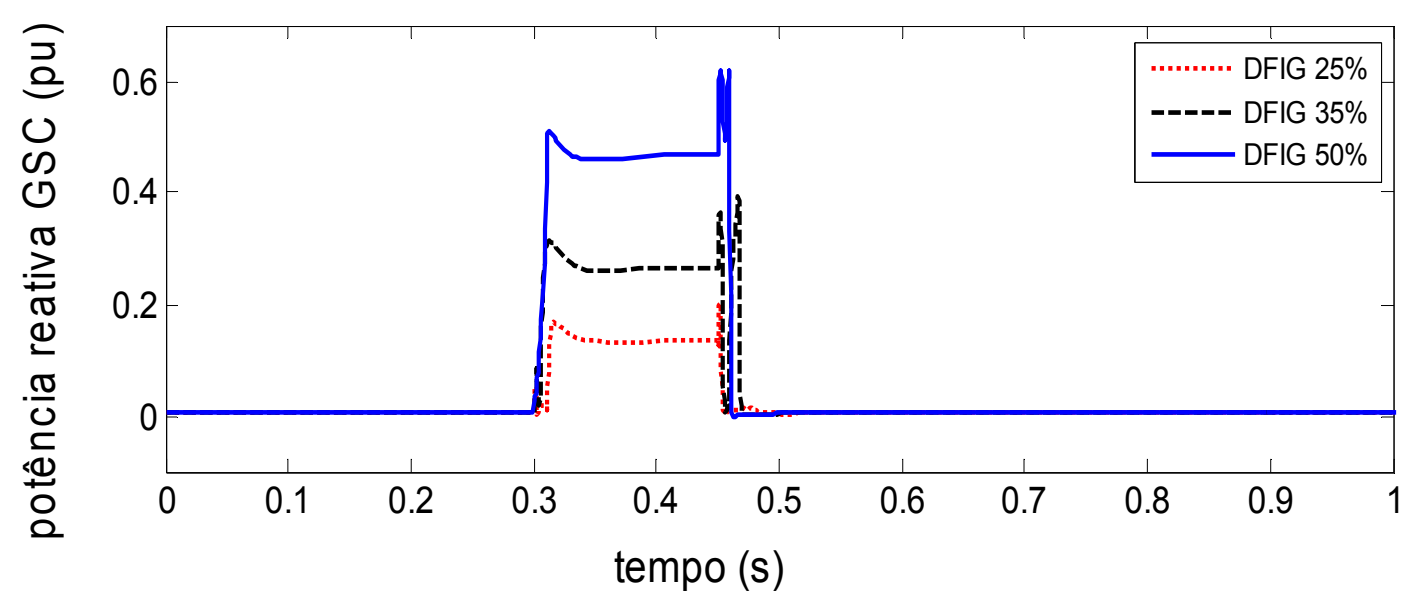

Figura 4.9 Potência reativa injetada pelo GSC durante curto-circuito eliminado em 150 ms.

Com a análise da Figura 4.10, constatamos que o único caso com injeção efetiva de potência reativa para a rede elétrica, no ponto de conexão da fazenda eólica, é a do GSC de $50 \%$, sendo que, para as outras duas capacidades, não há injeção de potência reativa para a rede. A tensão no link CC não atingiu valores muito elevados em nenhuma das três capacidades analisadas (Figura 4.11). A potência reativa, injetada pelo GSC de $25 \%$ e pelo GSC de $35 \%$, é consumida pelo estator do DFIG, durante o curto-circuito. 


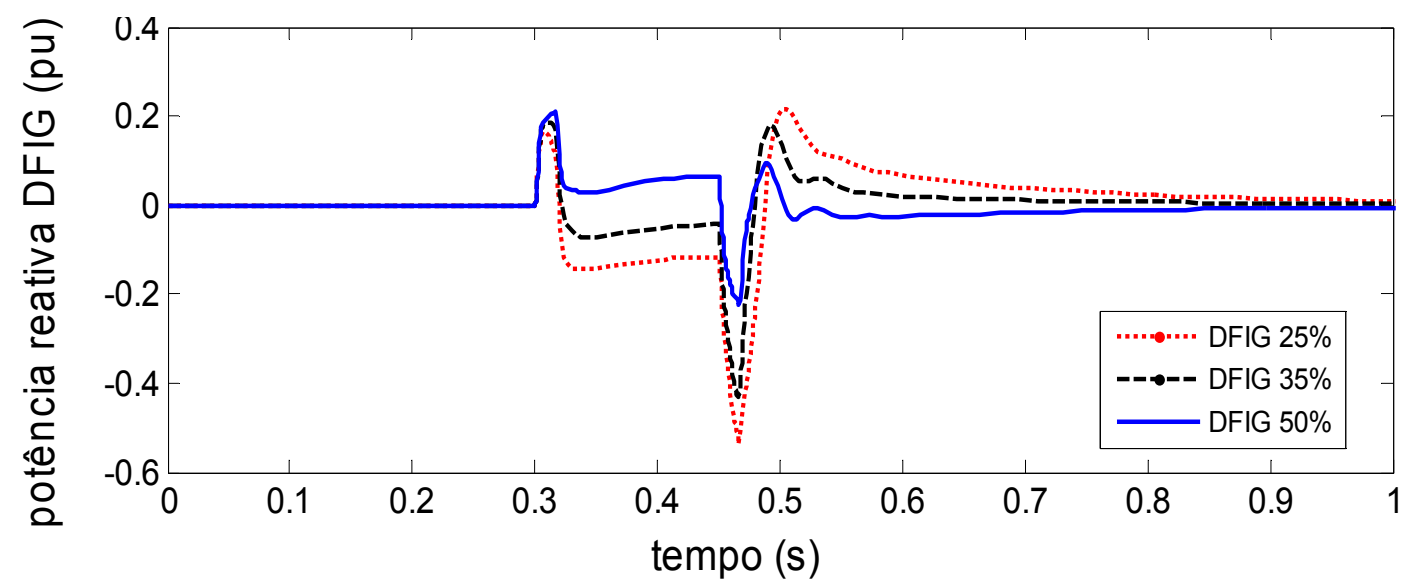

Figura 4.10 Potência reativa injetada pelo DFIG durante curto-circuito eliminado em 150 ms.

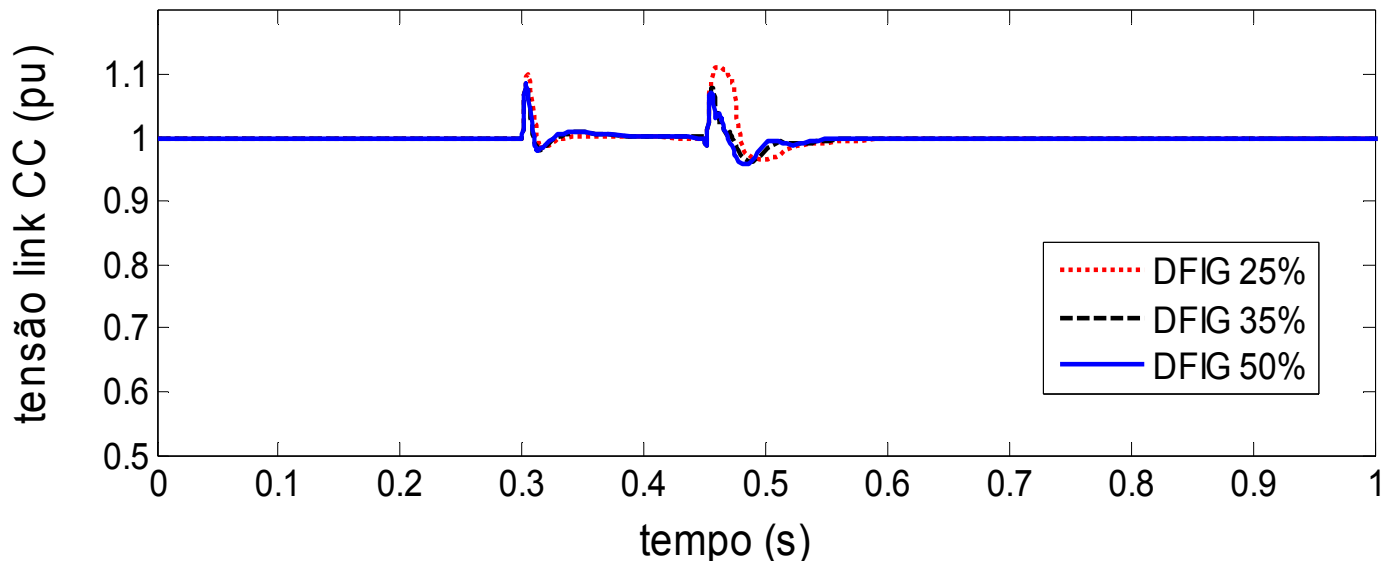

Figura 4.11 Tensão no link CC durante curto-circuito eliminado em 150 ms.

Com o aumento da tensão terminal, a injeção de potência ativa, também, apresentou valores mais elevados para a análise com o conversor de $50 \%$ da potência nominal do DFIG (Figura 4.12). Este fato, embora não abordado nestes estudos, poderia ser importante para a regulação de freqüência da rede.

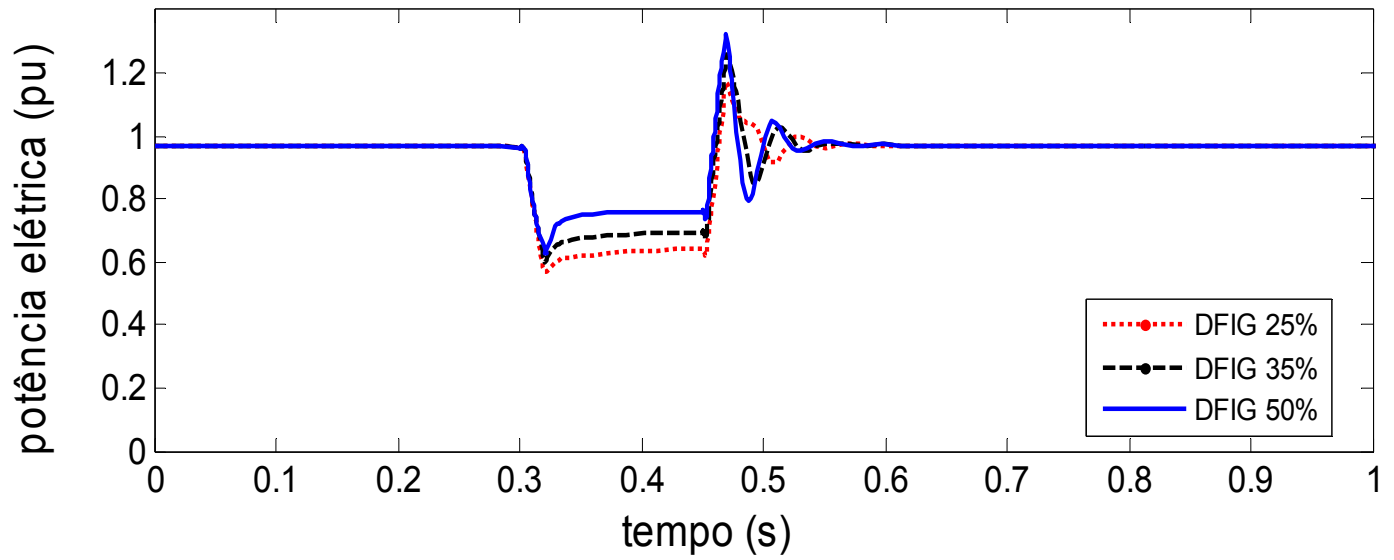

Figura 4.12 Potência elétrica injetada pelo DFIG durante curto-circuito eliminado em 150 ms. 
A Figura 4.13 mostra a velocidade da turbina durante a falta. Neste caso, em que o RSC continuou controlando velocidade e não houve ativação do crowbar, tal variação de velocidade poderia ser mais crítica durante o bloqueio total do RSC. Contudo, esta variação foi menor quando o conversor de $50 \%$ foi usado, devido ao maior suporte de potência reativa ao estator do DFIG, durante a falta. Em conseqüência dessa menor variação de velocidade do rotor, o ângulo de passo das hélices da turbina variou menos, quando comparado com a variação desenvolvida com o conversor de $25 \%$ ou de $35 \%$ (Figura 4.14 ).

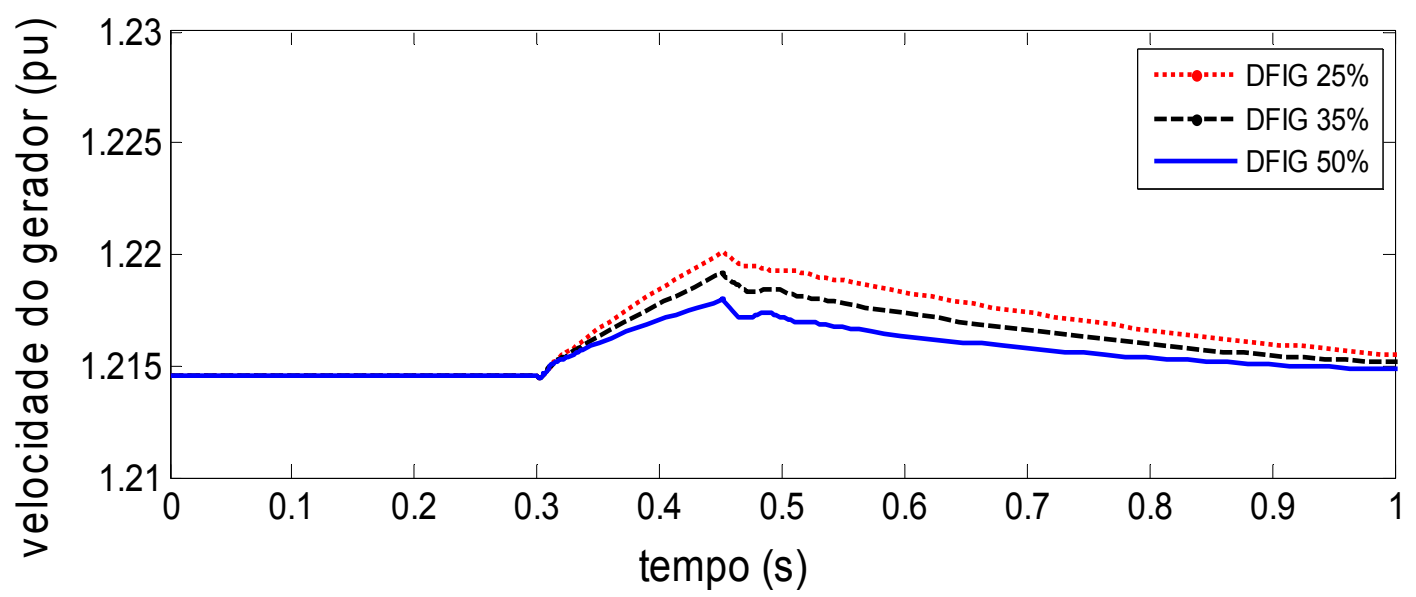

Figura 4.13 Velocidade do DFIG durante curto-circuito eliminado em $150 \mathrm{~ms}$.

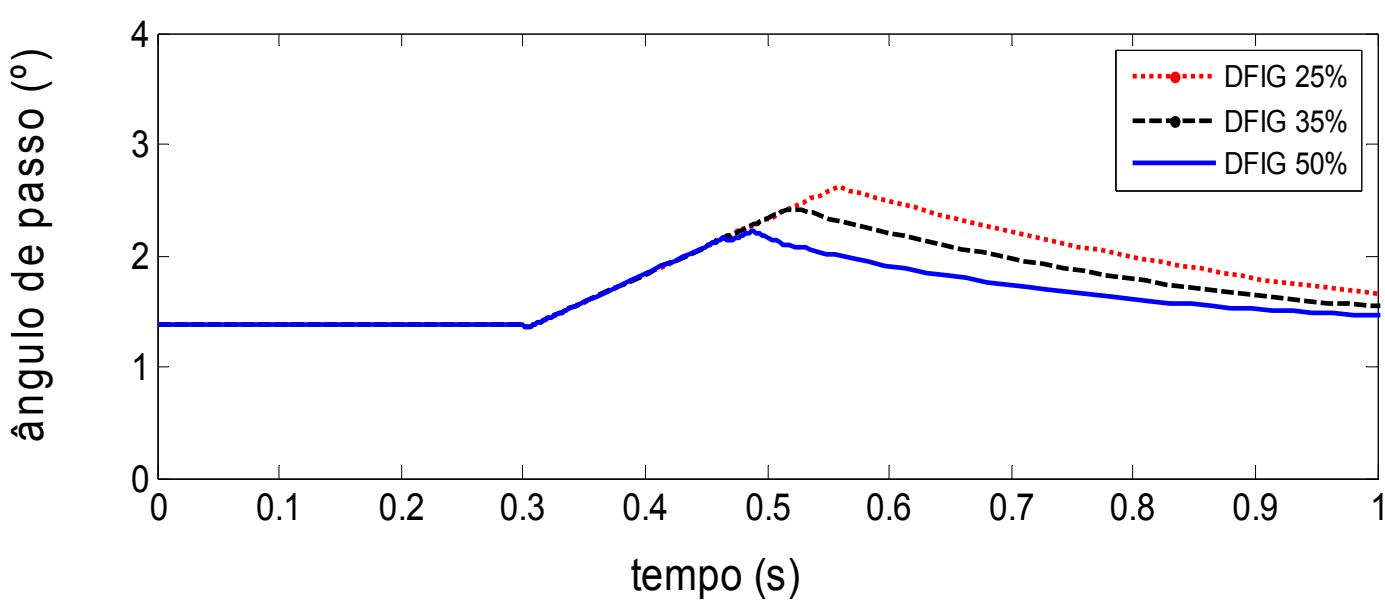

Figura 4.14 Ângulo de passo das hélices durante curto-circuito.

Outra possibilidade para melhorar a injeção de reativos durante curtocircuitos, porém mantendo a capacidade dos conversores mais baixa, é o uso de STATCOM no ponto de conexão da fazenda eólica com a rede ([80]). Para que os níveis de exigências de alguns países, quanto à injeção de potência reativa durante 
curto-circuitos, sejam atendidos, foram investigadas outras estratégias de controle e de proteção dos conversores.

\subsection{Análises Dinâmicas de Diferentes Estratégias de Controle}

Em um gerador síncrono, o controle da injeção de potência reativa é realizado, mediante controle da excitação da máquina. Quando ocorre um curtocircuito na rede elétrica, a tensão, no ponto de conexão com a rede, diminui drasticamente. Desta forma, a excitação do gerador síncrono aumenta a injeção de reativos, de forma a melhorar o perfil de tensão do sistema. Com a maior penetração de turbinas eólicas nos sistemas de transmissão de energia elétrica, também é desejável que seus geradores contribuam com a injeção de potência reativa, durante curto-circuitos. Utilizando variações dos esquemas de controle descritos na Figura 4.4, para o RSC, e na Figura 4.6, para o GSC, três diferentes estratégias de controle (A, B e C) foram analisadas, durante curto-circuitos no sistema de transmissão teste (Figura 3.7).

Na estratégia A, os controles do RSC e do GSC são mantidos em operação normal durante o curto-circuito, porém o RSC passa a controlar a tensão terminal em $1 \mathrm{pu}$, suspendendo o controle de fator de potência unitário $\left(Q^{*}(\mathrm{pu})=0\right)$. Essa modificação é feita diretamente no esquema de controle, sendo apresentado na Figura 4.15. Desta forma, a potência reativa é injetada, somente, pelo RSC.

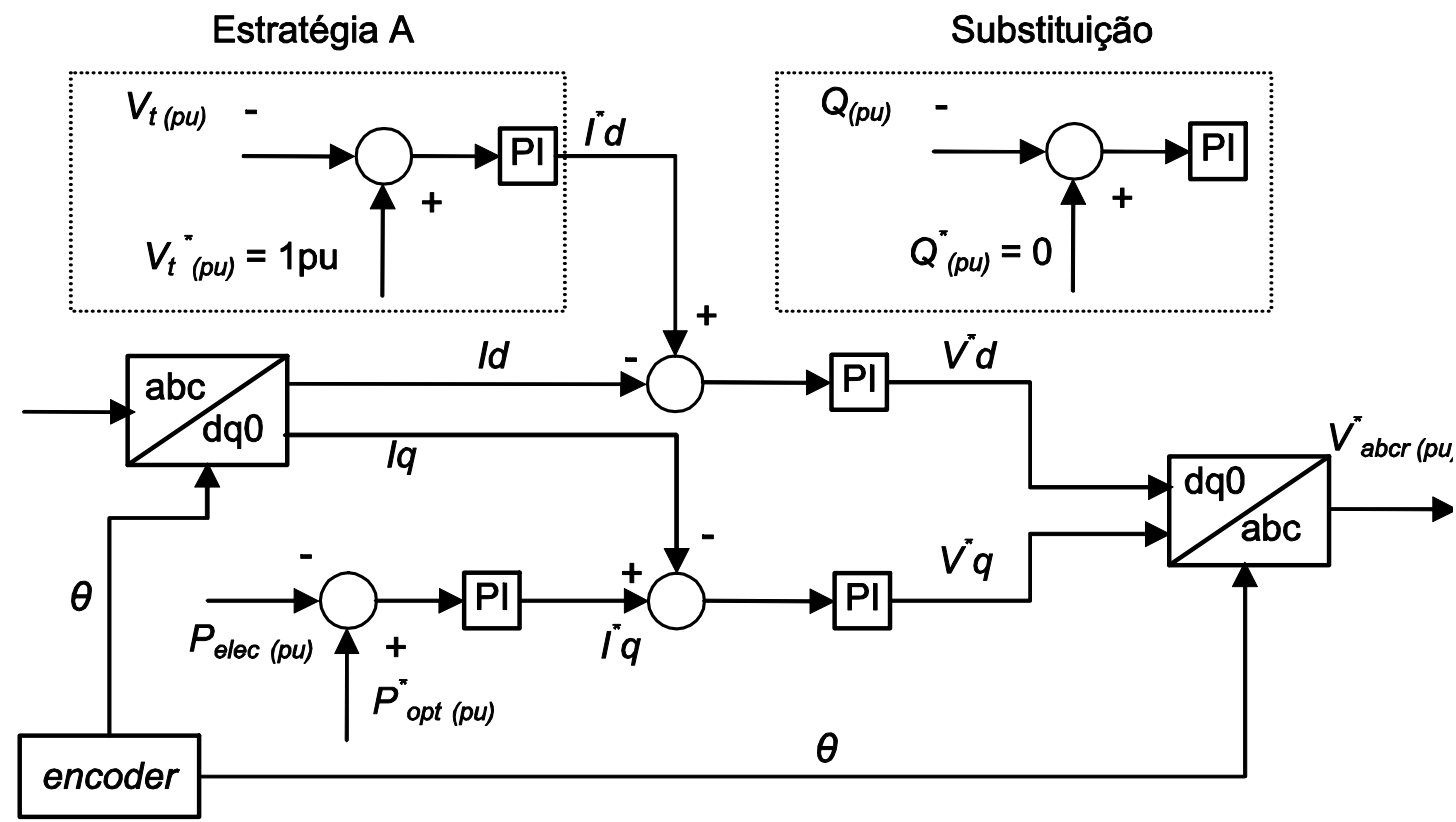

Figura 4.15 Estratégia A: diagrama esquemático do controle do RSC do DFIG durante curto-circuito. 
Durante o uso da estratégia $B$, os controles do RSC operam da mesma forma que para a estratégia A. O GSC controla a tensão no link CC e injeta o máximo de reativos possível na rede elétrica, respeitando suas características nominais segundo a equação (4.17). Ou seja, a corrente de eixo direto de referência $\left(I_{d}^{*}\right)$ é determinada pelo controle da tensão no link $C C$, sendo que a corrente máxima de referência de eixo em quadratura $\left(I_{q}^{*}\right)$ é determinada utilizando a equação (4.17). A potência reativa é injetada pelo RSC e pelo GSC.

Durante o uso da estratégia C, o controle de fator de potência unitário do RSC é desativado, sendo substituído por $I_{d}^{*}=0$, porém a função de controlar a potência elétrica ótima continua em operação (Figura 4.16). Os controles do GSC operam como descritos na estratégia B. Desta forma, a injeção de potência reativa é feita apenas pelo GSC.

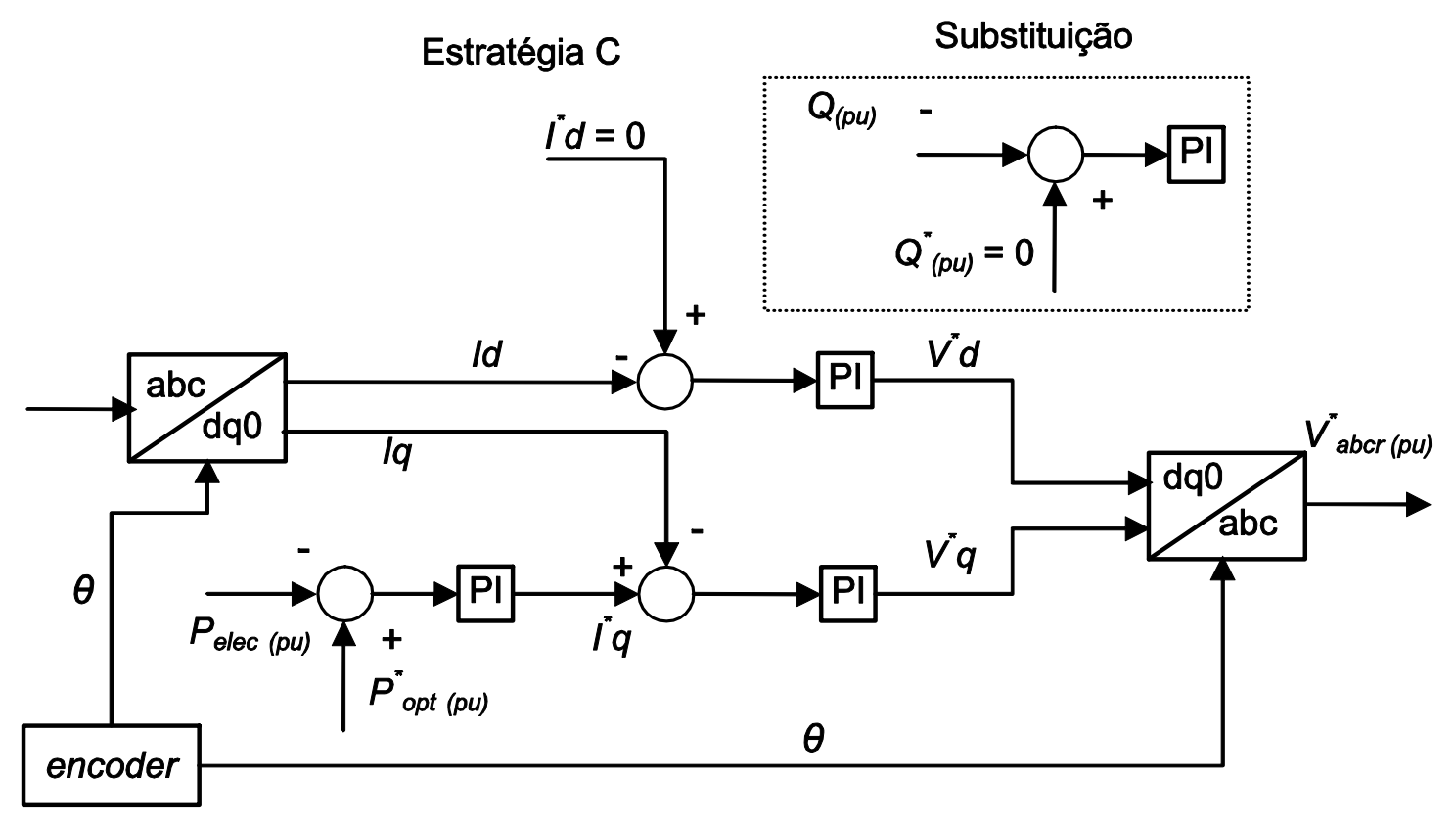

Figura 4.16 Estratégia C: diagrama esquemático do controle do RSC do DFIG durante curto-circuito.

A Tabela 4.1 apresenta de forma simplificada as estratégias de controle adotadas para o RSC e para o GSC. Estas estratégias de controle foram analisadas, considerando, primeiramente, um curto-circuito trifásico na barra 5 do sistema de transmissão teste (Figura 3.7). Nesta análise, os valores da tensão nos terminais da fazenda eólica não chegam à zero. $O$ fato de o curto-circuito ser distante da fazenda eólica explica a observação de uma tensão residual. 
A segunda análise considera um curto-circuito trifásico nos terminais da fazenda eólica, levando os valores da tensão terminal a zero.

Tabela 4.1 Resumo das estratégias de controle do RSC e do GSC analisadas.

\begin{tabular}{|c|c|c|c|c|}
\hline & Operação normal & Estratégia A & Estratégia B & Estratégia C \\
\hline $\mathrm{RSC} \rightarrow \boldsymbol{I}_{d}^{*}$ & $\begin{array}{c}\text { fator de potência } \\
\text { unitário }\end{array}$ & tensão terminal & tensão terminal & \\
\hline $\mathrm{RSC} \rightarrow \boldsymbol{I}^{*}{ }_{q}$ & $\begin{array}{c}\text { potência elétrica } \\
\text { ótima }\end{array}$ & $\begin{array}{c}\text { potência elétrica } \\
\text { ótima }\end{array}$ & $\begin{array}{c}\text { potência elétrica } \\
\text { ótima }\end{array}$ & $\begin{array}{c}\text { potência elétrica } \\
\text { ótima }\end{array}$ \\
\hline $\mathrm{GSC} \rightarrow I_{d}^{*}$ & tensão link CC & tensão link CC & tensão link CC & tensão link CC \\
\hline $\mathrm{GSC} \rightarrow \boldsymbol{I}_{q}^{*}$ & & 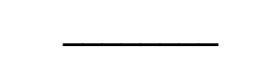 & potência reativa & potência reativa \\
\hline
\end{tabular}

\subsubsection{Curto-Circuito no Sistema de Transmissão}

As principais variáveis, para um curto-circuito na barra 5 do sistema de transmissão, eliminado em 150 ms, são mostradas na sequência (da Figura 4.17 até a Figura 4.24). A tensão terminal da fazenda eólica atingiu valores mais elevados, quando a estratégia $B$ foi adotada (Figura 4.17). A potência reativa injetada na rede foi maior, também, quando a estratégia B foi utilizada (Figura 4.18), sendo que a estratégia $C$ não se mostrou eficiente.

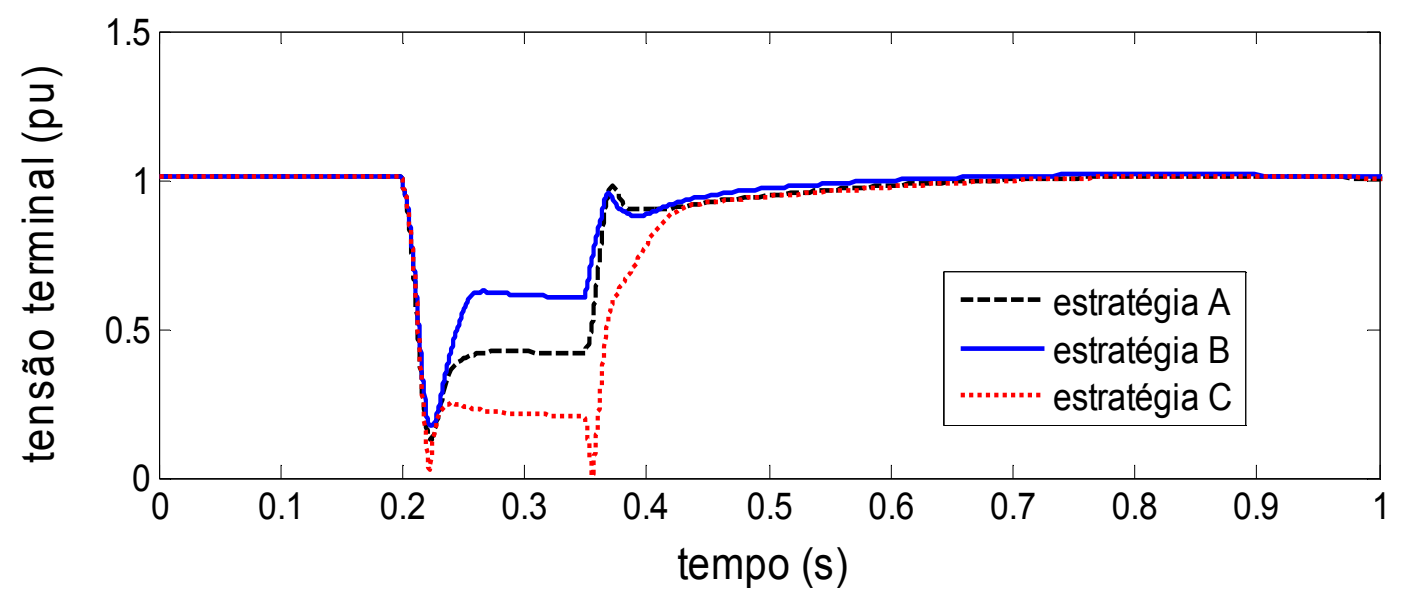

Figura 4.17 Tensão terminal da fazenda eólica durante curto-circuito na B5, eliminado em 150 ms. 


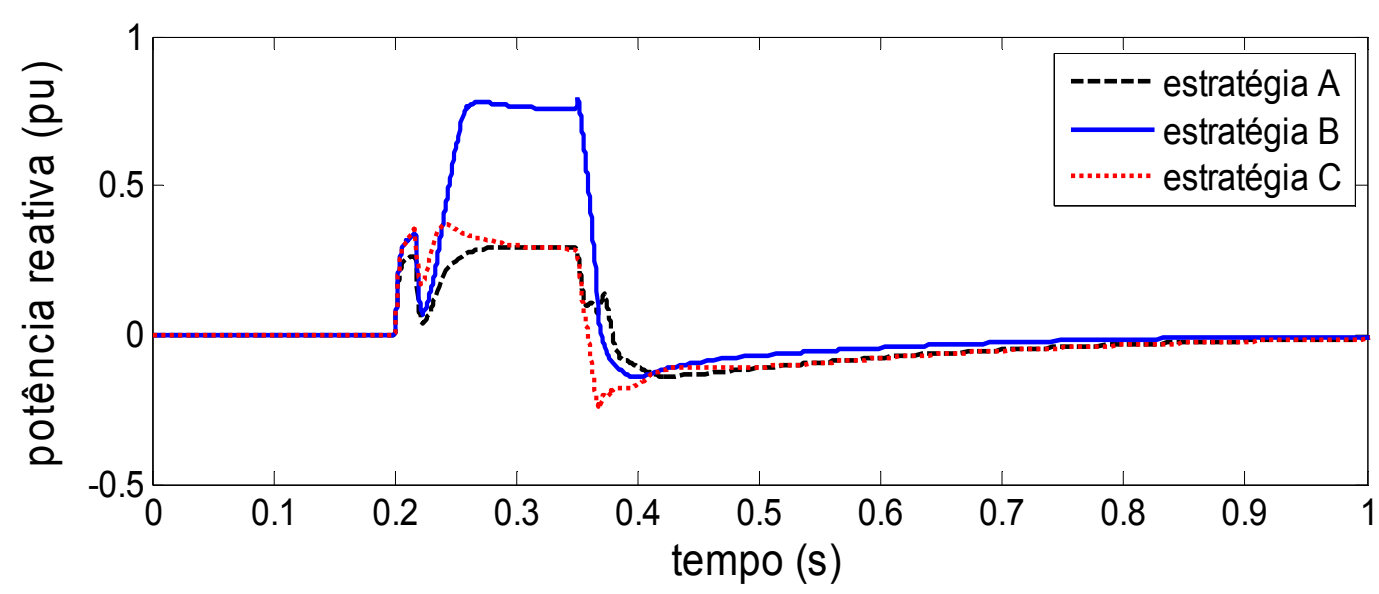

Figura 4.18 Potência reativa injetada durante curto-circuito na B5, eliminado em 150 ms.

A injeção de potência ativa foi realizada, apenas, pela estratégia A. Tanto a estratégia B, quanto a $C$, revelaram-se ineficazes (Figura 4.19). As estratégias B e a C priorizam a injeção de potência reativa, via GSC, enquanto a estratégia $A$, apenas pelo RSC. Isso quer dizer que a potência ativa, injetada na estratégia $A$, foi feita, principalmente, pelo GSC.

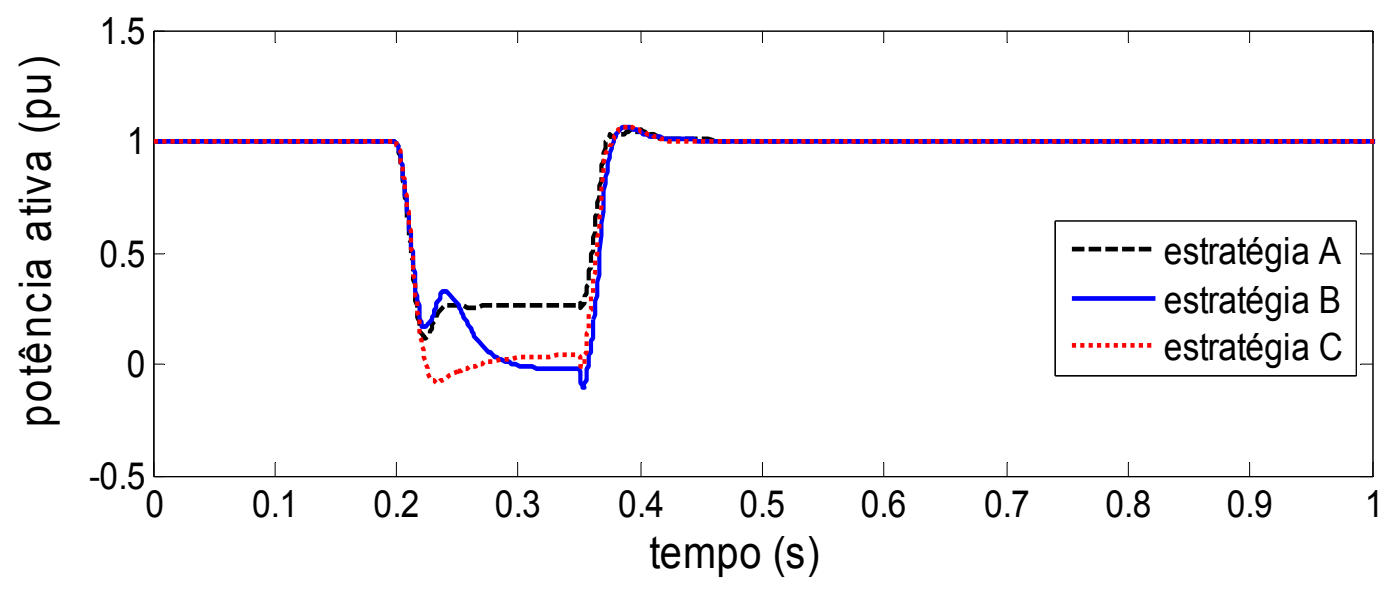

Figura 4.19 Potência ativa injetada durante curto-circuito na B5, eliminado em 150 ms.

A tensão no link CC teve comportamento similar para os três casos, como pode ser visto na Figura 4.20, sem atingir tensões muito elevadas, e que sensibilizariam o sistema de proteção.

A velocidade atingida pela estratégia A foi a mais baixa (Figura 4.21), consequentemente, a atuação do ângulo de passo, também, foi o menos requisitado, como pode ser observado na Figura 4.22. 


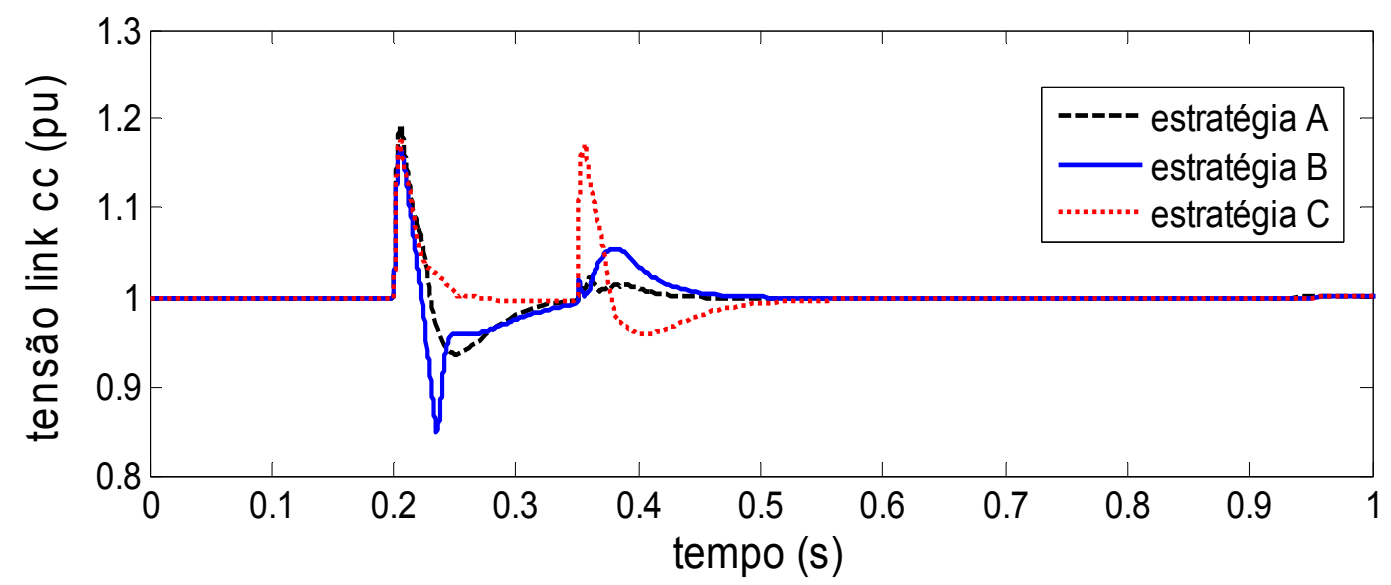

Figura 4.20 Tensão no link CC durante curto-circuito na B5, eliminado em 150 ms.

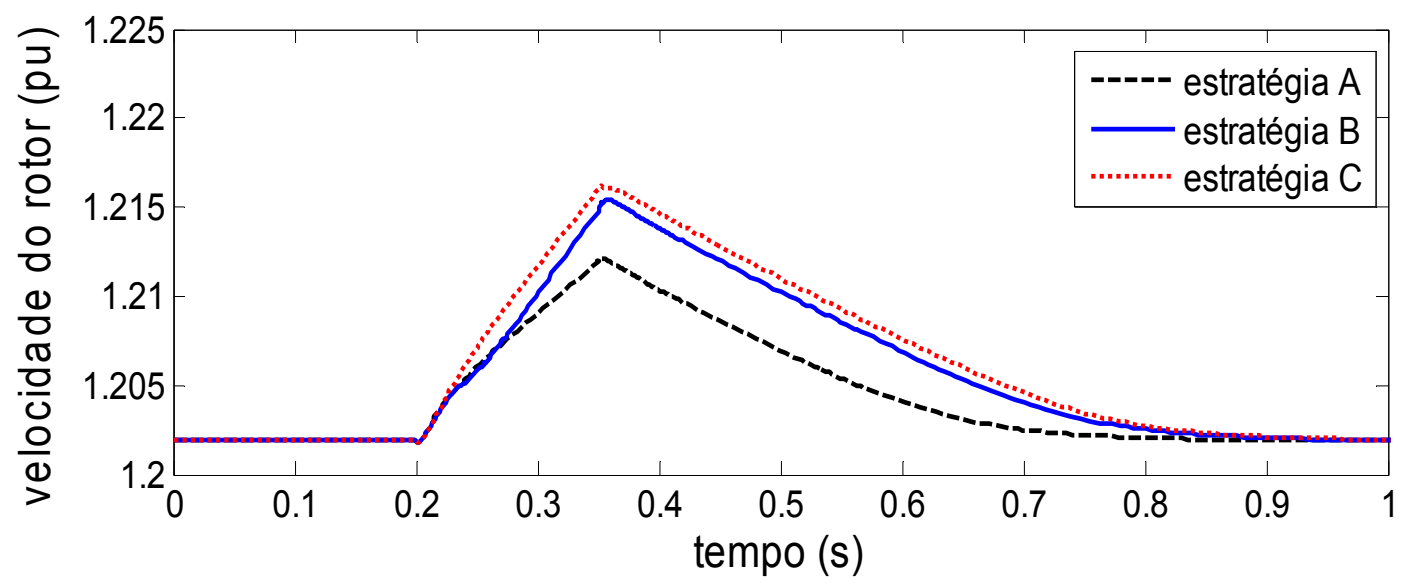

Figura 4.21 Velocidade do rotor durante curto-circuito na B5, eliminado em $150 \mathrm{~ms}$.

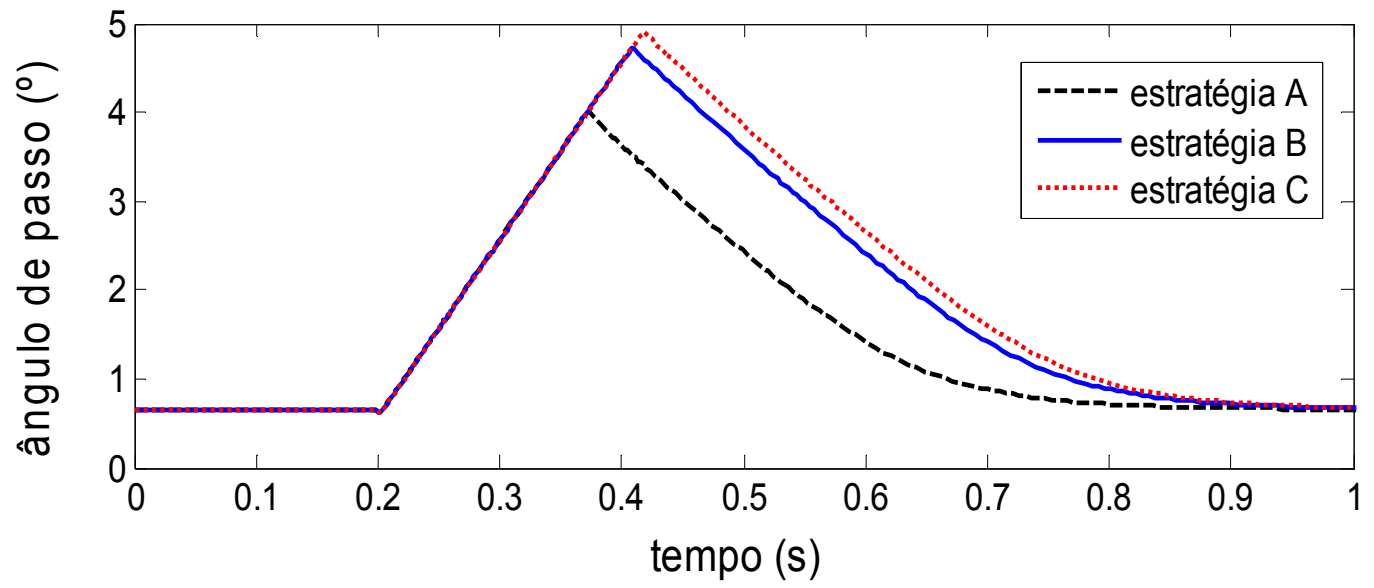

Figura 4.22 Ângulo de passo das pás durante curto-circuito na B5, eliminado em 150 ms. 
Os efeitos das três estratégias de controle, também, puderam ser verificados na barra de conexão da hidroelétrica, a qual é equipada com gerador síncrono. A Figura 4.23 mostra que a tensão, em seus terminais, atingiu o valor mais elevado, quando a estratégia $B$ foi utilizada, sendo que a oscilação de velocidade do gerador síncrono, também, foi mais atenuada com essa estratégia (Figura 4.24).

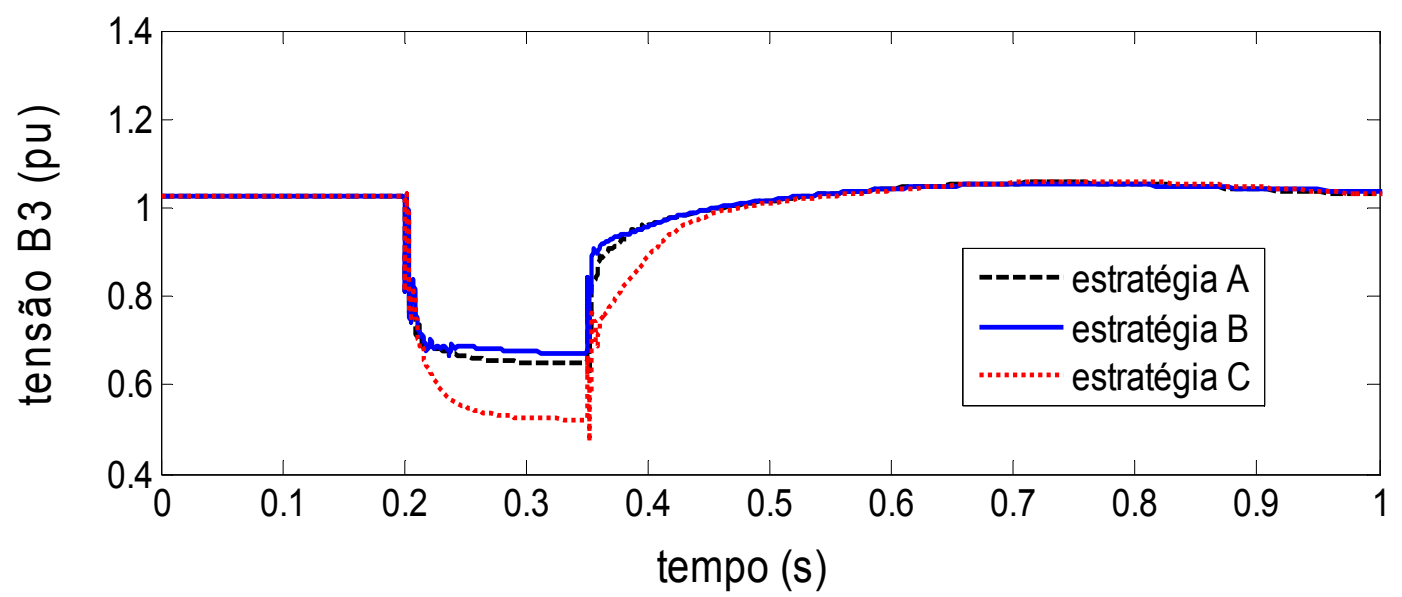

Figura 4.23 Tensão terminal da hidroelétrica durante curto-circuito na B5, eliminado em $150 \mathrm{~ms}$.

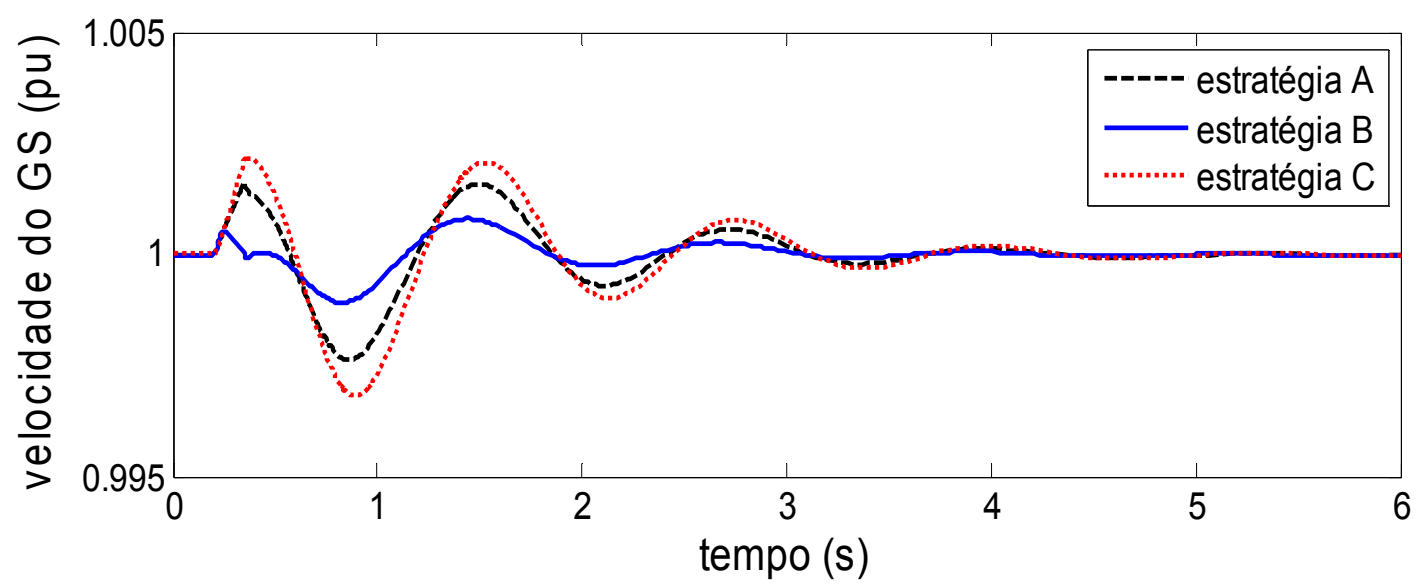

Figura 4.24 Velocidade do gerador síncrono (B3) durante curto-circuito na B5, eliminado em $150 \mathrm{~ms}$.

\subsubsection{Curto-Circuito nos Terminais da Fazenda Eólica}

Para um curto-circuito eliminado em $150 \mathrm{~ms}$, na barra de conexão da fazenda eólica com sistema de transmissão, a tensão terminal e a tensão no link CC são mostradas na Figura 4.25 e na Figura 4.26, respectivamente. Com um curto-circuito severo no ponto de conexão da fazenda eólica, o GSC das estratégias $A, B$ e $C$ não consegue injetar corrente reativa na rede, visto que a corrente de eixo direto de referência $\left(I_{d}^{*}\right)$, que controla a tensão no link CC, tem prioridade sobre a corrente de 
referência de eixo em quadratura $\left(I_{q}^{*}\right)$, que controla a injeção de corrente reativa. Desta forma, as estratégias A e B apresentam, exatamente, os mesmos resultados, tendo suas curvas sobrepostas. A estratégia C não é eficaz, pois o efeito positivo da injeção de corrente reativa é anulado pelo controle da tensão do link CC.

A tensão terminal no ponto de conexão da fazenda eólica atingiu valor mais elevado, quando as estratégias A e B foram usadas (Figura 4.25).

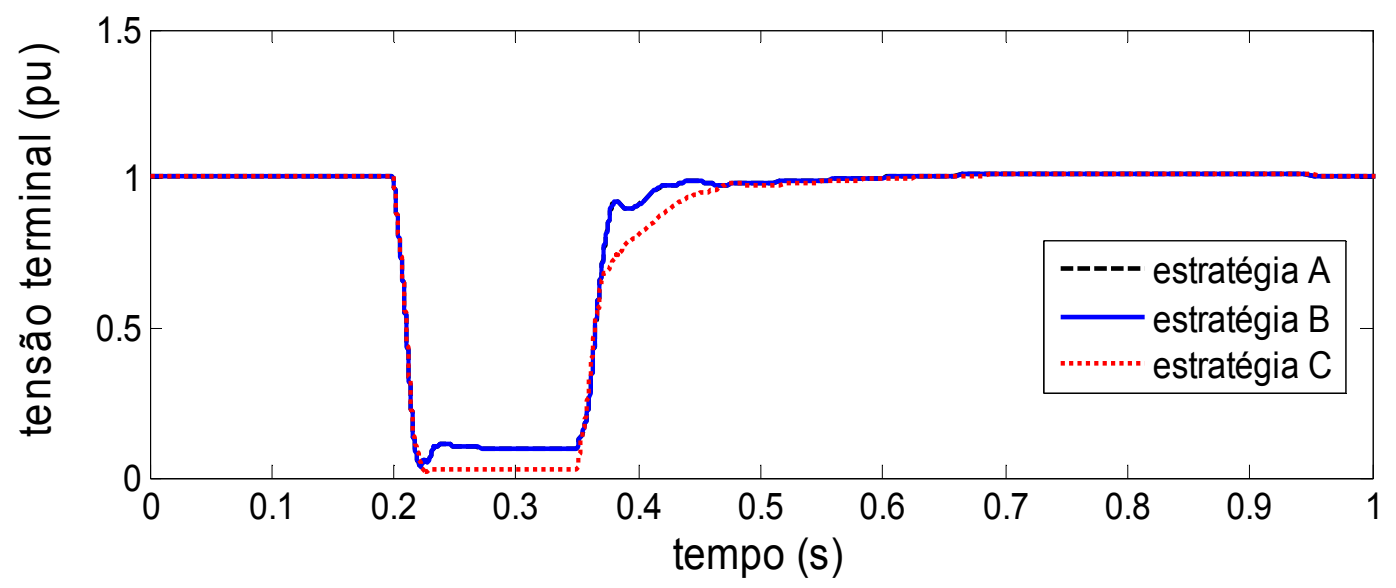

Figura 4.25 Tensão terminal da fazenda eólica durante curto-circuito na B7, eliminado em $150 \mathrm{~ms}$.

A tensão no link CC atinge valores muito elevados nas 3 estratégias de controle, próximos a 2 pu, como observado na Figura 4.26. Desta forma, em uma condição real, a fazenda eólica seria desconectada da rede pelo sistema de relés de proteção. Porém, para seguir as normativas de conexão com a rede elétrica, durante curto-circuitos, alguns sistemas de proteção, utilizando o crowbar e o dc-chopper, são analisados, a seguir.

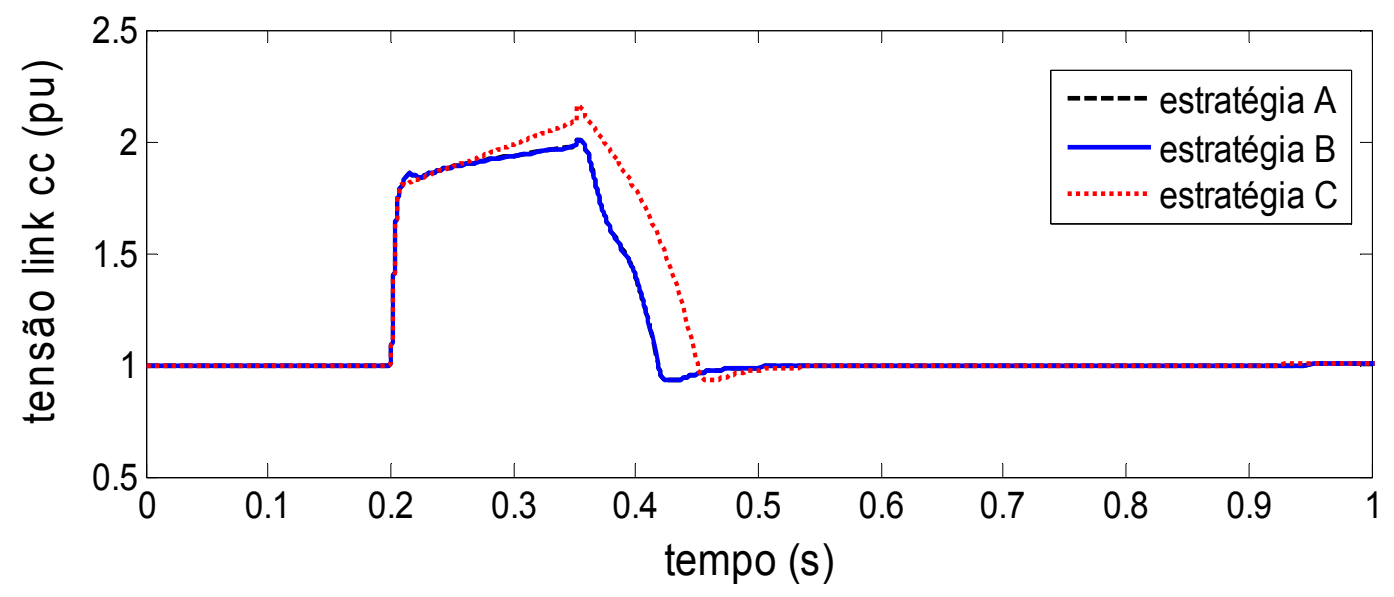

Figura 4.26 Tensão no link CC durante curto-circuito na B7, eliminado em 150 ms. 


\subsection{Análises Dinâmicas de Diferentes Estratégias de Proteção}

Dois equipamentos de proteção, introduzidos, recentemente, em algumas turbinas eólicas, foram modelados e implementados, para possibilitar a análise da operação ininterrupta de turbinas eólicas equipadas com geradores de indução duplamente alimentados.

O sistema crowbar consiste na inserção de resistências (variáveis ou fixas) em série, com o enrolamento do rotor, de forma a limitar as altas correntes induzidas nesse enrolamento, durante curto-circuitos na rede elétrica. Tal inserção é feita, após a interrupção da ligação dos enrolamentos do rotor com o RSC. O tempo de atuação do crowbar deve garantir que as correntes do rotor se encontrem dentro de valores, no máximo, próximo aos nominais. Durante a atuação do crowbar, o DFIG opera como um gerador de indução convencional de gaiola de esquilo. Caso o crowbar seja desconectado antes do tempo adequado e a correntes voltarem a assumir valores elevados, uma indesejada segunda ou eventual terceira entrada em operação do sistema deverá ocorrer. O valor fixo da resistência do crowbar, utilizado nestas análises, é de $80 \%$ do valor da resistência do rotor. A resistência equivalente $\left(R_{T}\right)$ durante a operação do sistema, considerando a resistência do enrolamento do rotor $\left(R_{R}\right)$ e a resistência do crowbar $\left(R_{\text {crowbar }}\right)$, pode ser calculada, segundo Akhmatov ([73]), por:

$$
R_{T}=R_{R}+R_{\text {crowbar }}
$$

O dc-chopper é um conversor CC/CC com tensão controlável, que dissipa em um conjunto de resistências $\left(R_{\text {chopper }}\right)$, o desbalanço de potência ativa entre o RSC e o GSC no link CC. Esse sistema não é essencial para operação ininterrupta da turbina eólica, porém estende a faixa de operação durante curto-circuitos severos no sistema elétrico. O modelo simplificado, utilizado nestas análises, é proposto por Erlich et al. em ([79]). A equação que expressa a potência elétrica dissipada $\left(P_{\text {chopper }}\right)$, durante a operação do conjunto de resistências do dc-chopper $\left(\mathrm{R}_{\text {chopper }}\right)$, pode ser calculada de acordo com a equação (4.19):

$$
P_{\text {chopper }}=V_{C C}^{2} / R_{\text {chopper }}
$$


sendo,

$\begin{array}{lll}P_{\text {chopper }} & = & \text { potência elétrica dissipada no sistema } d c \text {-chopper }(\mathrm{W}) ; \\ R_{c h o p p e r} & = & \text { resistência do sistema } d c \text {-chopper }(\mathrm{ohm}) ; \\ V_{c c} & = & \text { tensão no link cc }(\mathrm{V}) ;\end{array}$

Utilizando combinações dos sistemas de proteção e de controle descritos anteriormente, três diferentes estratégias foram analisadas, durante curto-circuitos no sistema de transmissão teste. Tais estratégias ( $D, E$ e $F$ ) visaram melhorar a injeção de potência reativa na rede elétrica, durante curto-circuitos. A condição de operação normal dos controles é a mesma descrita na Tabela 4.1.

Durante a estratégia $D$, quando um curto-circuito na rede é detectado, o RSC é bloqueado e o sistema crowbar é inserido, em série, com o enrolamento do rotor, operando por 200 ms. O GSC controla a potência reativa injetada e a tensão no link CC. Após os 200 ms, o RSC volta a operar, controlando tensão terminal e a potência elétrica ótima, enquanto que o GSC volta a controlar, apenas, a tensão no link CC.

Durante a estratégia E, o RSC e o GSC operaram da mesma forma que na estratégia $\mathrm{D}$, durante o curto-circuito, porém o tempo de atuação do sistema crowbar é de apenas $100 \mathrm{~ms}$. Após os $100 \mathrm{~ms}$, o RSC passa a controlar tensão terminal e potência elétrica ótima, e o GSC, apenas tensão no link CC.

A estratégia $F$ atua da mesma forma que a estratégia $E$, porém com 0 incremento do sistema dc-chopper. Este dispositivo é ativado quando a tensão no link CC ultrapassa 1,05 pu, sendo desativado com a volta à condição nominal.

A Tabela 4.2 apresenta, de forma simplificada, as estratégias de proteção adotadas. Estas estratégias foram analisadas, considerando, primeiramente, um curto-circuito trifásico na barra 5 do sistema de transmissão teste (Figura 3.7) e um curto-circuito trifásico nos terminais da fazenda eólica. Nesta segunda análise, a tensão terminal da fazenda eólica atinge valores bem próximos a zero. 
Tabela 4.2 Resumo das estratégias durante curto-circuitos de proteção e de controle analisadas.

\begin{tabular}{cccc}
\hline & Estratégia D & Estratégia E & Estratégia $\mathrm{F}$ \\
\hline $\mathrm{RSC} \rightarrow \boldsymbol{I}_{\boldsymbol{d}}^{*}$ & bloqueado por $200 \mathrm{~ms}$ & $\begin{array}{c}\text { bloqueado por } 100 \mathrm{~ms} \\
\text { /tensão terminal } \\
\text { bloqueado por } 100 \mathrm{~ms}\end{array}$ & $\begin{array}{c}\text { bloqueado } 100 \mathrm{~ms} \\
\text { /tensão terminal }\end{array}$ \\
\hline $\mathrm{RSC} \rightarrow \boldsymbol{I}_{q}^{*}$ & bloqueado por $200 \mathrm{~ms}$ & $\begin{array}{c}\text { bloqueado } 100 \mathrm{~ms} \\
\text { /potência elétrica ótima }\end{array}$ \\
$\mathrm{GSC} \rightarrow \boldsymbol{I}_{d}^{*}$ & tensão link CC & tensão link CC & tensão link CC \\
$\mathrm{GSC} \rightarrow \boldsymbol{I}_{q}^{*}$ & potência reativa & potência reativa & potência reativa \\
crowbar & 200 ms & 100 ms & 100 ms \\
\hline$d c$-chopper & desativado & desativado & ativado \\
\hline
\end{tabular}

\subsubsection{Curto-Circuito no Sistema de Transmissão}

Para um curto-circuito, na barra 5 do sistema de transmissão, eliminado em $150 \mathrm{~ms}$, as principais variáveis são mostradas da Figura 4.27 até a Figura 4.36. A tensão terminal da fazenda eólica atingiu valores mais elevados, quando as estratégias E e F foram usadas (Figura 4.27).

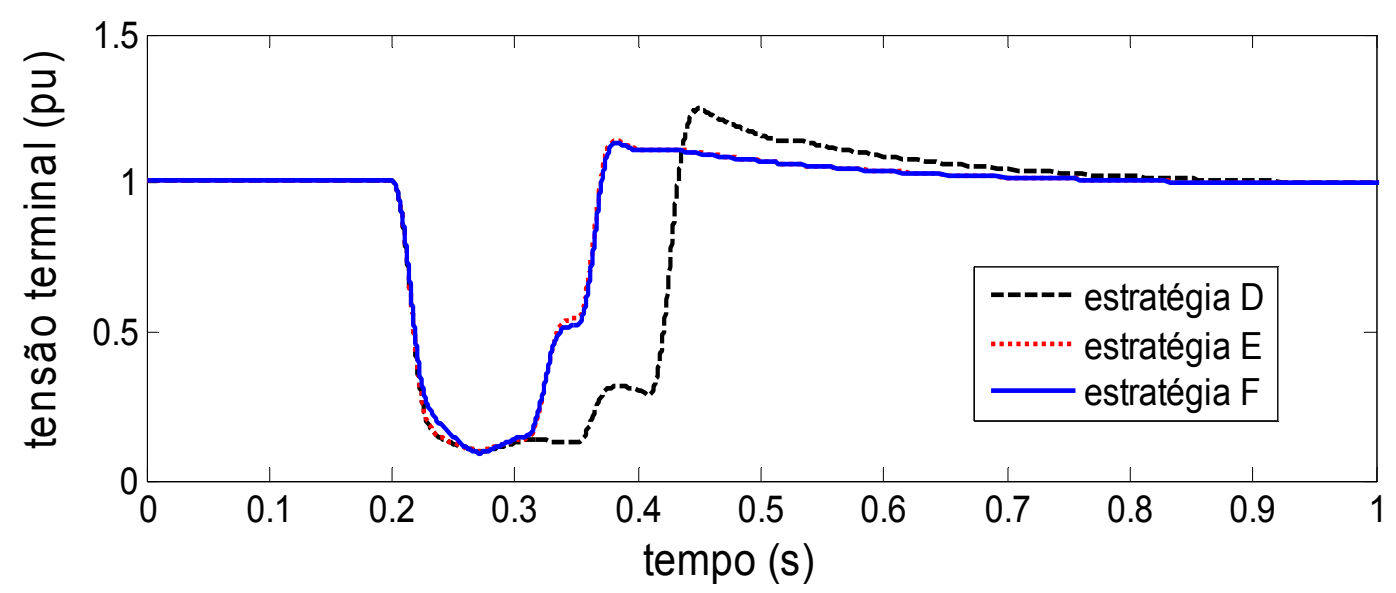

Figura 4.27 Tensão terminal da fazenda eólica durante curto-circuito na B5, eliminado em 150 ms. 
A potência reativa injetada na rede foi maior, quando ambas as estratégia foram adotadas (Figura 4.28), sendo que a estratégia $D$ se mostrou ineficiente. Como o sistema crowbar atua apenas 100 ms nas estratégias E e F, logo após sua saída de operação e a reconexão do RSC aos enrolamentos do rotor, é possível iniciar o controle da tensão terminal ainda durante o curto-circuito.

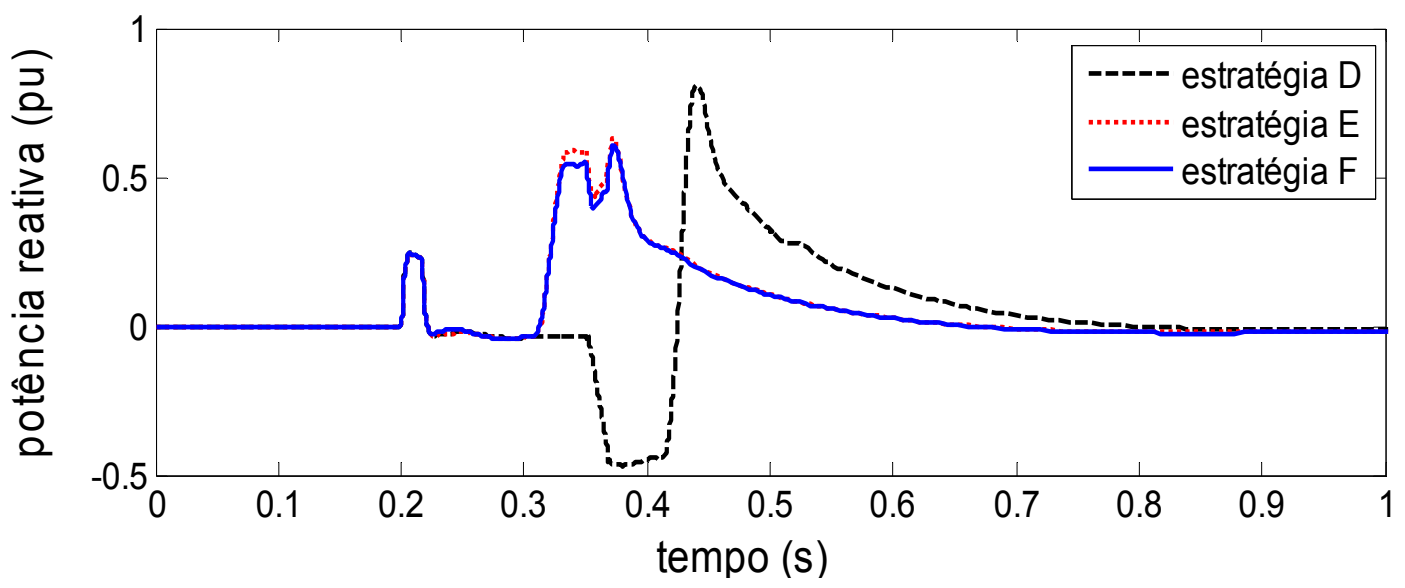

Figura 4.28 Potência reativa injetada durante curto-circuito na B5, eliminado em 150 ms.

Neste intervalo de 50 ms, entre a reconexão do RSC e a eliminação do curtocircuito, a injeção de corrente reativa nas estratégias $E$ e $F$ chega a 1 pu, como mostrado na Figura 4.29. Tal fato cumpre os requisitos dos operadores do sistema de transmissão alemão ([76]) e do sistema de transmissão espanhol ([77]), referentes à injeção de corrente reativa durante curto-circuitos no sistema de transmissão. Na Alemanha, os requisitos de conexão exigem injeção de 1 pu de corrente reativa durante curto-circuito similar, porém, na Espanha, 0,9 pu.

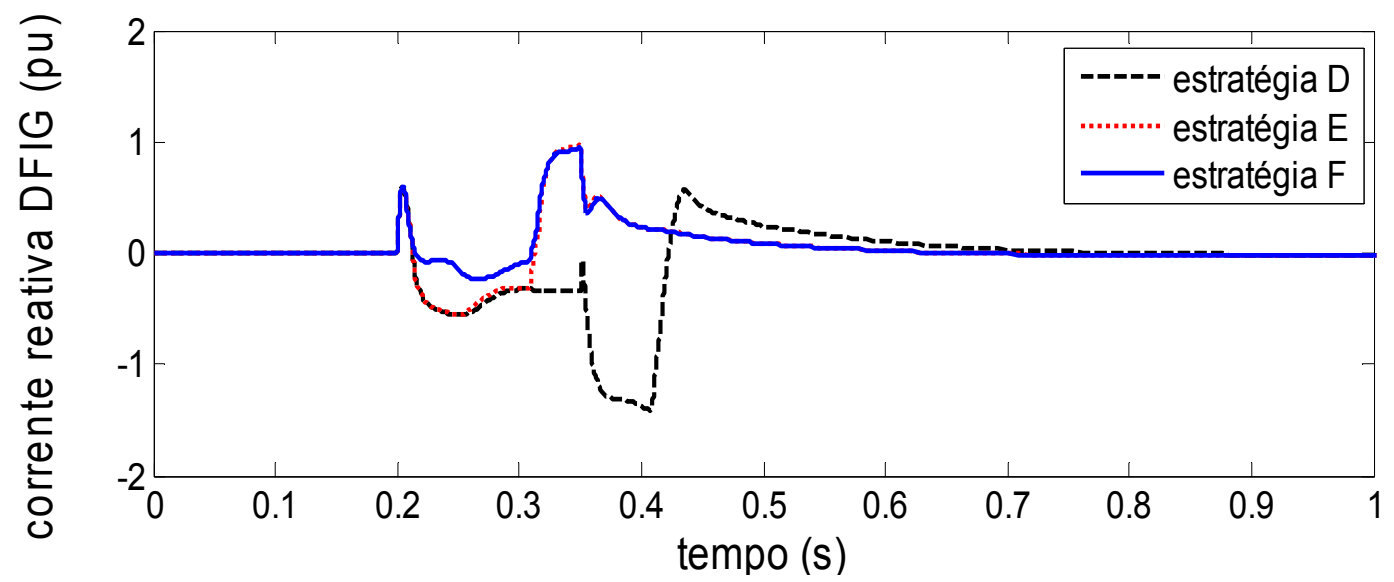

Figura 4.29 Corrente reativa injetada total durante curto-circuito na B5, eliminado em $150 \mathrm{~ms}$. 
Observa-se que com o uso das estratégias E e F, o DFIG injeta potência ativa durante o curto-circuito e volta a injetar potência ativa nominal mais rapidamente do que com a estratégia D (Figura 4.30).

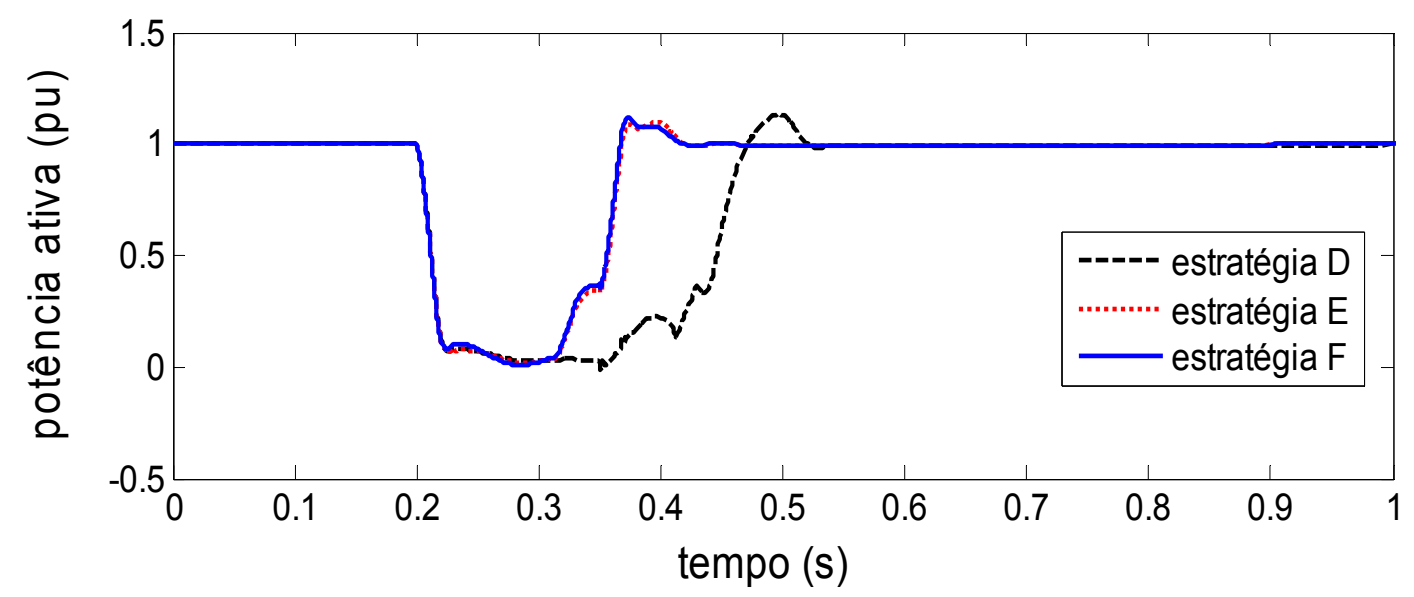

Figura 4.30 Potência ativa injetada durante curto-circuito na B5, eliminado em 150 ms.

A tensão no link de corrente contínua é mantida, dentro dos limites, nas três estratégias, porém a estratégia $\mathrm{F}$ obteve o melhor desempenho, como pode ser observado na Figura 4.31.

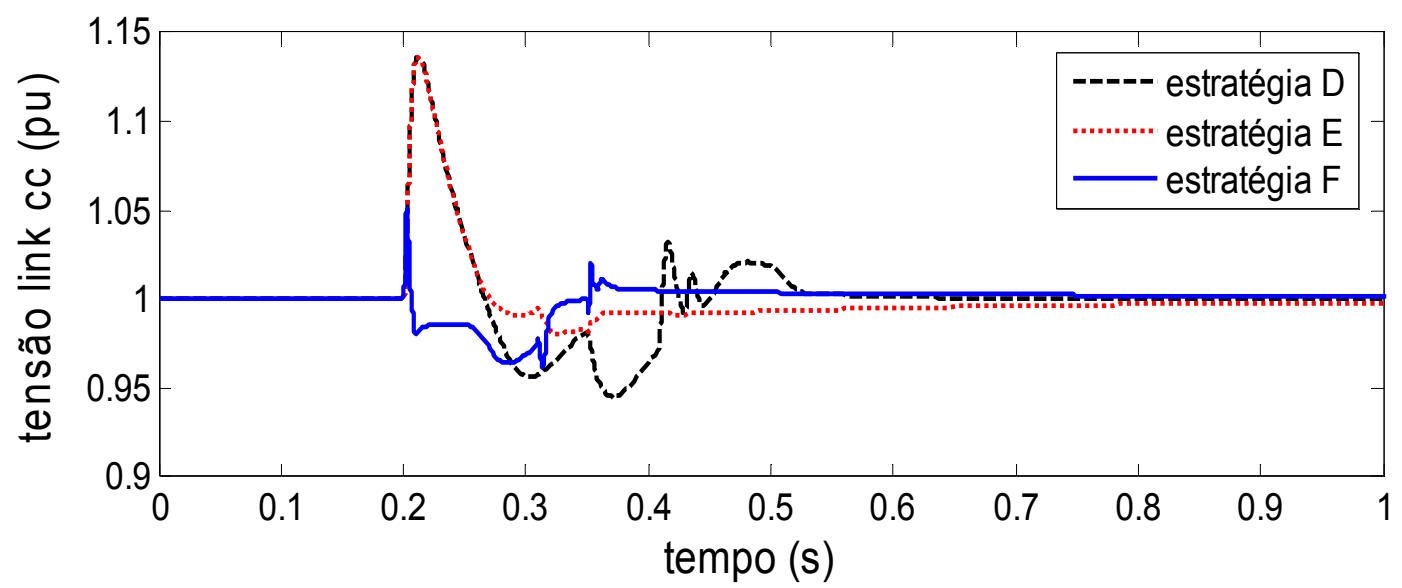

Figura 4.31 Tensão no link CC durante curto-circuito na B5, eliminado em 150 ms.

Como a tensão no link CC é restabelecida rapidamente, com uso da estratégia F, o GSC pode iniciar a injeção de potência reativa logo após a detecção do curto-circuito e utilizar, praticamente, toda a capacidade do GSC, como pode ser vista na Figura 4.32. Desta forma, assim que a tensão no link CC ultrapassa 1,05 pu, o desbalanço de potência começa a ser dissipado no dc-chopper, como mostrada na Figura 4.33. 


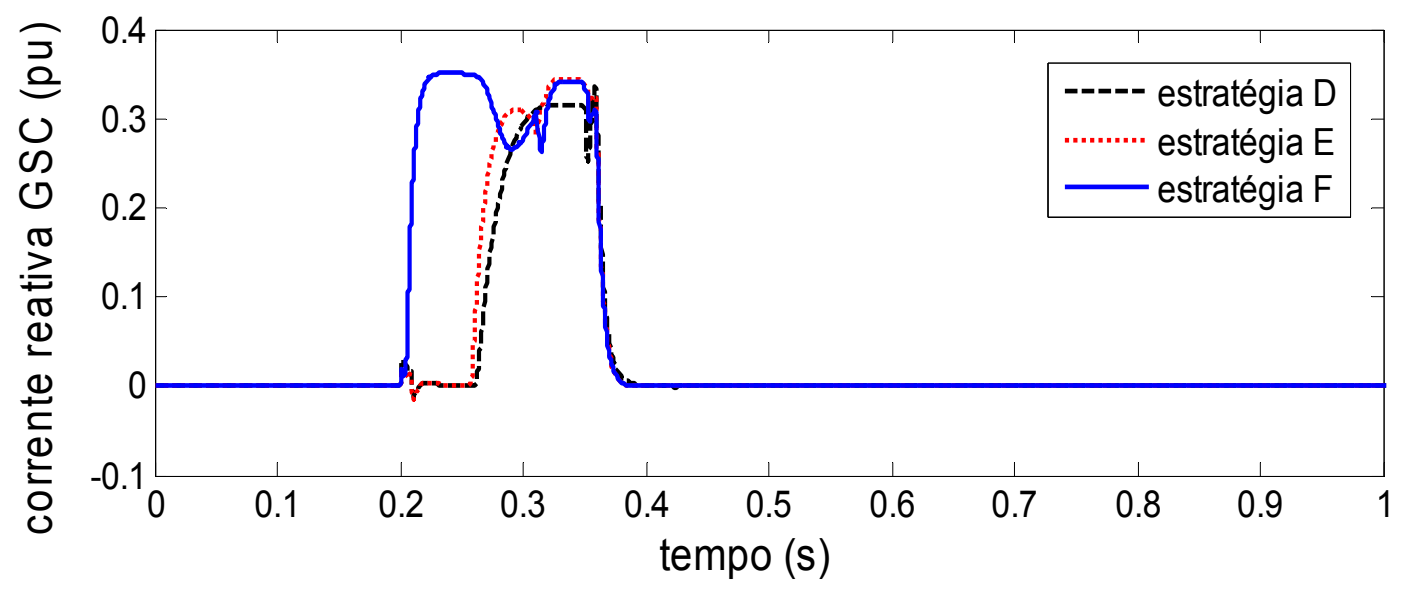

Figura 4.32 Corrente reativa injetada pelo GSC durante curto-circuito na B5, eliminado em 150 ms.

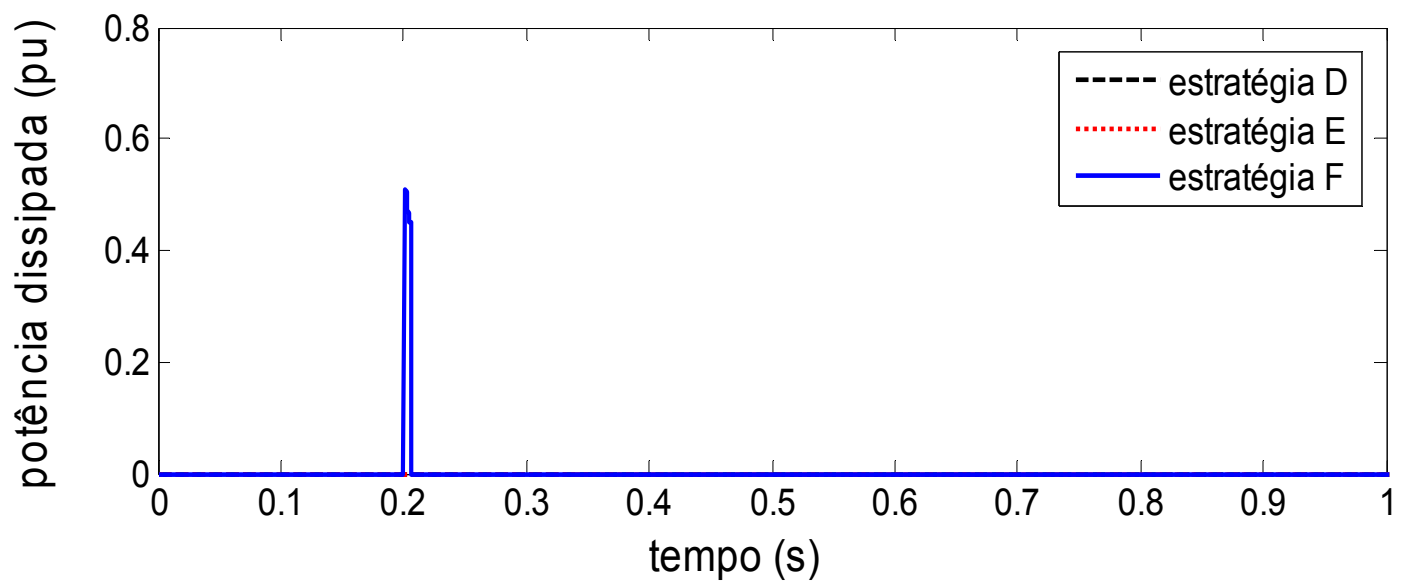

Figura 4.33 Potência dissipada no dc-chopper durante curto-circuito na B5, eliminado em $150 \mathrm{~ms}$.

A velocidade do gerador atingiu valores mais baixos utilizando as estratégias $\mathrm{E}$ e $\mathrm{F}$, tal fato é explicado pela reativação do RSC ser $100 \mathrm{~ms}$ mais rápida do que com a estratégia D (Figura 4.34). Porém, a estratégia $F$ teve um desempenho levemente superior ao da estratégia $\mathrm{E}$, pois o GSC injetou mais corrente reativa durante a falta, como mostrado na Figura 4.32. O comportamento do controle do ângulo das pás seguiu a tendência do comportamento da velocidade (Figura 4.35).

A tensão no barramento da usina hidroelétrica, atingiu valores de tensão terminal mais elevados para as estratégias E e F, como mostrado na Figura 4.36. 


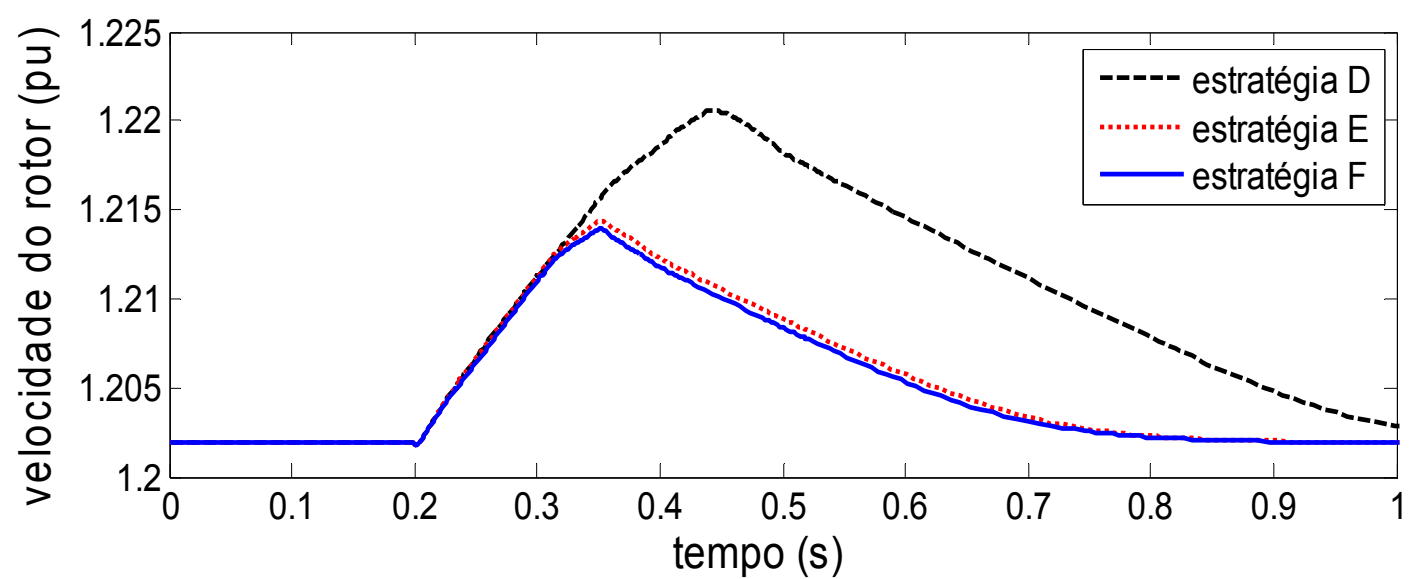

Figura 4.34 Velocidade do rotor durante curto-circuito na B5, eliminado em $150 \mathrm{~ms}$.

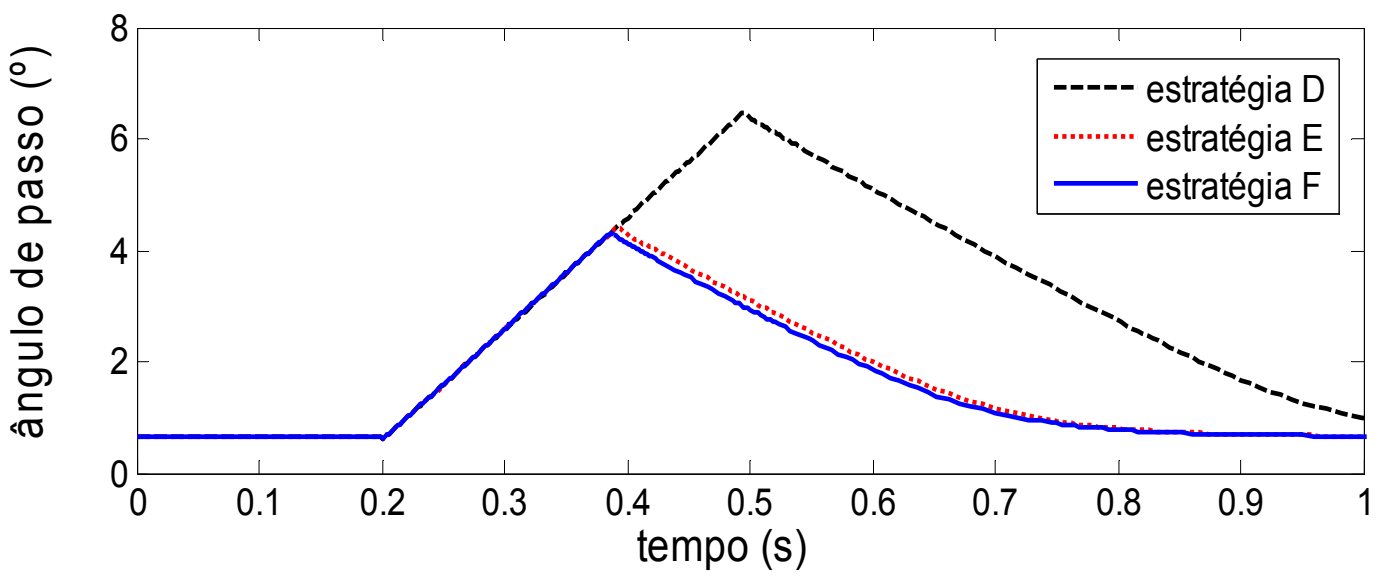

Figura 4.35 Ângulo de passo das hélices durante curto-circuito na B5, eliminado em 150 ms.

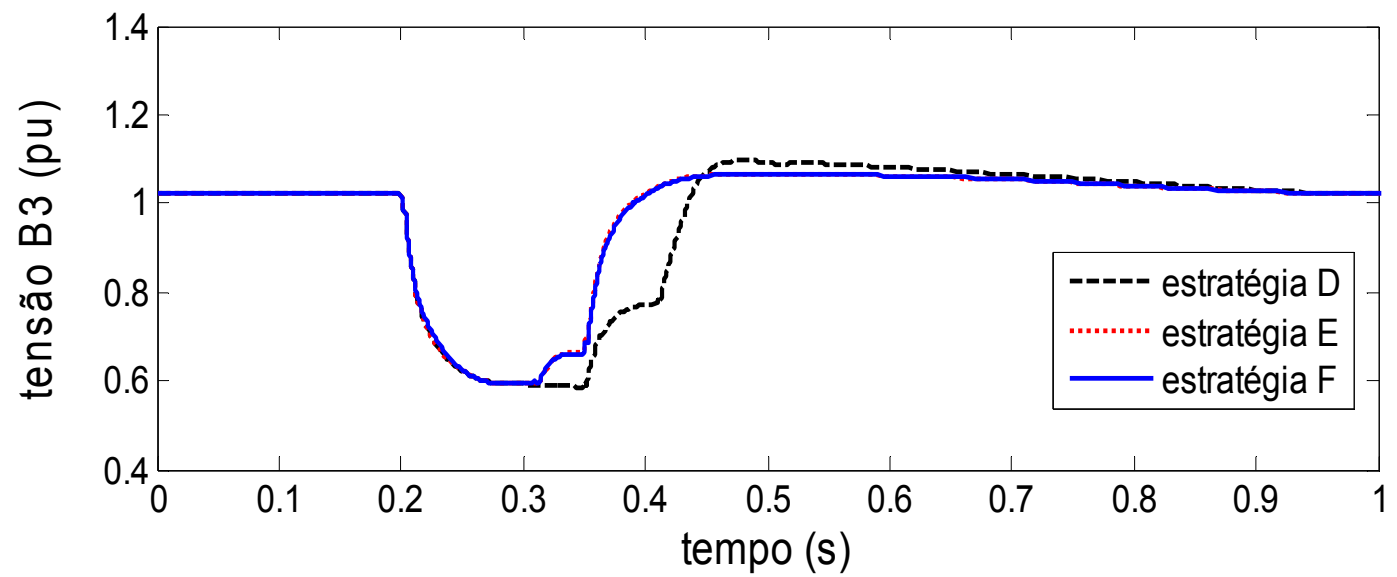

Figura 4.36 Tensão terminal da hidroelétrica durante curto-circuito na B5, eliminado em $150 \mathrm{~ms}$. 


\subsubsection{Curto-Circuito nos Terminais da Fazenda Eólica}

As principais variáveis para um curto-circuito eliminado em $150 \mathrm{~ms}$, no ponto de conexão da fazenda eólica com o sistema de transmissão, são mostradas, da Figura 4.37 até a Figura 4.47. Com um curto-circuito mais severo, a tensão terminal da fazenda eólica atinge valores próximos a zero. A estratégia $F$ mostrou-se mais eficaz, como indica a Figura 4.37, atingindo valores mais elevados de tensão terminal durante o curto-circuito.

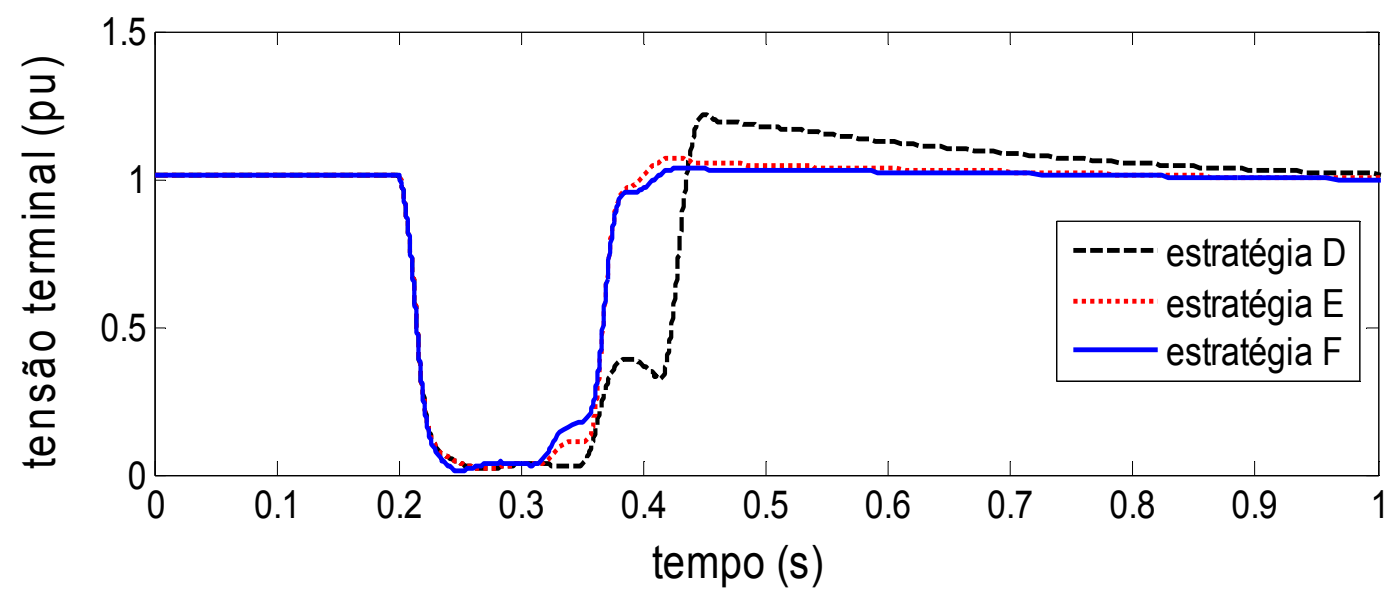

Figura 4.37 Tensão terminal da fazenda eólica durante curto-circuito na B7, eliminado em $150 \mathrm{~ms}$.

Após a atuação do sistema crowbar, a injeção de potência reativa (Figura 4.38) é retomada nas estratégias $E$ e $F$. Porém, como nas estratégias $D$ e $E$ a tensão no link CC ainda se encontra muito alta, o GSC não consegue injetar corrente reativa durante o curto-circuito (Figura 4.39).

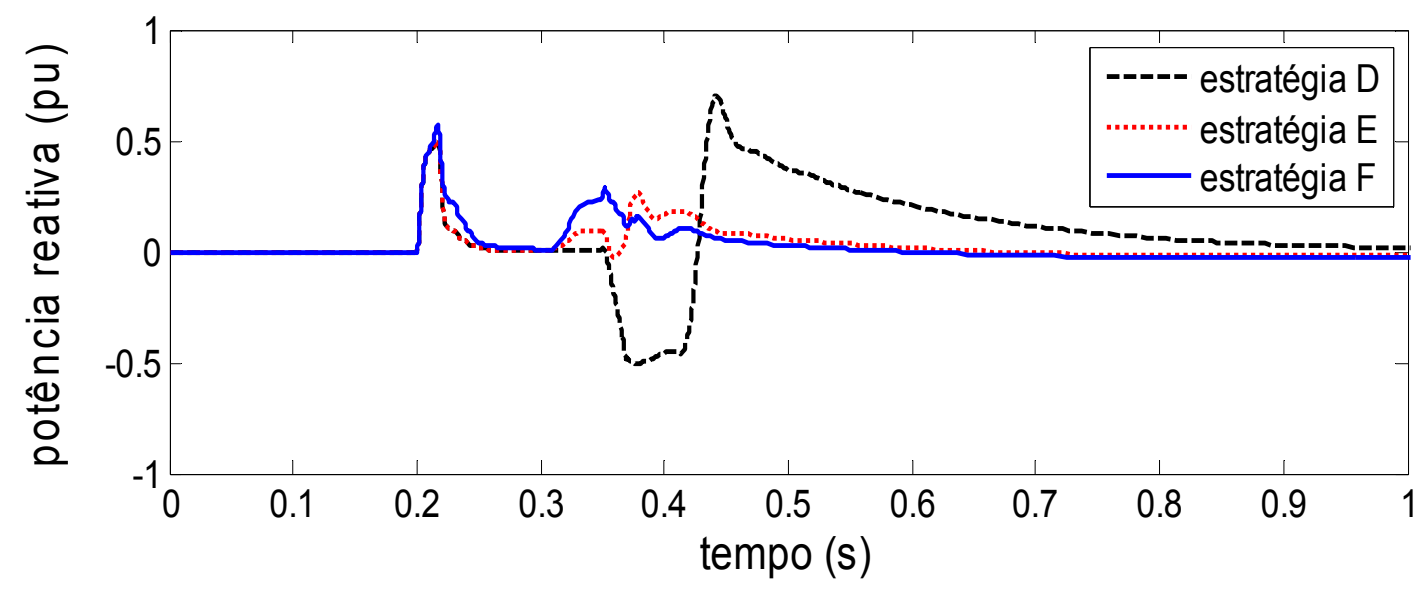

Figura 4.38 Potência reativa injetada durante curto-circuito na B7, eliminado em 150 ms. 


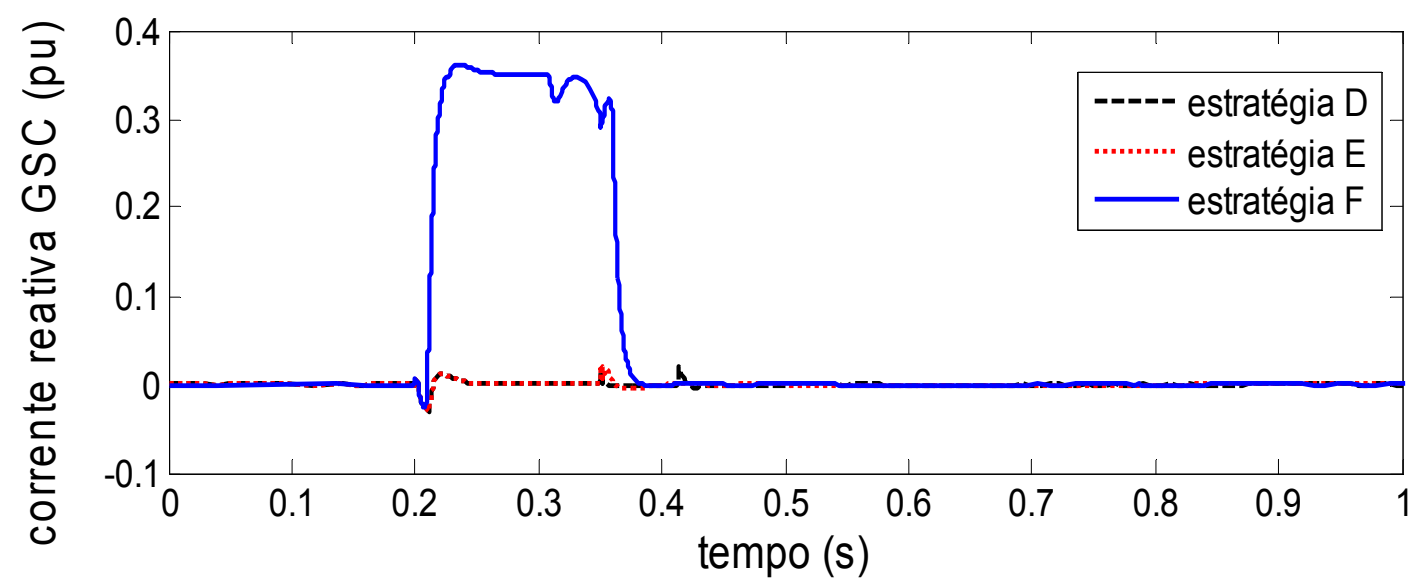

Figura 4.39 Corrente reativa injetada pelo GSC durante curto-circuito na B7, eliminado em $150 \mathrm{~ms}$.

Consequentemente, a corrente reativa total injetada pelo DFIG não é suficiente para atingir o valor exigido pela norma técnica, o qual é atingindo apenas para a estratégia F, como mostrado na Figura 4.40.

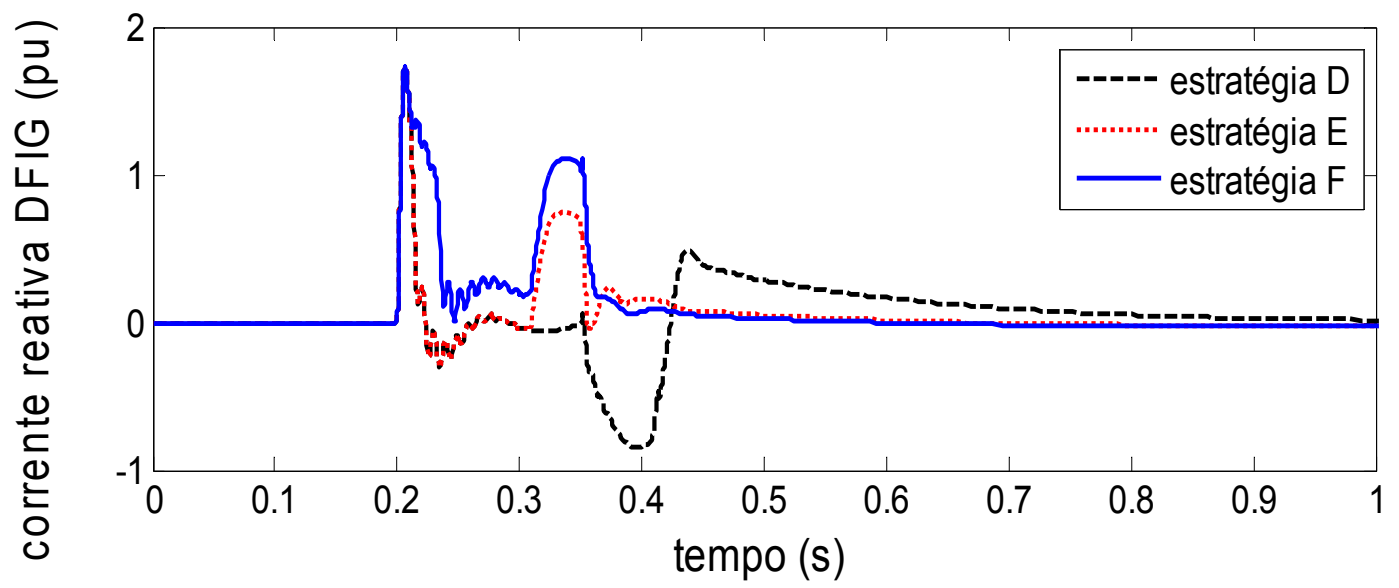

Figura 4.40 Corrente reativa injetada total durante curto-circuito na B7, eliminado em $150 \mathrm{~ms}$.

A injeção de potência ativa durante a falta é, praticamente, nula para as três estratégias sugeridas. Porém, nas estratégias E e $F$ observa-se um consumo de potência ativa durante 5 milissegundos, no instante seguinte à eliminação da falta (Figura 4.41). Tal fato configura operação como motor, podendo ser explicada a partir das curvas de conjugado eletromagnético, visualizadas da Figura 4.42. Nessas curvas, os conjugados eletromagnéticos das estratégias $\mathrm{E}$ e $\mathrm{F}$ atingem valores positivos, dentro do mesmo intervalo. Tais valores são resultado da injeção instantânea de tensão nos enrolamentos do rotor pelo RSC. 
A ação do controle do RSC muda dinamicamente a posição da curva de conjugado eletromagnético em relação aos valores de escorregamento, como será apresentado no capítulo seguinte, na Figura 5.7 e na Figura 5.8.

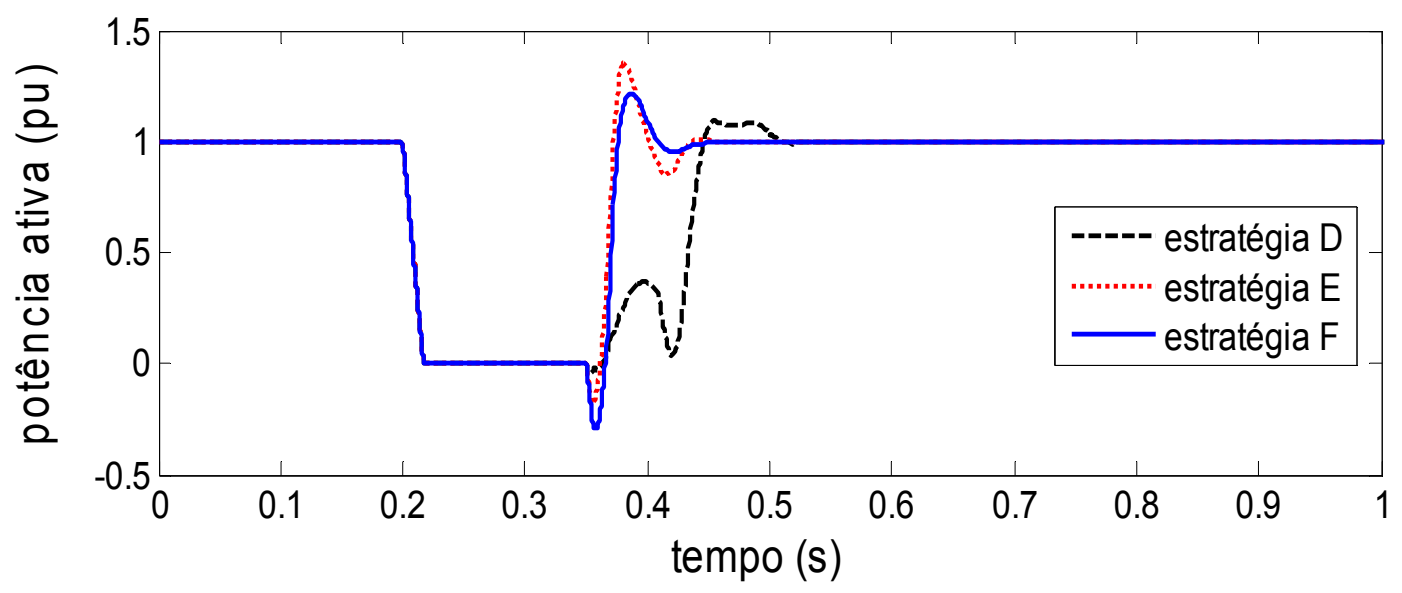

Figura 4.41 Potência ativa injetada durante curto-circuito na B7, eliminado em 150 ms.

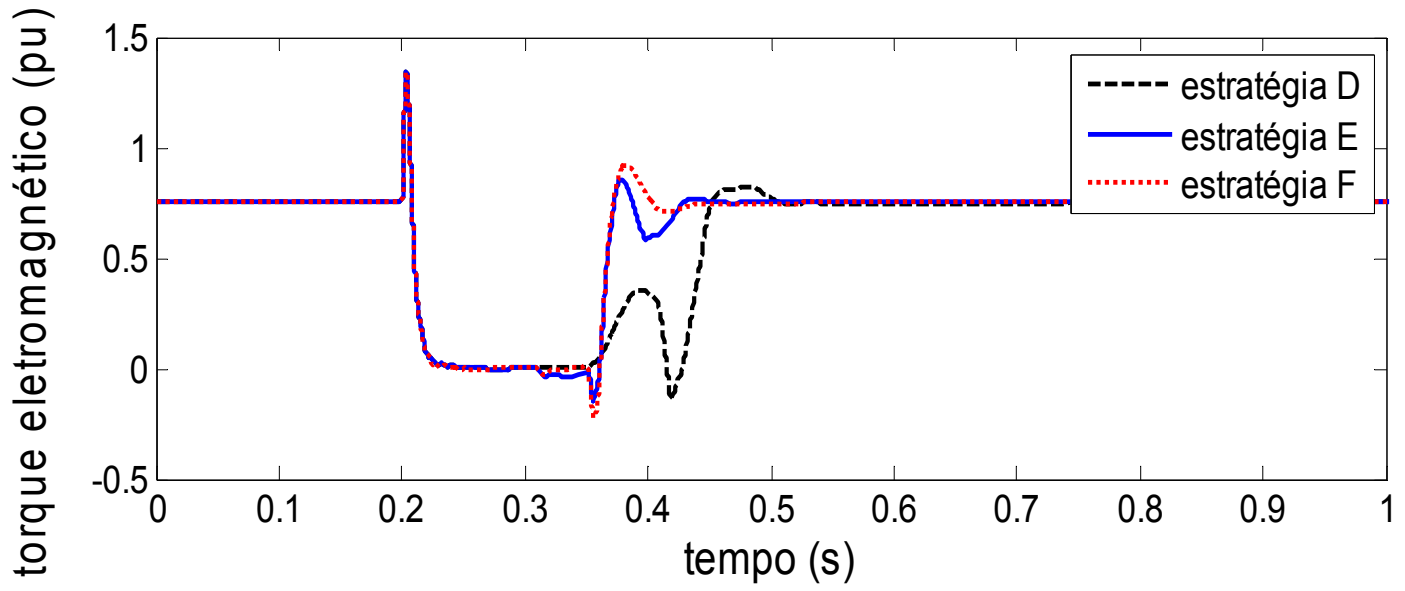

Figura 4.42 Conjugado eletromagnético negativo durante curto-circuito na B7, eliminado em 150 ms.

A tensão no link CC só é mantida dentro de limites, que garantam sua operação, utilizando a estratégia $F$ (Figura 4.43), pois os geradores com as estratégias $\mathrm{D}$ e $\mathrm{E}$ seriam desconectados por relés de proteção. Como esperado, a potência dissipada no dc-chopper foi maior do que no curto-circuito na barra 5 (Figura 4.44). 


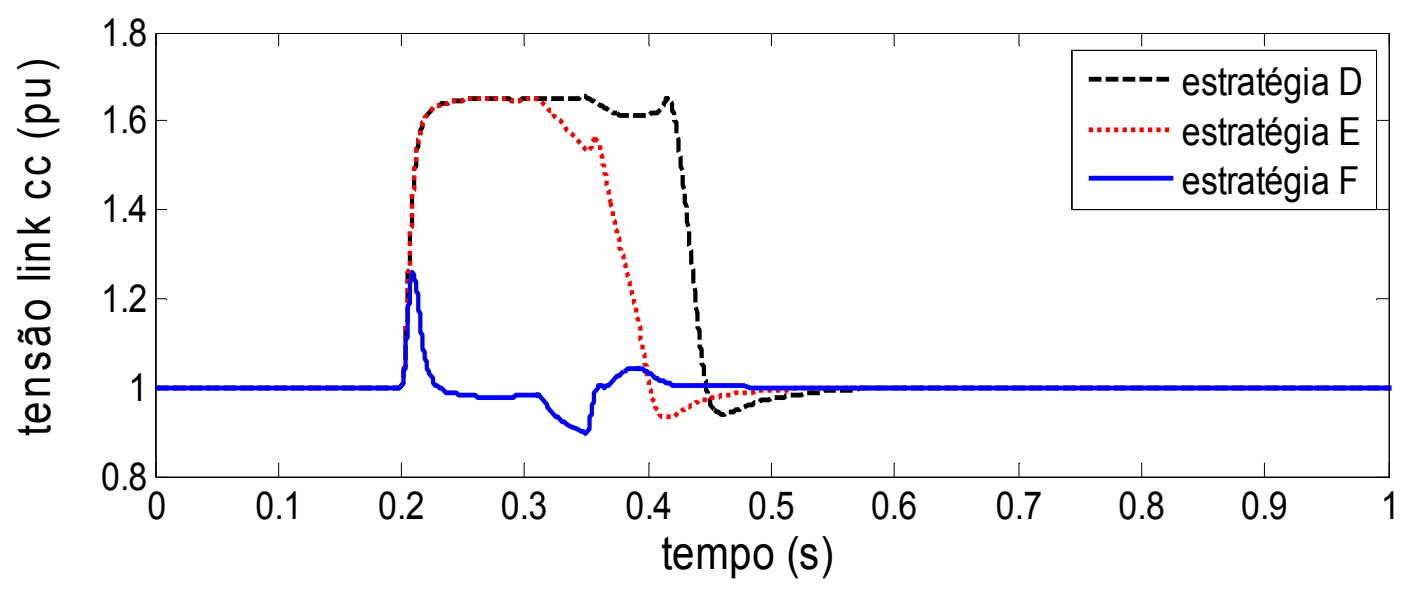

Figura 4.43 Tensão no link CC durante curto-circuito na B7, eliminado em 150 ms.

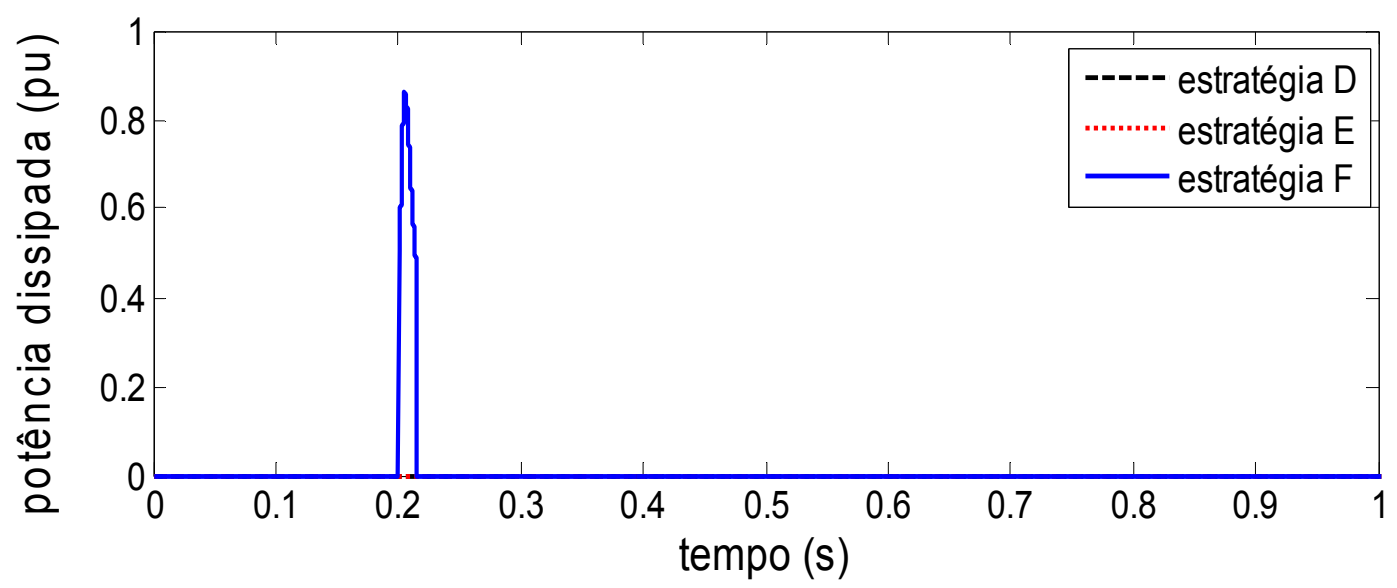

Figura 4.44 Potência dissipada no dc-chopper durante curto-circuito na B7, eliminado em $150 \mathrm{~ms}$.

A velocidade do gerador atingiu valores mais baixos utilizando as estratégias E e F, como mostra a Figura 4.45. Tal fato pode ser explicado pelo uso do sistema crowbar durante um período inferior ao da duração do curto-circuito, reativando mais rapidamente o RSC para controlar a potência elétrica ótima e a tensão terminal. Desta forma, a combinação desses fatores contribui positivamente para a estabilidade do DFIG. A estratégia $F$ teve um desempenho levemente superior, pois, além do uso do crowbar, o GSC injetou mais corrente reativa durante a falta (Figura 4.40). Analisando a Figura 4.46, podemos constatar o comportamento similar do controle do ângulo das pás ao da velocidade do rotor. A tensão no barramento B3, onde a usina hidroelétrica, equipada com um gerador síncrono convencional, está conectada, atingiu valores de tensão terminal equivalentes para as 3 estratégias, porém, após a eliminação da falta, a estratégia $D$ influenciou negativamente a 
retomada de tensão (Figura 4.47). As oscilações na velocidade do gerador síncrono não foram igualmente menores para a estratégia E e F (figura omitida).

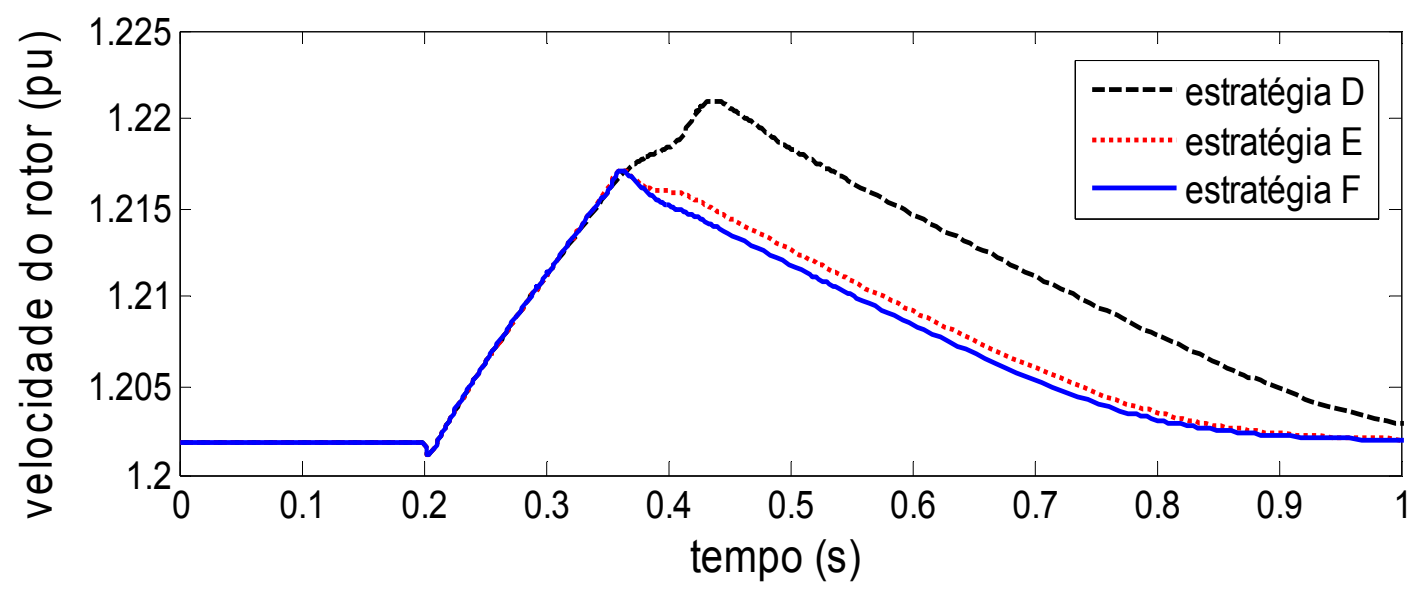

Figura 4.45 Velocidade do rotor durante curto-circuito na B7, eliminado em $150 \mathrm{~ms}$.

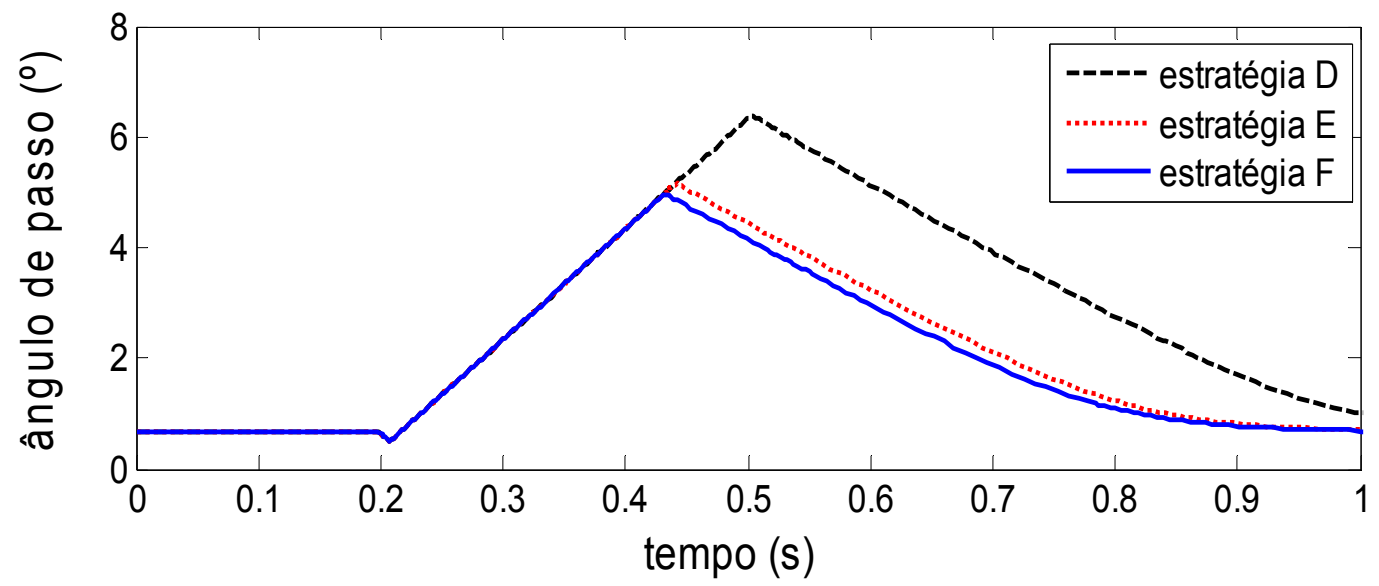

Figura 4.46 Ângulo de passo das hélices durante curto-circuito na B7, eliminado em 150 ms.

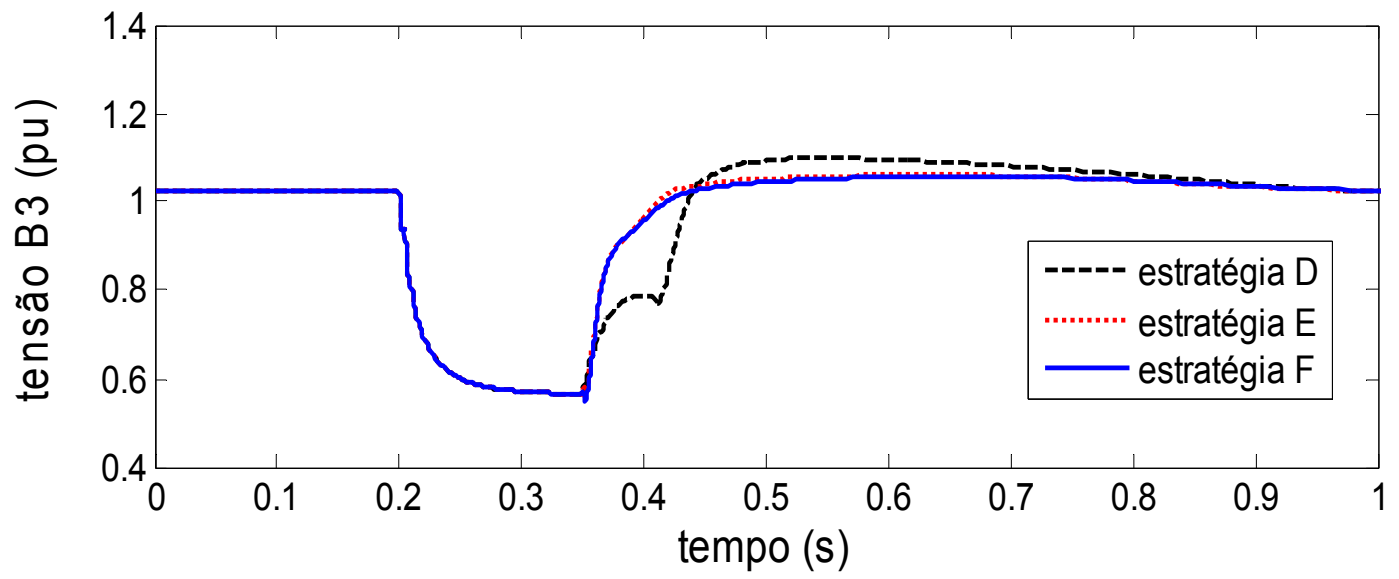

Figura 4.47 Tensão terminal da hidroelétrica durante curto-circuito na B7, eliminado em $150 \mathrm{~ms}$. 


\subsection{Considerações Gerais}

De forma sucinta, os seguintes comentários e conclusões podem ser feitos a respeito do capítulo 4:

- A capacidade do GSC é fundamental para a injeção de potência reativa, durante curto-circuitos no sistema elétrico. Com injeção efetiva de potência reativa na rede elétrica, as tensões terminais do ponto de conexão da fazenda eólica e dos barramentos mais próximos são influenciadas positivamente. Durante a atuação do sistema crowbar, apenas o GSC pôde contribuir com a tensão terminal.

- Para requerimentos de rede, os quais exijam a injeção de corrente reativa durante curto-circuitos no sistema elétrico, a utilização de sistemas de proteção, combinando o crowbar e o dc-chopper, deve ser adotada. Principalmente, para garantir a operação ininterrupta durante curto-circuitos mais severos. Porém, para requisitos de rede menos rigorosos, nos quais apenas a operação ininterrupta é exigida, apenas o sistema crowbar pode ser adotado.

- O tempo de atuação do sistema crowbar deve ser cuidadosamente analisado para que seu prolongamento não influencie, de forma negativa, a operação do sistema elétrico. 


\section{Capítulo 5}

\section{MÉTODO ANALÍTICO PARA ANÁLISE DE ESTABILIDADE DE GERADORES DE INDUÇÃO DUPLAMENTE ALIMENTADOS}

Um curto-circuito na rede de energia elétrica pode levar o DFIG à perda de estabilidade. Porém, as novas normas de conexão de geradores eólicos à rede de energia elétrica exigem que esses geradores se mantenham conectados durante curto-circuitos na rede elétrica. Sendo assim, é importante que a proteção do gerador atue, desconectando-o somente em casos de eminência de perda da estabilidade.

Embora os estudos já desenvolvidos sobre estabilidade de DFIG's apresentem valiosas contribuições sobre o comportamento desses geradores durante distúrbios na rede elétrica ([71]-[73], [94]-[97]), verifica-se que a literatura sobre o assunto não contempla expressões analíticas para a investigação da estabilidade, como os métodos já existentes para análise de geradores síncronos ([48]). Neste contexto, esta tese de doutorado apresenta uma contribuição original, em forma de desenvolvimento de um método analítico para a avaliação da estabilidade de geradores de indução duplamente alimentados. Para isso, inicialmente, é discutido o comportamento do DFIG durante um curto-circuito trifásico aplicado em seus terminais

\subsection{Estabilidade de Geradores de Indução}

Durante a ocorrência de curto-circuitos na rede elétrica, os geradores de indução duplamente alimentados, assim como os geradores de indução com rotor de gaiola de esquilo, tendem a acelerar. Tal fato pode ser explicado, devido à redução momentânea do conjugado eletromagnético, gerando um desbalanço entre este e o conjugado mecânico. A velocidade do rotor continua aumentando, enquanto o curtocircuito não é eliminado e, após sua eliminação, o gerador pode perder a estabilidade, dependendo da velocidade alcançada pelo rotor no instante da eliminação do curto-circuito. 
O comportamento descrito anteriormente, é reproduzido através de simulações de um DFIG conectado a uma rede elétrica, durante um curto-circuito trifásico, utilizando o SimPowerSystems ([49]). Foram realizadas simulações de estabilidade transitória (simulações dinâmicas), em que todos os componentes da rede foram representados por modelos trifásicos. O gerador de indução foi representado pelo modelo descrito no início deste capítulo, em que os transitórios do estator foram desconsiderados, como usual nesse tipo de análise ([47], [48]). Todos os parâmetros do modelo utilizado estão referenciados ao estator da máquina, utilizando os eixos dq do rotor como referência. Com isso, as tensões do rotor estão referenciadas para o lado do estator. Uma fonte de tensão é utilizada para representar a tensão aplicada ao rotor.

As simulações são realizadas utilizando o sistema apresentado na Figura 5.1, o qual é composto por um gerador de indução duplamente alimentado de $2 \mathrm{MW}$, conectado a uma rede de distribuição, composta por um alimentador e uma subestação de 2,4 kV. Uma tensão de $-0,067$ pu de eixo direto é aplicada ao rotor do gerador e um conjugado mecânico negativo de 1 pu é aplicado ao gerador. Nas simulações, após o sistema atingir os valores de regime permanente, um curtocircuito é aplicado na barra 2 da rede. O curto-circuito é eliminado em diferentes instantes de tempo e sem alteração na configuração da rede.

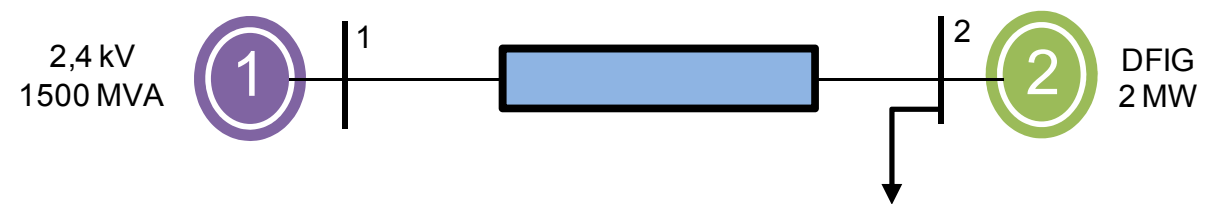

Figura 5.1 Sistema teste para estudo da estabilidade do DFIG.

O comportamento da tensão terminal e da velocidade do rotor, para três diferentes durações de curto-circuito, respectivamente 675; 680 e 685 ms, são apresentados na Figura 5.2 e na Figura 5.3. Como pode ser observada, a tensão terminal do gerador não retorna ao seu valor nominal, quando o curto-circuito é eliminado em $685 \mathrm{~ms}$. Dessa forma, o sistema perderá a estabilidade, caso o gerador não seja desconectado do restante da rede.

O comportamento da tensão terminal pode ser associado ao comportamento da velocidade do rotor. Tal relação pode ser observada na Figura 5.2 e na Figura 5.3 
para o caso em que a tensão terminal do gerador não retorna ao seu valor de operação em regime permanente. Da mesma forma, a velocidade do rotor também não retorna a um valor estável de operação, acelerando monotonicamente. Neste caso, o aumento da velocidade do rotor aumenta o consumo de potência reativa da máquina de indução e, com isso, dependendo dos parâmetros e configuração do sistema, pode ocorrer instabilidade.

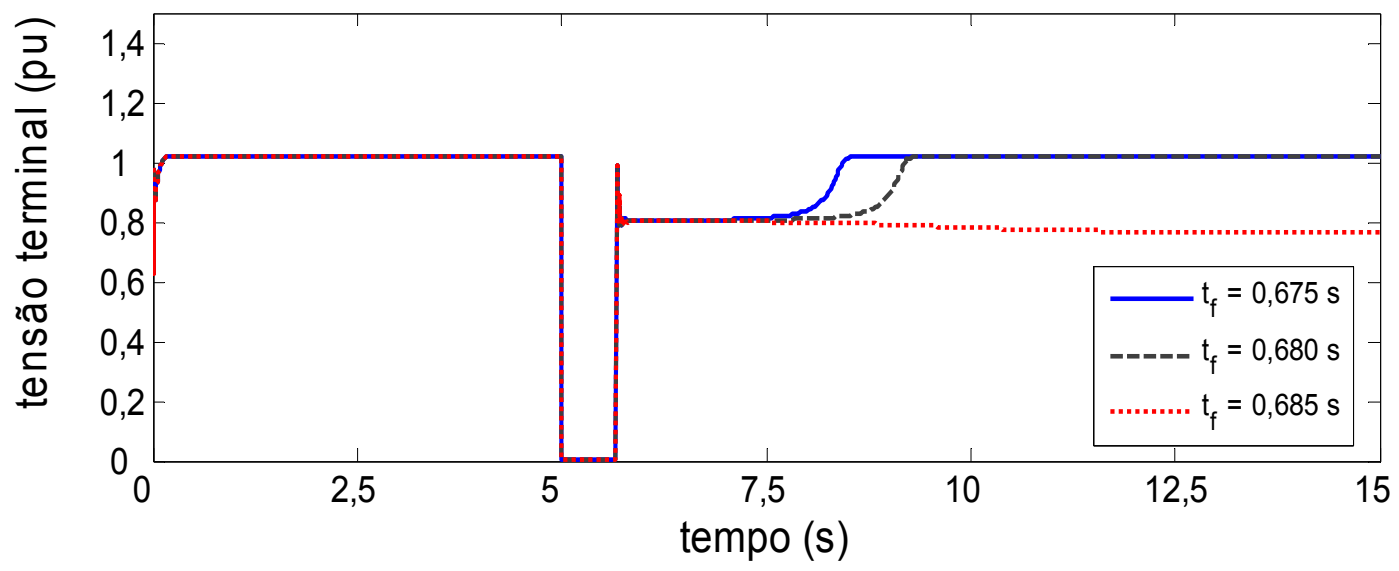

Figura 5.2 Tensão terminal durante curto-circuito trifásico.

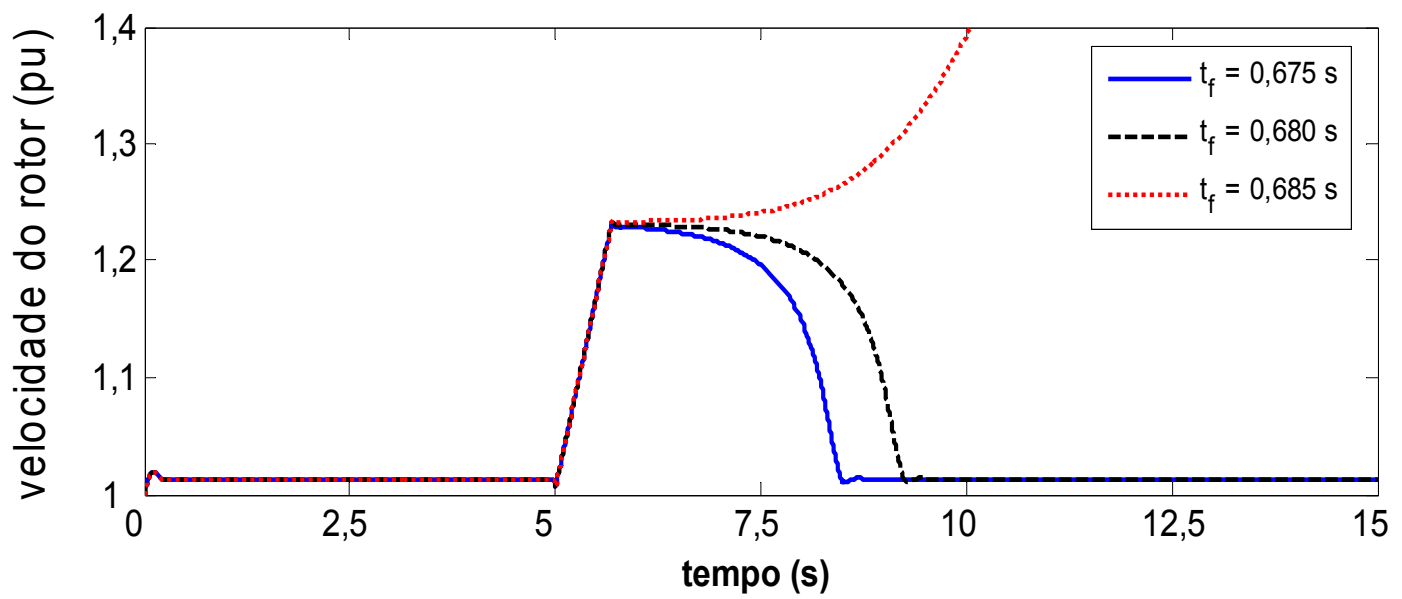

Figura 5.3 Velocidade do rotor durante curto-circuito trifásico.

Baseando a análise de estabilidade no comportamento da velocidade do rotor do gerador, pode-se analisar o comportamento do DFIG de forma similar à realizada para o gerador de indução com rotor em gaiola de esquilo, isto é, pode-se associar um valor de velocidade crítica para a velocidade do rotor do gerador ([56]). O conceito de velocidade crítica é importante, pois, o gerador, ao atingir tal velocidade, mesmo com a eliminação da falta, perde a estabilidade. A velocidade crítica do rotor 
já foi discutida para geradores de indução com rotor em gaiola de esquilo em ([56], [98]) e pode ser estendida para o estudo do DFIG. No exemplo previamente apresentado, a velocidade crítica é 1,233 pu, conforme mostra a Figura 5.4. Nesta figura, verifica-se que os casos em que a velocidade do rotor não atinge tal valor, o gerador retorna a um ponto de operação estável.

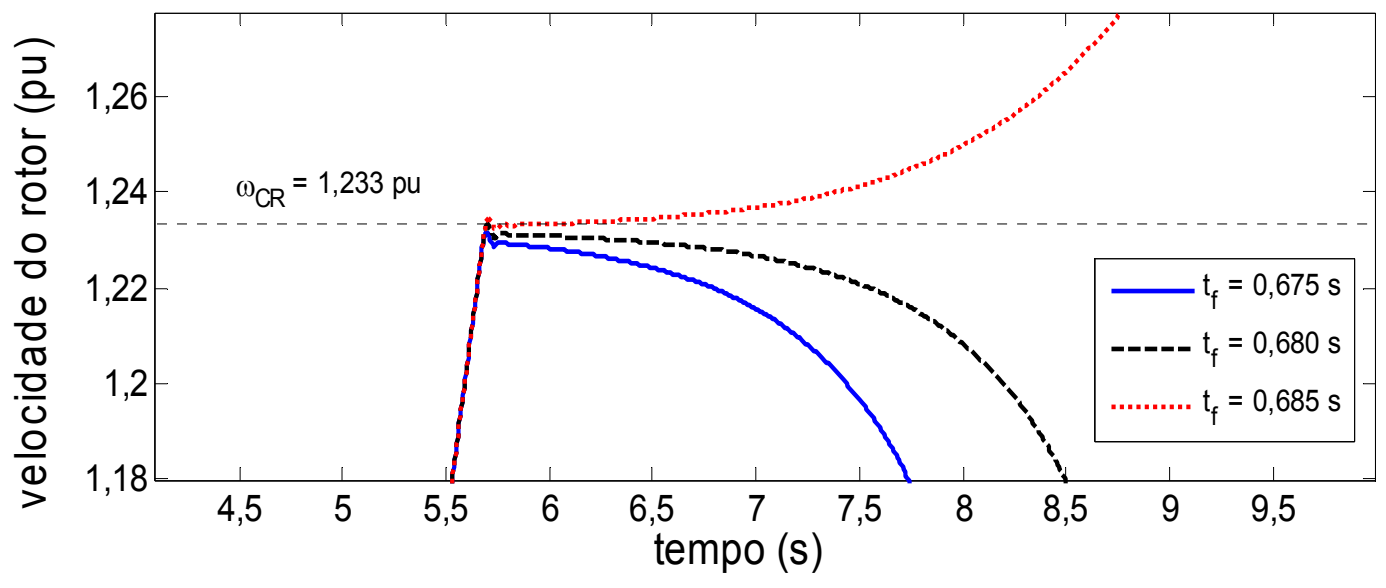

Figura 5.4 Velocidade crítica do gerador.

O conceito de velocidade crítica foi empregado no desenvolvimento de um método analítico para determinar o tempo crítico de eliminação da falta para o caso de geradores de indução duplamente alimentados.

\subsection{Formulação Analítica}

O aumento da velocidade do rotor durante o curto-circuito, é regido pela equação (4.13), a qual representa o equilíbrio eletromecânico da máquina de indução, sendo esta reescrita na equação (5.1). Essa equação relaciona a diferença entre o conjugado mecânico aplicado à máquina e o conjugado eletromagnético desenvolvido por ela, com a variação da velocidade do rotor. Inicialmente, durante a falta, considera-se que o conjugado mecânico aplicado à máquina mantém-se constante, o mesmo não ocorre com o conjugado eletromagnético desenvolvido pela máquina durante o curto-circuito, o qual depende das correntes da máquina.

$$
\frac{d}{d t} \omega_{r}=\frac{1}{2 \cdot H} \cdot\left(T_{e}-T_{m}\right)
$$


Considerando um caso severo, no qual a tensão nos terminais da máquina, durante um curto-circuito trifásico, cai à zero, a corrente no rotor da máquina será nula após um curto período de transitórios eletromagnéticos de corrente e, conseqüentemente, o conjugado eletromagnético desenvolvido pela máquina, também, será nulo. Após a eliminação do curto-circuito, a corrente do rotor dependerá do escorregamento e, por conseguinte, da velocidade do rotor no instante de eliminação do curto. Essas relações podem ser estudadas, por meio do circuito equivalente de regime permanente da máquina, apresentado na Figura 5.5. Nesta figura, o DFIG é representado por uma máquina de indução com rotor bobinado, e uma fonte de tensão é conectada aos terminais do seu rotor. É importante destacar que, tanto os parâmetros do rotor, quanto o valor da tensão aplicada no mesmo estão referenciados para o lado do estator da máquina.

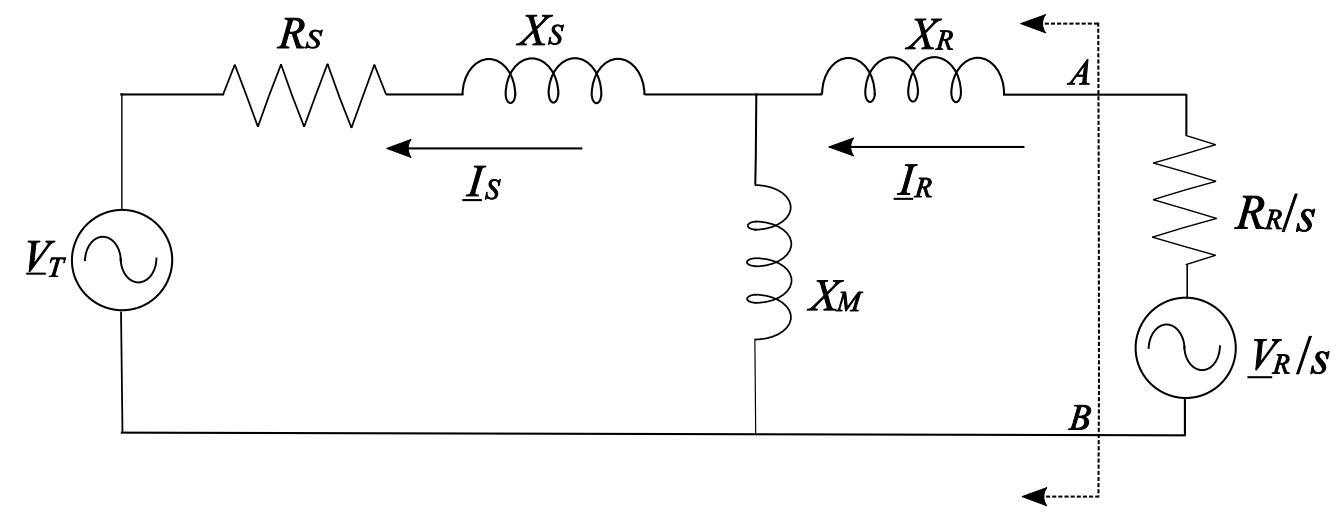

Figura 5.5 Circuito equivalente de um DFIG em regime permanente.

Na figura, tem-se:

$\begin{array}{lll}\underline{V}_{T} & = & \text { fasor da tensão aplicada ao estator }(\mathrm{pu}) ; \\ \underline{I}_{S} & = & \text { fasor da corrente do estator }(\mathrm{pu}) ; \\ \underline{I}_{R} & = & \text { fasor da corrente do rotor }(\mathrm{pu}) ; \\ \underline{V}_{R}=V_{d R}+\mathrm{j} V_{q R} & = & \text { fasor da tensão aplicada ao rotor da máquina }(\mathrm{pu}) ; \\ Z_{S}=R_{S}+\mathrm{j} X_{S} & = & \text { impedância do estator }(\mathrm{pu}) ; \\ Z_{M}=j X_{M} & = & \text { impedância de magnetização }(\mathrm{pu}) ; \\ R_{R} & = & \text { resistência do rotor }(\mathrm{pu}) ; \\ j X_{R} & = & \text { reatância do rotor }(\mathrm{pu}) ;\end{array}$


$\omega_{S}$

$\omega_{R}$

$s=\left(\omega_{S}-\omega_{R}\right) / \omega_{S}$
$=$ freqüência angular do sistema;

= freqüência angular do rotor;

$=\quad$ escorregamento da máquina de indução.

A corrente do rotor da máquina pode ser mais facilmente calculada com a redução do circuito equivalente da máquina pela aplicação do Teorema de Thévenin nos pontos $A$ e $B$ da Figura 5.5, resultando no circuito representado pela Figura 5.6.

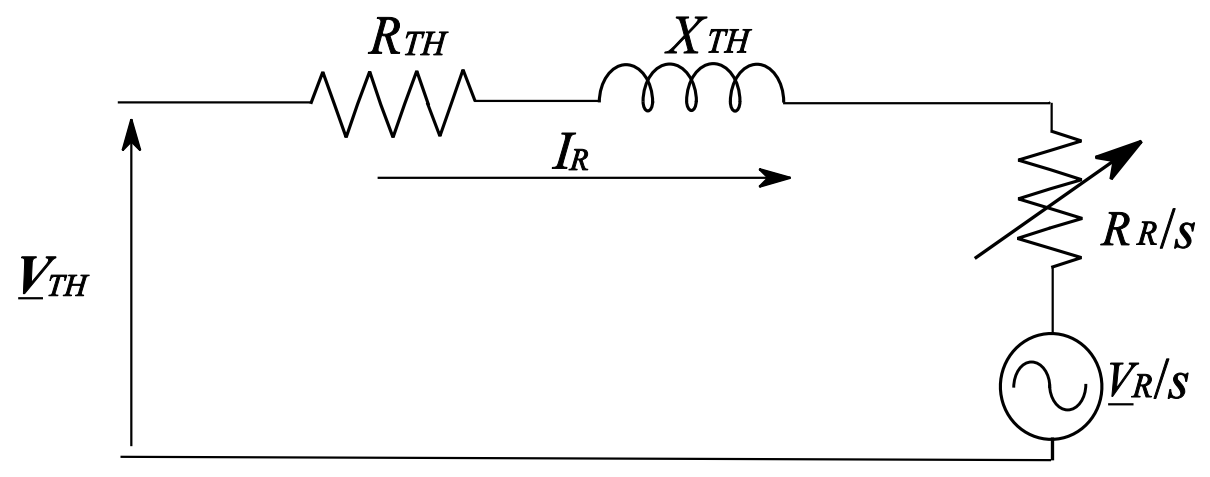

Figura 5.6 Equivalente de Thévenin do DFIG.

Os parâmetros equivalentes de tensão e impedância de Thévenin, obtidos pela redução do circuito, são dados por:

$$
\begin{aligned}
& \underline{V}_{T H}=\frac{j X_{m}}{R_{S}+j\left(X_{S}+X_{m}\right)} \cdot \underline{V}_{T} \\
& Z_{T H}=R_{T H}+j X_{T H} \\
& =\left(\frac{R_{S} \cdot X_{m}^{2}}{R_{S}^{2}+\left(X_{S}+X_{m}\right)^{2}}\right)+j\left(\frac{X_{m} \cdot\left(R_{S}^{2}+X_{S}^{2}+X_{S} \cdot X_{m}\right)}{R_{S}^{2}+\left(X_{S}+X_{m}\right)^{2}}+X_{R}\right)
\end{aligned}
$$

sendo,

$\underline{V}_{T H}=V_{d T H}+j V_{q T H}=$ fasor da tensão equivalente de Thévenin (pu).

A partir do circuito equivalente de Thévenin do DFIG, pode-se calcular a corrente do rotor, a qual é dada por: 


$$
\underline{I}_{R}=\frac{s \cdot \underline{V}_{T H}-\underline{V}_{R}}{s \cdot\left(R_{T H}+j X_{T H}\right)+R_{R}}
$$

O conjugado eletromagnético fornecido ao eixo gerador é dado pela relação entre a potência no entreferro do gerador, a qual depende da corrente do rotor, e da velocidade do gerador, resultando em:

$$
\begin{aligned}
T_{E} & =\frac{P_{E}}{\omega_{S} \cdot(1-s)} \\
& =\frac{1}{\omega_{S} \cdot(1-s)} \cdot\left(\frac{1-s}{s}\right) \cdot\left[\left|\underline{I}_{R}\right|^{2} \cdot R_{R}+\operatorname{Re}\left\{\underline{V}_{R} \cdot \operatorname{conj}\left(\underline{I}_{R}\right)\right\}\right]
\end{aligned}
$$

A partir dessa equação, é possível obter a relação de conjugado eletromagnético, com o escorregamento para diferentes parâmetros da máquina, tais como as curvas apresentadas na Figura 5.7 e na Figura 5.8, nas quais foram empregados diferentes valores de $V_{d R}$ e $V_{q R}$. Destaca-se que, segundo a convenção empregada neste trabalho, valores positivos de conjugado eletromagnético e mecânico indicam operação como motor, ao passo que valores negativos indicam operação como gerador.

A Figura 5.7 mostra o conjugado eletromagnético para a aplicação de uma tensão de componente de eixo direto nos enrolamentos do rotor. Com o aumento desta tensão, o valor de conjugado eletromagnético fornecido pela máquina, na região de operação como gerador, aumenta, porém, na região de operação como motor, o máximo conjugado eletromagnético diminui.

A Figura 5.8 mostra o conjugado eletromagnético para a aplicação de uma tensão negativa de componente de eixo em quadratura, nos enrolamentos do rotor. Com o aumento desta tensão negativa, tanto para a região de operação como motor, quanto na região como gerador, o conjugado eletromagnético máximo aumenta em módulo, ao passo que uma tensão positiva diminui o módulo do conjugado eletromagnético máximo para ambas as regiões de operação. 


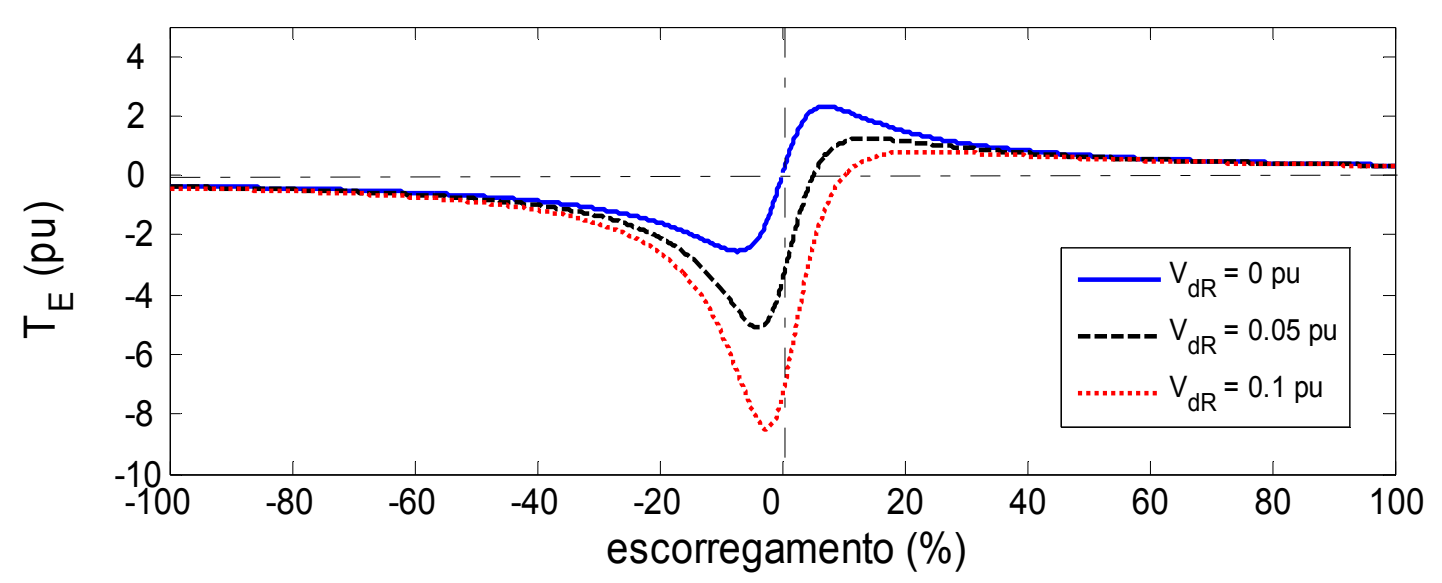

Figura 5.7 Curvas de conjugado eletromagnético pelo escorregamento para $V_{q R}=0$.

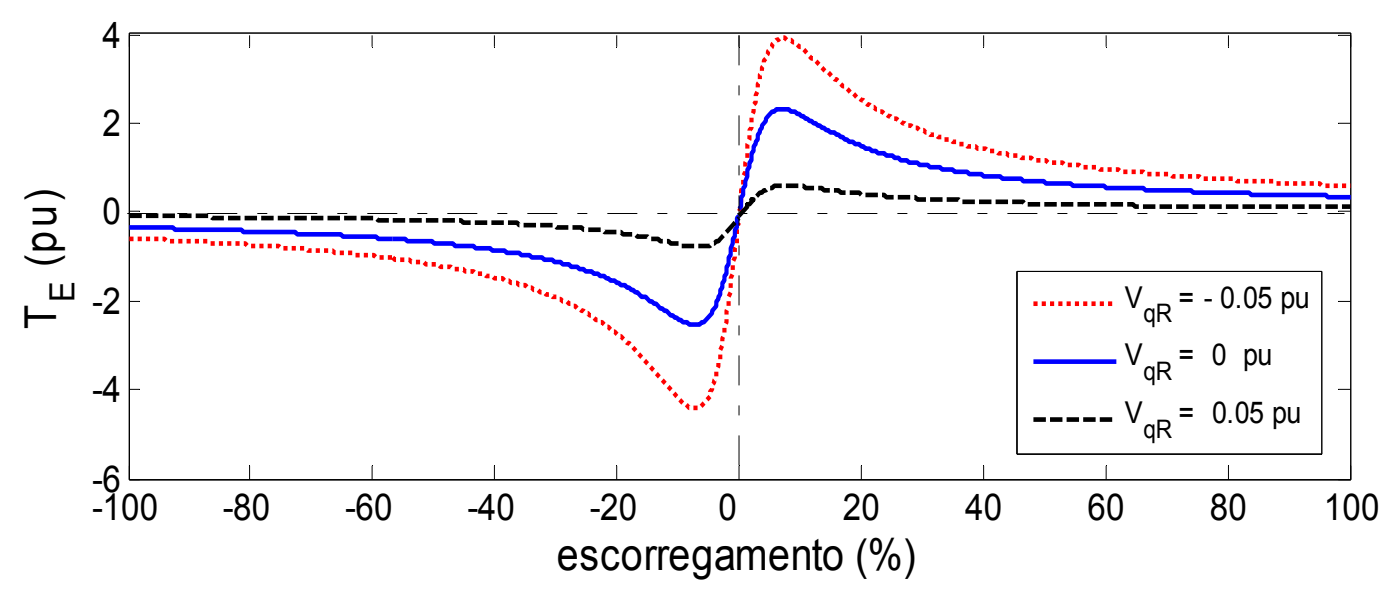

Figura 5.8 Curvas de conjugado eletromagnético pelo escorregamento para $V_{d R}=0$.

As curvas de conjugado eletromagnético do DFIG são importantes na análise de sua estabilidade, conforme verificado pelo estudo dos pontos de operação do gerador e que é apresentado mais adiante. Para esta análise, será utilizada a região da curva em que o conjugado eletromagnético é negativo, a qual corresponde à operação da máquina como gerador.

Dessa forma, com a intenção de facilitar a análise, a Figura 5.9 apresenta os valores de conjugado eletromagnético multiplicados por (-1). Com base na Figura 5.9, percebe-se que o conjugado mecânico $T_{M}$, aplicado à máquina intercepta a curva de conjugado eletromagnético $T_{E}$ em dois pontos distintos $(A$ e $B)$, os quais correspondem respectivamente ao ponto de equilíbrio estável e equilíbrio instável de operação da máquina como gerador. Tais pontos satisfazem a equação de equilíbrio eletromecânico da máquina de indução, a qual é dada pela equação (5.1). 


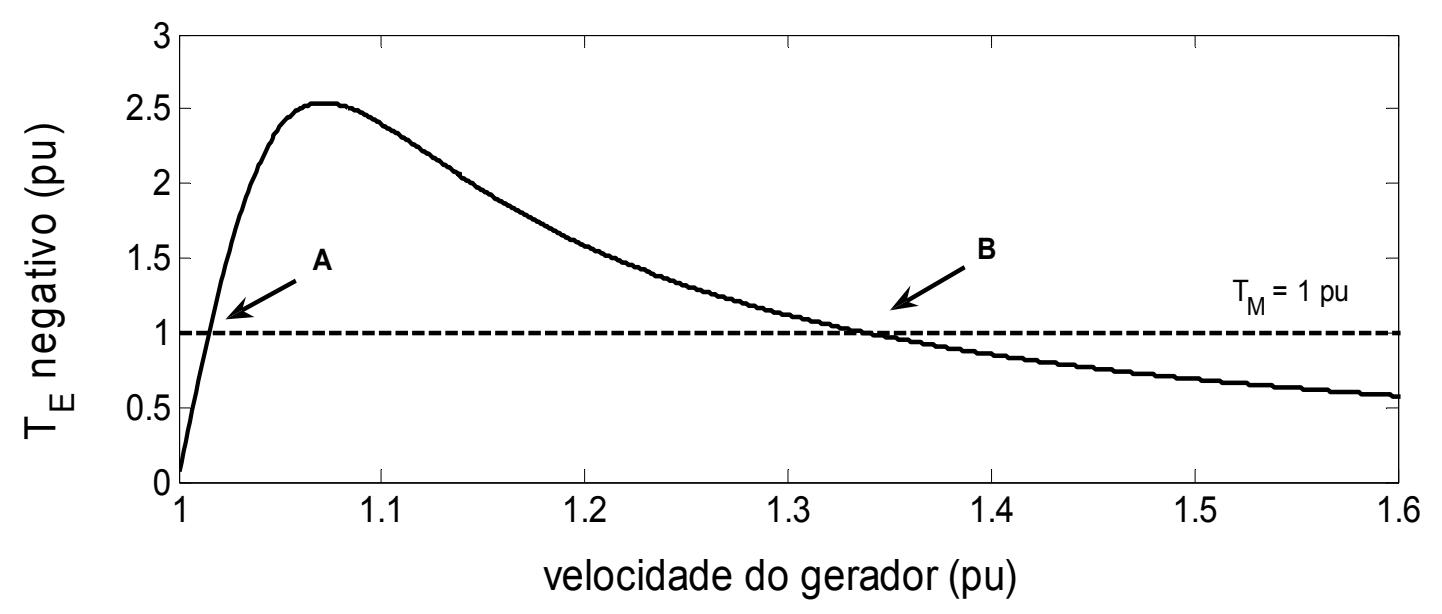

Figura 5.9 Curva de conjugado eletromagnético negativo para operação como gerador.

O estudo do comportamento do gerador de indução duplamente alimentado, durante uma falta, pode ser realizado de forma similar ao estudo do comportamento de um gerador de indução com rotor em gaiola de esquilo. Dessa forma, quando ocorre uma falta, a velocidade do rotor aumenta, visto que o conjugado mecânico torna-se maior que o conjugado eletromagnético. Por exemplo, na Figura 5.10, antes da ocorrência da falta, o gerador está operando no ponto $A$, em que a velocidade do rotor é $\omega_{0}$. Uma falta trifásica é, então, aplicada aos terminais do gerador e, por conseguinte, o conjugado eletromagnético diminui para zero, fazendo com que o ponto de operação do gerador desloque-se para $B$. Como resultado dessa alteração, a velocidade do rotor aumenta, de acordo com a equação (5.1), até o instante em que a falta é eliminada e o ponto de operação do gerador muda para $C$. Neste instante, o conjugado resultante é negativo e, consequentemente, a velocidade do rotor começa a diminuir e a retornar ao seu ponto de operação inicial, ponto $A$, ou seja, um ponto estável.

Caso a falta seja eliminada em um tempo maior, como mostrado na Figura 5.11, no instante de eliminação da falta, o novo ponto de operação é o ponto $C$, no qual o conjugado resultante é positivo, o que faz com que a velocidade do rotor continue aumentando, levando à perda de estabilidade do gerador. 


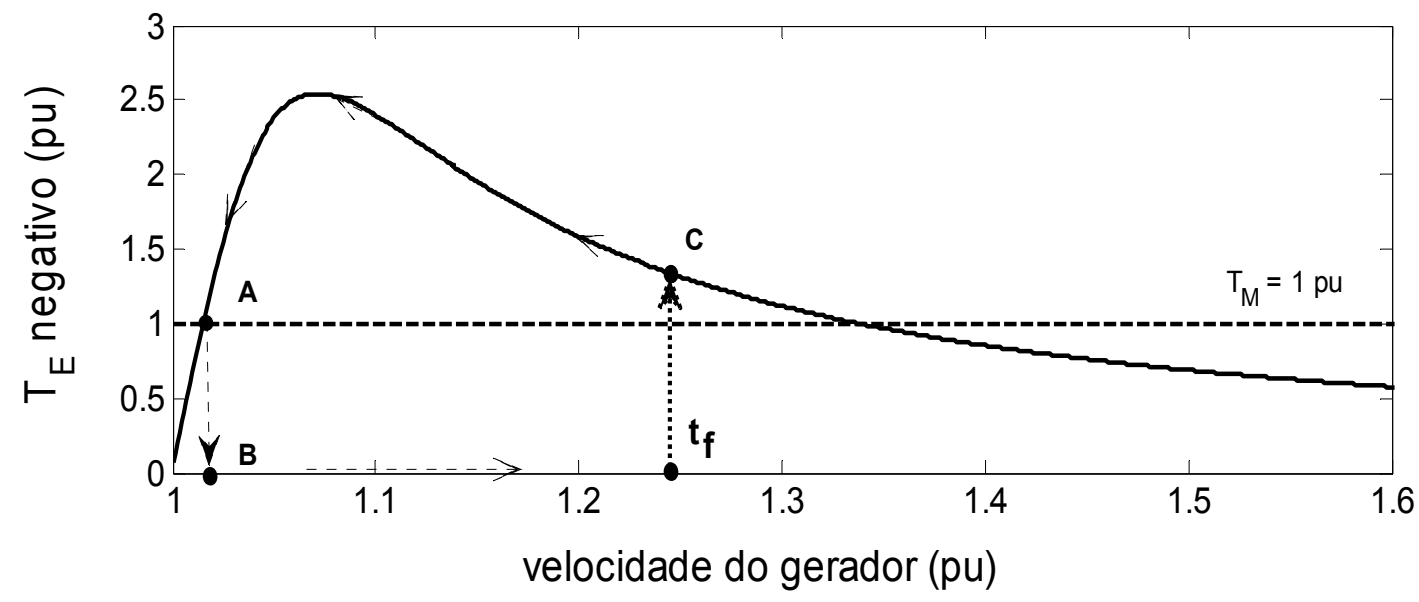

Figura 5.10 Trajetória de um sistema estável durante um curto-circuito trifásico.

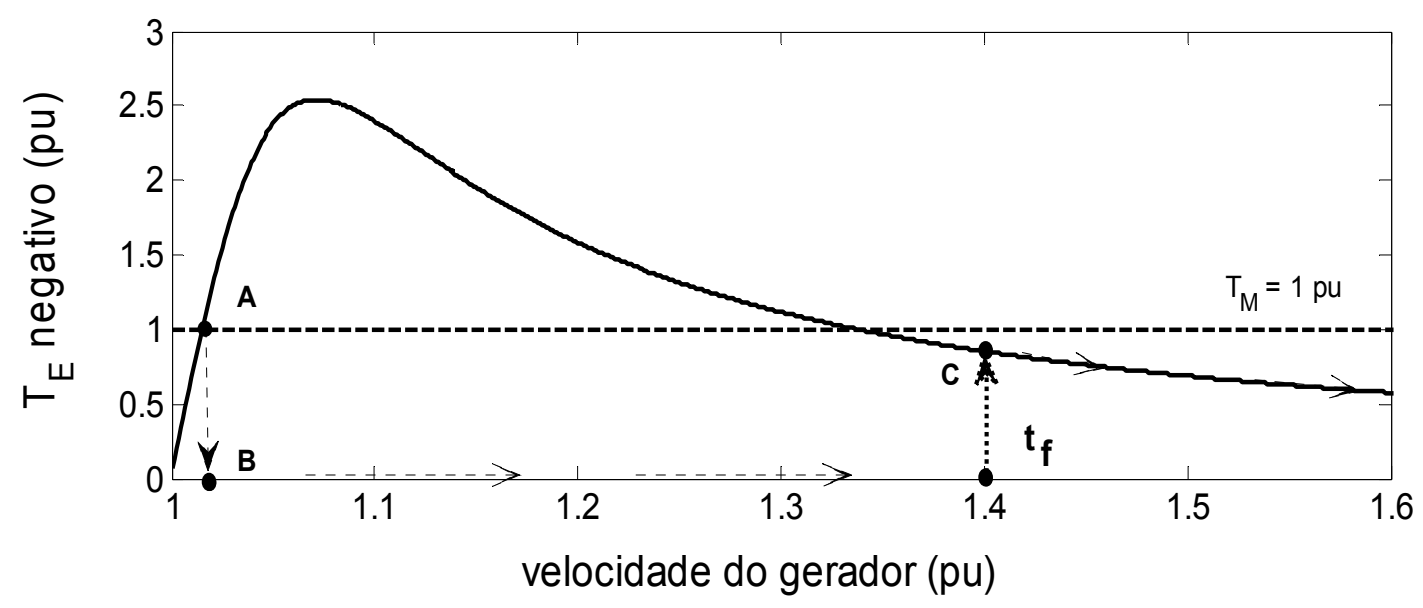

Figura 5.11 Trajetória de um sistema instável durante um curto-circuito trifásico.

Dessa forma, os pontos de operação em equilíbrio do gerador são obtidos pela intersecção das curvas de conjugado eletromagnético com conjugado mecânico. Analiticamente, esses pontos podem ser obtidos, igualando-se a expressão de conjugado eletromagnético com a equação de conjugado mecânico, resultando em:

$$
T_{M}=\frac{1}{S \cdot \omega_{S}} \cdot\left[\left|\underline{I}_{R}\right|^{2} \cdot R_{R}+\operatorname{Re}\left\{\underline{V}_{R} \cdot \operatorname{conj}\left(\underline{I}_{R}\right)\right\}\right]
$$

Substituindo a equação (5.4) em (5.6), obtém-se uma equação em função do escorregamento da máquina, a qual resulta em uma equação de segundo grau, cujos coeficientes são: 


$$
\begin{aligned}
& a=T_{M} \cdot \omega_{S} \cdot\left(R_{T H}^{2}+X_{T H}^{2}\right) \\
& b=2 \cdot \omega_{S} \cdot T_{M} \cdot R_{T H} \cdot R_{R}-R_{T H} \cdot K_{1}-X_{T H} \cdot K_{2}-R_{R} \cdot\left|\underline{V}_{T H}\right|^{2} \\
& c=T_{M} \cdot \omega_{S} \cdot R_{R}^{2}+R_{T H} \cdot\left|\underline{V}_{R}\right|^{2}+R_{R} \cdot K_{1}
\end{aligned}
$$

em que:

$$
\begin{aligned}
& K_{1}=V_{d R} \cdot V_{d T H}+V_{q R} \cdot V_{q T H} \\
& K_{2}=V_{d R} \cdot V_{q T H}-V_{q R} \cdot V_{d T H}
\end{aligned}
$$

Para o caso da máquina operando como gerador $\left(T_{M}<0\right)$ as soluções da equação são dois valores de escorregamento, calculados por:

$$
\begin{aligned}
& s_{1}=\frac{-b+\sqrt{\Delta}}{2 a} \\
& s_{2}=\frac{-b-\sqrt{\Delta}}{2 a}
\end{aligned}
$$

em que $\Delta=b^{2}-4 a c$.

Os dois valores de escorregamento, obtidos como solução da equação de condição de equilíbrio eletromecânico, são os pontos de operação do DFIG e, através deles, podem-se obter dois valores de velocidade da máquina, os quais correspondem à velocidade de operação e à velocidade crítica, dadas por:

$$
\begin{aligned}
& \omega_{0}=1-s_{1}=1-\frac{-b+\sqrt{\Delta}}{2 a} \\
& \omega_{C R}=1-s_{2}=1-\frac{-b-\sqrt{\Delta}}{2 a}
\end{aligned}
$$


O tempo crítico de eliminação da falta é obtido, integrando-se a equação (5.1), em que o conjugado eletromagnético é zero, e a velocidade inicial e a velocidade final do rotor são substituídas pelas equações (5.14) e (5.15), respectivamente. A partir da manipulação dessa equação obtém-se o tempo necessário para que a velocidade do rotor aumente, a partir da velocidade de operação, até a velocidade crítica. Dessa forma, o tempo crítico resulta em:

$$
t_{c r i t}=\frac{2 \cdot H}{a \cdot T_{M}} \cdot \sqrt{\Delta}
$$

A expressão (5.16) permite calcular diretamente o tempo crítico de eliminação da falta, o qual, para ser determinado, via um programa de análises dinâmicas, demandaria diversas simulações seqüenciais. Embora essa expressão tenha sido obtida para um sistema composto por um gerador conectado diretamente a uma fonte de tensão, ela pode ser facilmente empregada para sistemas mais complexos mediante uso do Teorema de Thévenin. Por exemplo, para o sistema apresentado na Figura 5.12, o seguinte circuito equivalente pode ser obtido:

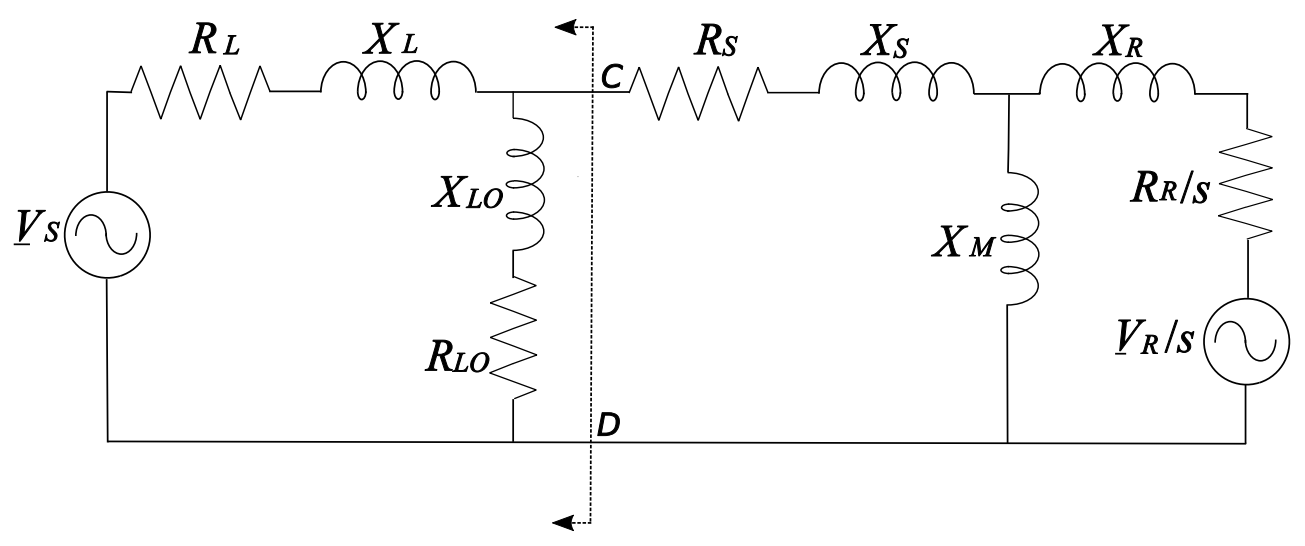

Figura 5.12 Circuito equivalente do sistema completo.

Nesta figura, além dos parâmetros já apresentados na Figura 5.5, tem-se:

$\underline{V}_{s}=$ fasor de tensão da subestação $(p u)$;

$Z_{L}=R_{L}+j X_{L}=$ impedância equivalente que representa a linha de distribuição $(\mathrm{pu})$;

$Z_{L O}=R_{L O}+j X_{L O}=$ impedância equivalente que representa a carga $(\mathrm{pu})$. 
Mediante uso do Teorema de Thévenin, o circuito apresentado na Figura 5.12 pode ser reduzido para o circuito da Figura 5.6. De fato, qualquer sistema mais complexo, incluindo cargas, desde que estas sejam representadas por um modelo de impedância constante, pode ser facilmente reduzido para o circuito apresentado na Figura 5.6. Para isso, calcula-se o equivalente de Thévenin à esquerda dos pontos $C$ e $D$ dados na figura, cujos parâmetros são dados, neste exemplo, por:

$$
\begin{aligned}
& Z_{T H}^{\prime}=R_{T H}^{\prime}+j X_{T H}^{\prime}=\frac{Z_{L O} \cdot Z_{L}}{Z_{L O}+Z_{L}} \\
& \underline{V}_{T H}^{\prime}=\underline{V}_{S} \cdot \frac{Z_{L O}}{Z_{L O}+Z_{L}}
\end{aligned}
$$

Para considerar o sistema completo os parâmetros equivalentes da rede devem ser associados ao modelo da máquina, resultando no circuito apresentado na Figura 5.13. Neste circuito, se a impedância equivalente de Thévenin da rede for somada à impedância do estator, ele apresentará a mesma configuração do circuito ilustrado na Figura 5.5, o que torna possível a aplicação do método analítico desenvolvido.

Assim sendo, para a aplicação das expressões previamente desenvolvidas, é necessário substituir $\underline{V}_{T}$ da equação (5.2) por $\underline{V}_{T H}^{\prime}$, substituir $R_{S}$ e $X_{S}$ por $\left(R_{S}+R_{T H}^{\prime}\right)$ e $\left(X_{S}+X_{T H}^{\prime}\right)$, respectivamente, na equação (5.3). Após essas alterações, na sequência, as demais equações podem ser aplicadas. Assim, desde que seja possível calcular o equivalente de Thévenin para o sistema, o método para análise de estabilidade do gerador de indução pode ser aplicado, considerando o sistema completo.

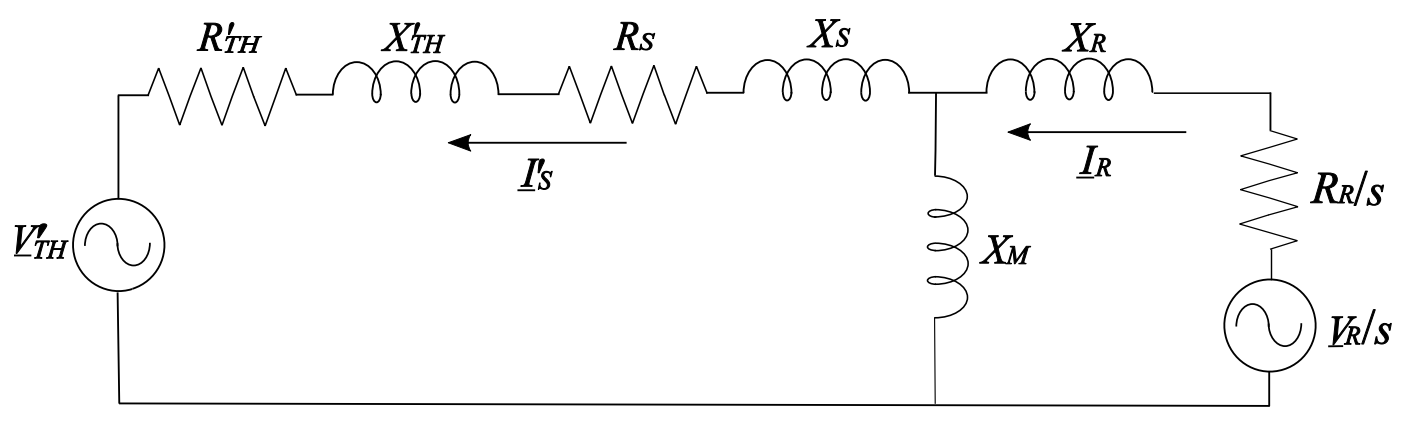

Figura 5.13 Equivalente de Thévenin do sistema teste. 
Um exemplo da importância da consideração dos parâmetros da rede pode ser visualizado na Figura 5.14, na qual constam as curvas de conjugado eletromagnético e mecânico, versus velocidade do rotor com e sem os parâmetros da rede. Neste exemplo, foram utilizados dados encontrados no Apêndice $C$, com uma tensão de eixo em quadratura de 0,02 pu aplicada ao rotor. A velocidade crítica do rotor é menor, quando os parâmetros da rede são considerados. Desse modo, se os parâmetros da rede não são considerados, os cálculos resultariam em um tempo crítico de eliminação da falta maior que o real com o sistema completo.

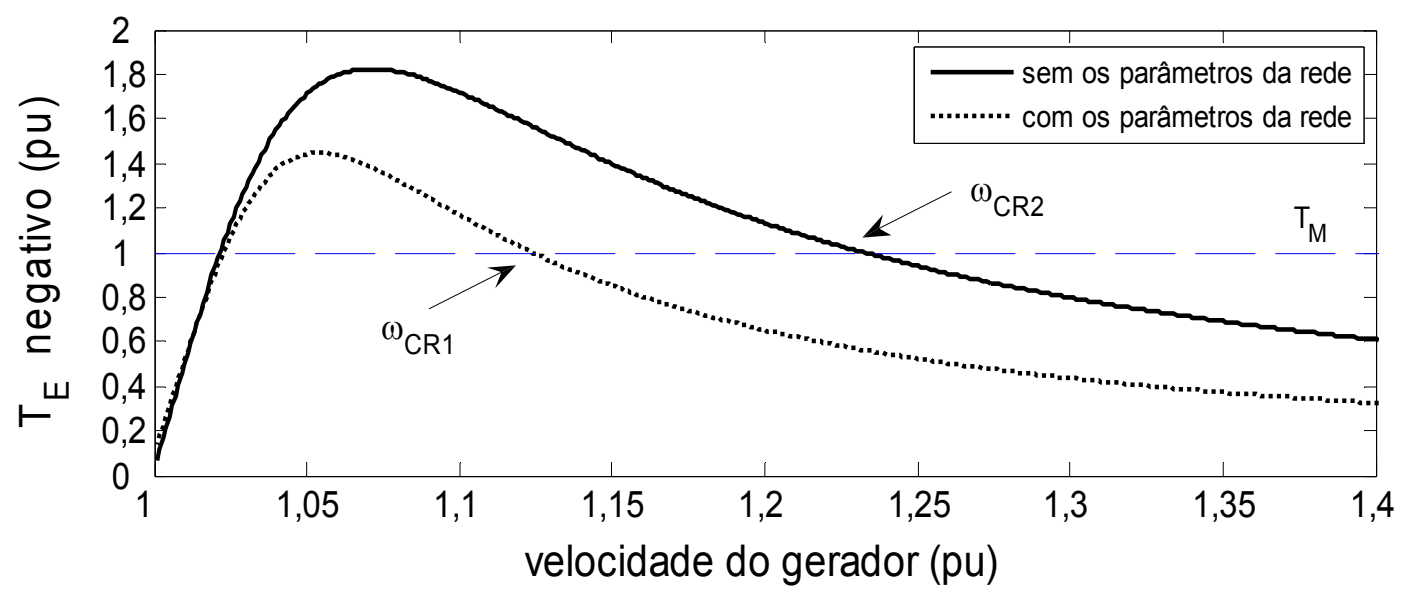

Figura 5.14 Curvas de conjugado eletromagnético considerando os parâmetros da rede.

\subsection{Validações do Método Analítico}

Para a validação do método analítico foram realizadas comparações dos resultados obtidos pelas expressões analíticas com os resultados provenientes de numerosas simulações. As simulações foram realizadas, utilizando 0 SimPowerSystems, no qual se simula a operação do sistema ilustrado na Figura 5.1, cujos dados detalhados podem ser encontrados no Apêndice C. O modelo da máquina de indução é o mesmo descrito no capítulo 4. Como já apresentado na seção 5.1, o curto-circuito é aplicado na barra 2 e eliminado sem alteração da configuração da rede. O tempo crítico é obtido aumentando gradualmente o tempo de eliminação da falta, de 10 em 10 ms para cada simulação, até que a velocidade do rotor do gerador não retorne ao valor de operação estável.

Durante e após a ocorrência de um curto-circuito na rede elétrica, diferentes estratégias de controle podem ser utilizadas. A principal finalidade das estratégias 
de controle, nesta situação, é evitar danos ao conversor do lado do rotor (RSC), no entanto, procura-se, também, fornecer o máximo suporte de potência reativa para a rede elétrica, durante o distúrbio, como visto no capítulo 4. Nas simulações realizadas para validação da metodologia analítica, optou-se pela estratégia mais conservadora, isto é, os conversores back-to-back são retirados de operação no instante da ocorrência do curto-circuito e, depois de eliminada a falta, os conversores são reativados. Portanto, durante o período de curto-circuito, o gerador opera como uma máquina de indução com rotor de gaiola de esquilo. Na reinicialização dos conversores, as tensões de referência de eixo direto e de eixo em quadratura são as mesmas da operação em regime-permanente, isto é, antes da ocorrência do curto-circuito. Nas simulações, a tensão resultante da operação do conversor é representada por uma fonte de tensão aplicada aos terminais do rotor, dessa forma, tensão nula nos terminais do rotor representa a retirada de operação do conversor.

Para o cálculo analítico do tempo crítico, uma vez que os parâmetros do sistema estão em pu, conforme a Figura 5.12, calculam-se as variáveis do equivalente de Thévenin, $Z_{T H}^{\prime}$ e $\underline{V}_{T H}^{\prime}$, pelas equações (5.17) e (5.18). Tais parâmetros devem ser representados, conforme a Figura 5.13, a qual, também, contém os parâmetros da máquina em pu. Somando-se as impedâncias do estator e equivalente do sistema, $Z_{s}^{\prime}=Z_{s}+Z_{T H}^{\prime}$, o circuito apresentará a mesma configuração do modelo da máquina e, dessa forma, através das equações (5.2) e (5.3) são obtidos $Z_{T H}$ e $V_{T H}$. Com a determinação de $Z_{T H}$ e $V_{T H}$, o tempo crítico pode ser calculado, por meio da expressão (5.16).

O comportamento do tempo crítico, em relação a variações na tensão aplicada ao rotor da máquina, é mostrado na Figura 5.15 e na Figura 5.16. Comparando os resultados obtidos pelo método analítico com os obtidos, por meio das simulações computacionais, verifica-se que são bastante similares, validando as expressões desenvolvidas e apresentadas originalmente nesta tese. 


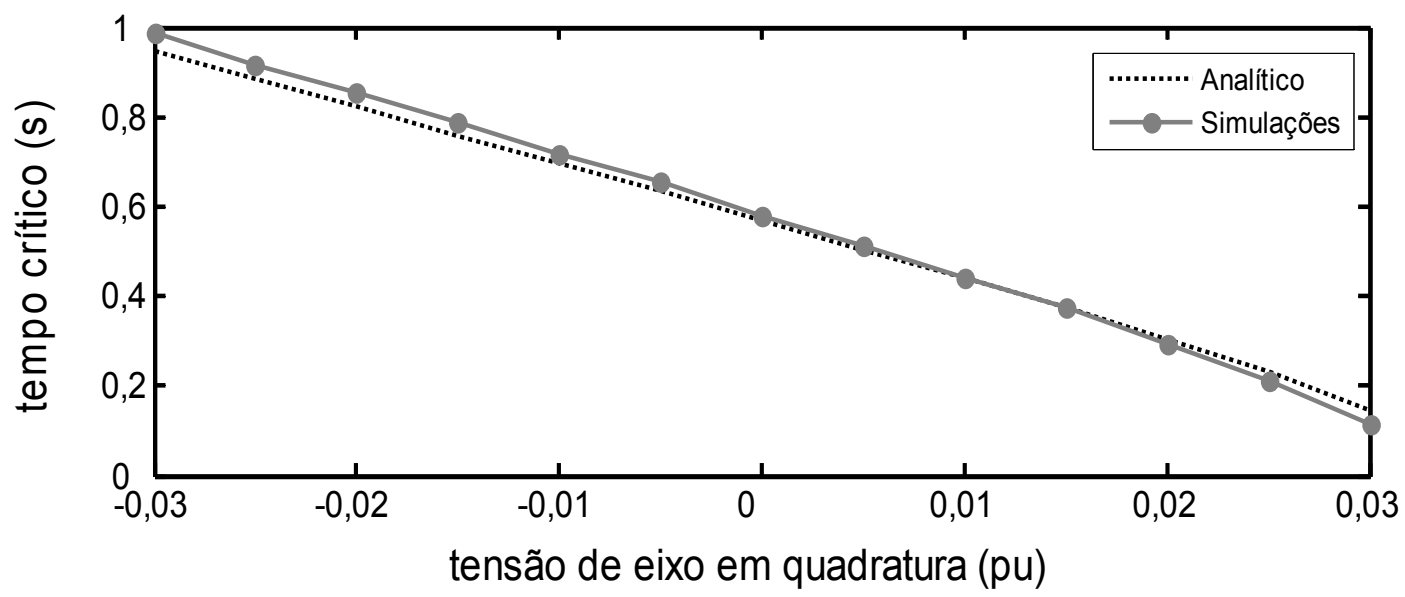

Figura 5.15 Estudo de sensibilidade: variação da tensão de eixo em quadratura no rotor $\left(\mathrm{V}_{\mathrm{qR}}\right)$.

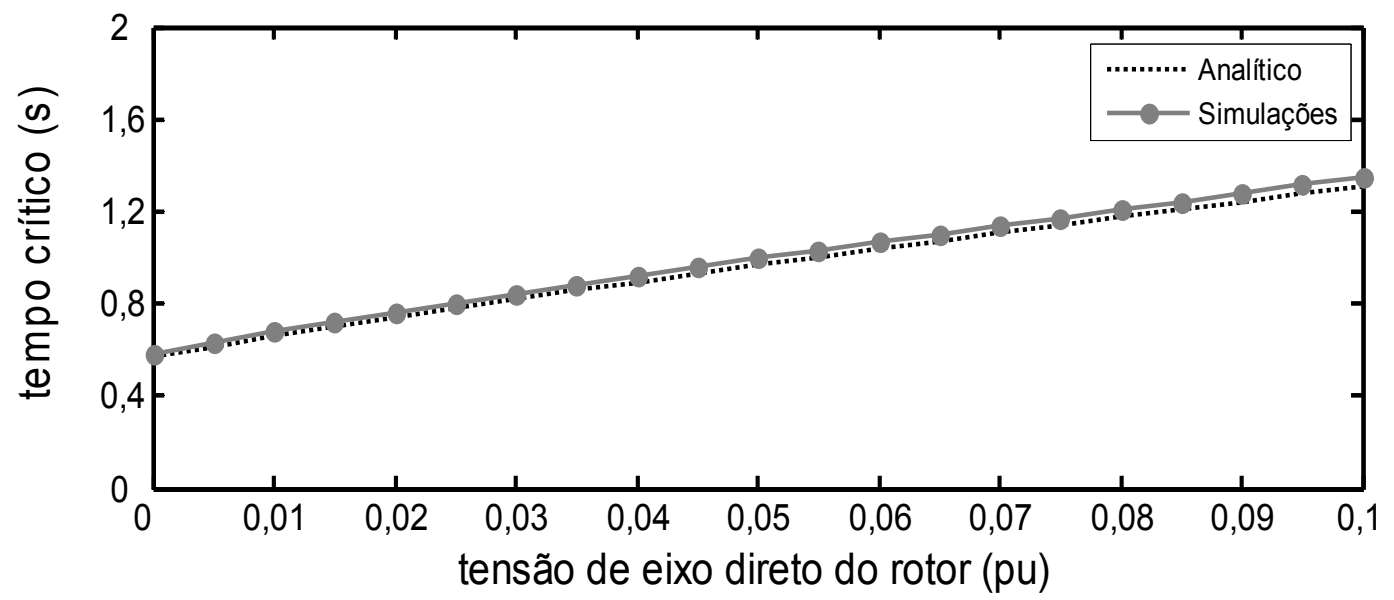

Figura 5.16 Estudo de sensibilidade: variação da tensão de eixo direto aplicada ao rotor $\left(\mathrm{V}_{\mathrm{dR}}\right)$.

A análise do que é apresentado na Figura 5.15 e da Figura 5.16 permite identificar a influência da tensão aplicada nos enrolamentos do rotor na estabilidade da máquina. Observando a representação gráfica da Figura 5.15, verificamos que o aumento da tensão de eixo em quadratura do rotor afeta negativamente a estabilidade do gerador, ao passo que, um aumento na tensão de eixo direto afeta positivamente a estabilidade do gerador, conforme observado na Figura 5.16.

A variação do tempo crítico pode ser explicada, com base na curva de conjugado eletromecânico por velocidade do gerador. Como o tempo crítico referese ao tempo que a velocidade do rotor leva para ir da velocidade de operação inicial à velocidade crítica, quanto maior a diferença entre esses valores, maior o tempo crítico. Esse fenômeno pode ser observado na Figura 5.17 e na Figura 5.18, que 
foram obtidas pela aplicação das equações de cálculo de velocidade de operação e de velocidade crítica, equações (5.14) e (5.15), respectivamente.

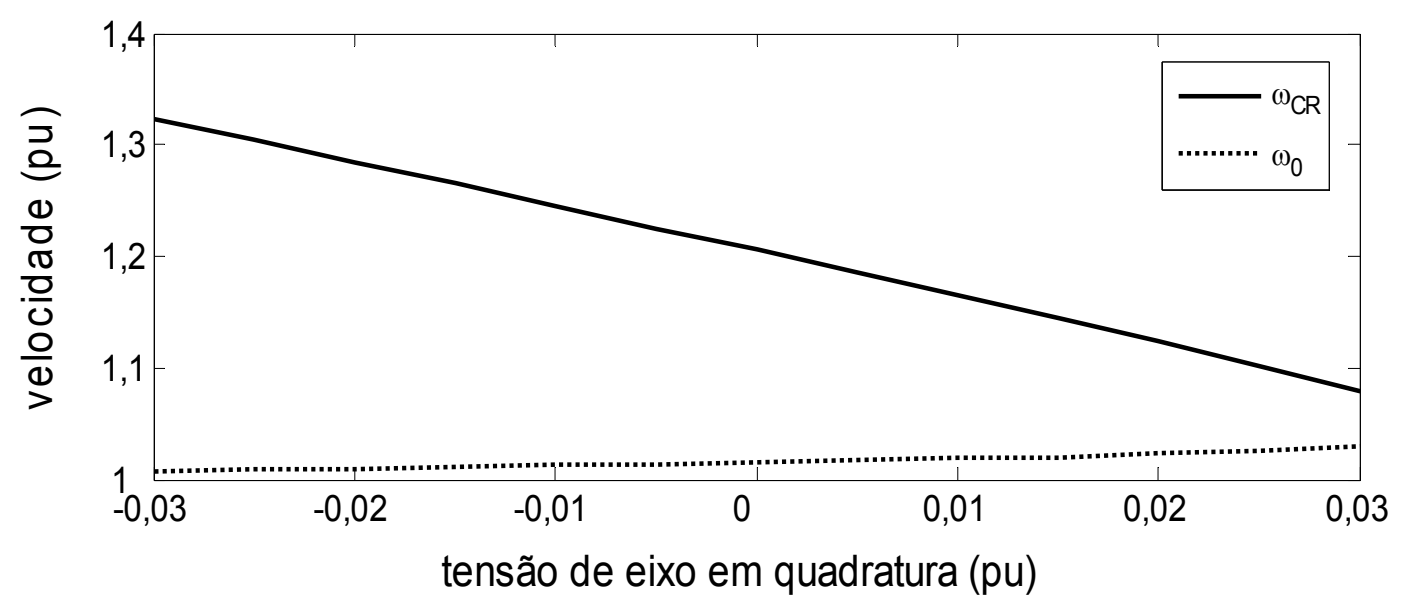

Figura 5.17 Velocidade em função da tensão de eixo em quadratura aplicada ao rotor $\left(V_{\mathrm{qR}}\right)$.

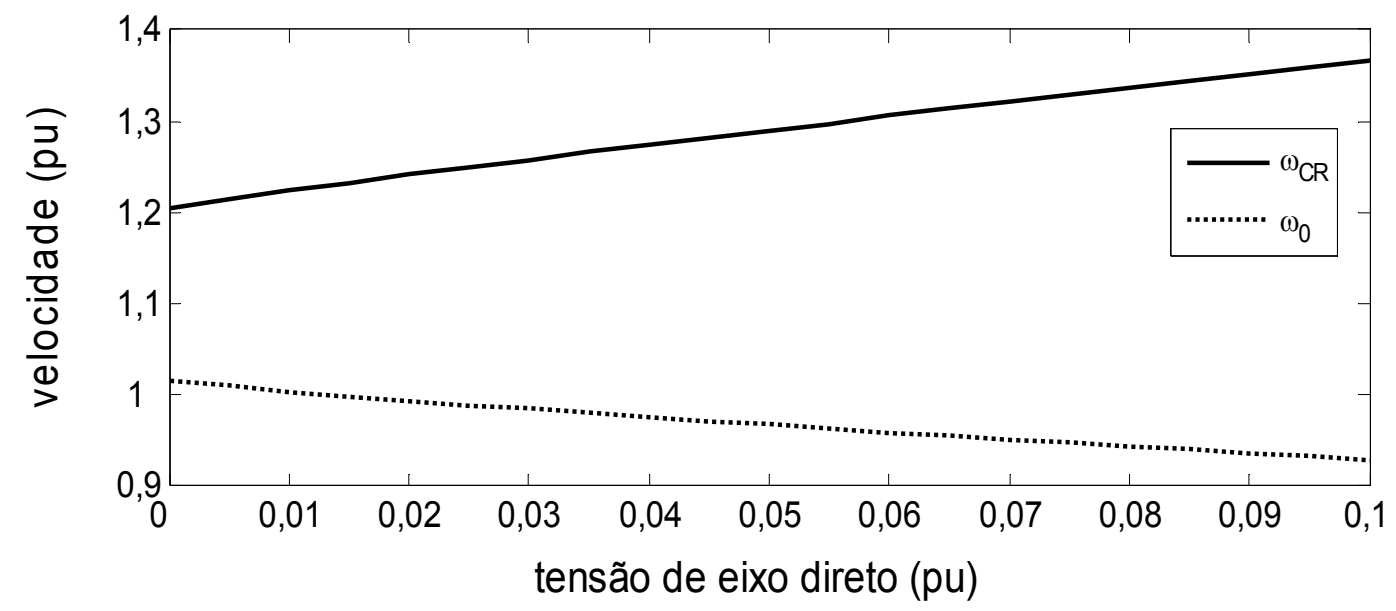

Figura 5.18 Velocidade em função da tensão de eixo direto aplicada ao rotor $\left(V_{\mathrm{dR}}\right)$.

Com base na Figura 5.17, verificamos que o aumento da tensão de eixo em quadratura aplicada ao enrolamento do rotor da máquina produz um aumento na velocidade de operação e uma redução da velocidade crítica do rotor, resultando na diminuição do tempo crítico, conforme verificado e apresentado na Figura 5.15. Já o aumento na tensão de eixo direto tende a diminuir a velocidade de operação e aumentar a velocidade crítica do rotor, resultando em aumento do tempo crítico de eliminação da falta.

A influência da tensão aplicada no enrolamento do rotor na estabilidade do sistema pode, também, ser associada à potência reativa consumida ou fornecida 
pelo gerador de indução, conforme se verifica através dos resultados das simulações apresentados na Figura 5.19 e na Figura 5.20. Nessas figuras, valores positivos de potência reativa indicam que o gerador está enviando potência reativa para a rede elétrica, ao passo que, valores negativos de potência reativa indicam absorção de potência reativa da rede elétrica pelo gerador. Examinando o conteúdo da Figura 5.19, constata-se que o aumento na tensão de eixo em quadratura aumenta o consumo de potência reativa do gerador. A Figura 5.20 mostra que o aumento da tensão de eixo direto diminui o consumo de potência reativa do gerador. A partir dessas constatações e da comparação da Figura 5.15 e da Figura $5.16 \mathrm{com}$ a Figura 5.19 e com a Figura 5.20, respectivamente, chega-se à conclusão de que, quanto mais potência reativa o gerador estiver enviando para o sistema mais esse gerador estará colaborando com a estabilidade da rede.

A associação dos valores de tensão aplicados ao rotor com a potência reativa consumida/absorvida pelo gerador de indução pode, também, ser associada à velocidade de operação do rotor, por exemplo, na Figura 5.17, à medida que a tensão de eixo em quadratura aumenta, a velocidade de operação do rotor também aumenta e, com isso, o gerador passa a consumir mais potência reativa. $\mathrm{O}$ caso inverso ocorre com o aumento da tensão de eixo direto; pela Figura 5.18, verifica-se que seu aumento ocasiona uma diminuição na velocidade de operação do rotor, resultando em diminuição da potência reativa consumida pelo gerador, como pode ser visualizada na Figura 5.20.

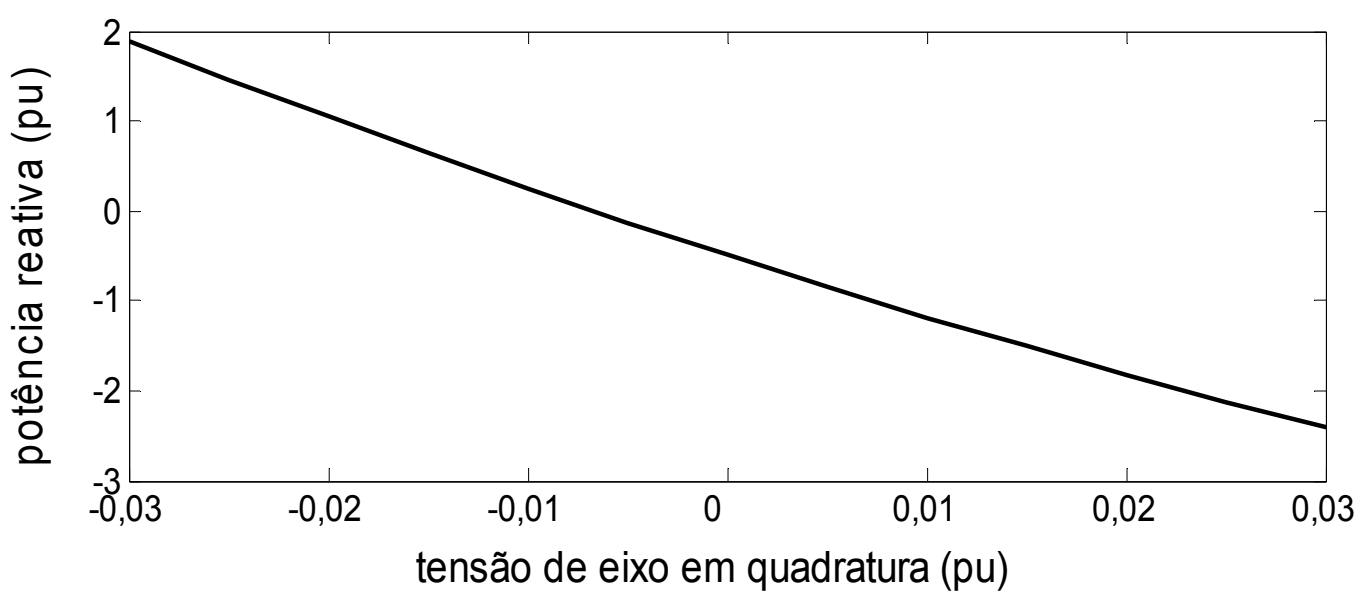

Figura 5.19 Potência reativa em função da tensão de eixo em quadratura aplicada ao rotor. 


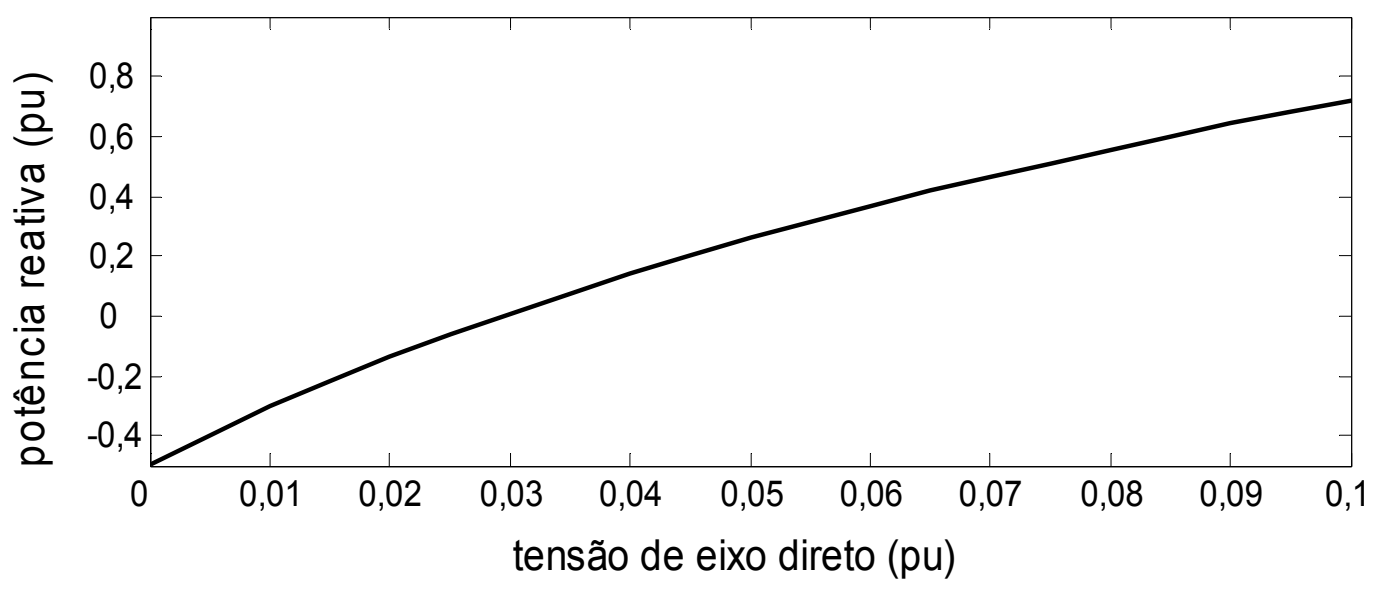

Figura 5.20 Potência reativa em função da tensão de eixo direto aplicada ao rotor.

A Tabela 5.1 apresenta um resumo dos efeitos da variação da tensão aplicada nos enrolamentos do rotor do DFIG. De forma geral, o aumento $(\lambda)$ do tempo crítico de eliminação da falta está relacionado com a diminuição $(\searrow)$ da tensão de eixo em quadratura e com o aumento da tensão de eixo direto. Porém, na velocidade de operação da turbina eólica, prevalece a velocidade ótima de operação descrita na Figura 3.5.

Tabela 5.1 Resumo dos efeitos da variação da tensão aplicada no enrolamento do rotor do DFIG.

\begin{tabular}{cccc}
\hline Variação da tensão no rotor & $\mathrm{t}_{\text {crit }}$ & $\omega_{0}$ & potência reativa \\
\hline $\mathrm{V}_{\mathrm{qR}}(\nearrow)$ & $\searrow$ & $\nearrow$ & $\searrow$ \\
$\mathrm{V}_{\mathrm{qR}}(\searrow)$ & $\nearrow$ & $\searrow$ & $\nearrow$ \\
$\mathrm{V}_{\mathrm{dR}}(\nearrow)$ & $\nearrow$ & $\searrow$ & $\nearrow$ \\
$\mathrm{V}_{\mathrm{dR}}(\searrow)$ & $\searrow$ & $\nearrow$ & $\searrow$ \\
\hline
\end{tabular}

\subsection{Considerações Gerais}

O método analítico, apresentado neste capítulo, contribui, originalmente, para a realização de análises em estudos de estabilidade frente a grandes perturbações de geradores de indução duplamente alimentados. Os seguintes comentários e conclusões podem ser feitos, a respeito do capítulo 5: 
- A aplicação do método analítico proposto facilita a compreensão dos fenômenos relacionados à perda de estabilidade de geradores de indução duplamente alimentados.

- O método pode ser implementado computacionalmente e se tornar uma ferramenta de análises e estudos de técnicas para melhorar a estabilidade desses geradores durante faltas, de forma a atender os requisitos técnicos de conexão de fazendas eólicas. 


\section{Capítulo 6}

\section{GERADORES SÍNCRONOS A ÍMÃS PERMANENTES (PMG)}

Não obstante o uso de ímãs permanentes em turbinas eólicas de médio e de grande porte ser, ainda, limitado na indústria, esta tecnologia apresenta uma série de vantagens, em relação aos geradores de indução e, até mesmo, em relação aos geradores síncronos com excitação ([99], [18]). Dentre as vantagens, destacam-se:

- Não necessitam de circuitos externos de excitação.

- Não apresentam perdas nos circuitos de campo.

- Possibilidade de operação em baixa velocidade.

- Não necessitam de caixas de engrenagens, operando em baixa rotação.

- Menor custo com manutenção (sem escovas e caixas multiplicadoras).

O termo PMG, neste trabalho, está relacionado com todos os tipos de geradores síncronos com ímãs permanentes (PM). Nessas máquinas, o fluxo magnético é gerado por um conjunto a ímãs permanentes, geralmente instalados no rotor, o qual opera na velocidade síncrona. As máquinas a ímãs permanentes podem ser classificas, de acordo com a direção do fluxo magnético em relação ao seu eixo, em: radial (convencional), axial e transversal. Muitas configurações diferentes destas máquinas podem ser encontradas na literatura ([100]-[107]). Porém, os estudos desenvolvidos, nesta tese, levaram em conta os geradores síncronos a ímãs permanentes de fluxo radial (PMSG) e o de fluxo transversal (TFG) conectados à rede elétrica, via conversores baseados em IGBT's (Figura 6.1).

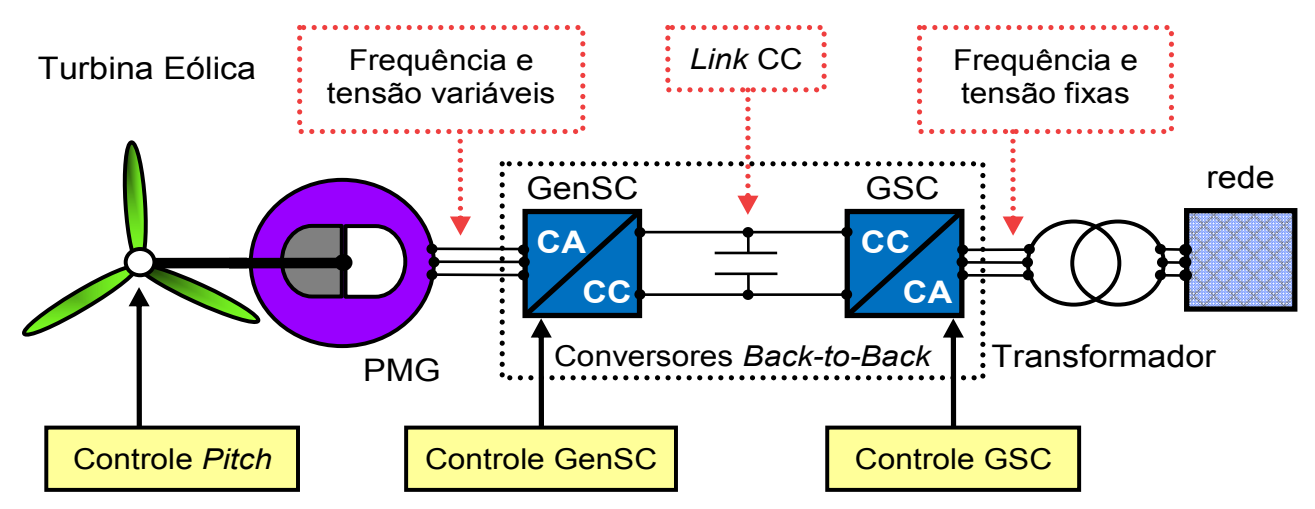

Figura 6.1 Diagrama genérico dos geradores síncronos a ímãs permanentes (PMG) estudados. 
Estes conversores são muito similares aos utilizados no DFIG, porém com estratégias distintas de controle, além de a potência nominal ser, pelo menos, 100\% da potência nominal do gerador. Esta configuração permite, também, a operação com velocidade variável, maximizando a geração de energia elétrica em diferentes pontos de operação.

\subsection{Modelo Dinâmico do Gerador Síncrono a Î́mãs Permanentes de Fluxo Radial (PMSG)}

O estator desta máquina tem distribuição senoidal, similar ao da máquina de indução. O conjunto a ímãs permanentes é montado na superfície laminada do rotor, sendo este interno e com simetria radial bidimensional. A maioria dos estudos de estabilidade de sistemas de energia elétrica, equipados com PMG, esta relacionada com esta máquina ([61]-[64]).

O modelo aerodinâmico utilizado considerou as curvas de coeficiente de potência sugeridas por Slootweg (Figura 3.2). Esta escolha está baseada no fato de que as turbinas equipadas com PMSG são, em geral, turbinas modernas. Destacase que o modelo do gerador síncrono com ímãs permanentes de fluxo radial está disponível na biblioteca do SimPowerSystems, porém, não inclui as perdas no ferro e tão pouco os efeitos da saturação. As equações dinâmicas dessas máquinas são bem mais simples do que as equações do DFIG, sendo elas ([49]):

- Sistema Elétrico

$$
\begin{aligned}
& \frac{d}{d t} i_{d}=\frac{1}{L_{d}} \cdot v_{d}-\frac{R}{L_{d}} \cdot i_{d}+\frac{L_{q}}{L_{d}} \cdot \omega_{r} \cdot i_{q} \\
& \frac{d}{d t} i_{q}=\frac{1}{L_{q}} \cdot v_{q}-\frac{R}{L_{q}} \cdot i_{q}+\frac{L_{d}}{L_{q}} \cdot \omega_{r} \cdot i_{d}-\frac{\lambda \cdot \omega_{r}}{L_{q}} \\
& T_{e}=1,5 \cdot p \cdot\left[\lambda \cdot i_{q}+\left(L_{d}-L_{q}\right) \cdot i_{d} \cdot i_{q}\right]
\end{aligned}
$$


- Sistema Mecânico

$$
\begin{aligned}
& \frac{d}{d t} \omega_{r}=\frac{1}{2 \cdot H} \cdot\left(T_{e}-T_{m}\right) \\
& \frac{d}{d t} \theta_{r}=\omega_{r}
\end{aligned}
$$

sendo:

$R \quad=\quad$ resistência do estator (ohm).

$L_{d}, L_{q}=\quad$ indutância do estator de eixo direto e de eixo em quadratura $(H)$.

$i_{d}, i_{q}=\quad$ corrente do estator de eixo direto e de eixo em quadratura (A).

$v_{d}, v_{q}=\quad$ tensão do estator de eixo direto e de eixo em quadratura $(\mathrm{V})$

$\lambda=$ amplitude do fluxo magnético dos PM nas fases do estator $(\mathrm{Wb})$.

$p=$ número de pares de pólo.

$H \quad=\quad$ constante de inércia (segundo).

$\omega_{r} \quad=\quad$ velocidade angular do rotor $(\mathrm{rad} / \mathrm{s})$.

$\theta_{r}=$ posição elétrica angular do rotor (rad. elétricos)

$T_{e} \quad=\quad$ conjugado eletromagnético (N.m)

$T_{m} \quad=\quad$ conjugado mecânico $(\mathrm{N} . \mathrm{m})$

\subsection{Modelo Dinâmico do Gerador Síncrono a Ímãs Permanentes de Fluxo Transversal (TFG)}

Esta máquina foi inicialmente desenvolvida por $\mathrm{H}$. Weh nos anos 80 , porém, para operar como motor ([100]-[104]). Atualmente, mais de 11 distintas geometrias são descritas na literatura ([105], [107]). Considerando essas geometrias, pode-se dividi-las em: montados à superfície ou com fluxo concentrado; lado duplo ou lado simples. As máquinas de fluxo magnético concentrado (flux-concentrating) apresentam maior relação torque-massa, quando comparada com as máquinas a ímãs montados à superfície. O estator pode ser construído com laminas ou com pó 
prensado de material ferromagnético. $\mathrm{O}$ baixo fator de potência, a dificuldade de construção e o ruído audível produzido por sua rotação são exemplos de desvantagens que ainda não foram superadas.

O fato de que o TFG tem a maior relação conjugado eletromagnético por quilo de material ativo, comparado até com outras máquinas a ímãs permanentes, tem despertado o interesse de alguns fabricantes e centros de pesquisa Europeus para aplicação em turbinas eólicas no mar (offshore wind turbines). Estas turbinas têm características diferentes das turbinas instaladas em terra, pois os custos de manutenção, das torres de sustentação, das subestações, etc., são muito mais elevados no mar do que o custo em terra. Além disso, nessas regiões as condições climáticas são muito severas ([100]-[103]).

No Instituto de Maquinas Elétricas da RWTH Aachen University foi desenvolvida uma configuração trifásica de fluxo concentrado (Figura 6.2 e Figura 6.3). Tal máquina (dados nominais: 25 kW, 600 rpm, 400 Nm, $205 \mathrm{~V}, 70$ A) possui estator interno refrigerado à água e rotor externo, sendo em $U$ o formato de sua parte ferromagnética. Os cálculos das perdas nesta máquina, considerando sua geometria tridimensional completa, foram realizados via método dos elementos finitos ([108]).

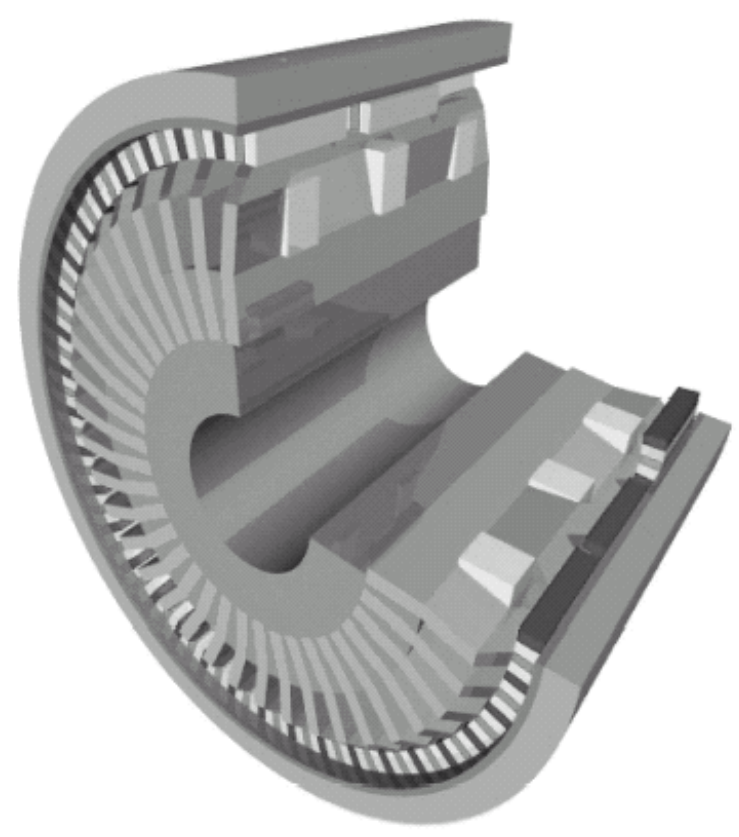

Figura 6.2 Desenho da máquina de fluxo transversal trifásica desenvolvida em Aachen (Alemanha). 


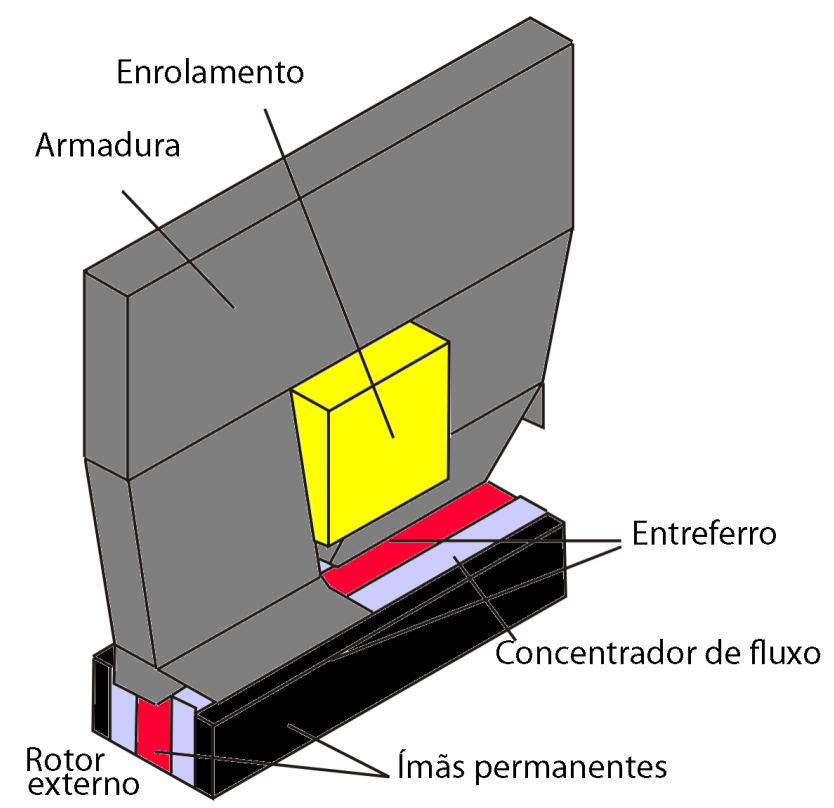

Figura 6.3 Um par de pólos linearizado da fase A da máquina desenvolvida em Aachen.

O modelo do TFG não está disponível na biblioteca do SimPowerSystems e de nenhum outro software comercial, pois não existem equações gerais analíticas que representem a resposta dinâmica desta máquina. Uma possibilidade para simular o comportamento dinâmico da mesma é a utilização simultânea de dois softwares (um de elementos finitos e um de análises dinâmicas de sistemas elétricos). A cada iteração são trocados dados entre os dois softwares, porém, tal simulação levaria muito tempo para ser feita visto que a análise por elementos finitos é tridimensional e o intervalo de tempo de interesse relativamente longo.

Foi adotada outra possibilidade, cujo tempo de simulação é muito inferior ao descrito acima, porém, mantendo alta confiabilidade e precisão ([51]). Primeiramente, determinou-se, isoladamente, via elementos finitos (simulação magnetoestática tridimensional), o fluxo magnético concatenado na fase A para um par de pólos, utilizando a geometria apresentada na Figura 6.3. Esta simplificação foi possível pelo fato de esta geometria se repetir ao longo do enrolamento e, também, pelo fato de que as três fases são desacopladas magneticamente entre si ([108]).

As simulações foram feitas para diferentes posições elétricas do rotor $\left(0^{\circ}\right.$ a $360^{\circ}$ ) e, também, para diferentes valores de corrente ( 0 a $135 \mathrm{~A}$ ), de forma a determinar a matriz de fluxo concatenado por fase $\lambda(i, \theta)$. Para cada simulação, foi determinado o fluxo magnético que circula na região da armadura. A representação 
das fases $\mathrm{B}$ e $\mathrm{C}$ consiste no deslocamento dos valores obtidos da matriz resultante em $-120^{\circ}$ e $120^{\circ}$, respectivamente. Posteriormente, estas matrizes foram utilizadas no SimPowerSystems, de forma a modelar a equação (6.6), que é a equação geral de máquinas elétricas. Destaca-se que este modelo inclui as perdas no ferro, bem como os efeitos da saturação.

$$
v(t)=-R \cdot i(t)+\frac{d}{d t} \lambda(i, \theta)
$$

Expandindo a equação (6.6), teremos:

$$
v(t)=-R \cdot i(t)+\left[\left(\frac{d}{d i} \lambda(i, \theta)\right) \cdot \frac{d}{d t} i+\left(\frac{d}{d \theta} \lambda(i, \theta)\right) \cdot \frac{d}{d t} \theta\right]
$$

Para modelar a equação (6.7) no SimPowerSystems, deve-se isolar o termo diferencial da corrente:

$$
\frac{d}{d t} i=\left[v(t)+R \cdot i(t)-\left(\frac{d}{d \theta} \lambda(i, \theta)\right) \cdot \omega_{r}\right] \cdot\left(\frac{d}{d i} \lambda(i, \theta)\right)^{-1}
$$

sendo:

$v(t)=$ tensão terminal $(\mathrm{V})$.

$R \quad=\quad$ resistência do estator $(\Omega)$.

$i=$ corrente elétrica $(\mathrm{A})$.

$\theta=$ posição elétrica do rotor $\left({ }^{\circ}\right)$.

$\omega_{r}=\quad$ velocidade angular do rotor $(\mathrm{rad} / \mathrm{s})$.

$t=$ tempo (s).

$\lambda=$ fluxo magnético concatenado por fase (weber).

Com os valores armazenados na matriz $\lambda(i, \theta)$, calculam-se duas outras matrizes, de forma a satisfazer a equação (6.8). Tais matrizes são implementadas como look-up tables no SimPowerSystems, sendo elas apresentadas na Figura 6.4 e na Figura 6.5. Os valores do conjugado eletromagnético, também, foram determinados a partir das simulações, utilizando o método dos elementos finitos e calculados através da equação (6.9). Para implementação direta no 
SimPowerSystems como look-up table, tais valores foram armazenados em uma matriz, mostrada na Figura 6.6.

$$
T_{e}=i(t) \cdot\left(\frac{d}{d \theta} \lambda(i, \theta)\right) \cdot p
$$

sendo:

$p=$ número de pares de pólos.

$T_{e} \quad=\quad$ conjugado eletromagnético (N.m).

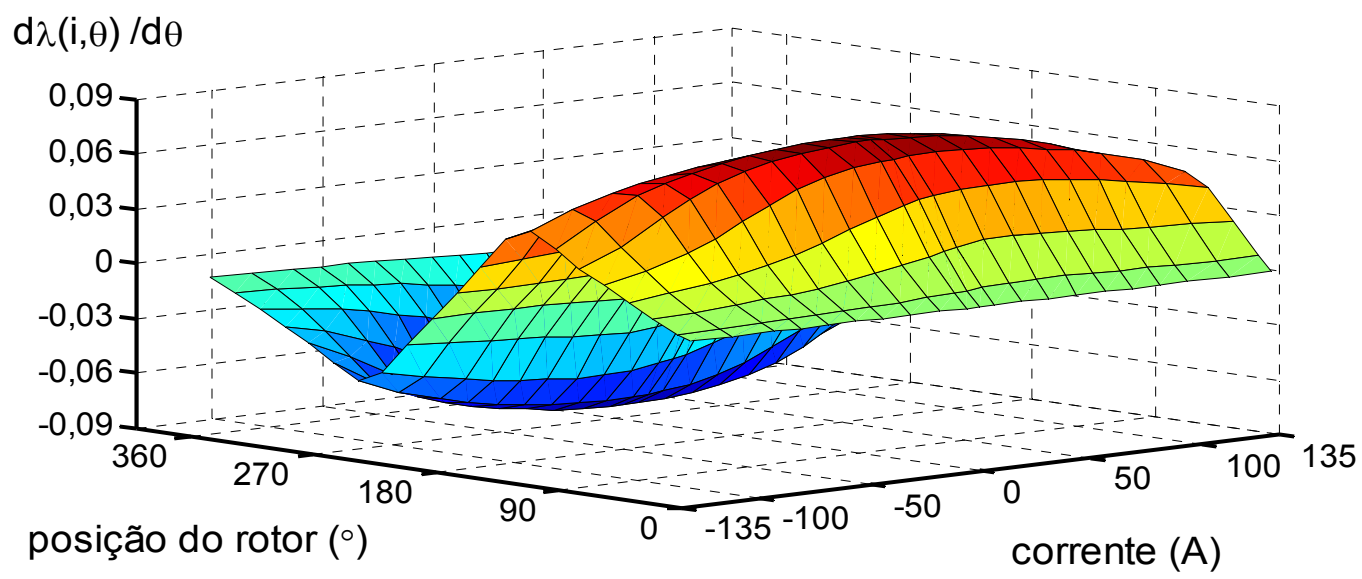

Figura 6.4 Valores armazenados na matriz $d \lambda(i, \theta) / d \theta$

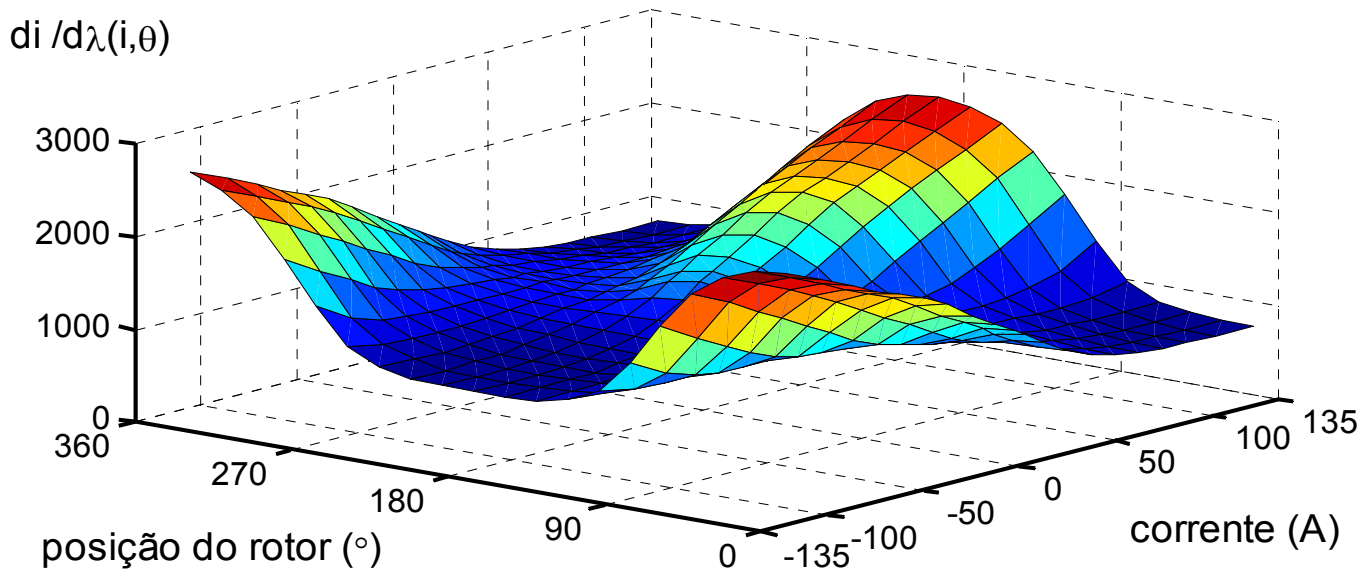

Figura 6.5 Valores armazenados na matriz $d i / d \lambda(i, \theta)$ 


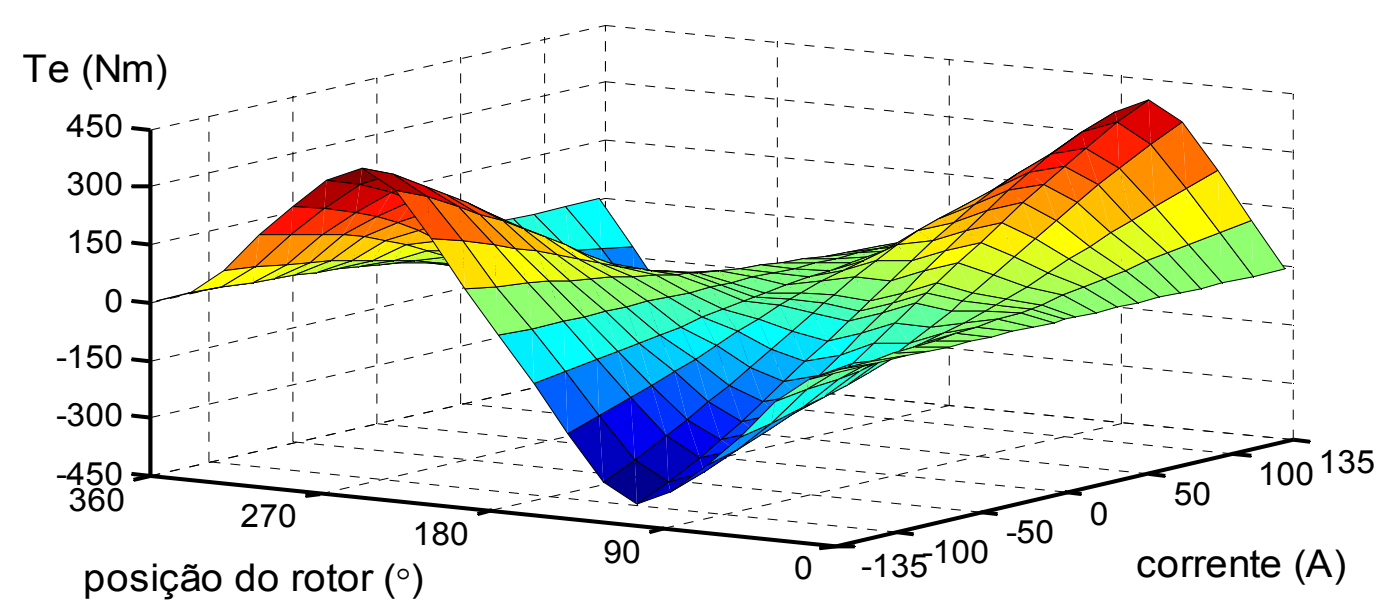

Figura 6.6 Valores armazenados de conjugado eletromagnético.

A Figura 6.7 ilustra a representação no SimPowerSystems da fase A do TFG, utilizando look-up tables, através das equações (6.8) e (6.9).

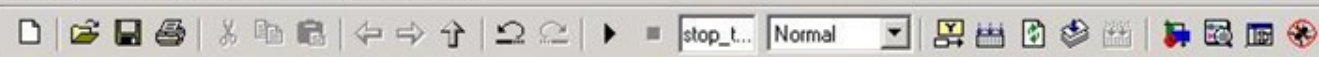

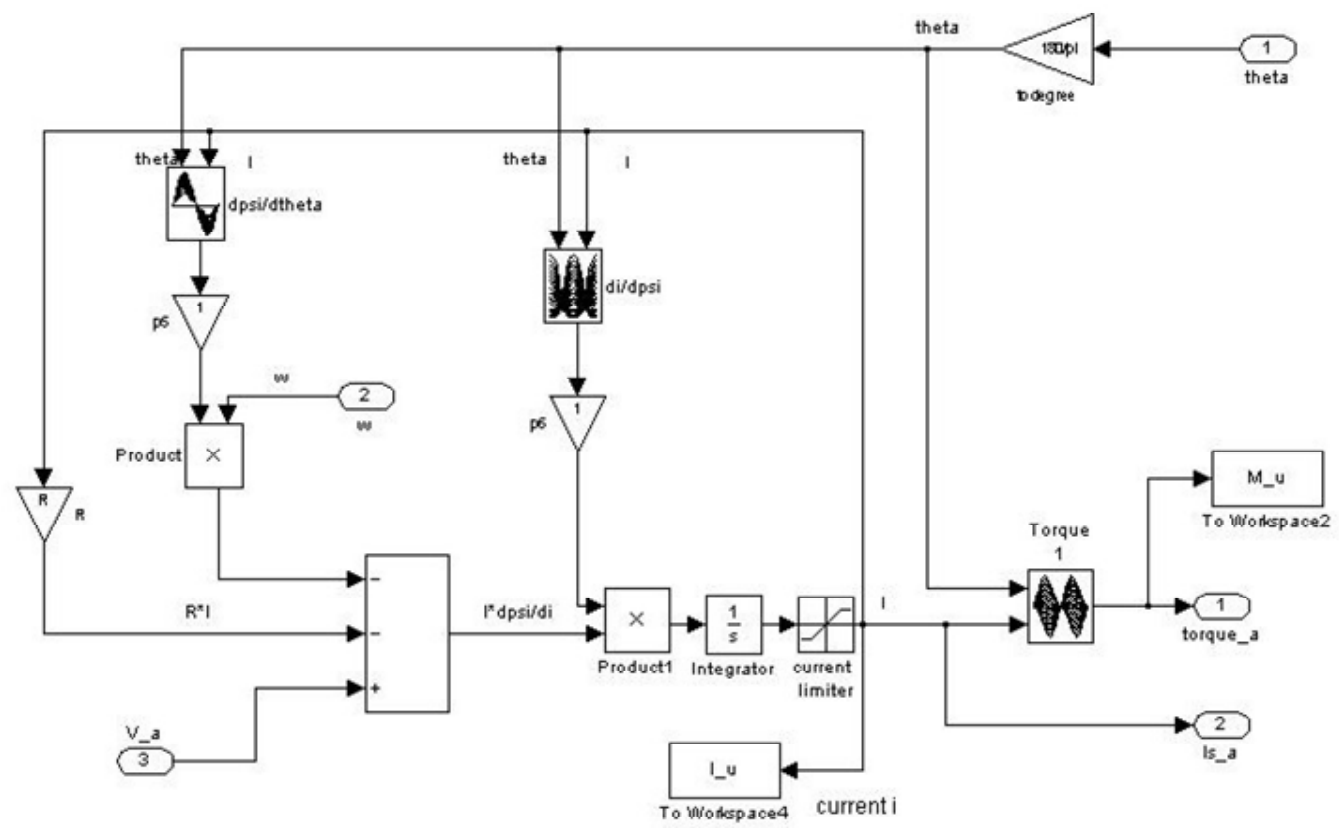

Figura 6.7 Representação da fase A utilizando look-up tables no SimPowerSystems. 
Para obter o modelo completo trifásico do TFG, incluiu-se a representação da fase $B$, da fase $C$ e as equações (6.10) e (6.11) do sistema mecânico. Além disso, como essa máquina foi inicialmente desenvolvida para tração elétrica, e a velocidade nominal é distinta da velocidade da turbina eólica modelada nesta tese, é necessário o uso de um multiplicador de velocidade com relação de 1:27,5.

$$
\begin{aligned}
& \frac{d}{d \theta} \omega_{r}=\frac{1}{J} \cdot\left(T_{e}-T_{m}\right) \\
& \frac{d}{d \theta} \theta_{m}=\omega_{r}
\end{aligned}
$$

sendo:

$J=$ soma dos coeficientes de inércia da turbina e do gerador $\left(\mathrm{kg} \cdot \mathrm{m}^{2}\right)$.

$T_{m} \quad=\quad$ conjugado mecânico (N.m).

$T_{e} \quad=\quad$ conjugado eletromagnético (N.m).

$\theta_{m}=$ posição mecânica angular do rotor (rad).

\subsection{Modelo do controle dos Conversores em Regime Permanente}

De forma geral, os conversores que convertem a freqüência da potência gerada por turbinas eólicas equipadas com PMG são similares entre si. Além disso, a potência nominal dos conversores deve ser, no mínimo, igual à potência nominal do gerador elétrico. Destaca-se que estes modelos não estão disponíveis na biblioteca do SimPowerSystems, tendo sido desenvolvidos seguindo diretrizes expostas em ([56]-[64]).

A principal função do conversor do lado do gerador (GenSC) é controlar a velocidade de operação do gerador (Figura 6.8), seguindo a operação com velocidade variável, conforme apresentada na Figura 3.5. Destaca-se que o controle de fator de potência unitário do lado do gerador não foi incluído no controle de corrente de eixo direto $\left(I_{d}^{*}\right)$, portanto $I_{d}^{*}$ é igual a 0 (zero). A velocidade ótima de referência $\left(\omega_{r}^{*}\right.$ opt $)$ é comparada com a velocidade atual do gerador, sendo que o erro é processado por um regulador PI. A saída desse regulador fornece a corrente de

referência de eixo em quadratura $I_{q}^{*}$ desejada no gerador que, juntamente com o 
valor de referência da corrente de eixo direto $I_{d}^{*}$ (igual a 0 ), são enviados ao controlador de corrente. Após uma transformação dq0-abc, com a posição exata do rotor fornecida pelo encoder, as correntes de referência $\left(I_{\text {abcs }}^{*}\right)$ são comparadas com as correntes atuais $\left(l_{a b c s}\right)$. Desta forma, as tensões de referência $\left(V_{a b c s}^{*}\right)$ desejadas na saída do GenSC são determinadas. Neste trabalho, os conversores são considerados ideais, portanto, os valores de $V_{\text {abcs, }}^{*}$ obtidos na saída do controlador da Figura 6.8, são utilizados, diretamente, na entrada dos modelos do PMSG e do TFG.

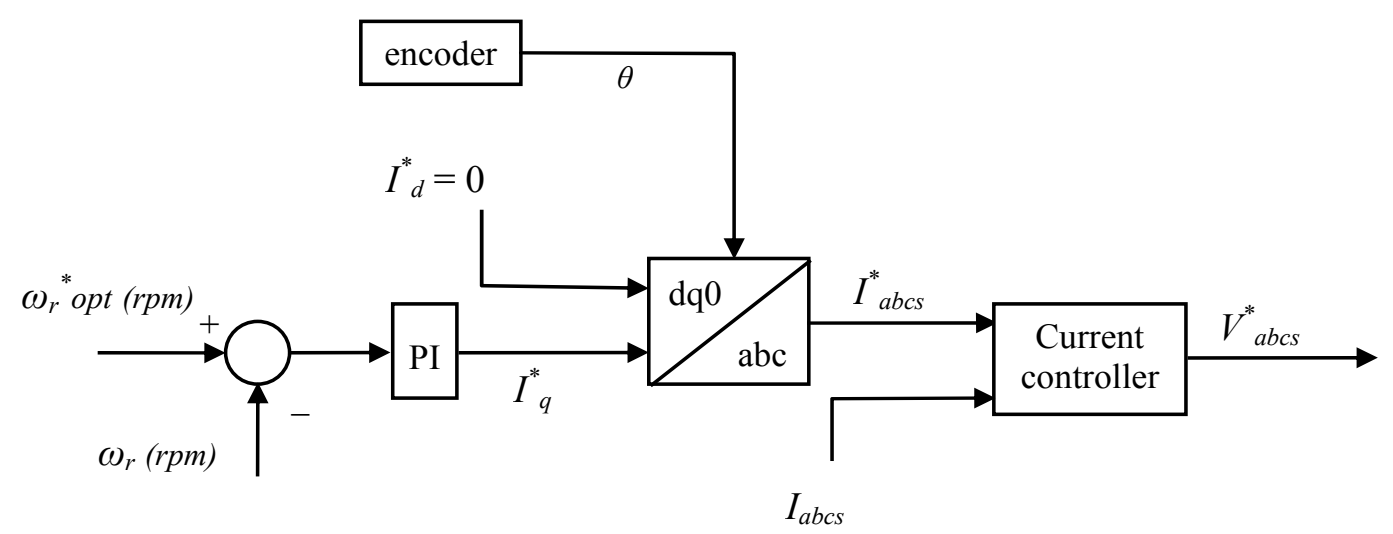

Figura 6.8 Controlador do conversor conectado ao gerador (GenSC).

A função do conversor do lado da rede (GSC) é permitir que a potência ativa, fornecida pelo PMG, seja transferida para a rede elétrica, controlando a tensão no link de corrente contínua. Além disso, tal conversor controla a tensão no ponto de conexão com a rede elétrica (ou o fator de potência). O controlador $\mathrm{C}_{2}$ emprega um PLL (Phase Locked Loop) para sincronizar a tensão alternada na saída do conversor com a componente fundamental da fase $A$ da tensão terminal. Portanto, o PLL fornece o ângulo $\phi$ para a transformação abc-dq0 (e dq0-abc).

Para controlar tensão no link CC, a tensão atual $\left(V_{d c}\right)$ é medida e comparada com o valor de referência $\left(V_{d c}^{*}=1 \mathrm{pu}\right)$ e o erro é processado por um regulador $\mathrm{PI}$, fornecendo a corrente de referência de eixo direto $I_{d}^{*}$. O valor de referência $I_{d}^{*}$ é comparado com a corrente de eixo direto atual $l_{d}$ e processado por um regulador $\mathrm{PI}$, o qual fornece a tensão de referência de eixo direto $V_{d}^{*}$ (Figura 6.9).

A tensão terminal no ponto de conexão com a rede elétrica é controlada através da troca de potência reativa. O valor atual da tensão terminal $\left(V_{t}\right)$ é 
comparado com o valor de referência $\left(V_{t}^{*}\right)$ e o erro é processado por um regulador $\mathrm{PI}$, fornecendo a corrente de referência de eixo direto $I_{q}^{*}$. Este regulador tem uma característica em declive (droop), usualmente $\pm 5 \%$, que permite a tensão terminal variar ligeiramente. Isso é adotado para evitar um comportamento oscilatório do controlador. A valor de referência $I_{q}^{*}$ é comparado com o valor atual, sendo que o erro é processado por um regulador $\mathrm{PI}$, fornecendo a tensão de referência de eixo em quadratura $V_{q}^{*}$. Finalmente, $V_{a b c \_g r i d}^{*}$ são as tensões trifásicas desejadas na saída do conversor em pu (Figura 6.9).

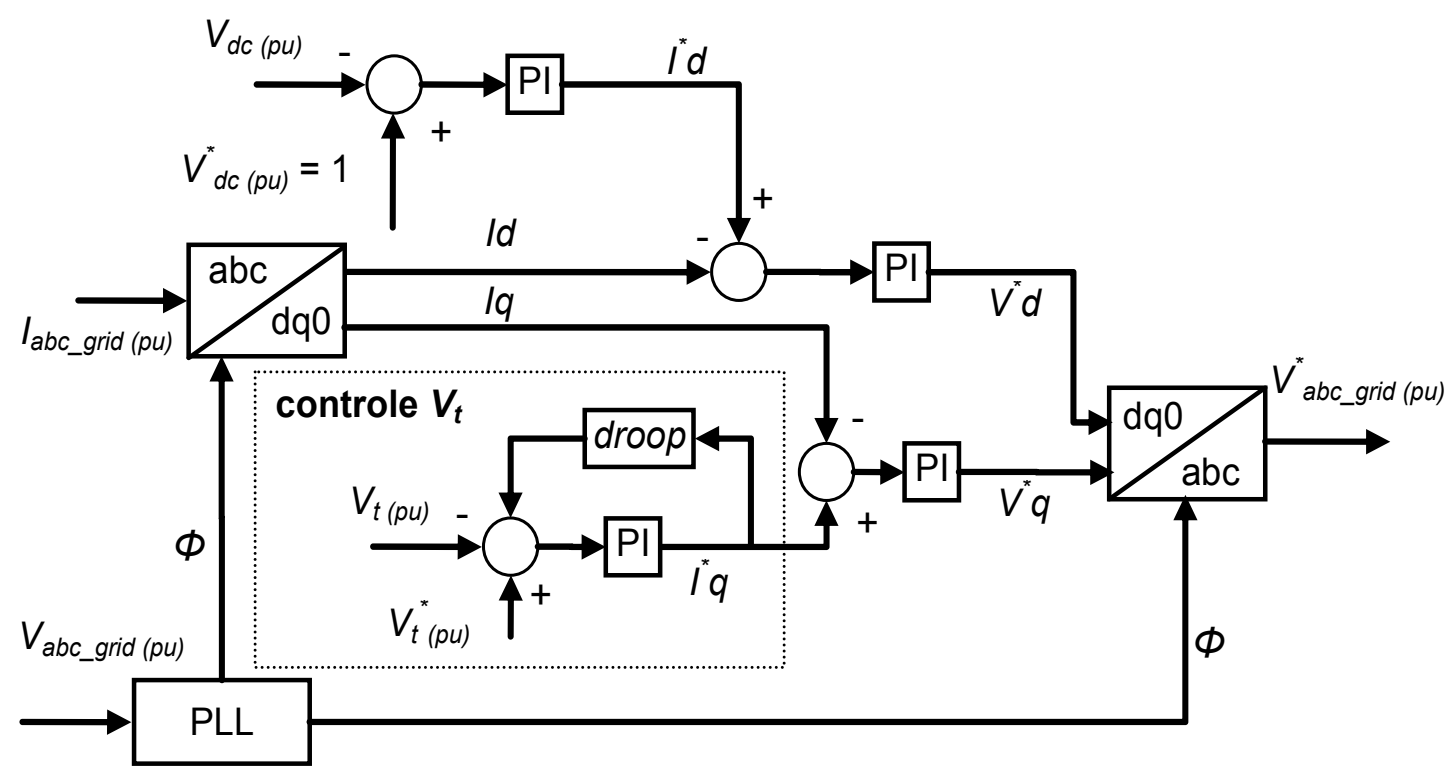

Figura 6.9 Diagrama esquemático do controle GSC do PMSG em regime permanente.

Para representar a capacidade nominal do GSC, foi acrescentada uma lógica para limitar a corrente de referência total $\left(I^{*}\right)$ do controlador, tal limite é mostrado na equação (4.17). A capacidade do GSC dos PMG's, normalmente, é maior do que 1 pu. Tal fato pode ser explicado considerando que, em condições nominais (100\% de injeção de potência ativa), o controle da injeção/consumo de potência reativa deve estar disponível.

$$
I^{*}=\sqrt{\left(I_{d}^{*}\right)^{2}+\left(I_{q}^{*}\right)^{2}}
$$

Destaca-se que o GSC descrito acima foi utilizado apenas no PMSG, sendo que o TFG foi considerado conectado diretamente em um link CC comum com tensão ideal. 


\subsection{Análise Dinâmica de Turbinas Eólicas equipadas com TFG}

Há uma grande possibilidade de as conexões entre as turbinas eólicas offshore serem em corrente contínua, mesmo que a transmissão para a terra seja feita em corrente alternada ([9]). Portanto, como o interesse por tal gerador é para aplicações offshore ([101]-[103]), o conversor ligado ao estator do TFG faz a ligação da máquina a uma rede de corrente contínua ideal, representada por uma fonte de tensão constante. Destaca-se que o controle de fator de potência unitário poderia ser incluído no controle de corrente de eixo direto $\left(I^{*} d\right)$, mostrado na Figura 6.8 , visto que o fator de potência do TFG é muito baixo (por volta de 0,7 ). Porém, nestas análises, tal controle não foi modelado.

O comportamento em regime permanente, determinado a partir do modelo dinâmico descrito no capítulo 4, é mostrado na Figura 6.10, Figura 6.11 e na Figura 6.12. As simulações dinâmicas foram feitas separadamente, uma para cada velocidade do vento (no intervalo entre $2 \mathrm{~m} / \mathrm{s}$ e $20 \mathrm{~m} / \mathrm{s}$, com passo de $0,5 \mathrm{~m} / \mathrm{s}$ ), sendo que para cada simulação, foram guardados os valores finais, em regime permanente, das variáveis mais importantes.

O modelo do TFG foi combinado com o modelo dinâmico do controle de ângulo de passo das hélices, para que a complementaridade com o controle de velocidade pudesse, também, ser analisada. Enquanto a potência elétrica gerada não atinge 1 pu (Figura 6.10), o controle de velocidade ajusta a velocidade ótima de operação (Figura 6.11) e o controle de ângulo de passo fica na posição zero (Figura 6.12). Entretanto, após este valor, o controle de ângulo entra em operação, de forma a limitar a potência elétrica gerada, para que está não ultrapasse a capacidade nominal do gerador elétrico. Algumas filosofias de controle e de operação estendem a velocidade variável para além do ponto de operação nominal, de forma a minimizar flutuações de injeção de potência ativa na rede elétrica. 


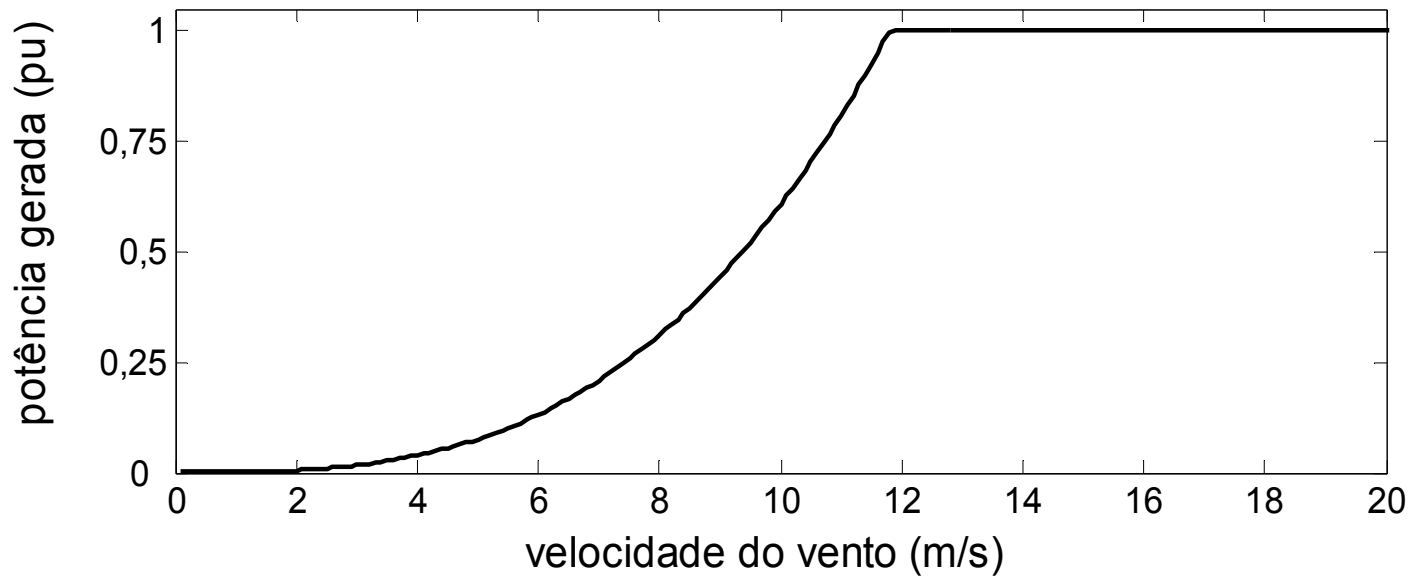

Figura 6.10 Potência elétrica do TFG para diferentes valores de velocidade do vento.

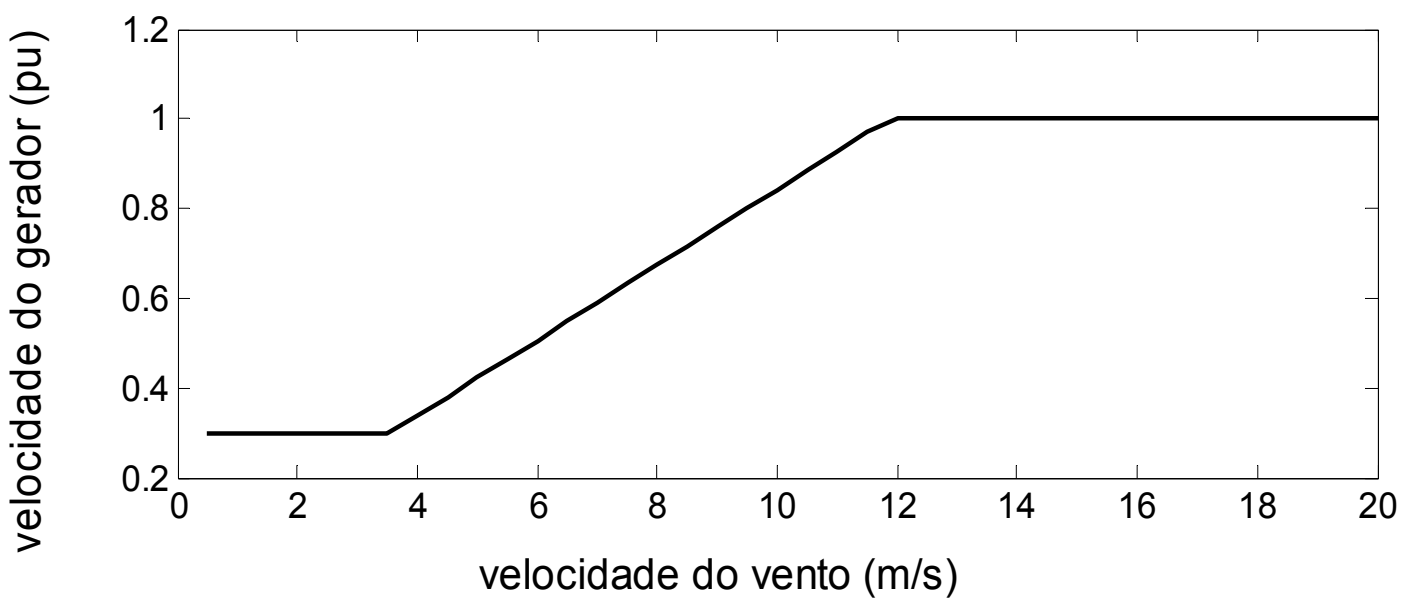

Figura 6.11 Velocidade de operação do TFG para diferentes velocidade do vento.

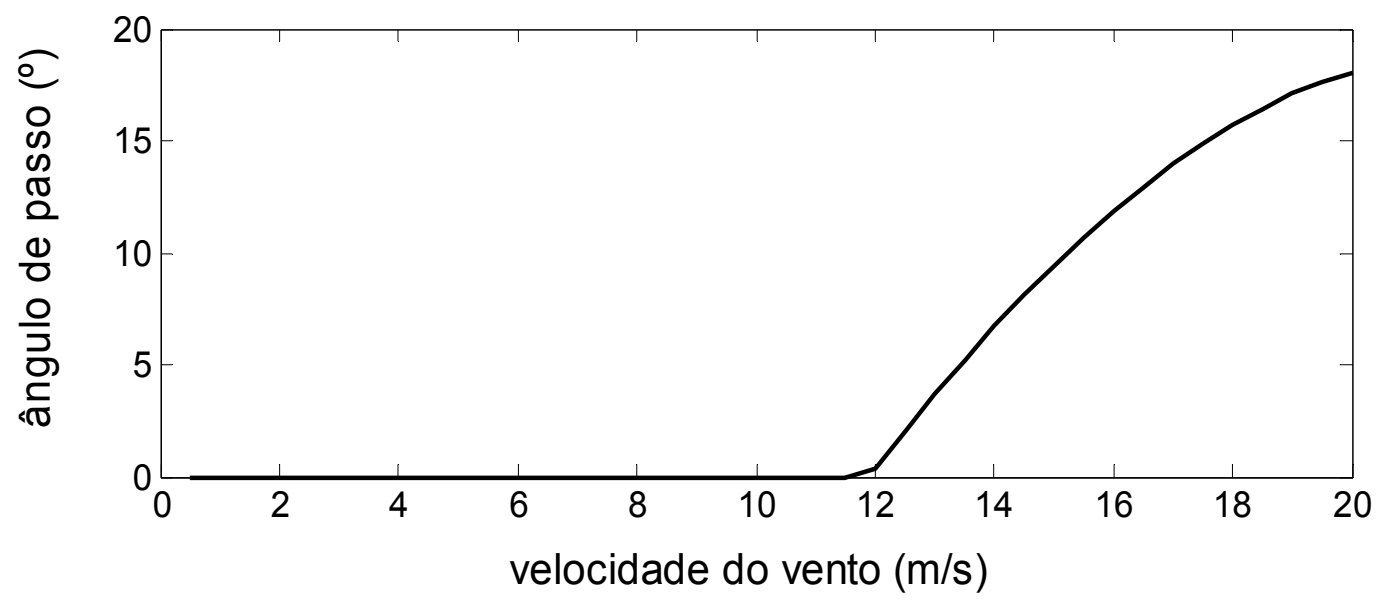

Figura 6.12 Ângulo de passo do TFG para diferentes valores de velocidade do vento. 
Tendo em vista que a modelagem do TFG não inclui a conexão com a rede elétrica, foi realizada uma análise, para avaliar perturbações na velocidade do vento (Figura 6.13). Para perturbações na velocidade do vento em torno de $16 \mathrm{~m} / \mathrm{s}$, o controle do GenSC mantém a velocidade do TFG fixa em 1 pu, enquanto que o controle de ângulo de passo das hélices atua para manter a potência elétrica gerada em 1 pu.

Durante a perturbação na velocidade do vento (Figura 6.13), o controle de velocidade mantém a velocidade do gerador fixa (Figura 6.14). O valor da velocidade ótima do gerador não é atualizado de acordo com a velocidade instantânea do vento, e, sim, de acordo com uma média considerando alguns minutos. Como a perturbação na velocidade do vento é em torno de $16 \mathrm{~m} / \mathrm{s}$, o TFG deveria gerar $1 \mathrm{pu}$ de potência elétrica. Contudo, como o controle de ângulo de passo depende de um atuador mecânico para rotacionar as hélices, a velocidade de sua atuação é mais lenta do que a variação na velocidade do vento (Figura 6.15). Desta forma, o efeito do controle de ângulo é limitado, sendo que a potência elétrica sofre oscilações, seguindo a tendência de variação do vento (Figura 6.16).

Uma forma de melhorar a flutuação de potência ativa injetada por este sistema é o uso do controle de velocidade, combinado com o controle do ângulo de passo das hélices. Como mostrada na Figura 3.3 e na Figura 3.4, a potência gerada pode ser controlada pela velocidade de operação determinada pelo GenSC. Além disso, este controle tem atuação mais rápida do que o controle eletromecânico das hélices da turbina.

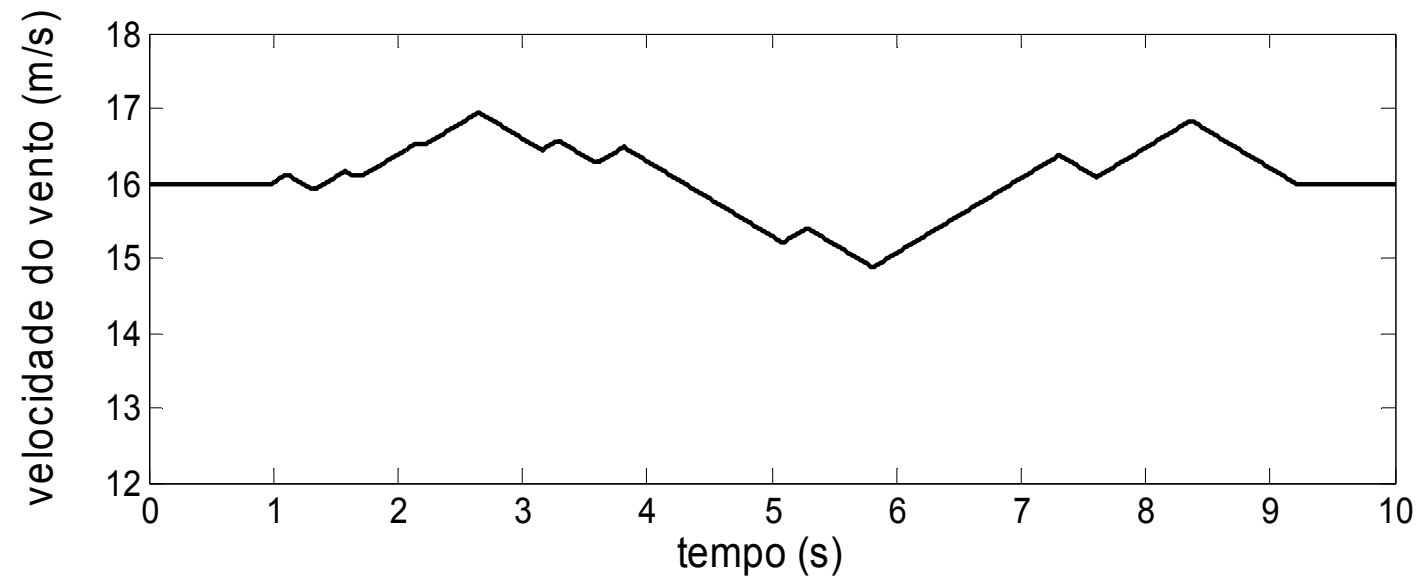

Figura 6.13 Perturbação na velocidade do vento. 


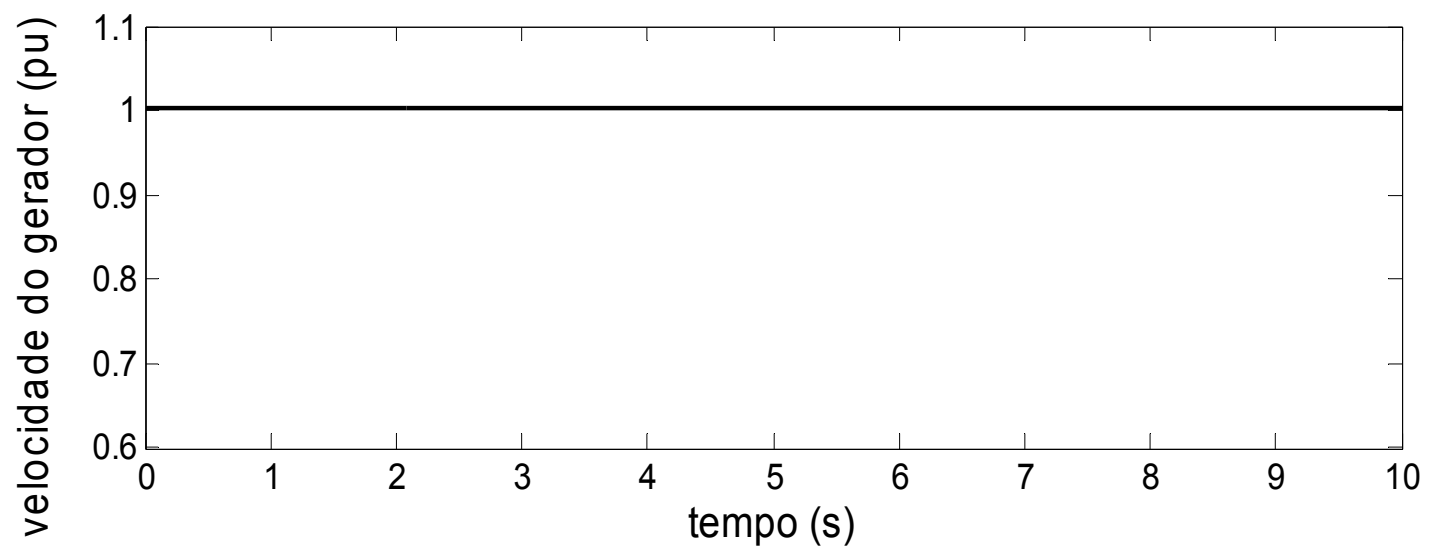

Figura 6.14 Velocidade do TFG durante perturbação na velocidade do vento.

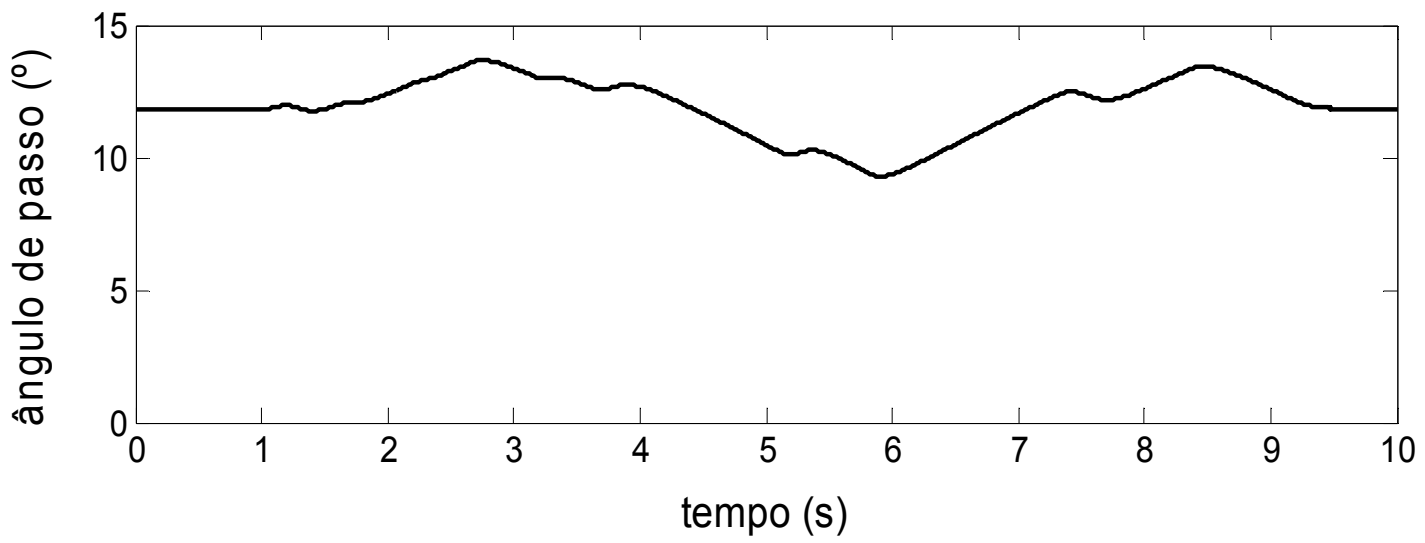

Figura 6.15 Atuação do controle de ângulo de passo durante a perturbação na velocidade do vento.

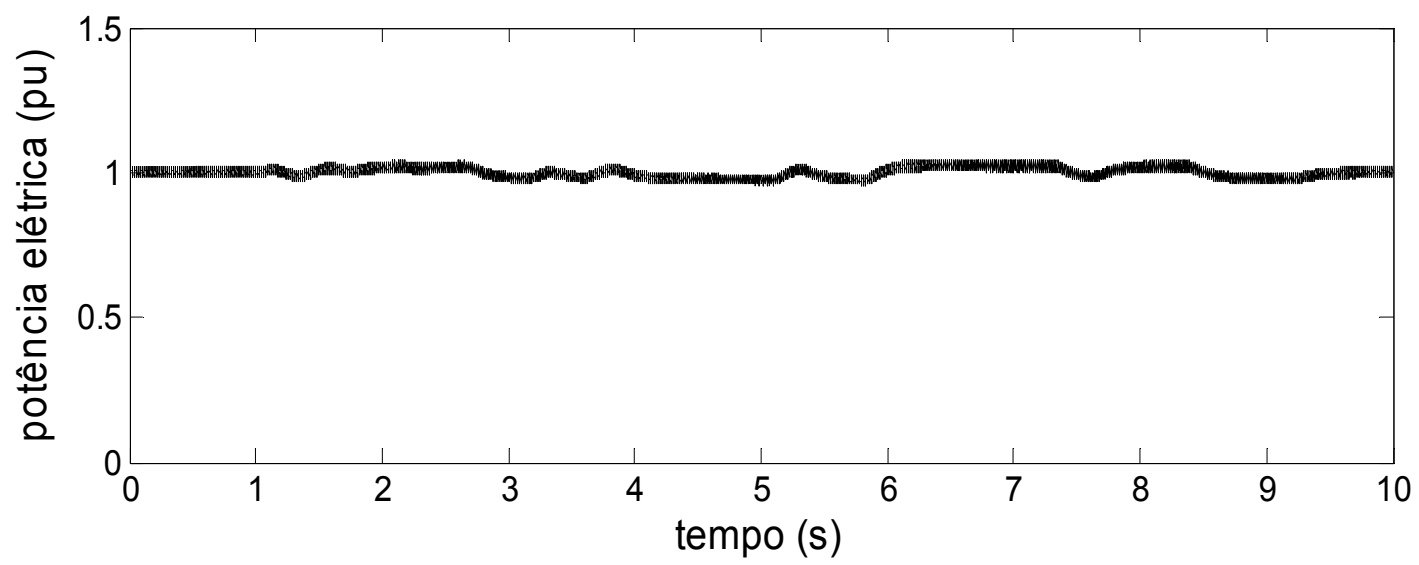

Figura 6.16 Potência elétrica desenvolvida pelo TFG durante perturbação na velocidade do vento. 


\subsection{Análise Dinâmica de Turbinas Eólicas equipadas com PMSG}

Embora os conversores sejam similares aos do DFIG, o fato de que o conversor do PMSG transfere à rede toda a energia elétrica gerada, faz com que alguns fatores se tornem mais restritivos (por exemplo, a injeção de potência reativa durante operação injetando potência ativa nominal) e, por outro lado, outros se tornem menos restritivos (por exemplo, altas correntes induzidas nos circuitos do rotor durante curto-circuitos na rede). Para operação durante curto-circuitos na rede elétrica, algumas modificações na estratégia de controle podem ser feitas ([61], [64], [109]).

Para estudar o comportamento durante faltas na rede elétrica, dois tipos de controle prioritário de corrente do GSC foram analisados. A potência nominal do GSC é igual a $110 \%$ da potência nominal do gerador síncrono. Portanto, a equação (4.17), que limita as correntes de eixo direto e em quadratura, tem a corrente nominal $\left(I^{*}\right)$ igual a 1,1 pu. Os controles prioritários estudados nesta tese são descritos a seguir:

- prior. ativa (prioridade para potência ativa via corrente $\left.I^{*} d\right)$ - a corrente de referência $I^{*} d$ pode atingir 1,05 pu e a corrente $I^{*} q$, apenas 0,32 pu;

- prior. reativa (prioridade para potência reativa via corrente $I^{*} q$ ) - a corrente de referência $I^{*} d$ pode atingir apenas 0,46 pu e a corrente $I^{*} q 1,0$ pu;

Os modelos descritos foram conectados à rede teste de distribuição, apresentada na Figura 3.6. Os dados do gerador podem ser encontrados em ([61]). Considerou-se a velocidade do vento constante em $11,8 \mathrm{~m} / \mathrm{s}$ durante a falta, sendo que do ângulo de passo é mantido constante em $0^{\circ}$ (zero grau, ou seja, hélice totalmente na vertical). Quando a tensão terminal atinge valores inferiores a $0.9 \mathrm{pu}$, iniciam-se os controles prioritários de corrente do GSC. Destaca-se que o GenSC continua controlando a velocidade do rotor. A evolução das principais variáveis é mostrada da Figura 6.17 até a Figura 6.22.

A tensão terminal da fazenda eólica atingiu valor mais elevado, quando o controle do GSC priorizou a potência reativa, como mostrado na Figura 6.17. 


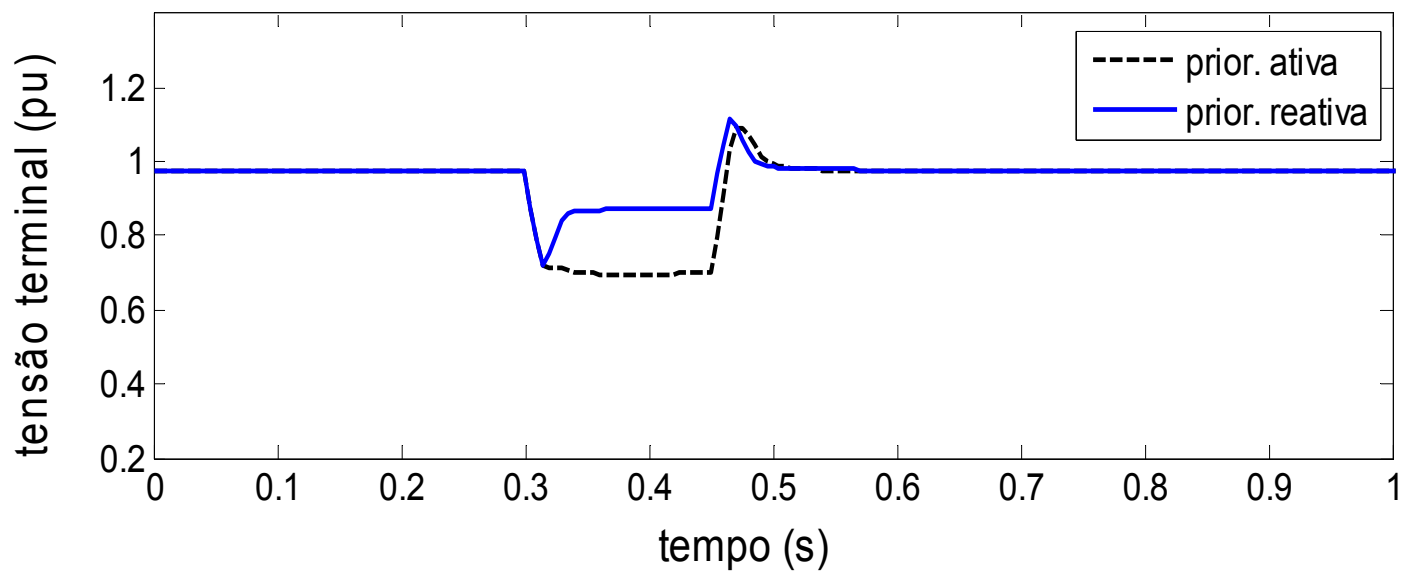

Figura 6.17 Tensão terminal da fazenda eólica durante curto-circuito na B5, eliminado em 150 ms.

Tal fato pode ser explicado, obviamente, pela maior injeção de potência reativa durante a falta, mostrada na Figura 6.18. Nos dois casos, a corrente nominal do GSC foi atingida (Figura 6.19).

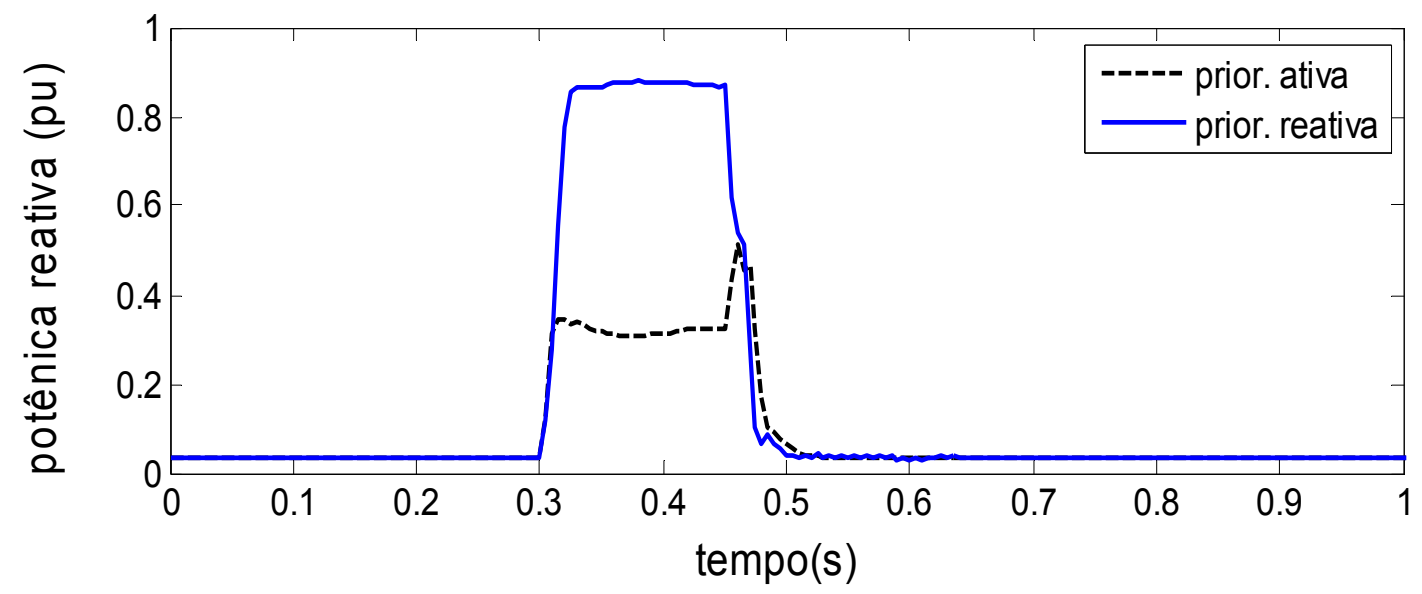

Figura 6.18 Potência reativa injetada durante curto-circuito na B5, eliminado em 150 ms.

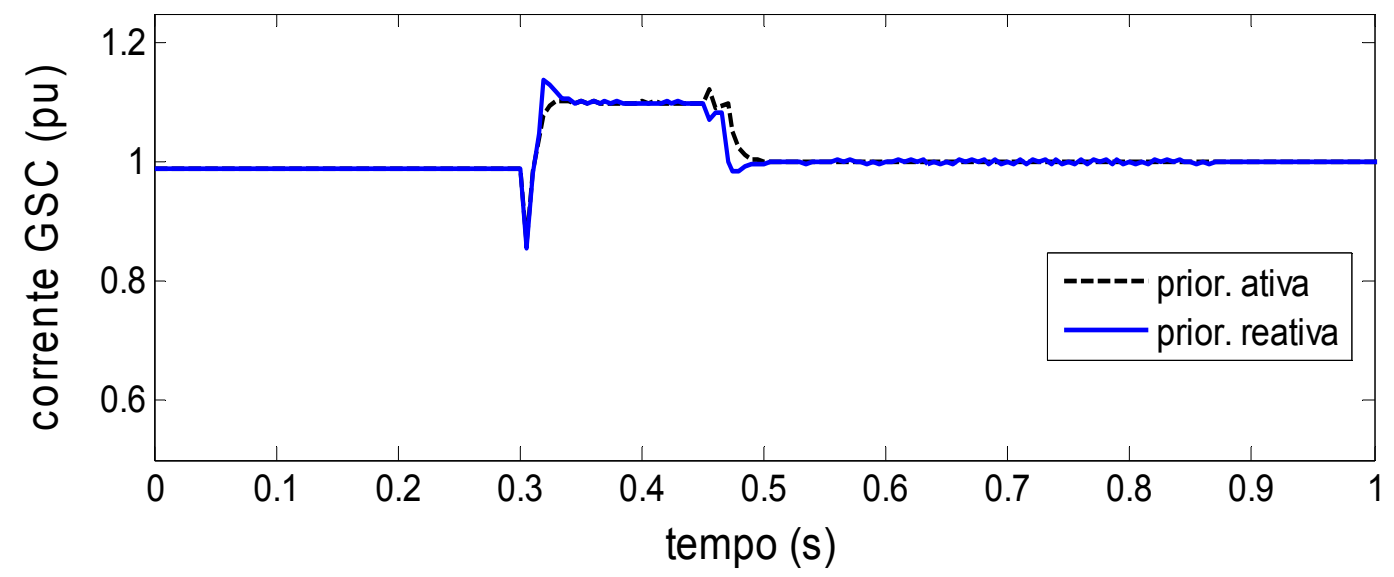

Figura 6.19 Corrente reativa injetada pelo GSC durante curto-circuito na B5, eliminado em 150 ms. 
A potência ativa injetada durante o curto-circuito na barra 5 foi maior, quando o controle que prioriza a potência ativa foi utilizado (Figura 6.20). Porém, a tensão no link CC foi mais elevada para o uso do controle que prioriza a potência reativa, como visto na Figura 6.21. Tal controle deixa de injetar potência ativa para priorizar a potência reativa e, desta forma, o desbalanço entre a potência ativa gerada e a potência ativa efetivamente injetada na rede acaba por elevar a tensão no link CC.

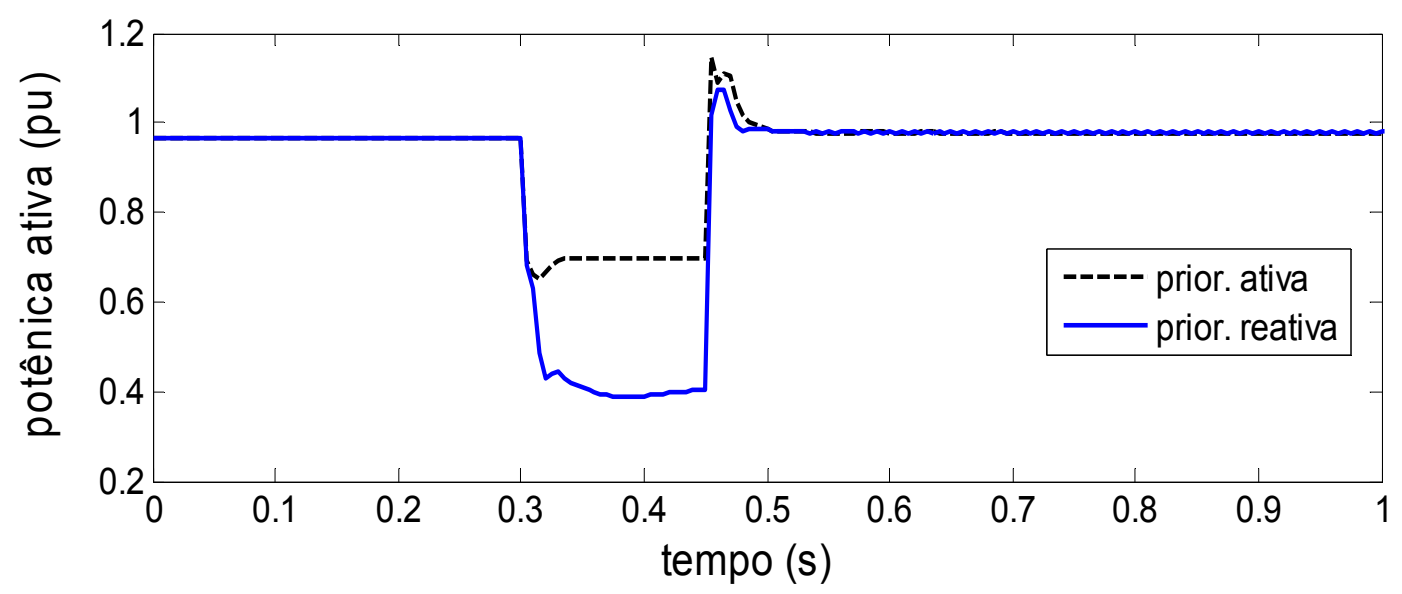

Figura 6.20 Potência ativa injetada durante curto-circuito na B5, eliminado em 150 ms.

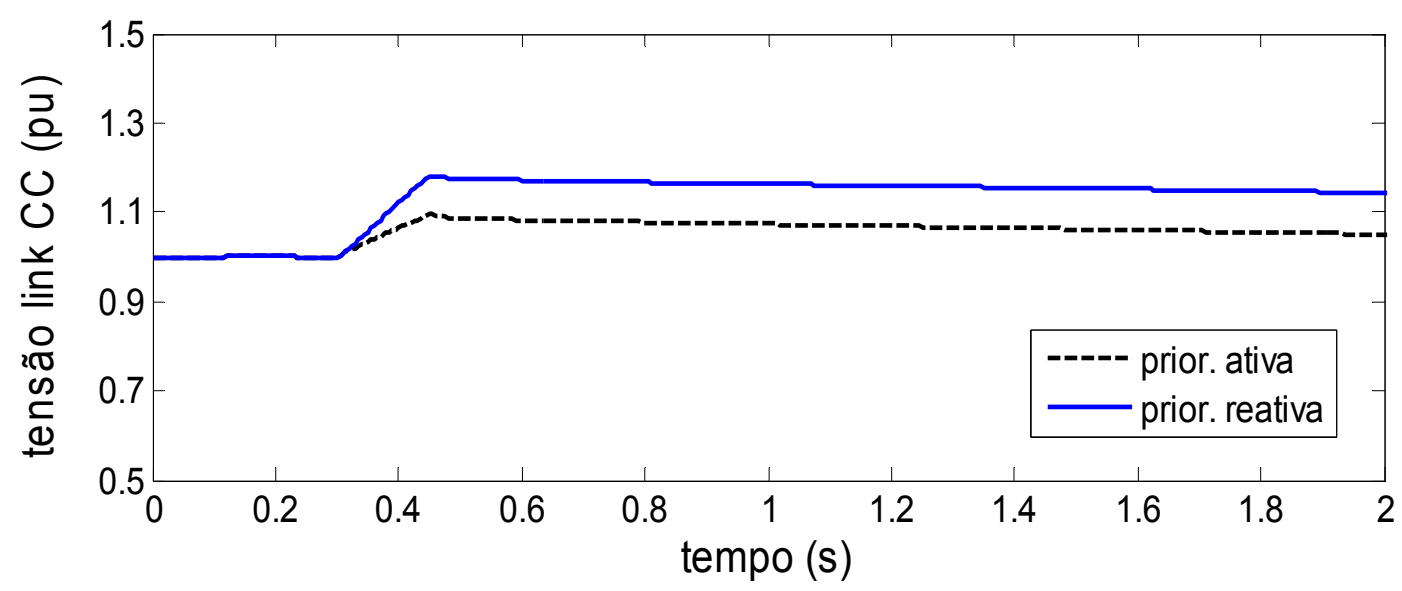

Figura 6.21 Tensão no link CC durante curto-circuito na B5, eliminado em 150 ms.

Dado que o PMSG não tem seus circuitos do estator conectados à rede elétrica, sua velocidade depende, apenas, do controle do GenSC. Desta forma, a diferença de velocidade do rotor durante o curto-circuito foi muito pequena, como mostrado na Figura 6.22. 


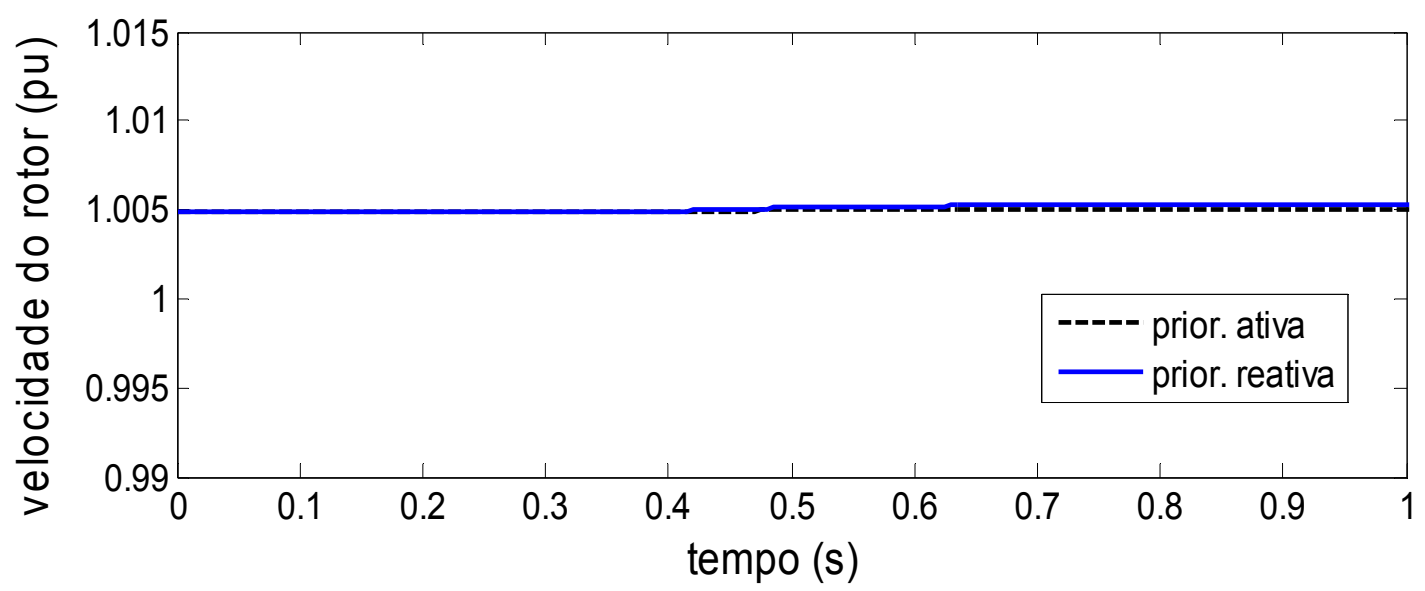

Figura 6.22 Velocidade do rotor durante curto-circuito na B5, eliminado em $150 \mathrm{~ms}$.

Para curto-circuitos mais severos, os quais levam a tensão terminal à zero, algum sistema de proteção deve ser acionado. Em uma operação emergencial, a velocidade do gerador poderia ser variada pelo controle do GenSC para que a geração de potência ativa fosse diminuída, instantaneamente. Além disso, a utilização do controle de ângulo de passo, para diminuição instantânea da potência gerada, poderia ser utilizada. Outra possibilidade é a desconexão momentânea entre o PMSG e o GenSC, diminuindo assim o desbalanço de potência ativa efetivamente injetada na rede e a gerada. Desta forma, a tensão no link CC não atingirá valores elevados, de forma a garantiria a operação ininterrupta.

\subsection{Considerações Gerais}

De forma sucinta, os seguintes comentários e conclusões podem ser feitos a respeito do capítulo 6 :

- O modelo computacional completo do TFG equipando uma turbina eólica de velocidade variável foi apresentado originalmente nesta tese de doutorado. Adicionalmente, foram realizadas análises dinâmicas frente a perturbações na velocidade do vento, como também as análises para a determinação da curva de potência para diferentes velocidades do vento.

- As investigações sobre o TFG apresentadas neste capítulo, mostram que o controle genérico utilizado necessita modificações para que seu desempenho 
dinâmico possa contemplar a conexão com a rede elétrica, aumentando, assim, as possibilidades de análises.

- Com as análises desenvolvidas com o modelo dinâmico da turbina eólica equipada com PMSG, constataram-se diferenças fundamentais em relação aos controles do DFIG. Porém, o controle do GSC, que prioriza a potência reativa, mostrou-se um potencial campo para aprofundamento dos estudos mostrados nesta tese.

- Para análises de curto-circuitos severos, o modelo dinâmico da turbina eólica equipada com PMSG deve contemplar alguma (ou uma combinação delas) forma de diminuir instantaneamente a potência ativa gerada. 


\section{Capítulo 7}

\section{CONCLUSÕES}

Embora diversas conclusões obtidas com o desenvolvimento deste trabalho tenham sido discutidas ao final de cada capítulo, a seguir, são apresentadas as principais conclusões de forma simplificada, para permitir uma visão global. Além disso, incluem-se algumas recomendações para trabalhos futuros.

\section{Geradores de indução duplamente alimentados (DFIG):}

- No capítulo 4, analisou-se o impacto da capacidade do conversor do lado da rede no desempenho dinâmico do DFIG. Tal análise mostrou que, com o uso do conversor de $50 \%$ da capacidade nominal do gerador elétrico, a injeção de potência reativa na rede elétrica foi mais efetiva durante o curto-circuito. Da mesma forma, a tensão terminal da fazenda eólica atingiu valores mais elevados para o uso do conversor de $50 \%$.

- A análise de diferentes estratégias de controle mostrou que utilizando, simultaneamente, o controle de tensão terminal pelo RSC e de injeção de potência reativa pelo GSC, a tensão terminal atinge valores mais elevados durante curto-circuito. Porém, para curto-circuitos mais severos, a tensão no link CC chega a valores acima de 2 pu, impossibilitando a operação ininterrupta do gerador.

- Com a análise do uso do sistema crowbar, constatou-se que o tempo de inserção nos enrolamentos do rotor deve ser minimizado. Desta forma, o RSC pode iniciar o controle de tensão terminal mais rapidamente, antes mesmo da eliminação do curto-circuito. No caso de curto-circuitos severos, faz-se necessária mais de uma inserção do sistema crowbar durante o curto-circuito, dificultando, assim, a retomada do controle da tensão terminal pelo RSC.

- Para requisitos de conexão com a rede, os quais exijam a injeção de corrente reativa durante curto-circuitos no sistema elétrico, a utilização de sistemas de 
proteção, combinando o crowbar e o dc-chopper, deve ser adotado. Principalmente, para garantir a operação ininterrupta durante curto-circuitos severos. Porém, para requisitos de rede menos rigorosos, nos quais apenas a operação ininterrupta é exigida, pode ser adotado, unicamente, o sistema crowbar.

- No Capítulo 5, foi proposto um método analítico para calcular o tempo crítico de eliminação da falta para geradores de indução duplamente alimentados. Além de facilitar a compreensão dos fenômenos relacionados à perda de estabilidade destes geradores, tal método pode ser implementado computacionalmente como uma ferramenta adicional para análise de estabilidade.

\section{Geradores síncronos a ímãs permanentes (PMG):}

- No Capítulo 6, dois tipos de geradores síncronos a ímãs permanentes foram estudados, o de fluxo radial e o de fluxo transversal. O modelo dinâmico proposto da turbina eólica equipada com o TFG possibilita análises de perturbação na velocidade do vento.

- Considerando as análises do PMSG, constatou-se a importância da estratégia de controle utilizada, sendo que o uso de uma estratégia, que priorize a injeção de potência reativa, melhora a estabilidade e os níveis de tensão do sistema elétrico. Para curto-circuitos não tão severos, na rede elétrica, a tensão no link de corrente contínua se mantém dentro dos limites. Porém, durante curto-circuitos severos, deve-se utilizar alguma estratégia para limitar a potência elétrica gerada. Desta forma, a tensão no link de corrente contínua pode ser eficazmente controlada.

\subsection{Sugestão para Trabalhos Futuros}

Algumas propostas para dar sequência aos trabalhos desenvolvidos nesta tese são dadas, a seguir: 
- Desenvolvimento de modelos dinâmicos completos, para turbinas equipadas com geradores síncronos de ímãs permanentes fluxo radial. Tal tecnologia será, em breve, mais comum no sistema elétrico brasileiro, desta forma, o estudo do impacto da conexão destas novas tecnologias será fundamental.

- Simulação de uma parte do sistema brasileiro de transmissão, da Região Nordeste (primeiramente), utilizando o modelo proposto para o DFIG, de forma a analisar o impacto na estabilidade do sistema, com a contribuição de injeção de potência reativa durante diferentes tipos de curto-circuitos. Desta forma, será possível levantar possíveis questionamentos, aos atuais requisitos brasileiros de conexão com a rede elétrica.

- Desenvolvimento de uma metodologia analítica, para determinar o tempo de atuação do sistema crowbar e, para determinar o valor ideal da resistência a ser inserida. 


\section{REFERÊNCIAS}

[1] Hansen, H. C. Forsøgsmøllen in Askov. Dansk Udysyns Forlag, 1981. (em dinamarquês)

[2] CRESESB Atlas do Potencial Eólico Brasileiro. 2001. (Disponível em: http://www.cresesb.cepel.br/index.php?link=/atlas_eolico_brasil/atlas.htm)

[3] European Wind Energy Association. Wind Energy - The Facts. Março, 2009. (Relatório Técnico, 2009)

[4] Global Wind Energy Council. Global Wind 2008 Report. 2009. (Relatório Técnico, 2009)

[5] Banco de Informações de Geração - ANEEL. Disponível em: <http://www.aneel.gov.br> Acesso em 10 de agosto de 2009.

[6] Jenkins, N., et al. Embedded generation. The Institution of Engineering and Technology, 2000.

[7] Ackermann, T.; Andersson, G.; Söder, L. Distributed generation: a definition. Electric Power Systems Research, v. 57, no. 3, p. 195-204, 2001.

[8] IEEE Standards 1547. IEEE Standards for Interconnecting Distributed Resources with Electric Power Systems, 2003.

[9] Ackermann, T. Wind Power in Power Systems. 1. ed. Wiley, 2005.

[10] European Wind Energy Association. Large Scale Integration of Wind Energy In The European Power Supply: analysis, issues and recommendations. December, 2005. (Relatório Técnico, 2005)

[11] Fairley, P. Germany's Green-Energy. IEEE Spectrum, Agosto, 2009.

[12] Li, H.; Chen, Z. Overview of different wind generator systems and their comparisons. IET Renewable Power Generation, vol. 2, no. 2, pp. 123138, 2008.

[13] Global Wind Energy Advisory. Global Wind Turbine Supply Market Share Update. Fevereiro, 2009. (Relatório, 2009)

[14] Molly, J. P. Status der Windenergienutzung in Deutschland - Stand 31.12.2008. DEWI GmbH, 2009. (Disponível em: <http:/l www.windenergie.de>)

[15] Goy, Leonardo Leilão de energia eólica tem 441 projetos habilitados. Jornal O Estado de S. Paulo, 17 de julho de 2009.

[16] European Wind Energy Association. Economic Development, Wind Directions, Abril/Maio, 2008.

[17] DIEESE Informe sobre o desempenho do setor Automotivo, Fevereiro, 2009. (disponível em: http://www.cntm.org.br/publicacoes.asp)

[18] Polinder, H.. et al. Comparison of direct-drive and geared generator concepts for wind turbines. IEEE Transactions on Energy Conversion, vol. 21, no. 3, pp. 725-733, 2006.

[19] European Wind Energy Association. The Economics of Wind Energy. Março, 2009. (Relatório, 2009) 
[20] Mathew, Sathyajith Wind Energy: Fundamentals, Resource Analysis and Economics. Springer, Netherlands, 2006.

[21] Departamento de Gestão do Setor Elétrico (DGSE) Informativo Tarifário. $4^{a}$ Ed., Junho, 2009.

[22] Scott, C. F. Variable Speed Motor Control, Transactions of the AIEE, vol. 20, pp. 111-114, Julho, 1902.

[23] Cooper, W. Methods of Speed-Control, Transactions of the AIEE, vol. 20, pp. 197-213, Julho, 1902.

[24] Storer, N. W. Three-Wire System for Variable Speed Motor Work. Transactions of the AIEE, vol. 20, pp. 127-133, Julho, 1902.

[25] Neidhofer, G. Early three-phase Power. IEEE Power and Energy Magazine, vol. 5, no. 5, pp. 88-100, 2007.

[26] Blalock, T.J. Electrification of a major steel mill: Part I - Early use of direct current power. IEEE Industry Application Magazine, vol. 11, no. 3, pp. 9-13, Maio/Junho, 2005.

[27] Blalock, T.J. Electrification of a major steel mill: Part 2 - Development of the 25$\mathrm{Hz}$ system. IEEE Industry Application Magazine, vol. 11, no. 5, pp. 9-11, Setembro/Outubro, 2005.

[28] Blalock, T.J. Electrification of a major steel mill: Part 3 - Introduction of $60-\mathrm{Hz}$ power at Bethlehem works. IEEE Industry Application Magazine, vol. 11, no. 6, pp. 10-13, Novembro/Dezembro, 2005.

[29] Blalock, T.J. Steam-powered rolling mills at Bethlehem Steel. IEEE Industry Application Magazine, vol. 12, no. 5, pp. 11-13, Setembro/Outubro, 2006.

[30] Blalock, T.J. Electrification of a Major Steel Mill: Part 5 - Scherbius and Kraemer Drives. IEEE Industry Application Magazine, vol. 13, no. 4, pp. 8-11, Julho/Agosto, 2007.

[31] Krämer, C. New method for regulating the speed of induction motors. Elektrotechnische Zeitschrift, vol. 31, pp. 734-737, 1908. (em alemão)

[32] Behrend, B. A. The Induction Motor and Other Alternating Current Motors. McGraw-Hill Book Co., Londres, 1921.

[33] Kosow, Irving L. Control of Electric Machines. Prentice Hall, 1973.

[34] Meyer, F. W.; Sykes, W. The Economical Speed Control of Alternating-Current Motors Driving Rolling Mills. Transactions of the AIEE, vol. 31, no.2, pp. 20672095, Novembro, 1912.

[35] Horton, M. D. The Clymer Drive System. IEEE Industry Applications Magazine, vol. 12, no.6, pp. 8-10, Novembro/Dezembro, 2006.

[36] Clymer, C. C. Large Adjustable-Speed Wind-Tunnel Drive. Transactions of the AIEE, vol. 61, no. 3, pp. 156-158, Março, 1942.

[37] Schräge, H. K. New 3-phase Commutator Motor with Shunt Field Control and Brush Shifting. Elektrotechnische Zeitschrift, vol. 35, pp. 89-93, 1914. (em alemão) 
[38] Conrad, A. G.; Zweig, F.; Clarke, J. G. Theory of the Brush-Shifting A-C Motor I. Transactions of the AIEE, vol. 60, no.8, pp. 829-834, Agosto, 1941.

[39] Conrad, A. G.; Zweig, F.; Clarke, J. G. Theory of the Brush-Shifting A-C Motor II. Transactions of the AIEE, vol. 60, no.8, pp. 834-836, Agosto, 1941.

[40] Conrad, A. G.; Zweig, F.; Clarke, J. G. Theory of the Brush-Shifting A-C Motor III. Transactions of the AIEE, vol. 61, no.7, pp. 502-506, Julho, 1942.

[41] Conrad, A. G.; Zweig, F.; Clarke, J. G. Theory of the Brush-Shifting A-C Motor IV. Transactions of the AIEE, vol. 61, no.7, pp. 507-513, Julho, 1942.

[42] Alexanderson, E. F. W.; Edwards, M. A.; Willis, C. H. Electronic Speed Control of Motors. Transactions of the AIEE, vol. 57, no.6, pp. 343-354, Junho, 1938.

[43] Stöhr, V. M. Vergleich zwischen stromrichtermotor und untersynchroner stromrichterkaskade. Elektrotech. Maschinenbau, vol. 57, pp.581-591, Dezembro, 1939. (em alemão)

[44] Shockley, W., Sparks, M., and Teal, G. K. The p-n Junction Transistors. Physical Review, vol. 83, no. 1, pp.151-162, Julho, 1951.

[45] Alexanderson, E. F. W.; Edwards, M. A.; Willis, C. H. Control Applications of the Transistor. Proccedings of the IRE, vol. 40, no.11, pp. 1508-1511, Novembro, 1952.

[46] Carlin, P. W.; Laxson, A. S.; Muljadi, E. B. The History and State of the Art of Variable-Speed Wind Turbine Technology. National Renewable Energy Laboratory - NREL, Estados Unidos, Fevereiro, 2001. (Relatório Técnico, 2001)

[47] Krause, P. C. Analysis of electric machinery. McGraw-Hill Book Co., Nova York, 1986.

[48] Kundur, P. Power system stability and control. McGraw-Hill Inc., 1994.

[49] MathWorks SimPowerSystems - User's Guide: Version 5, MathWorks, 2009.

[50] Gieras, J. F. Performance Characteristics of a Permanent Magnet Transverse Flux Generator. IEEE International Conference on Electric Machines and Drives - IEMDC'05, pp. 1293 - 1299, Texas, 2005.

[51] Viorel, I.-A., et al. Transverse Flux Machines - Their behavior, design, control and applications. Mediamira, Romênia, 2003.

[52] Cigré Task Force 38.01.10. Modeling new forms of generation and storage. Cigré, 2001. (Relatório Técnico, 2001)

[53] Akhmatov, V. Variable-Speed Wind Turbines with Doubly-Fed Induction Generators, Part I: Modelling in Dynamic Simulation Tools. Wind Engineering, vol. 26, no. 2, pp. 85-108, 2002.

[54] Akhmatov, V. Variable-speed wind turbines doubly-fed induction generators part II: Power system stability. Wind Engineering, vol. 26, no.3, pp. 171-188, 2002.

[55] Akhmatov, V. Variable-speed wind turbines with doubly-fed induction generators - part III: Model with the back-to-back converters. Wind Engineering, vol. 27, no. 2, pp. 79-91, 2003. 
[56] Akhmatov, V. Analysis of Dynamic Behaviour of Electric Power Systems with Large Amount of Wind Power, Tese (doutorado) - Technical University of Denmark, Dinamarca, 2003.

[57] Slootweg, J. G.; Polinder, H.; Kling, W. L. Representing Wind Turbine Electrical Generating Systems in Fundamental Frequency Simulations. IEEE Transactions on Energy Conversion, vol. 18, no. 4, pp. 516-524, 2003.

[58] Sauer, P. W.; Pai, M. A. Power System Dynamics and Stability. Prentice Hall, Upper Saddle River, NJ, 1998.

[59] Arrillaga, J.; Watson, N. R. Computer Modelling of Electrical Power Systems. 2. Ed., Wiley, 2001.

[60] Akhmatov, V.; Nielsen, A.H.; Pedersen, J.K.; Nymannc, O. Variable-speed wind turbines with multi-pole synchronous permanent magnet generators. Part I: Modelling in dynamic simulation tools. Wind Engineering, vol. 27, no. 6, pp. 531-548, Dezembro, 2003.

[61] Akhmatov, V. Modelling and Ride-through Capability of Variable Speed Wind Turbines with Permanent Magnet Generators. Wind Energy, vol. 9, no. 4, pp. 313-326, Julho/Agosto, 2006.

[62] Conroy, J.; Watson, R. Torsional Damping Control of Gearless Full-Converter Large Wind Turbine Generators with Permanent Magnet Synchronous Machines. Wind Engineering, vol. 31, no. 5, pp. 325-340, Outubro, 2007.

[63] Jauch, C. Transient and dynamic control of a variable speed wind turbine with synchronous generator. Wind Energy, vol. 10, no. 3, pp. 247-269, Fevereiro, 2007.

[64] Hansen, A. D.; Michalke, G. Modelling and Control of Variable-speed Multi-pole Permanent Magnet Synchronous Generator Wind Turbine. Wind Energy, vol. 11, no. 5, pp. 537-554, Setembro/Outubro, 2008.

[65] Smith, G. A.; Nigim, K. A. Wind-energy recovery by a static Scherbius induction generator. IEE Proceedings Generation, Transmission and Distribution, vol. 128, no. 6, pp. 317-324, Novembro, 1981.

[66] Krause, P.C.; Wasynczuk, O.; Hildebrandt, M.S. Reference frame analysis of a slip energy recovery system. IEEE Transactions on Energy Conversion, vol. 3, no.2, pp. 404-408, 1988.

[67] Park, R. H. Two-Reaction Theory of Synchronous Machines Generalized Method of Analysis - Part I. Transactions of the AIEE, vol. 48, no.3, pp. 716727, Julho, 1929.

[68] Park, R. H. Two-Reaction Theory of Synchronous Machines Generalized Method of Analysis - Part II. Transactions of the AIEE, vol. 52, no.2, pp. 352354, Junho, 1933.

[69] Yamamoto, M.; Motoyoshi, O. Active and reactive power control for doubly-fed wound rotor induction generator. IEEE Transactions on Power Electronics, vol. 32, no. 1, pp. 624-629, Janeiro/Fevereiro, 1991.

[70] Akhmatov, V., et al. Modelling and transient stability of large wind farms. International Journal on Electrical Power and Energy Systems, vol. 25, pp. 123-144, 2003. 
[71] Müller, S.; Deicke, M.; Doncker, R. W. Doubly fed induction generator systems for wind turbines. IEEE Industry Applications Magazine, vol. 8, no. 3, pp. 2633, Maio/Junho, 2002.

[72] Ekanayabe, J. B., et al. Dynamic modelling of doubly fed induction generator wind turbines. IEEE Transactions on Power Systems, vol. 18, pp. 803-809, 2003.

[73] Akhmatov, V. Variable-speed wind turbines with doubly-fed induction generators - part IV: Uninterrupted operation features at grid faults with converter control coordination. Wind Engineering, vol. 27, no. 6, pp. 519-529, 2003.

[74] Morren, J.; de Haan, S. W. H. Ridethrough of wind turbines with doubly fed induction generator during a voltage dip. IEEE Transactions on Energy Conversion, vol. 20, no. 2, pp. 295-306, Julho, 2005.

[75] Jauch, C.; Matevosyan, J.; Ackermann, T.; Bolik, S. International Comparison of Requirements for Connection of Wind Turbines to Power Systems. Wind Energy, vol. 8, no. 3, pp. 537-554, Setembro/Outubro, 2008.

[76] Grid Code: High and Extra High Voltage. E.ON Netz GmbH Tech. Rep., Status: 1, 2006. (Resolução Normativa)

[77] P.0.12.3 Requisitos de Respuesta frente a Huecos de Tensión de las Instalaciones Eólicas (em espanhol), BOE no. 254, pp. 37017-37019, Outubro, 2006. (Resolução Normativa)

[78] Submódulo 3.6 - Requisitos Técnicos Mínimos para a Conexão à Rede Básica. Operador Nacional do Sistema (ONS), Resolução Normativa $n^{\circ}$ 372/09, Agosto, 2009. (Resolução Normativa)

[79] Erlich, I., et al. Modeling of Wind Turbines Based on Doulbly-Fed Induction Generators for Porwer System Stability Studies. IEEE Transactions on Power Systems, vol. 22, no. 3 pp. 909-919, 2007.

[80] Qiao, W.; Venayagamoorthy, G. K.; Harley, R. G. Real-Time Implementation of a STATCOM on a Wind Farm Equipped With Doubly Fed Induction Generators. IEEE Transactions on Industry Applications, vol. 45, no. 1, pp. 98-107, Janeiro/Fevereiro, 2009.

[81] Winkelman, J. R.; Javid, S. H. Control design and performance analysis of a 6 MW wind turbine generator. IEEE Transactions on PAS, vol. 102, no. 5, pp. 1340-1347, 1983.

[82] Abdin. E. S.; Xu, W. Control design and dynamic performance analysis of a wind turbine-induction generator unit. IEEE Transactions on Energy Conversion, vol. 15, no. 1, pp. 91-96, 2000.

[83] Heier, S. Grid Integration of Wind Energy Conversion Systems. 1 ed., John Wiley \& Sons Inc., 1998.

[84] Slootweg, J. G. Wind Power: Modelling and Impact on Power System Dynamics. Tese (doutorado) - Technical University of Delft, Holanda, 2003.

[85] Energy Research Centre (ECN). ECN-C--04-051 - Electrical and Control Aspects of Offshore Wind Farms II (Erao II). Junho, 2004. (Relatório Técnico, 2004) 
[86] Energy Research Centre (ECN). ECN-E--07-008 - Variable speed turbine dynamic model validation. JWT measurements and simulations. Janeiro, 2007. (Relatório Técnico, 2007)

[87] Muljadi, E., et al. Effect of Variable Speed Wind Turbine Generator on Stability of a Weak Grid. IEEE Transactions on Energy Conversion, vol. 22, no. 1, Março, 2007.

[88] European Wind Integration Study (EWIS). EWIS Wind Turbine Model Validation Report. Dezembro, 2008. (Relatório Técnico, 2008)

[89] Abildgaard, H. Experience of the Danish Transmission System Operator. Trabalho apresentado a IEA Technology Experts Meeting - grid integration of electricity from renewable, 2007, Paris. (Não publicado).

[90] Petru, T.; Thiringer, T. Active flicker reduction from a sea-based 2.5MW wind park connected to a weak grid. Proceedings of Nordic Workshop on Power and Industrial Electronics - NORPIE, 13-16 Junho, Aalborg, Dinamarca, 2000.

[91] Krüger, T.; Andresen, B. Vesta OptiSpeed-advanced control strategy for variable speed wind turbines. Proceedings of European Wind Energy Conference - EWEC, pp. 983-986, 2-6 Julho, Copenhague, Dinamarca, 2001.

[92] Burton, T., et al. Wind Energy Handbook. 1 ed., John Wiley \& Sons, 2001.

[93] Hansen, M. O. L. Aerodynamics of Wind Turbines. 2 ed., FiSH Books, Enfield, 2008.

[94] Mullane, A.; Lightbody, G.; Yacamini, R. Wind-turbine fault ride-through enhancement. IEEE Transactions on Power Systems, vol. 20, no. 4, pp. 1329-1937, 2005.

[95] Nielsen, J. N., et al. Modelling and Fault-Ride-Trough Tests of Siemens Wind Power 3.6 MW Variable-speed Wind Turbines. Wind Engineering, vol. 31, no. 6, pp. 441-452, 2007.

[96] Kayikçi, M.; Milanovic, J. V. Assessing Transient Response of DFIG-Based Wind Plants-The Influence of Model Simplifications and Parameters. IEEE Transactions on Power Systems, vol. 23, no. 2, pp. 545-554, Maio, 2008.

[97] Xu, L.; Yao, L.; Sasse, C. Grid Integration of Large DFIG-Based Wind Farms Using VSC Transmission. IEEE Transactions on Power Systems, vol. 22, no. 3, Agosto, 2007.

[98] Samuelsson, O.; Lindahl, S. On Speed Stability. IEEE Transactions on Power Systems, vol. 20, no. 2, pp. 1179-1180, 2005.

[99] NREL Report No. SR-500-35524. NREL Northern Power Systems WindPACT Drive Train Alternative Design Study Report. USA, Outubro, 2004. (Relatório Técnico, 2004)

[100]Grauers, A. Design of Direct-driven Permanent-magnet Generators for Wind Turbines. Tese (doutorado), Chalmers University of Technology, Gothenburg, Suécia, 1996. 
[101]Hystad, J. Transverse Flux Generators in Direct-driven Wind Energy Converters. Tese (doutorado), Norwegian University of Science and Technology, Trondheim, Noruega, 2000.

[102]Dubois, M. R. Optimized Permanent Magnet Generator Topologies for Direct-Drive Wind Turbines. Tese (doutorado), Delft University of Technology, Delft, Holanda, 2004.

[103]Svechkarenko, D. On Analytical Modeling and Design of a Novel Transverse Flux Generator for Offshore Wind Turbines. Tese (prédoutorado), The Royal Institute of Technology - KTH, Stockholm, Suécia, 2007.

[104]Krøvel, Ø.; Nilssen, R.; Nysveen, A. A Study of the Research Activity in the Nordic Countries on Large Permanent Magnet Synchronous Machines. Nordic Workshop on Power and Industrial Electronics - NORPIE, Noruega, 2004.

[105]Dubois, M. R.; Polinder, H. Study of TFPM machines with toothed rotor applied to direct-drive generators for wind turbines. Nordic Workshop on Power and Industrial Electronics - NORPIE, Noruega, 2004.

[106]Gieras, J. F. Performance Characteristics of a Permanent Magnet Transverse Flux Generator. IEEE International Conference on Electric Machines and Drives - IEMDC'05, pp. 1293 - 1299, Texas, Maio, 2005.

[107]Yicheng, C.; Pillay, P.; Khan, A. PM Wind Generator Topologies. IEEE Transactions on Industry Applications, vol. 41, no. 6, pp. 1619-1626, Nov.Dec. 2005.

[108]Blissenbach, R.; Henneberger, G. Numerical calculation of 3D eddy current fields in transverse flux machines with time stepping procedures. The International Journal for Computation and Mathematics in Electrical and Electronic Engineering - COMPEL, vol. 20, No. 1, pp. 152-166, 2001.

[109]Ullah, N.R.; Thiringer, T.; Karlsson, D. Voltage and Transient Stability Support by Wind Farms Complying With the E.ON Netz Grid Code. IEEE Transactions on Power Systems, vol. 22, no. 4, pp. 1647-1656, 2007. 


\section{APÊNDICE A - Publicações Durante o Doutorado}

Durante o período de doutoramento, publicaram-se artigos em conferências internacionais, bem como artigos em revistas indexadas, sendo uma delas no Institute of Electrical and Electronics Engineers (IEEE). A seguir, a lista de publicações é apresentada:

\section{A) Publicações em Revistas Indexadas}

SAKAMOTO, M. M.; CARDOSO, J. R.; MACHADO, J. M.; SALLES, M. B. C. A Twodimensional Delaunay Refinement Algorithm Using an Initial Pre-refinement from the Boundary Mesh. IEEE Transactions on Magnetics, v. 44, pp. 1418-1421, 2008.

SALLES, M. B. C.; CARDOSO, J. R. Análise de Estabilidade de Geradores de Indução Utilizados em Turbinas Eólicas de Velocidade Fixa. Exacta (São Paulo), v. 6, p. 217-228, 2009.

\section{B) Publicações em Conferências Internacionais}

SALLES, M. B. C.; CARDOSO, J. R.; FREITAS FILHO, W.; GRILO, A. P.; RAHMANN, C.; HAMEYER, K. Control Strategies of Doubly Fed Induction Generators to Support Grid Voltage. IEEE International Electric Machines and Drives Conference IEMDC 2009, Miami, 2009.

RAHMANN, C.; HAUBRICH, H.-J.; VARGAS, L.; SALLES, M. B. C. Investigation of DFIG with Fault Ride-Through Capability in Weak Power Systems. International Conference on Power Systems Transients - IPST 2009, Kyoto, 2009.

SALLES, M. B. C.; HAMEYER, K.; CARDOSO, J. R.; FREITAS FILHO, W. Dynamic Analysis of Wind Turbines Considering New Grid Code Requirements. XVIII International Conference on Electrical Machines - ICEM'08, Vilamoura, 2008.

CARDOSO, J. R.; CECCONI, V.; Di TOMMASO, A. O.; CASCIA, D. L.; MICELI, R.; ROSAS, P.; SALLES, M. B. C.; SARTORI, C. A. F.; SILVA, S. R.; OLIVEIRA, R. Wind Electrical Energy Generating Systems EMC. A Dedicated Experimental Simulator for Tests. XVIII International Conference on Electrical Machines - ICEM'08, Vilamoura, 2008. 
SALLES, M. B. C.; HAMEYER, K.; CARDOSO, J. R.; FREITAS FILHO, W.; BLISSENBACH, R. Dynamic Modeling of Wind Turbines based on Transverse Flux Permanent Magnet Generator. Thirteenth Biennial IEEE Conference on Electromagnetic Field Computation - CEFC 2008, Atenas, 2008.

SAKAMOTO, M. M.; CARDOSO, J. R.; MACHADO, J. M.; SALLES, M. B. C. A Delaunay Refinement Algorithm Using an Initial Pre-refinement from the Boundary Mesh. 16th International Conference on the Computation of Electromagnetic Fields COMPUMAG 2007, v.1, pp. 87-88, Aachen, 2007.

COSTA, M. C.; SALLES, M. B. C.; CARDOSO, J. R.; FILHO, M. L. P. A New Methodology for Electromagnetic Analysis of Umbilical Cables Using 2D-Finite Element Method. 16th International Conference on the Computation of Electromagnetic Fields COMPUMAG 2007, Aachen, 2007.

SALLES, M. B. C.; FREITAS FILHO, W.; MORELATO, A.; CARDOSO, J. R. Impact of Blade Angle Control Signal of Wind Turbines Using Induction Generator on Voltage Stability of Distribution Systems. VII Conferência Internacional de Aplicações Industriais INDUSCON 2006, Recife, 2006. 


\section{APÊNDICE B - Requisitos para Operação de Turbinas Eólicas}

Na Figura B. 1 e na Figura B. 2, apresentam-se os requisitos de operação durante curto-circuitos, os quais são exigidos, a partir de 2006, por um dos quatro operadores do sistema de transmissão alemão ([76]). Na Figura B. 3 e na Figura B. 4 , apresentam-se os requerimentos de operação durante curto-circuitos para turbinas eólicas conectadas no sistema elétrico espanhol ([77]). Tais requerimentos passaram a ser exigidos em 2006.

Destaca-se que os requisitos alemão e espanhol (além do português, não apresentado) são os mais restritivos atualmente no mundo. A maioria dos países com alta penetração de geração de energia eólica exige apenas que as turbinas não se desconectem da rede elétrica durante curto-circuitos. Maiores detalhes destas normas podem ser encontrados em referências de acesso público ([76], [77]). $\mathrm{Na}$ Figura B. 1, o termo STI (Short Term Interruption) indica a região na qual as turbinas eólicas baseadas no DFIG podem interromper momentaneamente sua operação, desta forma o sistema crowbar pode ser utilizado.

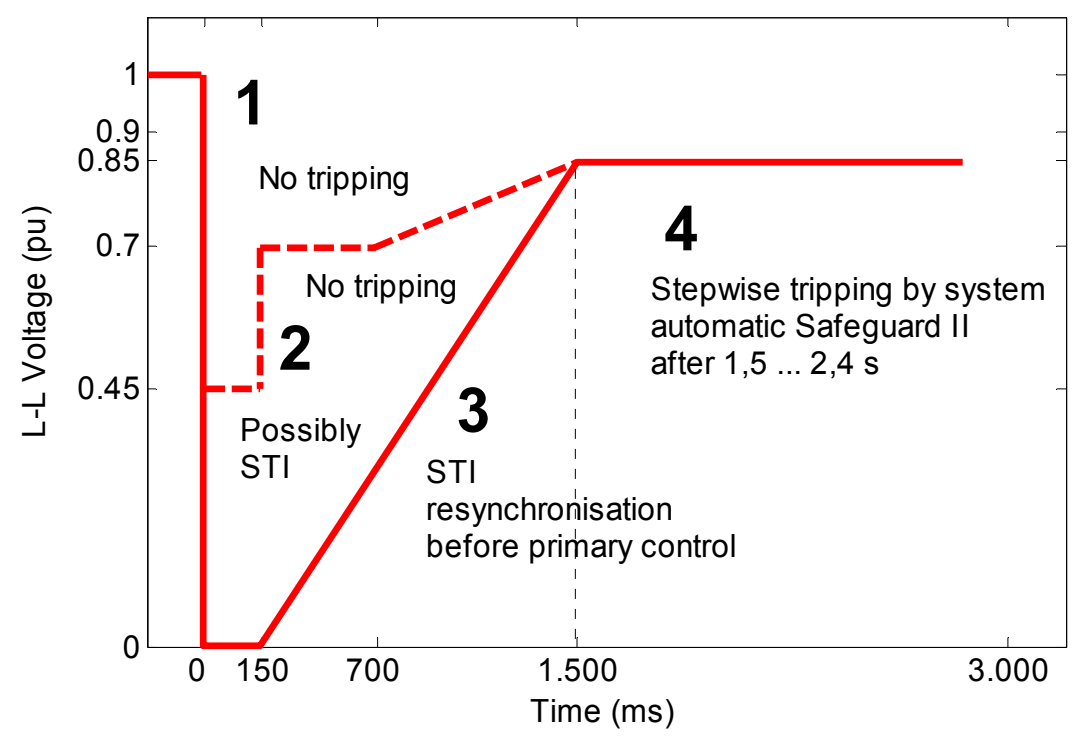

Figura B. 1 Requisitos do operador do sistema de transmissão alemão (E.on Netz) para operação durante curto-circuitos (fault-ride through) (Fonte: [76]). 


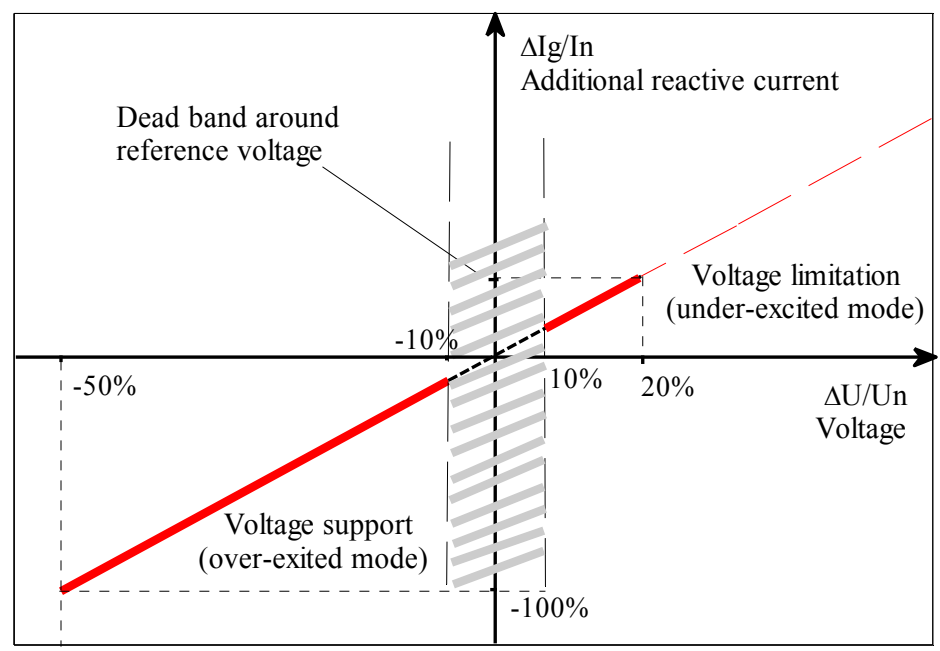

Figura B. 2 Requisitos do operador do sistema de transmissão alemão (E.on Netz) para regulação de tensão terminal, durante curto-circuitos (injeção de corrente reativa) (Fonte: [76]).

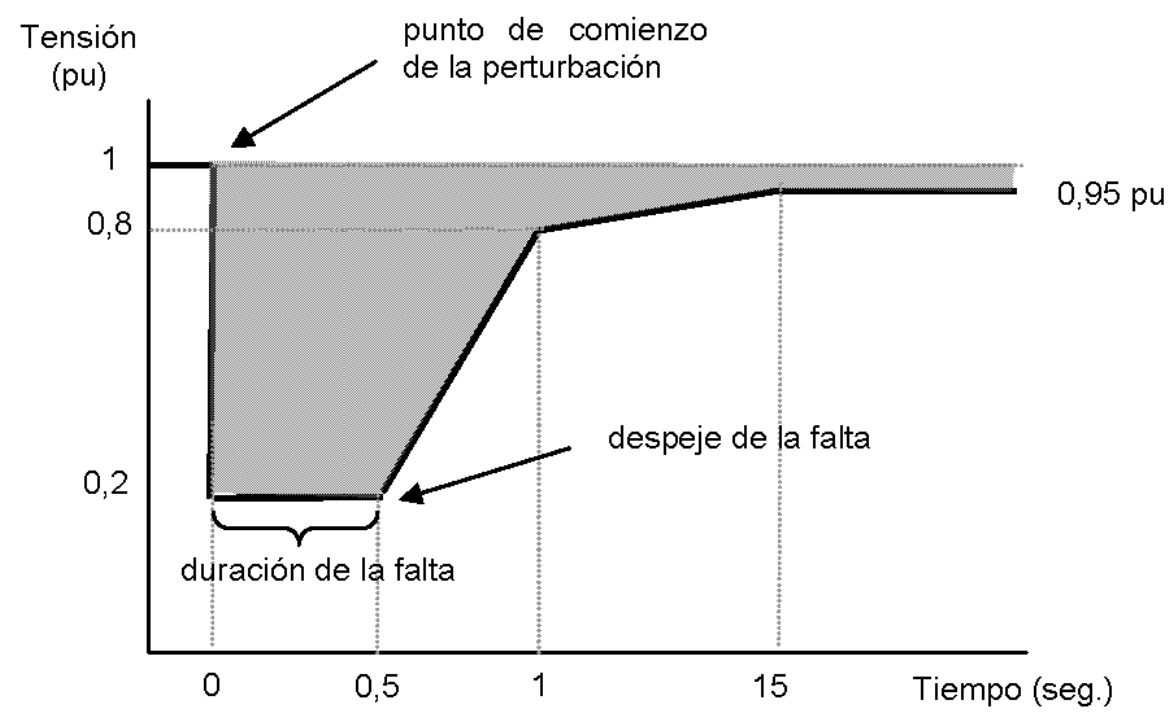

Figura B. 3 Requisitos do operador do sistema de transmissão espanhol para operação durante curto-circuitos (fault-ride through) (Fonte: [77]). 


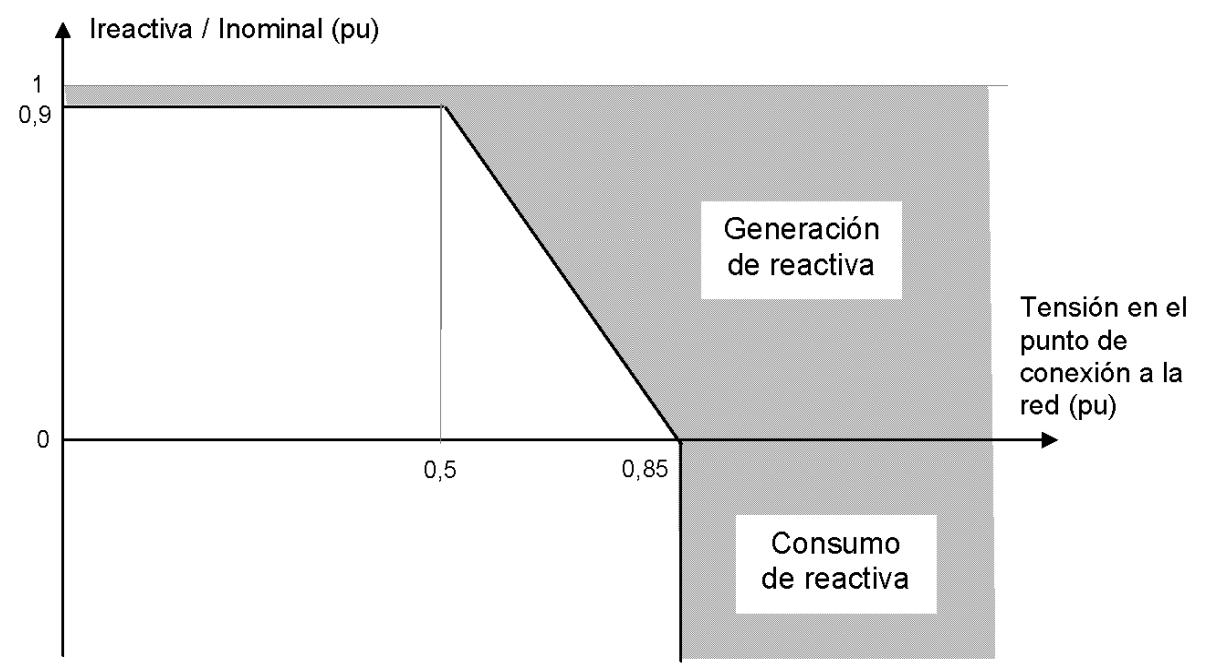

Figura B. 4 Requisitos do operador do sistema de transmissão espanhol para regulação de tensão terminal durante curto-circuitos (injeção de corrente reativa) (Fonte: [77]).

No Brasil, os requisitos de injeção de corrente reativa, até o presente momento, não são exigidos. Na Figura B. 5 apresenta-se os requisitos para operação durante curto-circuitos na rede básica de transmissão. Esses requisitos constam no Submódulo 3.6 dos procedimentos de rede, de 2009, do Operador Nacional do Sistema Elétrico (ONS) ([78]).

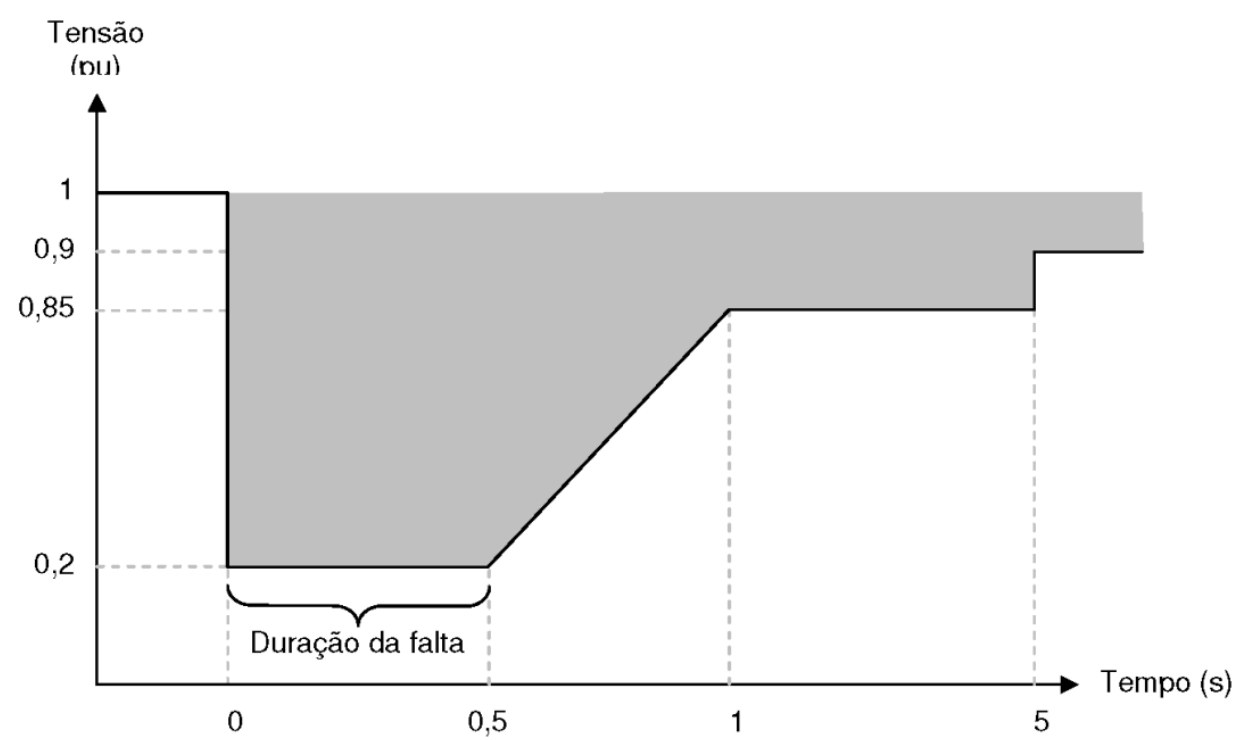

Figura B. 5 Requisitos do Operador Nacional do Sistema Elétrico (ONS) para operação durante curto-circuitos (fault-ride through) (Fonte: [78]). 


\section{APÊNDICE C - Dados de Simulação}

A seguir, apresentam-se os dados da rede elétrica empregada neste trabalho, assim como os parâmetros dos diversos controladores utilizados de forma a permitir que os resultados apresentados sejam facilmente reproduzidos.

\section{C.1 Dados do sistema de distribuição}

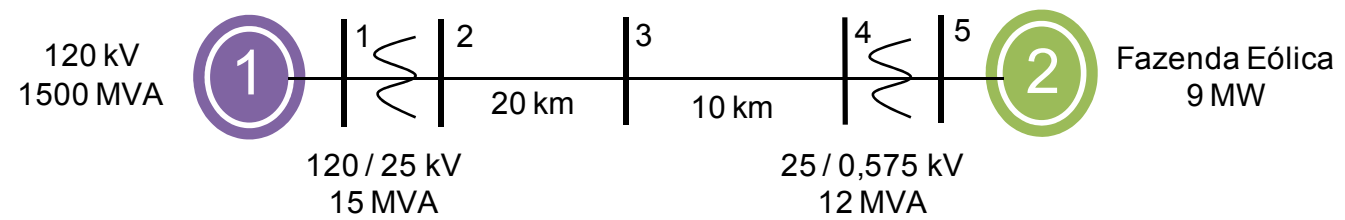

Figura C. 1 Diagrama unifilar do sistema de distribuição teste.

Dados da subestação:

- Nível de curto-circuito: 1500 MVA

- Reatância equivalente: $0,0308 \mathrm{H}$

- Tensão nominal: 120 kV

- Freqüência nominal: $60 \mathrm{~Hz}$

Tabela C. 1 Dados dos transformadores do sistema de distribuição.

\begin{tabular}{ccccccccccc}
\hline ramo & $S n(\mathrm{MVA})$ & $V_{1}(\mathrm{kV})$ & $R_{1}(\mathrm{pu})$ & $L_{1}(\mathrm{pu})$ & $V_{2}(\mathrm{kV})$ & $R_{2}(\mathrm{pu})$ & $\begin{array}{c}L_{2} \\
(\mathrm{pu})\end{array}$ & $\begin{array}{c}R m \\
(\mathrm{pu})\end{array}$ & $\begin{array}{c}L m \\
(\mathrm{pu})\end{array}$ & tap \\
\hline $1-2$ & 47 & 120 & $0,08 / 30$ & 0,08 & 25 & $0,08 / 30$ & 0,08 & 500 & 500 & 1,0 \\
$4-5$ & 12 & 25 & $0,025 / 30$ & 0,025 & 575 & $0,025 / 30$ & 0,025 & 500 & 500 & 1,0 \\
\hline
\end{tabular}

Tabela C. 2 Dados dos alimentadores do sistema de distribuição.

\begin{tabular}{ccccc}
\hline ramo & $R(\Omega / \mathrm{km})$ & $L(\mathrm{mH} / \mathrm{km})$ & $C(\mathrm{~F} / \mathrm{km})$ & Distância $(\mathrm{km})$ \\
\hline $2-3$ & 0,1153 & $1,05 \mathrm{e}-3$ & $11,33 \mathrm{e}-9$ & 20 \\
$3-4$ & 0,1153 & $1,05 \mathrm{e}-3$ & $11,33 \mathrm{e}-9$ & 10 \\
\hline
\end{tabular}




\section{C.2 Dados do sistema de transmissão}

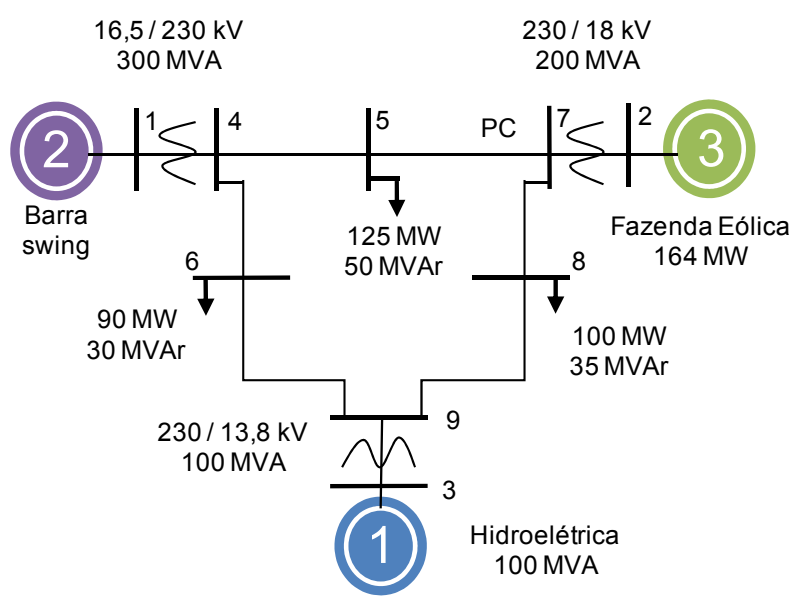

Figura C. 2 Diagrama unifilar do sistema de transmissão teste - WSCC3 modificado.

Tabela C. 3 Dados da barra swing.

\begin{tabular}{cccc}
\hline Nível de curto-circuito & Relação X/R & Tensão Terminal & Frequência nominal \\
\hline 5000 MVA & 100 & $16,5 \mathrm{kV}$ & $60 \mathrm{~Hz}$ \\
\hline
\end{tabular}

Tabela C. 4 Dados dos transformadores do sistema de transmissão.

\begin{tabular}{ccccccccccc}
\hline ramo & $S n(\mathrm{MVA})$ & $V_{1}(\mathrm{kV})$ & $R_{1}(\mathrm{pu})$ & $L_{1}(\mathrm{pu})$ & $V_{2}(\mathrm{kV})$ & $R_{2}(\mathrm{pu})$ & $L_{2}(\mathrm{pu})$ & $R m(\mathrm{pu})$ & $L m(\mathrm{pu})$ & tap \\
\hline $1-4$ & 300 & 16,5 & 0 & 0,0576 & 230 & 0 & 0,0576 & 500 & 500 & 1,0 \\
$2-7$ & 200 & 18 & 0 & 0,0576 & 230 & 0 & 0,0625 & 500 & 500 & 1,0 \\
$3-9$ & 110 & 13,8 & 0 & 0,0576 & 230 & 0 & 0,0586 & 500 & 500 & 1,0 \\
\hline
\end{tabular}

Tabela C. 5 Dados dos alimentadores do sistema de transmissão.

\begin{tabular}{cccc}
\hline ramo & $R(\mathrm{pu})$ & $X(\mathrm{pu})$ & $b_{\text {sh }}(\mathrm{pu})$ \\
\hline $4-5$ & 0,0100 & 0,0850 & 0,0880 \\
$4-6$ & 0,0170 & 0,0920 & 0,0790 \\
$5-7$ & 0,0320 & 0,1610 & 0,1530 \\
$6-9$ & 0,0390 & 0,0720 & 0,0745 \\
$7-8$ & 0,0085 & 0,0720 & 0,0745 \\
$8-9$ & 0,0119 & 0,1008 & 0,1045 \\
\hline
\end{tabular}


Tabela C. 6 Dados do gerador síncrono da hidroelétrica.

\begin{tabular}{cccccccccccccc}
\hline $\begin{array}{c}S n \\
(\mathrm{MVA})\end{array}$ & $\begin{array}{c}P_{m} \\
(\mathrm{pu})\end{array}$ & $H(\mathrm{~s})$ & $\begin{array}{c}R_{s} \\
(\mathrm{pu})\end{array}$ & $\begin{array}{c}X_{l} \\
(\mathrm{pu})\end{array}$ & $\begin{array}{c}X_{d} \\
(\mathrm{pu})\end{array}$ & $\begin{array}{c}X_{d}^{\prime} \\
(\mathrm{pu})\end{array}$ & $\begin{array}{c}X^{\prime \prime}{ }_{d} \\
(\mathrm{pu})\end{array}$ & $\begin{array}{c}X_{q} \\
(\mathrm{pu})\end{array}$ & $\begin{array}{c}X^{\prime \prime} \\
(\mathrm{pu})\end{array}$ & $\begin{array}{c}T_{d o}^{\prime}(\mathrm{s}) \\
(\mathrm{s})\end{array}$ & $\begin{array}{c}T^{\prime \prime}{ }_{d o} \\
(\mathrm{~s})\end{array}$ & $\begin{array}{c}T_{q o}^{\prime} \\
(\mathrm{s})\end{array}$ & $p$ \\
\hline 100 & 0,85 & 12,04 & 0,0031 & 0,005 & 1,3125 & 0,1813 & 0,13 & 1,2578 & 0,10 & 5,89 & 0,04 & 0,099 & 20 \\
\hline
\end{tabular}

Tabela C. 7 Dados do sistema de excitação (IEEE - tipo 1) do gerador síncrono da hidroelétrica.

\begin{tabular}{ccccccccccc}
\hline$T_{r}(\mathrm{~s})$ & $K_{A}$ & $T_{A}(\mathrm{~s})$ & $K_{e}$ & $T_{e}(\mathrm{~s})$ & $T_{b}(\mathrm{~s})$ & $T_{c}(\mathrm{~s})$ & $K_{f}$ & $T_{f}(\mathrm{~s})$ & $E_{\text {fmax }}(\mathrm{pu})$ & $K_{p}$ \\
\hline 0,005 & 250 & 0,1 & 1 & 0,65 & 0 & 0 & 0,048 & 0,95 & 7 & 0 \\
\hline
\end{tabular}

\section{C.3 Dados do sistema teste do capítulo 5}

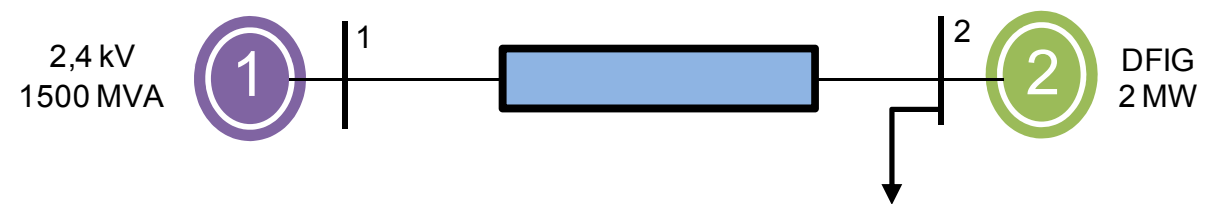

Figura C. 3 Sistema teste para estudo da estabilidade do DFIG.

Tabela C. 8 Dados da rede elétrica e da carga do sistema teste do capítulo 5.

\begin{tabular}{ccccc}
\hline$V_{s}(k V)$ & $R_{L}(\mathrm{pu})$ & $X_{L}(\mathrm{pu})$ & $P_{L O}(M W)$ & $f p$ \\
\hline 2,4 & 0,043 & 0,054 & 0,60 & 0,94 \\
\hline
\end{tabular}

\section{C.4 Dados dos geradores de indução duplamente alimentado (DFIG).}

Tabela C. 9 Dados dos geradores de indução duplamente alimentado utilizado no capítulo 4.

\begin{tabular}{ccccccccc}
\hline$P_{G}(\mathrm{MW})$ & $V n(\mathrm{~V})$ & $R s(\mathrm{pu})$ & $L s(\mathrm{pu})$ & $R^{\prime} r(\mathrm{pu})$ & $L^{\prime} r(\mathrm{pu})$ & $L m(\mathrm{pu})$ & $H(\mathrm{~s})$ & $p$ \\
\hline 9 & 575 & 0,01 & 0,1 & 0,01 & 0,08 & 3 & 3 & 2 \\
165 & 575 & 0,01 & 0,1 & 0,01 & 0,08 & 3 & 3 & 2 \\
\hline
\end{tabular}

Tabela C. 10 Dados do gerador de indução duplamente alimentado utilizado no capítulo 5.

\begin{tabular}{ccccccccccc}
\hline$P_{G}(\mathrm{MW})$ & $R s(\mathrm{pu})$ & $X s(\mathrm{pu})$ & $\operatorname{Rr}(\mathrm{pu})$ & $X r(\mathrm{pu})$ & $X m(\mathrm{pu})$ & $H(\mathrm{~s})$ & $\mathrm{T}_{\mathrm{M}}(\mathrm{pu})$ & $\mathrm{V}_{\mathrm{dR}}(\mathrm{pu})$ & $\mathrm{V}_{\mathrm{qR}}(\mathrm{pu})$ & $p$ \\
\hline 2 & 0,01 & 0,1 & 0,0140 & 0,0980 & 3,5 & 1,5 & -1 & 0 & $-0,0068$ & 2 \\
\hline
\end{tabular}




\section{C.5 Dados do gerador síncrono a ímãs permanentes de fluxo radial (PMSG).}

Tabela C. 11 Dados do gerador de indução duplamente alimentado utilizado no capítulo 6.

\begin{tabular}{ccccccccc}
\hline$P_{G}(\mathrm{MW})$ & $R s(\mathrm{ohm})$ & $L_{d}(\mathrm{H})$ & $L_{q}(\mathrm{H})$ & $\lambda(\mathrm{Wb})$ & $\mathrm{J}\left(\mathrm{kg} \cdot \mathrm{m}^{2}\right)$ & $\mathrm{T}_{\mathrm{M}}(\mathrm{N} . \mathrm{m})$ & $\mathrm{F}(\mathrm{N} \cdot \mathrm{m} . \mathrm{s})$ & $p$ \\
\hline 10 & 0,021 & $6,963 \mathrm{e}-3$ & $4,974 \mathrm{e}-3$ & 0,0980 & $3,535 \mathrm{e} 6$ & -880.117 & 0 & 38 \\
\hline
\end{tabular}

\section{C.6 Dados dos controladores.}

Tabela C. 12 Dados dos reguladores PI's empregados nos conversores do DFIG (seções 4.3 e 4.4).

\begin{tabular}{ccccc|cccc}
\hline \multicolumn{4}{c|}{ RSC } & \multicolumn{4}{c}{ GSC } \\
\hline & $I_{d}^{*}{ }_{d}$ & $I^{*}{ }_{q}$ & $V^{*}{ }_{d}$ & $V^{*}{ }_{q}$ & $I^{*}{ }_{d}$ & $I^{*}{ }_{q}$ & $V^{*}{ }_{d}$ & $V^{*}{ }_{q}$ \\
$K_{p}$ & 0,05 & 1 & 0,3 & 0,3 & 0,002 & 1,25 & 1 & 1 \\
$K_{i}$ & 5 & 100 & 8 & 8 & 0,05 & 300 & 100 & 100 \\
\hline
\end{tabular}

Tabela C. 13 Dados dos reguladores Pl's empregados pelos conversores do DFIG (seção 4.5).

\begin{tabular}{cccccc|cccc}
\hline & \multicolumn{4}{c|}{ RSC } & \multicolumn{4}{c}{ GSC } \\
\hline & $\begin{array}{c}I^{*}{ }_{d} \\
(\text { controle Q) }\end{array}$ & $\begin{array}{c}I^{*}{ }_{d} \\
\left(\text { controle } V_{t}\right)\end{array}$ & $I^{*}{ }_{q}$ & $V^{*}{ }_{d}$ & $V^{*}{ }_{q}$ & $I^{*}{ }_{d}$ & $I^{*}{ }_{q}$ & $V^{*}{ }_{d}$ & $V^{*}{ }_{q}$ \\
$K_{p}$ & 0,05 & 0,6 & 1 & 0,3 & 0,3 & 0,002 & 1,25 & 1 & 1 \\
$K_{i}$ & 5 & 16 & 100 & 8 & 8 & 0,05 & 300 & 100 & 100 \\
\hline
\end{tabular}

Tabela C. 14 Dados dos reguladores Pl's empregados pelos conversores do PMSG (seção 6.5).

\begin{tabular}{ccccc|cccc}
\hline & \multicolumn{4}{c|}{ GenSC } & \multicolumn{4}{c}{ GSC } \\
\hline & $I^{*}{ }_{d}$ & $I^{*}{ }_{q}$ & $V^{*}{ }_{d}$ & $V^{*}{ }_{q}$ & $I^{*}{ }_{d}$ & $I^{*}{ }_{q}$ & $V^{*}{ }_{d}$ & $V^{*}{ }_{q}$ \\
$K_{p}$ & - & 5000 & - & - & 2 & 2 & 0,4 & 1 \\
$K_{i}$ & - & 10 & - & - & 300 & 300 & 1000 & 1000 \\
\hline
\end{tabular}

Tabela C. 15 Dados dos reguladores Pl's empregados pelos conversores do TFG (seção 6.4).

\begin{tabular}{ccccc}
\hline \multicolumn{5}{c}{ GenSC } \\
\hline & $I^{*}{ }_{d}$ & $I^{*}{ }_{q}$ & $V^{*}{ }_{d}$ & $V^{*}{ }_{q}$ \\
$K_{p}$ & - & 0,1 & - & - \\
$K_{i}$ & - & 80 & - & - \\
\hline
\end{tabular}

